\title{
INCLUSÃO DAS DIMENSÕES SOCIAL E ECOLÓGICA EM PLANOS DE MANEJO PARA FLORESTAS DE RÁPIDO CRESCIMENTO
}

\author{
FABIANO ANTONIO RODRIGUES
}

Engenheiro Florestal

Orientador: Prof. Dr. LUIZ CARLOS ESTRAVIZ RODRIGUEZ

Dissertação apresentada à Escola Superior de Agricultura "Luiz de Queiroz", Universidade de São Paulo, para obtenção do título de Mestre em Recursos Florestais, Área de Concentração: Recursos Florestais, com opção em Manejo de Florestas de Produção.

PIRACICABA

Estado de São:Paulo - Brassil . : :

Fevereiro-.2002. 


\title{
Dados Internacionais de Catalogação na Publicação (CIP) DIVISĀO DE BIBLIOTECA E DOCUMENTAÇĀO - ESALQ/USP
}

\author{
Rodrigues, Fabiano Antonio \\ Inclusâo das dimensర́es social e ecológica em planos de manejo para florestas de \\ rápido crescimento / Fabiano Antonio Rodrigues. - - Piracicaba, 2002. \\ $101 \mathrm{p}$. \\ Dissertação (mestrado) - - Escola Superior de Agricultura Luiz de Queiroz, 2002. \\ Bibliografia. \\ 1. Ecologia florestal 2. Manejo florestal 3. Produçâo vegetal 4. Recursos naturais \\ I. Titulo
}

CDD 634.9 
Aos meus pais Mirinha e Toninho $e$ minha irmã Michelle, com todo meu carinho e gratidão, dedico. 


\section{AGRADECIMENTOS}

Ao Luiz, por ter me adotado no mundo acadêmico, pelas bilhares de oportunidades, pelos puxões de orelha e principalmente por ter se tornado um grande amigo.

Aos meus pais Mirinha e Toninho pelo incondicional apoio em todos os momentos de minha vida.

Aos meus tios Cidinha e Thadeu e meus primos Aliny e Raphael, por serem sempre meu porto seguro.

À Ludmila, pelo Pedro e a Isabelle, por sua paciência, seu sorriso e cumplicidade. Por agüentar minhas chatices e pela sensação de nos conhecermos a tanto tempo.

Ao Passarinho, pela sinceridade e por dividir a paternidade da Taba e da Preta.

À Valéria por trazer o equilíbrio a nossa casa.

À Tatiana por ser, entre meus colegas de mestrado, a única pessoa que não se espantou com o assunto tratado. Pelo companheirismo em todas as empreitadas durante o curso.

À Zezé, pelas oportunidades e sinceridade.

Ao Ivo, por ter me permitido acompanhar sua ascensão e por ouvir grande parte de minhas histórias.

Ao Professor Caixeta pelas brilhantes aulas de pesquisa operacional e por sua postura.

Ao meu amigo Cabelo por me apoiar à distância mesmo sem ter a idéia do que realmente faz um engenheiro florestal. 
À Gheler por sempre ter cuidado de mim.

Ao Nelore, pelas pizzas e por ter passado nos últimos anos do "status" de colega para o de grande amigo.

À Pêra minha amiga do passado, presente e futuro.

Ao Professor Fernando Seixas pelos cuidados na correção deste trabalho.

À Marina pelas horas de bate papo sobre os rumos da humanidade.

À Juá por me considerar um conselheiro.

Ao Jefferson, por estar sempre disposto a ajudar.

À Silvana, por me despertar para o mundo do Delphi e dos bancos de dados relacionais.

À Nenén pela certeza de sua constante presença mesmo que distante.

À Anna Júlia por me agüentar durante horas enquanto meus modelos rodavam.

À VCP pelo fornecimento das informações do estudo de caso representada pelos engenheiros Fausto e Cláudio sempre muito atenciosos.

À CAPES pelo apoio financeiro.

Ao Departamento de Ciências Florestais por ter me servido de "moradia" nos últimos oito anos. 


\section{SUMÁRIO}

Página

RESUMO viii

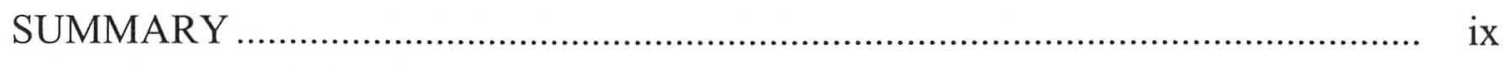

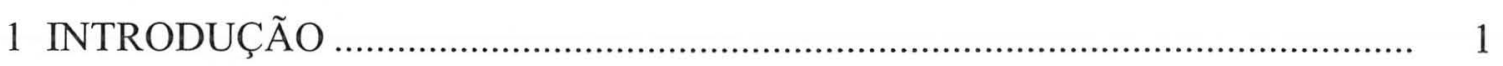

2 REVISÃO DE LITERATURA ...................................................................... 4

2.1 Modelo tradicional de elaboração de planos de manejo ........................... 4

2.2 Sustentabilidade e gestão florestal ...................................................... 7

2.2.1 Planos de manejo e seus aspectos sócio-econômicos ............................. 10

2.2.2 Planos de manejo e seus aspectos ecológicos .................................... 11

2.3 Conflitos entre objetivos ............................................................ 14

2.3.1 Determinação dos níveis ótimos de produção ........................................ 14

2.3.2 Métodos de solução de conflitos entre objetivos ................................... 16

2.4 Modelos que otimizam múltiplos objetivos ......................................... 16

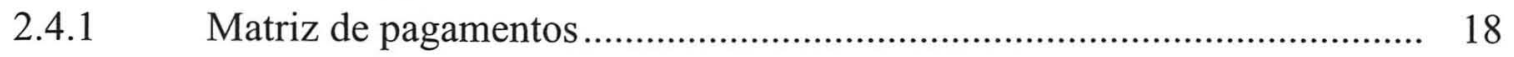

2.4.2 Programação por metas.................................................................... 19

2.4.2.1 Programação compromisso ......................................................... 21

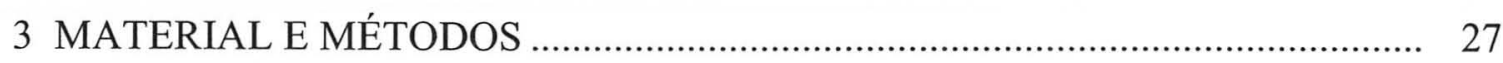

Caracterização da área..................................................................... 27

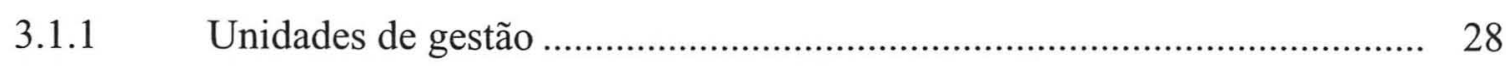

3.1.2 Atividades de condução da floresta ................................................... 28

3.1.3 Geração de alternativas de regimes de manejo ................................... 33

3.1.4 Cálculo dos valores dos regimes................................................. 35

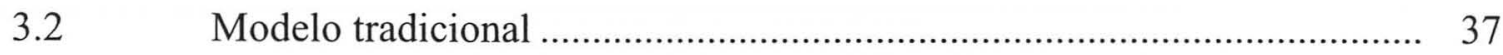

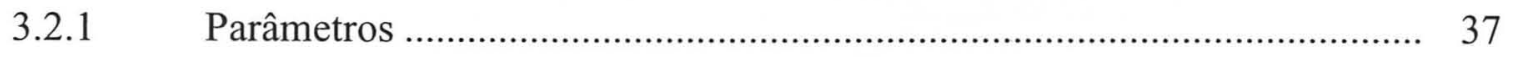




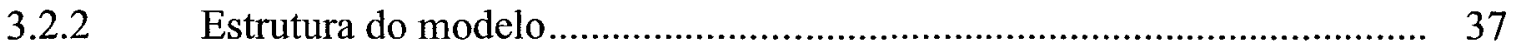

3.3 Modelos que otimizam múltiplos objetivos .................................... 39

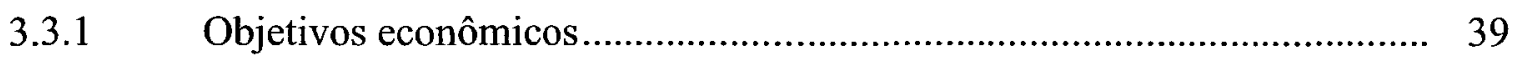

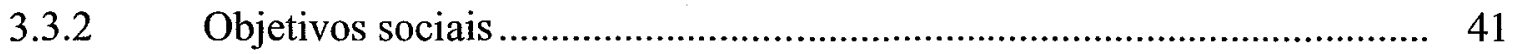

3.3.3 Objetivos ecológicos................................................................. 43

3.3.4 Matriz de pagamentos ............................................................... 44

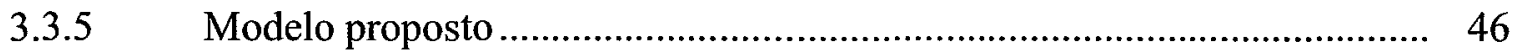

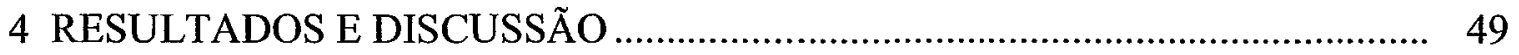

4.1 Modelo tradicional ............................................................. 49

4.2 Modelos que otimizam múltiplos objetivos ..................................... 52

4.2.1 Maximização do valor total do projeto ........................................... 53

4.2.2 Maximização da produção anual ................................................... 54

4.2.3 Minimização do número de intervenções de colheita........................... 56

4.2.4 Minimização das variações anuais de horas-homem ............................... 58

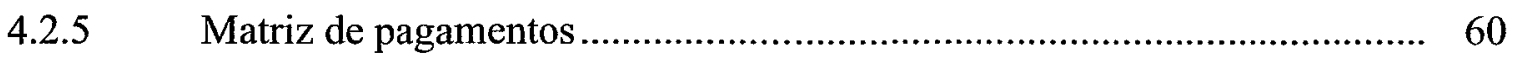

4.2.6 Mòdelo de programação compromisso métrica $L=1 \ldots \ldots \ldots \ldots \ldots \ldots \ldots \ldots . . \ldots 2$

4.2.7 Modelo de programação compromisso métrica $L=\infty$........................ 64

4.3 Comparação entre modelo tradicional e os modelos propostos ............... 67

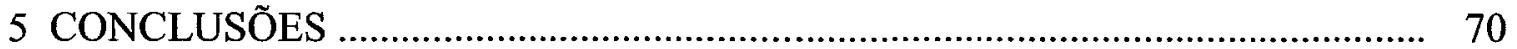

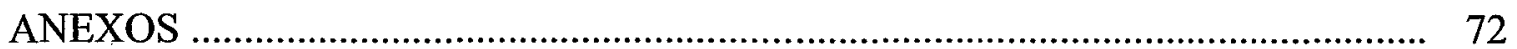

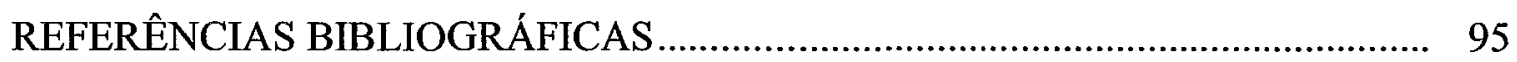




\title{
INCLUSÃO DAS DIMENSÕES SOCIAL E ECOLÓGICA EM PLANOS DE MANEJO PARA FLORESTAS DE RÁPIDO CRESCIMENTO
}

\author{
Autor: FABIANO ANTONIO RODRIGUES \\ Orientador: Prof. Dr. LUIZ CARLOS ESTRAVIZ RODRIGUEZ
}

\section{RESUMO}

Objetivos tradicionalmente utilizados para manejo de produções sustentáveis são substituídos por objetivos de manejo sustentável do ecossistema. A substituição sugere uma visão multi-objetivo do manejo florestal. Este trabalho procura utilizar tendências sustentáveis para a geração de prescrições de manejo florestal. Um modelo de programação compromisso é proposto para compor um plano de manejo para as unidades de produção. $\mathrm{O}$ modelo foi aplicado em uma área de produção responsável pelo suprimento de uma fábrica de papel e celulose localizada na região sudeste do Brasil. Quatro critérios foram considerados (a) o valor presente do projeto florestal, (b) a otimização do volume produzido anualmente, (c) as variações de demanda anual por horas-homem, (d) a minimização do número de intervenções de colheita. 


\title{
THE INCLUSION OF ECOLOGICAL AND SOCIAL DIMENSION IN FOREST MANAGEMENT PLANS
}

\author{
Author: FABIANO ANTONIO RODRIGUES \\ Adviser: Prof. Dr. LUIZ CARLOS ESTRAVIZ RODRIGUEZ
}

\section{SUMMARY}

Traditional forestry objectives aimed at sustainable yield management are being replaced with sustainable ecosystem management. The replacement suggests a multiobjective view of forest management. This work tries to use sustainability trends in a prescriptive focus of forest management. A compromise programming model was proposed to compose forest-level management plans. The model was used in a forest plantation responsible to supply a pulp and paper mil in southwest of Brazil .Four criterias was considered (a) the net present value of the forest project over the planning horizon, (b) the optimization of harvest volume in each cutting period, (c) the demand variation of labour, (d) the efficiency of harvest intervention. 


\section{INTRODUÇÃo}

Provas de que os recursos naturais renováveis vêm sendo usados de forma inconseqüente são regularmente veiculadas pela mídia nacional e internacional. A grande quantidade de evidências que comprovam um acelerado ritmo de devastação resultou na inquietação de vários setores da sociedade, que passaram a pressionar as autoridades por atitudes que revertam ou amenizem a situação. Isto tem estimulado o setor privado a adotar medidas que minimizem os danos, e instigado governos e legisladores a implementarem novas políticas ambientais.

Entre as deliberações da "United Nations Conference on Environment and Sustainable Development" (UNCED,1992), no item que trata do combate ao desflorestamento, são descritas diretrizes de trabalho para a promoção da utilização eficiente e avaliação dos valores de bens e serviços providos por florestas. Entre as atividades relacionadas, o documento prevê a formulação de critérios e normas para o manejo, conservação e desenvolvimento sustentável para todos os tipos de florestas, sem se deixar de lado os componentes sociais.

O conceito de qualidade passa a enfocar a manutenção da produção mantendo todos os processo envolvidos em equilíbrio. Sustentabilidade, a palavra que traduz a preocupação com todo o processo produtivo passa a ser discutida e definida por vários autores e para o consumidor final passa a ser sinônimo de qualidade.

Como forma de avaliação da qualidade de produtos provenientes de povoamentos florestais, mundialmente, várias instituições têm procurado desenvolver e 
sistematizar critérios e indicadores baseados em determinações e tratados que imponham restrições ao manejo de florestas. Estes critérios abordam questões como a qualidade da água, ciclos bioquímicos, geração de renda, índices de diversidade, ecologia da paisagem entre outros.

Os diferentes critérios e indicadores, embora sejam quantificados com o objetivo único de manutenção da sustentabilidade, podem tornarem-se antagônicos e de difícil sistematização durante os processos de gestão dos povoamentos produtivos. Para o gestor, todos estes conflitos passam a ser considerados durante a elaboração dos planos de manejo que deverá avaliar o maior número de dimensões possíveis, os custos de oportunidade e os graus de aceitação de conflitos existentes.

Problemas decisionais que envolvem múltiplas dimensões são tratados pelos modelos de otimização vetorial, mais conhecidos por modelos de programação multicritério. Neste trabalho são levantados os possíveis efeitos dos planos de manejo de florestas de rápido crescimento sobre as dimensões ecológicas, sociais e econômicas do sistema de produção. Um modelo que considera múltiplas dimensões é proposto e aplicado em um estudo de caso em florestas de produção que abastecem uma planta de celulose.

A hipótese básica testada é a de que a elaboração de planos de manejo através da utilização de métodos que consideram simultaneamente objetivos econômicos, sociais e ecológicos geram resultados distintos dos planos obtidos por métodos tradicionais.

A pesquisa tem como principal objetivo a elaboração de planos de manejo para florestas de rápido crescimento, através de métodos que permitam a otimização simultânea de objetivos sociais, ecológicos e econômicos. Para a consecução desse objetivo, faz-se necessário:

- Caracterizar as dimensões sociais, ecológicas e econômicas dos planos de manejo de florestas de produção, identificando os indicadores a serem otimizados. 
- Sugerir um modelo de otimização para a elaboração de planos de manejo que considere ao menos um objetivo em cada uma das dimensões.

- Comparar o plano de manejo gerado pelo modelo que considera as três dimensões com o plano gerado pelo modelo tradicional. 


\section{REVISÃO DE LITERATURA}

Segundo Leuschener (1984), o plano de manejo, também conhecido como plano de colheita, determina a estrutura de distribuição de idades e o fluxo de produtos florestais com suas receitas e custos. Vários fatores devem ser considerados durante a elaboração desses planos, entre eles a situação atual e a configuração do povoamento, as estimativas de crescimento, a demanda atual por madeira, os custos de condução, as receitas obtidas com a colheita, as alternativas de manejo entre outros.

Samson (1988) define a elaboração do plano como um processo de decisões caracterizado pelo envolvimento de grande quantidade de alternativas e dimensões de valores. O gestor deverá escolher, entre as várias alternativas de manejo, o conjunto que gere os melhores resultados. As conseqüências desta escolha podem ser incertas e com impactos a curto e longo prazo.

A complexidade inerente ao processo de busca do melhor conjunto de alternativas de manejo leva o gestor a utilizar ferramentas de apoio à decisão. Quando baseadas em programação matemática, essas ferramentas possibilitam a escolha da alternativa ótima dentre as demais estratégias factíveis consideradas na análise (Kent, 1989).

\subsection{Modelo tradicional de elaboração de planos de manejo}

Para Buongiorno \& Gilles (1987), gestão florestal é a arte e a ciência de tomar decisões considerando a organização, o uso e a conservação das florestas. Estas decisões envolvem fatores biológicos, sociais e econômicos (Leuschener, 1984). Clutter et al., (1992) dividem o processo de gestão florestal em três partes: 
1. Decisão: composta pela identificação do problema, geração, avaliação de soluções possíveis e escolha da melhor alternativa;

2. Implementação ou operacionalização da alternativa escolhida;

3. Controle: que implica a avaliação do processo de implementação e comparação dos resultados obtidos com o que era previsto durante o processo de tomada de decisão.

A elaboração de modelos apóia a primeira parte do processo de gestão florestal. Os modelos tradicionais procuram, geralmente, solucionar problemas de manutenção do abastecimento de unidades de produção com madeira. O gestor tem como alternativas diferentes seqüências de atividades conhecidas como regimes de manejo (Clutter et al., 1992). A escolha do melhor conjunto de alternativas depende de critérios monetários ou volumétricos utilizados pelo gestor. Entre as diversas técnicas de programação matemática, a programação linear tem sido amplamente utilizada nas aplicações de gestão de povoamentos florestais para apoiar estas escolhas.

Johnson \& Scheurman (1977) consagraram a divisão das abordagens da programação linear aplicadas à elaboração de planos de colheita em dois grupos, denominados Tipo I e Tipo II. No modelo tipo I, as alternativas se referem a unidades de manejo em um povoamento que se mantêm íntegras ao longo do horizonte de planejamento. O modelo tipo II não mantém a identidade espacial inicial das unidades de manejo dificultando o acompanhamento das unidades no horizonte (Leuschener, 1984; Clutter et al., 1992).

Um modelo de programação linear é composto por uma função objetivo e um conjunto de restrições. A solução ótima é obtida por meio do algoritmo Simplex, uma adaptação de métodos de resolução de sistemas lineares por inversões sucessivas de matrizes (Caixeta-Filho, 2001). 
A função objetivo, aliada a um direcionamento de maximização ou minimização, caracteriza o critério de seleção das alternativas (Kent, 1989). Essas alternativas são representadas na função objetivo pelas variáveis de decisão, selecionadas ou desprezadas durante o processo de otimização. Nesse processo são consideradas as limitações e exigências do sistema de produção tais como quantidade de recursos disponíveis, demanda por produtos florestais, exigências legais e outras. Essas limitações, geralmente representadas por inequações, compõem o conjunto de restrições do modelo.

Leuschener (1984) descreve cinco etapas para a elaboração de um plano de manejo florestal: determinação do horizonte de manejo ou do tempo de duração do plano, identificação das unidades de manejo, determinação dos regimes alternativos para cada unidade de manejo, cálculo do valor de cada regime de acordo com objetivos considerados no problema e finalmente, otimização da função objetivo considerando suas restrições.

O tempo de duração do plano ou horizonte de planejamento deve ser longo bastante para que sejam considerados o ordenamento da floresta e a manutenção da produção periódica de madeira. A escolha das alternativas no presente deverão basear-se em seus efeitos no longo prazo. Ware \& Clutter (1971) e Leuschener (1990) sugerem para o horizonte, períodos de aproximadamente dois ciclos florestais completos. Em plantios de rápido crescimento, Rodriguez \& Borges (1999) utilizaram horizontes de planejamento que permitissem a condução de pelo menos um ciclo florestal e meio.

O plano tem como referência as unidades de manejo, compartimentos geograficamente identificados, com plantios de mesma idade, espécie e espaçamento. Estas unidades podem ser conduzidas de diferentes formas, através da escolha de um regime de manejo que determina a periodicidade de colheitas e a condução ou replantio da unidade. Considerando um número $\mathrm{R}$ fixo de regimes de manejo por unidade florestal e $\mathrm{n}$ unidades florestais, o número total de planos gerados a partir de todas as combinações possíveis é determinado por $\mathrm{R}^{\mathrm{n}}$. Os modelos de programação linear auxiliam o gestor indicando, dentre os $\mathrm{R}^{\mathrm{n}}$ planos, aquele que otimiza simultaneamente $\mathrm{o}$ 
critério de seleção e atende o conjunto de restrições que caracterizam o problema de manejo florestal.

O modelo básico trata como restrições as exigências mínimas e máximas de produção, a área máxima disponível de cada unidade florestal e certas limitações operacionais e orçamentárias (Clutter et al., 1992; Leuschener, 1990). Embora sejam flexíveis quanto ao número de restrições consideradas, os modelos de programação linear têm como limitação a utilização de apenas uma função objetivo.

A estruturação do modelo de decisão e escolha dos critérios de seleção dos regimes dependerá da forma como o gestor interpreta as relações de suas decisões com os seus efeitos durante a condução da floresta. Gladwin et al. (1995) dividem os paradigmas de produção em tecnocêntricos e ecocêntricos. Nos primeiros, atualmente dominantes, se inserem os modelos de gestão florestal. Nesses modelos, também conhecidos como modelos de rendimentos sustentáveis, existe apenas a preocupação com a manutenção dos fluxos de produção de madeira (Borges, 1999; Lima, 1997 e Van Bueren \& Blom, 1997). No outro extremo situa-se a visão ecocêntrica que basicamente ignora relações humanas fundamentais, tornando-a impraticável.

Gladwin et al. (1995) sugerem um paradigma intermediário que procure considerar todos os aspectos envolvidos em um processo de tomada de decisão sem comprometer a sustentabilidade do sistema de produção. Nos modelos tradicionais seria necessário considerar simultaneamente múltiplas dimensões, expandindo o objetivo básico que enfatiza o rendimento sustentável da madeira para uma análise que se preocupe com a sustentabilidade do sistema de produção. Inserido nesse paradigma, o gestor passaria a selecionar alternativas de manejo considerando além dos efeitos sobre o fluxo contínuo de produção, os impactos sobre o bem estar da sociedade e ambiente.

\subsection{Sustentabilidade e gestão florestal}

Segundo Ruitenbeek \& Cartier (1998), durante a busca da sustentabilidade procura-se prestar maior atenção nas necessidades de futuras gerações e suas 
ramificações sociais e ambientais em relação a decisões atuais de produção e consumo. Para Scott (1999), economicamente a busca da sustentabilidade tem significado dar maior atenção para os estoques ou para a capacidade de recompô-los com qualidade Ruitenbeek \& Cartier (1998) e Farrell et al.(2000) alertam que a este enfoque deve ser acrescentado o envolvimento não apenas de eficiência e rendimentos monetários mas também resiliência ecológica e intergeneralização de direitos e obrigações.

Como forma de avaliação da qualidade de povoamentos florestais e suas interfaces com os diferentes ecossistemas, várias instituições têm procurado desenvolver e sistematizar critérios e indicadores baseando-se em determinações de tratados internacionais que impõem restrições ao manejo de florestas (Van Bueren \& Blom, 1997). Para Gonzalez-Caban et al. (1994), estes critérios devem considerar informações de qualidade, integridade e responsabilidade dos setores que sofrem influências diretas ou indiretas da floresta.

Richardson et al. (1999) definem indicadores como medidas quantitativas ou qualitativas de um critério as quais, observadas periodicamente, demonstram tendências. Estes indicadores têm o objetivo de avaliar a sustentabilidade de áreas amplas a partir de medições pontuais (Cole et al., 1998). Embora procure-se minimizar o número de indicadores utilizados como ferramentas de diagnóstico e planejamento como sugerem Ruitenbeek \& Cartier (1998), sabe-se que nenhum parâmetro único terá o poder de diagnosticar e indicar a saúde ou situação de um ecossistema (Gonzalez-Caban et al., 1994).

Segundo Dykstra (1998), já existe um bom conhecimento de critérios e indicadores biofísicos a serem aplicados ao manejo florestal individual. Isto envolve critérios e indicadores relacionados ao manejo, a ecologia, a diversidade biológica e genética. Também alcançou-se bom conhecimento sobre os critérios e indicadores especiais que precisam ser considerados em avaliações de sustentabilidade de florestas manejadas por comunidades locais e florestas plantadas. Faltam ainda maior segurança e conhecimento no desenvolvimento de critérios e indicadores relacionados com aspectos sociais da floresta. 
São inúmeros os critérios e indicadores de sustentabilidade criados por diversos projetos internacionais que abordam diferentes escalas de abrangência (Van Bueren \& Blom, 1997). Os critérios e indicadores de escala local, focados na unidade de gestão, trazem geralmente informações descritivas, determinando direcionamentos de melhoria de qualidade. Gonzalez-Caban et al. (1994) listam como exemplos destes indicadores a dinâmica química da matéria orgânica, biomassa microbiana e respiração do solo, entre outros.

Segundo Smith \& Thwaites (1998) os indicadores regionais avaliam sustentabilidade em escala intermediária de abrangência. A estes indicadores são atribuídos valores agregados, os quais procuram reconhecer as causas das variações em indicadores locais. Com os indicadores regionais, é possível definir ações que resultem em melhorias dos indicadores locais.

As dificuldades em gerir questões ambientais faz com que muitos mecanismos necessários para a proteção do meio ambiente sejam negligenciados (Hunt \& Auster, 1990). Embora existam diversas iniciativas de parametrização de indicadores, ainda está distante a determinação de índices para regiões específicas. Alguns índices podem representar informações importantes para as escalas globais e ao mesmo tempo serem pouco representativos em escalas regionais (Ruitenbeek \& Cartier, 1998). Desta forma, a busca da sustentabilidade deve requerer certa flexibilidade de mudanças e adaptações, tendo como alternativas metodologias que permitam a utilização de tendências de melhoria durante os processos de decisão.

Smith \& Thwaites (1998) propõem, como forma de alcançar a sustentabilidade, a utilização de indicadores de insustentabilidade. Os autores afirmam que através do princípio da precaução consegue-se, com facilidade, relacionar práticas de manejo a seus efeitos prejudiciais. As evidências levariam o tomador de decisão a evitar certas práticas ou se possível, amenizar seus efeitos. Ruitenbeek \& Cartier (1998), em trabalho que propõem indicadores econômicos ressaltam que, de forma prática, os indicadores sugeridos sempre são definidos através de uma visão negativa. Os autores 
complementam dizendo que o manejo florestal sustentável ainda está indefinido, mas por outro lado, já existem noções do que constitui um manejo insustentável.

Através dos indicadores de insustentabilidade, passa-se a considerar os efeitos negativos gerados por determinada ação e minimizar estes efeitos corresponde a uma diretriz de conduta. Além disso, estes indicadores podem informar quão longe se está do uso sustentável de determinado recurso (Rennings \& Wiggering, 1997).

\subsubsection{Planos de manejo e seus aspectos sócio-econômicos}

Segundo dados da Sociedade Brasileira de Silvicultura (SBS, 2001), o setor florestal brasileiro participa de aproximadamente 4\% do PIB nacional, representando $8 \%$ das exportações. O setor é responsável pela geração de aproximadamente 2 milhões de empregos diretos e indiretos, dos quais 500 mil referem-se à mão-de-obra empregada nas plantações florestais.

Estima-se que o segmento de celulose e papel seja responsável pela geração de 100 mil empregos diretos e indiretos, dos quais 30 mil atuam em áreas de condução da floresta (Bracelpa, 2000). O estado de São Paulo absorve cerca de $22 \%$ da mão-de-obra destinada à condução da floresta, seguido pelo Paraná (18\%), Bahia (14\%), Minas Gerais (13\%) e Espirito Santo (9\%) (Bracelpa, 2000). A Tabela 1 apresenta distribuição de mão-de-obra utilizada nas atividades de condução da floresta.

Tabela 1. Mão-de-obra utilizada na produção florestal segundo a atividade no segmento celulose e papel em 1999 (número médio de empregados).

\begin{tabular}{lrrrr}
\hline Área de atuacão & \multicolumn{1}{c}{ Própria } & Terceiros & \multicolumn{1}{c}{ Total } & \multicolumn{1}{c}{$\%$} \\
\hline Administração & 1.139 & 85 & 1.224 & 4 \\
Viveiros & 866 & 521 & 1.387 & 5 \\
Preparo de solo & 414 & 1.032 & 1.446 & 5 \\
Plantio & 1.315 & 3.740 & 5.055 & 17 \\
Manutenção & 1.058 & 3.093 & 4.151 & 14 \\
Colheita & 2.564 & 6.892 & 9.456 & 32 \\
Transporte & 658 & 2.671 & 3.329 & 11 \\
Outros & 1.855 & 1.256 & 3.111 & 11 \\
Total & 9.869 & 19.260 & 29.159 & 100 \\
\hline
\end{tabular}

Fonte: Bracelpa, 2000 
Cronologicamente, os maiores índices de demanda por mão-de-obra ocorrem nas idades iniciais devido às atividades de preparo de solo e plantio. $\mathrm{O}$ plano de manejo indica o comportamento desta demanda ao determinar a forma de condução de cada unidade de gestão. A Figura 1 apresenta um exemplo de fluxo de mão-de-obra para duas alternativas de condução (regimes) de uma unidade de manejo. $\mathrm{O}$ primeiro regime sugere colheitas para os anos 5-10-15 e 20, demandando uma maior quantidade de horas em um mesmo período do horizonte quando comparado ao segundo que prescreve colheitas para os anos 1 e 9 .

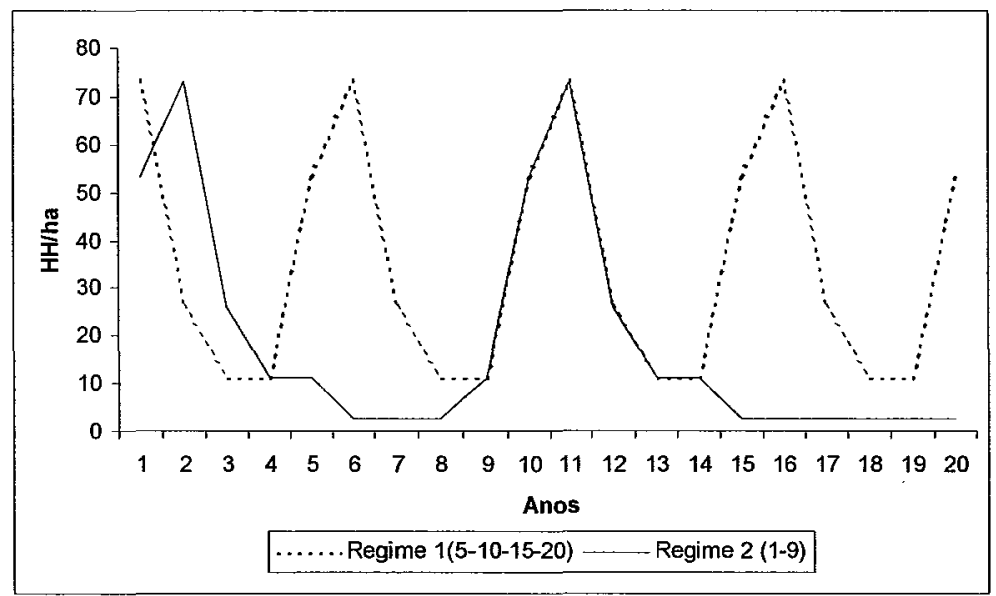

Figura 1- Fluxo de mão-de-obra anual em horas-homem por hectare(HH/ha) gerado por duas opções de regimes de manejo para para uma UG. (Fonte: dados de pesquisa)

Outro aspecto sócio-econômico dos planos de manejo refere-se ao seu retorno financeiro. Este valor dever ser positivo de forma a garantir a sustentabilidade do sistema produtivo (Ruitenbeek \& Cartier, 1998).

\subsubsection{Planos de manejo e seus aspectos ecológicos}

Florestas de produção são geralmente plantadas em solos pobres e mesmo assim, têm como resultado um bom desempenho produtivo. Muitos autores (Laclau; et al.,2000; Poggiani et al., 1998; Poggiani \& Schumacher 1997 e Reis et al. 1987) justificam este desempenho pela alta eficiência do processo de ciclagem interna de nutrientes na árvore. 
Embora seja evidente o aumento da produtividade resultante de práticas de manejo silvicultural intensivo, a manutenção destes níveis torna-se crítica quando considerado o longo prazo. Segundo Laclau et al. (2000), Morris et al. (1997), e Richardson et al. (1999) a simples análise da manutenção ou melhoria da produtividade florestal não é um bom indicador de sustentabilidade. Este indicador pode ser mascarado por práticas e materiais genéticos que compensam perdas de qualidade do sítio.

Para Fox (2000), a magnitude das variações dos níveis de produtividade no tempo depende das formas de manejo das propriedades físicas, químicas e biológicas do solo. Laclau et al. (2000) sugere, como forma de promover a sustentabilidade de solos, a manutenção ou melhoria destes fatores, que integrados caracterizam a capacidade de produção de biomassa do sítio.

Estes fatores estão fortemente ligados à estrutura física e ao balanço nutricional da floresta, composto de entradas por precipitação atmosférica, intemperismo de rochas e adubação, e de saídas por meio de erosão, lixiviação e exploração da madeira (Poggiani \& Schumacher, 1997). O montante líquido deste balanço torna-se disponível às plantas através dos ciclos nutricionais, os quais sofrem interferência direta das práticas de manejo (Laclau et al., 2000; Morris et al., 1997; Wang et al., 1996).

Os ciclos nutricionais podem ser externos, com a transferência de nutrientes para dentro e para fora do ecossistema florestal, e internos ocorrendo apenas dentro do ambiente florestal. A ciclagem interna pode ser dividida em bioquímica e biogeoquímica. A bioquímica trata da movimentação do nutriente dentro da própria árvore, translocando-o de tecidos mais velhos para mais jovens; já a biogeoquímica refere-se às trocas entre a biomassa arbórea e o solo (Pritchett \& Fisher,1987).

Poggiani \& Schumacher (1997) comparam a entrada de nutrientes via atmosfera com sua exportação nos diversos componentes da madeira através da colheita. Os autores estimam que as entradas de nutrientes, via precipitação atmosférica, podem ser suficientes para suprir a quantidade exportada, via exploração do lenho do tronco, se respeitado o período de recarga de nutrientes. 
A maior intensidade de colheitas em plantios florestais de rápido crescimento acarreta uma exportação considerável de nutrientes, sendo toleráveis apenas desbalanços nutricionais temporários (Poggiani et al., 1998). Segundo Poggiani \& Schumacher (1997) e Yanai et al. (2000), rotações muito curtas reduzem significativamente a capacidade do solo em repor os nutrientes exportados, sendo sugeridas rotações maiores que as geralmente utilizadas. Morris et al. (1997) alertam que a sustentabilidade de um sistema florestal poderá ser alcançada apenas se as ações de manejo forem tais que as rotações de produção sejam tão longas quanto as rotações ecológicas. O período deve ser determinado pelo tempo necessário para que o povoamento retorne às condições encontradas antes do distúrbio. A Figura 2 (Lima, 1997), apresenta de forma esquemática três situações de extração de madeira em determinado sítio e sua influência sobre a disponibilidade de nitrogênio.

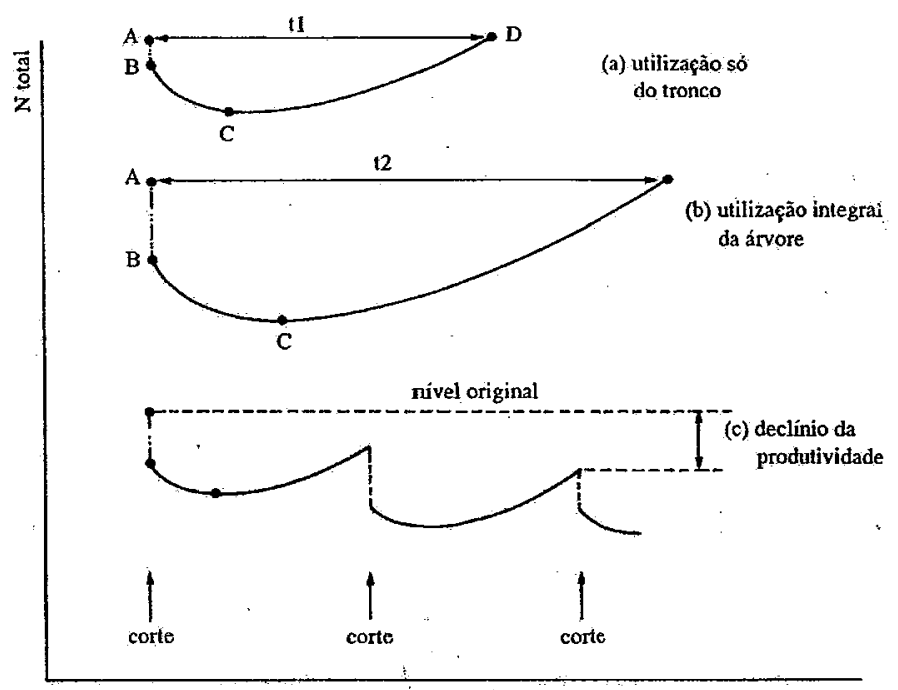

Figura 2 - Extração de madeira e sua influência sobre a disponibilidade de nitrogênio, onde: segmento $\mathrm{AB}$ representa a perda decorrente ao corte raso. $\mathrm{BC}$ perda por perturbação do sítio. CD acúmulo decorrente do crescimento de biomassa. A Situação (a) representa utilização apenas do tronco com período rotacional suficiente para a reposição dos nutrientes. A situação (b) representa a utilização integral da árvore com período rotacional suficiente para a 
reposição dos nutrientes. A situação (c) representa o efeito de colheitas prematuras quando considerado o capital nutricional (Lima, 1997).

Rotações muito curtas e a imposição de ciclos de apenas uma rotação submetem os solos à constante desestruturação, aumentando sua suscetibilidade de perdas por erosão, lixiviação e desequilíbrio da biota do solo. Para Yanai et al. (2000), outro impacto global resultante de rotações mais curtas é o da perda de carbono acumulado no solo. Isto indica que florestas plantadas com o objetivo de fixação de carbono deverão sofrer alterações em suas práticas de condução (Turner \& Lambert, 2000).

O prolongamento das rotações também se justifica pela correlação negativa existente entre o tamanho da árvore e a concentração dos elementos minerais nos componentes da madeira. Esta correlação ocorre devido à menor quantidade de tecidos ativos em relação às árvores mais novas, aliada à maior eficiência do ciclo bioquímico na translocação de nutrientes (Wang et al., 1996 e Laclau et al., 2000). O aumento da eficiência bioquímica em relação à idade propicia a diminuição das taxas de retirada de nutrientes do solo. Considerando constante a entrada de nutrientes via precipitação atmosférica, haverá uma redução progressiva do déficit nutricional local.

\subsection{Conflitos entre objetivos}

A busca da sustentabilidade é fortemente influenciada por atividades econômicas através de efeitos diretos como consumo de recursos, ou indiretos como nos processos de poluição. Além disso, as diferentes preocupações com a qualidade do manejo, embora tenham objetivo único de manutenção da sustentabilidade, podem tornar-se antagônicas.

\subsubsection{Determinação dos níveis ótimos de produção}

Segundo Romero (1997), o ponto de partida para análises ambientais consiste na aceitação de que não se pode desenvolver atividades econômicas sem promover alterações no ambiente. Por este motivo, os processos de decisão passam a considerar as externalidades, definidas por Wonnacott \& Wonnacott (1994) como efeitos do processo produtivo sobre pessoas ou empresas que não são necessariamente responsáveis pelo 
processo. A presença de externalidades resulta nas chamadas falhas de mercado, ocorrendo a perda da garantia do equilíbrio e eficiência esperados em um mercado de competição perfeita (Klemperer, 1996). São exemplos de externalidades ambientais negativas todas as formas de poluição de água, visual, ar e som.

A quantidade aceitável a ser produzida por uma atividade econômica pode ser encontrada através de análises da receita marginal. Klemperer (1996); Pearce et al. (1999) e Romero (1997) sugerem que para cada unidade produzida haverá um nível de impacto ao ambiente que poderá ser traduzido em custo marginal externo. Desta forma, ao igualar a receita marginal do produtor a este custo, encontra-se o nível de produção socialmente ótimo. Este nível será, provavelmente, mais baixo que a produção ótima para a empresa e mais alto que o de externalidade ótima para a sociedade.

Encontrar o valor de produção socialmente ótimo torna-se relativamente simples quando as externalidades possuem valor de mercado. Para Klemperer (1996), simplesmente por não haver mercado, nem sempre bens, serviços e impactos a recursos naturais poderão ser valorados monetariamente, impossibilitando o cálculo dos níveis sociais de produção. São exemplos de bens sem valor de mercado: beleza cênica, água limpa, qualidade do ar entre outros. Para solucionar este problema, algumas correntes de economistas têm procurado desenvolver métodos para calcular tais valores (Marques \& Comune, 1996).

Os métodos de valoração têm como principal problema a necessidade de redução dos benefícios e custos dos ativos ambientais em dimensões monetárias (Romero, 1997). $\mathrm{O}$ autor sugere que problemas de valoração ambiental seriam melhor analisados pela teoria da decisão multicritério. Através desta abordagem, os enfoques do ativo ambiental seriam tratados na forma de objetivos, mantendo suas dimensões naturais como número de visitantes, metros cúbicos, unidades monetárias entre outros. 
2.3.2 Métodos de solução de conflitos entre objetivos

Ao considerar múltiplos objetivos, a solução pode ser representada por um vetor onde cada elemento corresponde ao valor alcançado por cada objetivo. Este vetor reflete, matematicamente, os níveis de conflito entre os critérios de decisão utilizados. Desta forma, a melhor solução será dada pelo vetor que possuir os melhores valores para cada um de seus elementos. Segundo Romero (1993), para o mesmo problema poderão existir diversos vetores de soluçãoque atendam a todas as restrições. Conforme descrito por Pietrzak, (1999), a escolha do melhor vetor dependerá primeïramente de uma triagem, eliminando os vetores de solução dominados procurando identificar entre as soluções factíveis, aquelas que possuírem, no mínimo, um dos resultados superior ao encontrado em outros vetores. São descartados os vetores que têm como resultado soluções totalmente dominadas recebendo o nome de vetores não eficientes.

Após a triagem, escolhe-se o vetor de melhor solução para o problema. A situação ótima passa a ser relativa às prioridades de preocupações do centro de decisão em relação a cada objetivo. Devido à complexidade do problema, estas decisões devem ser apoiadas por ferramentas que melhor organizem o conjunto de soluções e, a partir das prioridades do centro de decisão, procurem as soluções mais próximas do ótimo. Os métodos multicrtério têm a função de escolher a melhor solução em um conjunto de soluções eficientes (Diaz-Balteiro \& Romero, 1998).

\subsection{Modelos que otimizam múltiplos objetivos}

Embora tenham indiscutivel utilidade, os modelos tradicionais de elaboração de planos de colheita possuem algumas limitações. Por utilizarem modelos matemáticos de programação linear, não é possível buscar soluções que procurem otimizar mais de um critério simultaneamente. Para modelos que consideram, além das variáveis de produção, os impactos sociais e ambientais do plano de colheita, torna-se necessária a utilização dos modelos de programação com objetivos múltiplos. 
Um modelo de programação com objetivos múltiplos tem a mesma estrutura do modelo tradicional, uma única função objetivo e um conjunto de restrições. Isto permite a utilização dos mesmos recursos computacionais para sua elaboração e execução. A diferença entre os dois modelos está na forma de representação da função objetivo, que no modelo múltiplo, agrupa todos os objetivos do problema (Steuer, 1986). Desta forma, o modelo deverá otimizar simultaneamente as seguintes equações:

$$
\begin{aligned}
& \max \left\{f_{1}(x)\right\} \\
& \max \left\{f_{2}(x)\right\} \\
& \vdots \\
& \max \left\{f_{k}(x)\right\}
\end{aligned}
$$

Sujeito a:

$x \in F$

O conjunto de equações (1) pode ser representado da seguinte forma:

$$
\begin{aligned}
& \text { Eff Obj }=\left[z_{1}, z_{2}, \ldots z_{k}\right] \\
& \text { Sujeito } a: \\
& f_{1}(x)=z_{1} \\
& f_{2}(x)=z_{2} \\
& \vdots \\
& f_{k}(x)=z_{k} \\
& x \in F
\end{aligned}
$$

onde: $\mathrm{f}_{\mathrm{i}}(\mathrm{x})$ i-ésima função objetivo;

$\mathrm{x}$ vetor de variáveis de decisão com $\mathrm{k}$ elementos;

$\mathrm{F}$ conjunto de restrições;

$\mathrm{k}$ número total de objetivos do modelo;

Eff representa a busca de soluções eficientes para o problema;

$\mathrm{Z}_{\mathrm{k}}$ variáveis de contabilização dos valores dos objetivos. 


\subsubsection{Matriz de pagamentos}

O primeiro passo do processo de busca por soluções eficientes ocorre através da obtenção da matriz de pagamentos (Romero 1993; Steuer, 1986 e Vincke, 1992). Esta matriz é obtida através da otimização individual dos objetivos, tendo seus efeitos sobre as outras funções armazenados em variáveis contábeis. A Tabela 2 apresenta exemplo ${ }^{1}$ de matriz de pagamentos obtida através da minimização do objetivo 1 calculando seus efeitos sobre o objetivo 2, e a maximização do objetivo 1 calculando seus efeitos sobre o objetivo 1 .

Tabela 2. Exemplo de matriz de pagamentos. Valores em negrito representam soluções ótimas para cada objetivo.

\begin{tabular}{lcc}
\hline Função Objetivo & Objetivo 1 & Objetivo 2 \\
\hline Minimizar objetivo 1 & $\mathbf{3}$ & 5 \\
Maximizar objetivo 2 & 10 & $\mathbf{1 5}$ \\
\hline
\end{tabular}

Fonte: Dados fictícios

A matriz de pagamentos, além de determinar os valores ótimos e anti-ótimos de cada objetivo, determina o nível de conflito entre ambos (Romero, 1993). Estes níveis podem ser representados pelas taxas de intercâmbio,ou seja, custos sobre um objetivo devido à escolha da estratégia que maximiza outro objetivo dado pela expressão. Cada linha da matriz de pagamentos representa um vetor de solução podendo ser representado graficamente como mostra a Figura 3.

As opções de soluções dadas pela matriz de pagamentos representam pontos extremos do conjunto de possíveis soluções para o problema (Steuer, 1986). Não havendo satisfação do centro decisor, este poderá procurar soluções intermediárias onde exista um equilíbrio de resultados entre todos os objetivos.

\footnotetext{
${ }^{1}$ Exemplo desenvolvido pelo autor.
} 


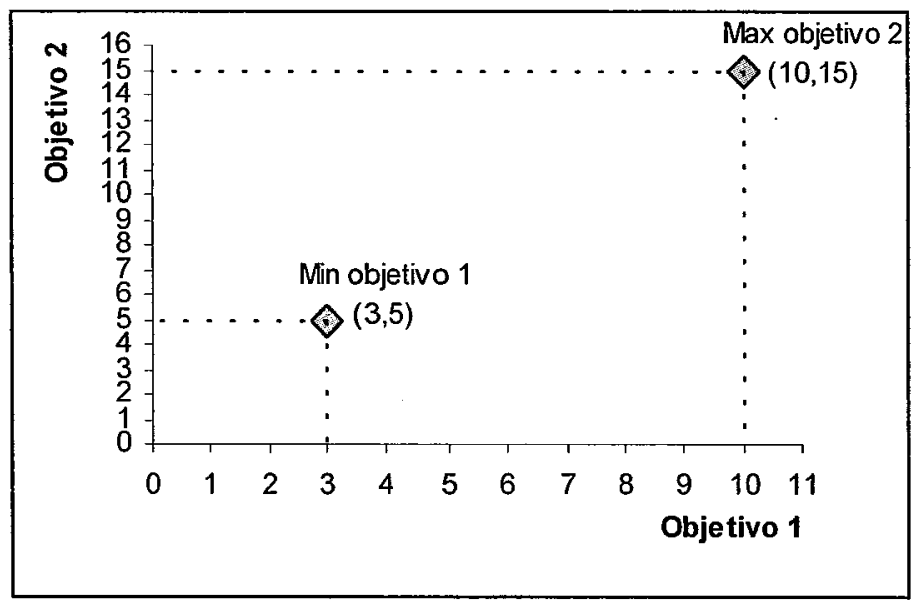

Figura 3 - Representação gráfica dos vetores de solução apresentados na Tabela 2.

Entre os métodos mais utilizados na busca por soluções que satisfaçam o centro decisor, têm destaque os modelos de programação por metas. (Vincke, 1992).

\subsubsection{Programação por metas}

Segundo Romero (1993), o primeiro passo para a composição de um modelo de programação por metas é definir os atributos relevantes ao modelo analisado. Um atributo pode ser considerado como a representação de um objetivo em uma função matemática $\mathrm{f}(\mathrm{x})$. Posteriormente, deve-se conhecer as aspirações do centro de decisão para cada atributo, tarefa geralmente executada com o apoio de grupos de especialistas que indicam valores tecnicamente aceitáveis para cada atributo (Mendonza \& Prabhu, 2000). Genericamente, a determinação dos atributos e valores indicados tecnicamente são representados pela equação (3):

$$
f_{j}(x)=t_{j}
$$

onde: $f_{j}(x)$ função matemática que representa o atributo $\mathrm{j}$;

$\mathrm{t}_{\mathrm{j}}$ é o valor sugerido pelo grupo de especialistas para o atributo $\mathrm{j}$;

A equação (4) deve ser inserida no modelo junto ao conjunto de restrições na forma de meta (Vincke, 1992). Isto é feito inserindo variáveis que armazenem os desvios 
dos valores obtidos pelos atributos em relação aos valores indicados pelos especialistas. A transformação da equação (3) em uma meta é dada pela equação (4):

$$
f_{j}(x)+n_{j}-p_{j}=t_{j}
$$

onde: $n_{j}$ corresponde ao desvio negativo em relação ao valor sugerido para o atributo $\mathrm{j}$; $\mathrm{p}_{\mathrm{j}}$ corresponde ao desvio positivo em relação ao valor sugerido para $\mathrm{o}$ atributo $\mathrm{j}$.

Baseado nos valores da Tabela 2, o modelo de programação por metas, para solução do problema utilizado como exemplo, terá como objetivo a minimização dos desvios indesejáveis em relação às aspirações do centro de decisão (equação (5)) estando sujeito às restrições representadas pelas equações (6), (7) e (8):

$\operatorname{Min} \mathrm{Z}=\mathrm{p}_{1}+\mathrm{n}_{2}$

sujeito a

$$
\begin{aligned}
& f_{1}(x)+n_{1}-p_{1}=4 \\
& f_{2}(x)+n_{2}-p_{2}=13 \\
& x \in F
\end{aligned}
$$

A solução obtida pelo modelo de programação por metas é apresentada para o grupo de especialistas que avaliará se os desvios em relação às metas propostas são aceitáveis. Este procedimento é utilizado por Mendonza \& Prabhu (2000). Após a análise, novas metas poderão ser propostas para a obtenção de novas soluções, repetindo o processo até que o grupo fique satisfeito com os resultados obtidos. Diaz-Balteiro \& Romero (1998) utilizam processo multicritério baseado em programação por metas para a formulação de modelo de planejamento florestal. O modelo considera como objetivos o valor presente do projeto, a manutenção do volume produzido anualmente, o ordenamento final da floresta e a distribuição de diâmetros esperados no inventário final. Romero et al. (1998) utilizam programação por metas para a determinação de idades ótimas de colheita, considerando a produção de madeira e seqüestro de carbono. 
Mendonza \& Prabhu (2000) utilizam modelos de programação por metas na avaliação de indicadores de sustentabilidade. Para a aplicação do método foi necessário o apoio de um grupo multidisciplinar de especialistas responsáveis pelo agrupamento dos principais indicadores a serem utilizados e dos valores considerados aceitáveis.

\subsubsection{Programação compromisso}

A programação compromisso pode ser considerada uma variação da programação por metas. Este enfoque utiliza como parâmetro os valores ótimos de cada objetivo (Vincke, 1992), que conforme exemplo da Tabela 2, seria representado pelo vetor $Z=[3,15]$. Esse vetor representa o melhor valor possível a ser alcançado pelo modelo quando respeitado o conjunto de restrições atuais. Genericamente o ponto ideal é representado pela equação (9):

$$
Z^{*}=\left[z_{1}^{*}, z_{2}^{*}, \ldots, z_{k}^{*}\right]
$$

onde $Z^{*}$ representa o vetor de solução ideal;

$$
\mathrm{z}_{\mathrm{j}}^{*} \text { é a solução ótima obtida para o objetivo } \mathrm{j} \text {. }
$$

Entre as soluções eficientes descritas por por Pietrzak (1999), os modelos de programação compromisso têm como objetivo formar um subconjunto de soluções que têm como compromisso a escolha de vetores próximos ao ponto ideal. Para selecionar estas soluções, o modelo utiliza funções de distância como critério, sendo a melhor solução aquela que possuir a menor distância em relação ao ponto ideal (Romero, 1997). A distância euclidiana entre dois pontos pode ser encontrada através da equação (10):

$$
d=\sqrt{\left(x_{1}^{1}-x_{1}^{2}\right)^{2}+\left(x_{2}^{1}-x_{2}^{2}\right)^{2}}
$$

onde $\left(x_{1}^{1}, x_{2}^{1}\right)$ são as coordenadas do ponto ótimo $x_{1}$;

$\left(x_{1}^{2}, x_{2}^{2}\right)$ são as coordenadas do ponto de solução alternativa $x_{2}$.

Uma generalização da expressão (10) que considera espaços n-dimensionais é dada pela equação (11): 


$$
d=\sqrt{\sum_{j=1}^{n}\left(x_{j}^{1}-x_{j}^{2}\right)^{2}}
$$

onde: $d$ representa quão distante a solução obtida encontra-se do ponto ideal.

n é o número de objetivos;

$x_{j}^{1}$ é a solução ótima do objetivo $\mathrm{j}$;

$x_{j}^{2}$ é o vetor de solução alternativo.

A Figura 4, utilizando o exemplo da Tabela 2, apresenta o esquema de distância entre o ponto ideal e uma solução intermediária. Considerando para o objetivo $1 \mathrm{o}$ valor de 8 unidades e para o objetivo 2, 11 unidades. Para o cálculo da distância euclidiana, representada por um triângulo retângulo, aplica-se a equação (11) resultando em 6,403 unidades.

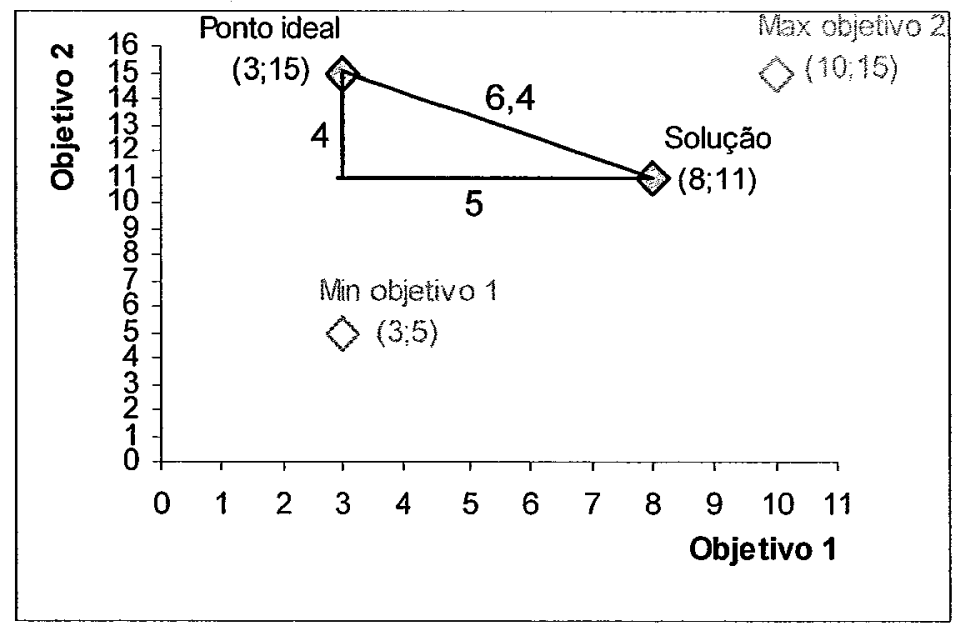

Figura 4 - Representação de distância entre o ponto ideal e uma solução alternativa para o modelo utilizado como exemplo.

Segundo Romero (1993) as ordens de grandeza de cada objetivo poderão influenciar de forma diferente a distância entre o ponto ideal e a solução obtida. Os objetivos que têm os resultados em maior ordem de grandeza poderão caracterizar 
situações de preferências sobre resultados de menor ordem. Para evitar tal discrepância, o autor sugere a normalização dos objetivos utilizando os melhores (ótimos) e piores (anti-ótimos) valores obtidos para cada objetivo, sendo a distância calculada da seguinte forma, equação (12):

$$
d=\sqrt{\sum_{j=1}^{n}\left(\frac{x_{j}^{1}-x_{j}^{2}}{x_{j}^{1}-x_{\bullet j}^{1}}\right)^{2}}
$$

onde: $x_{\bullet j}^{1}$ é o valor anti-ótimo do objetivo $\mathrm{j}$.

Desta forma, a distância entre o valor alcançado e o valor ótimo irá variar dentro do mesmo intervalo para todos os objetivos, $x_{j}^{1}=x_{j}^{2}=0$ e $x_{\bullet j}^{1}=x_{\bullet j}^{2}=1$. A melhor solução é aquela que minimiza a somatória de todas as distâncias em relação ao ponto ideal (Romero, 1993).

Além da forma euclidiana, generalizações do conceito de distância, como as estudadas por Minkowsky (descritas por Ferrer et al.,2000), poderão ser usadas para compor o conjunto compromisso. Conhecidas como família de métricas Lp, podem ser generalizadas pela equação (13):

$$
L_{p}=\left[\sum_{j=1}^{n}\left|x_{j}^{1}-x_{j}^{2}\right|^{p}\right]^{1 / p}
$$

onde: $\mathrm{Lp}$ representa a distância entre dois pontos para a métrica $\mathrm{p}$.

Variando o valor de $\mathrm{p}$ obtêm-se diferentes valores de distância da família de métricas Lp sendo que apenas as métricas 1 e 2 possuem significado geométrico. Utilizando os dados apresentados na Figura 4, foram calculados exemplos de distâncias para diferentes valores de $\mathrm{p}$, semelhantes aos exemplos fornecidos por Romero (1993).

$$
\begin{aligned}
& \mathrm{L}_{1}=|3-8|^{1}+|15-11|^{1}=9 \\
& \mathrm{~L}_{2}=\left[|3-8|^{2}+|15-11|^{2}\right]^{1 / 2}=6,403
\end{aligned}
$$




$$
\begin{aligned}
& L_{3}=\left[|3-8|^{3}+|15-11|^{3}\right]^{1 / 3}=5,739 \\
& L_{10}=\left[|3-8|^{10}+|15-11|^{10}\right]^{1 / 10}=5,051 \\
& L_{\infty}=\left[|3-8|^{\infty}+|15-11|^{\infty}\right]^{1 / \infty}=5
\end{aligned}
$$

A equação (14) representa a maior distância encontrada entre dois pontos, pois como se observa na Figura 4, representa a soma dos catetos do triângulo retângulo e a equação (15) representa a distância euclidiana mostrada na equação (11). Com o aumento do valor de $\mathrm{p}$ observam-se resultados cada vez menores, sendo o.menor obtido através da métrica Loo ou distância de Chebychev (Ferrer et al. 2000). Na equação (18), com $\mathrm{p}=\infty$, a distância assume o valor representado pelo maior cateto do triângulo retângulo.

Utilizando os conceitos de normalização semelhantes ao da equação (12), a equação geral de distância para a métrica $\mathrm{L}_{\mathrm{p}}$ é dada por (19):

$$
L_{p}=\left[\sum_{j=1}^{n}\left|\frac{x_{j}^{1}-x_{j}^{2}}{x_{j}^{1}-x_{\cdot j}^{1}}\right|^{p}\right]^{1 / p}
$$

A função objetivo do modelo de programação compromisso é representada pela equação (20). Essa equação é obtida, substituindo em (19) o valor do vetor de solução alternativa pela função que representa o iésimo objetivo, $\mathrm{f}_{\mathrm{i}}(\mathrm{x})$.

$$
L_{p}=\left[\sum_{j=1}^{n}\left|\frac{x_{j}^{1}-f_{j}(x)}{x_{j}^{1}-x_{\bullet j}^{1}}\right|^{p}\right]^{1 / p}
$$

O uso do algoritmo Simplex para programação linear permite apenas a solução da equação 20 para a métrica $\mathrm{p}=1$, que procurará minimizar a soma absoluta das distâncias entre cada objetivo e seu respectivo valor ótimo, sujeita às mesmas restrições $x \in F$.

Já com a métrica $\mathrm{p}=\infty$, o modelo tem como referência o maior desvio individual entre um objetivo e seu valor ótimo. É sobre este desvio que se promove a minimização, 
podendo ser implementada através de algoritmos de programação linear, conforme modelo apresentado pelas equações (21), (22) e (23) proposto por Ballestero (1997), Romero (1993), Steuer (1986) e Vincke (1992).

$\operatorname{Min} L_{\infty}=d$

Sujeito a

$$
\begin{aligned}
& x \in F \\
& \frac{x_{j}^{1}-f_{j}(x)}{x_{j}^{1}-x_{\bullet j}^{1}} \leq d \quad(j=1,2, \ldots n)
\end{aligned}
$$

A restrição representada pela equação (23) transfere para a variável d a distância entre o valor ótimo obtido pelo objetivo $\mathrm{j}$ e a solução encontrada. A restrição do tipo "menor ou igual" e o direcionamento dos desvios para a mesma variável resultam no efeito de minimização do maior desvio (Romero, 1993). Por obter resultados equilibrados para todos os objetivos (Ballestero, 1997), a métrica Lo mostra-se promissora para a solução de problemas que enfocam a sustentabilidade de sistemas de produção.

Alvez \& Clímaco (1999) utilizam método para a solução de problemas multiobjetivos de programação linear inteira. $\mathrm{O}$ método utiliza análises de sensibilidade para identificar as áreas dos pontos de referência que gerem um mesmo conjunto de soluções eficientes. As soluções são obtidas através da minimização das maiores distâncias entre as soluções eficientes e o vetor de referência utilizando programação compromisso.

Gonzalez-Pachón \& Romero (1999) em modelo que procura minimizar as distâncias entre pareceres de diversos grupos na busca de consenso para o ordenamento de alternativas, formulam modelos de programação por metas utilizando métricas que caracterizam os modelos de programação compromisso. A busca por soluções compromisso se baseou em propriedades como geração de soluções factíveis, ausência 
de dominância entre grupos e neutralidade. Estas propriedades fazem com que os modelos de programação compromisso sejam promissores para a elaboração de planos de manejo florestal que utilizam tendências ótimas ao invés de valores determinados por especialistas. 


\section{MATERIAL E MÉTODOS}

A elaboração do modelo que considera dimensões ecológicas, sociais e econômicas é baseada em informações de florestas plantadas de eucaliptos de propriedade da empresa Votorantin Celulose e Papel S/A (VCP). A empresa utiliza modelos de programação linear para a elaboração de seus planos de manejo, facilitando a obtenção das informações.

Este capítulo apresenta na sessão 3.1 as informações básicas de caracterização das áreas de produção e atividades de manejo utilizadas no estudo de caso. A partir dessas informações são descritas as formas de geração dos regimes alternativos de manejo e cálculos de seus valores monetários. A sessão 3.2 apresenta estrutura do modelo utilizado como parâmetro denominado modelo tradicional. A sessão 3.3 apresenta propostas de formulação de objetivos para as três dimensões e suas inserções em modelos multi-critério.

\subsection{Caracterização da área}

O estudo de caso é composto por 40 unidades de gestão distribuídas em 32 fazendas. As fazendas localizam-se no estado de São Paulo, região do Vale do Paraíba e são manejadas para o abastecimento de uma planta de produção de celulose no município de Jacareí. Com aproximadamente 8.500 hectares de efetivo plantio, a área de estudo, corresponde a $34 \%$ das áreas de produção da empresa na região. 


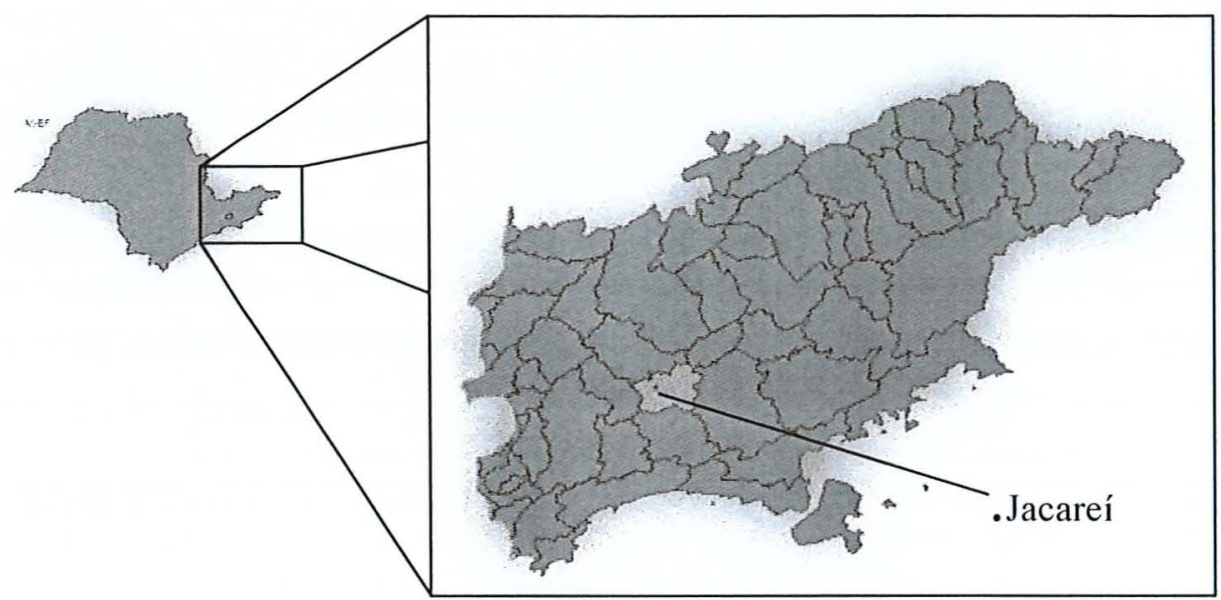

Figura 5 - Região de distribuição das fazendas utilizadas no estudo de caso com destaque para o município de Jacareí.

\subsubsection{Unidades de gestão}

As áreas de produção de madeira são divididas em unidades de gestão. A Tabela 3 lista informações de dimensões, material genético, idade, rotação e distância das unidades até a fábrica. Em cada unidade a empresa conduz apenas um material genético distribuído uniformemente por toda sua extensão.

Os volumes de colheita para cada unidade de gestão são estimados através de tabelas de produção para idades que variam entre 5 e 16 anos para a primeira e segunda rotação como mostra a Tabela 4 .

\subsubsection{Atividades de condução da floresta}

As formas de manejo das florestas podem ser descritas em seqüência cronológica de atividades. Os custos das atividade são compostos pela somatória das despesas com mão-de-obra, máquinas e insumos utilizados para a sua execução. Estas informações são utilizadas para o cálculo dos valores dos regimes. 
Tabela 3. Resumo das informações que compõem a área do estudo de caso.

\begin{tabular}{|c|c|c|c|c|c|c|}
\hline Fazenda & $\begin{array}{c}\text { Unidade de } \\
\text { Gestão }\end{array}$ & Rotação & $\begin{array}{c}\text { Código Material } \\
\text { Genético }\end{array}$ & $\begin{array}{c}\text { Área } \\
\text { (hectares) }\end{array}$ & $\begin{array}{l}\text { Idade } \\
\text { (anos) }\end{array}$ & $\begin{array}{l}\text { Distância da } \\
\text { Fábrica }(\mathrm{km})\end{array}$ \\
\hline Angola & 1 & 1 & 3 & 118.15 & 0 & 23 \\
\hline Santo Antonio 3 & 2 & 1 & 1 & 39.33 & 8 & 3 \\
\hline Banco & 3 & 1 & 3 & 374.6 & 0 & 22 \\
\hline Banco & 4 & 1 & 3 & 261.91 & 1 & 22 \\
\hline Barra Bonita & 5 & 1 & 1 & 139 & 5 & 33 \\
\hline Barra Limpa & 6 & 1 & 1 & 211.23 & 5 & 42 \\
\hline Bela Vista 3 & 7 & 1 & 1 & 156.13 & 5 & 33 \\
\hline Bela Vista 3 & 8 & 2 & 2 & 86.1 & 5 & 33 \\
\hline Santa Branca & 9 & 1 & 4 & 369.45 & 2 & 37 \\
\hline São Carlos & 10 & 1 & 1 & 339.08 & 3 & 32 \\
\hline Franco, Pena & 11 & 1 & 4 & 260.04 & 0 & 33 \\
\hline São Joaquim & 12 & 1 & 4 & 667.09 & 1 & 39 \\
\hline São José 4 & 13 & 1 & 1 & 206 & 5 & 32 \\
\hline São José 5 & 14 & 1 & 4 & 41.07 & 1 & 26 \\
\hline Santa Laura & 15 & 2 & 1 & 104.69 & 1 & 13 \\
\hline Santa Luzia & 16 & 1 & 1 & 193.1 & 1 & 25 \\
\hline Santa Maria & 17 & 1 & 4 & 473.5 & 2 & 40 \\
\hline Morro Azul & 18 & 1 & 1 & 465.32 & 5 & 46 \\
\hline São Pedro 2 & 19 & 1 & 1 & 236.1 & 3 & 28 \\
\hline Rogemar & 20 & 1 & 1 & 180.11 & 5 & 20 \\
\hline Rosa Helena & 21 & 1 & 1 & 75 & 4 & 34 \\
\hline Rosa Helena & 22 & 1 & 1 & 82 & 7 & 34 \\
\hline São Sebastão 3 & 23 & 1 & 1 & 78.98 & 6 & 21 \\
\hline São Silvestre & 24 & 1 & 1 & 145.79 & 7 & 1 \\
\hline Taboão & 25 & 1 & 1 & 290.04 & 4 & 40 \\
\hline Tietê & 26 & 1 & 4 & 51.51 & 1 & 30 \\
\hline Santo Antônio 2 & 27 & 1 & 5 & 75.55 & 1 & 62 \\
\hline Espirito Santo & 28 & 1 & 1 & 320.12 & 5 & 77 \\
\hline Hercília & 29 & 1 & 4 & 652.67 & 4 & 60 \\
\hline São Luiz & 30 & 1 & 1 & 159.52 & 6 & 73 \\
\hline Picapau Amarelo & 31 & 1 & 2 & 149.02 & 5 & 72 \\
\hline Santa Rita 2 & 32 & 1 & 5 & 123.4 & 0 & 60 \\
\hline Sertãozinho & 33 & 1 & 1 & 52.2 & 4 & 47 \\
\hline Sertãozinho & 34 & 2 & 1 & 30 & 6 & 47 \\
\hline Santa Terezinha 1 & 35 & 2 & 1 & 510.73 & 9 & 71 \\
\hline Karacy & 36 & 1 & 4 & 100 & 0 & 124 \\
\hline Karacy & 37 & 1 & 4 & 200 & 0 & 124 \\
\hline Karacy & 38 & 1 & 4 & 200 & 0 & 124 \\
\hline Karacy & 39 & 1 & 4 & 200 & 0 & 124 \\
\hline Karacy & 40 & 1 & 4 & 100 & 0 & 124 \\
\hline
\end{tabular}

Fonte: VCP (2001). 
Tabela 4. Produção estimada para os anos de colheita em primeira e segunda rotação das unidades de gestão (UG) utilizadas no estudo de caso

\begin{tabular}{|c|c|c|c|c|c|c|c|c|c|c|c|c|c|c|c|c|c|c|c|c|c|c|c|c|}
\hline \multirow[t]{2}{*}{$\mathbf{U G}$} & \multicolumn{12}{|c|}{$\begin{array}{c}\text { Rotação I } \\
\text { Idade }\end{array}$} & \multicolumn{12}{|c|}{$\begin{array}{c}\text { Rotação } 2 \\
\text { Idade }\end{array}$} \\
\hline & 5 & 6 & 7 & 8 & 9 & 10 & 11 & 12 & 13 & 14 & 15 & 16 & 5 & 6 & 7 & 8 & 9 & 10 & 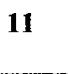 & 12 & 13 & 4 & 15 & 16 \\
\hline 1 & 271 & 318 & 50 & 373 & 388 & 407 & 422 & 5 & 7 & 457 & 66 & 474 & 230 & 270 & 298 & 317 & 330 & 347 & $50 \mathrm{f}$ & 372 & 382 & 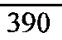 & & \\
\hline 2 & 207 & 231 & 7 & 275 & 288 & 300 & 312 & 321 & & 337 & & & & 6 & & 234 & 245 & 260 & & & & & & \\
\hline 3 & 56 & & & 53 & & & & & & 449 & & & & & & & & & & & & & & \\
\hline 4 & & & & & & & & & & & & & & & & & & & & & & & & \\
\hline 5 & & & & & & & & & & & & & & & & & & & & & & & & \\
\hline 6 & & & & & & & & & & & & & & & & & & & & & & & & \\
\hline 7 & 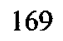 & & & & & & & & & & & & & & & & 213 & & & & & & & \\
\hline 8 & 69 & 201 & & 40 & & & & & & 300 & & & & & & & 209 & & & & & & & \\
\hline 9 & & & & & & & & & & & & & & & & & & & & & & & & \\
\hline 10 & & & & & & & & & & & & & & & & & & & & & & & & \\
\hline 11 & & & & & & & & & & & & & & & & & & & & & & & & \\
\hline 12 & & & & & & & & & & & & & & & & & & & & & & & & \\
\hline 13 & & & & & & & & & & & & & & & & & & & & & & & & \\
\hline 14 & & & & & & & & & & & & & & & & & & & & & & & & \\
\hline 15 & & & & & & & & & & & & & & & & & & & & & & & & \\
\hline 16 & & & & & & & & & & & & & & & & & & & & & & & & \\
\hline 17 & & & & & & & & & & & & & & & & & & & & & & & & \\
\hline 18 & & & & & & & & & & & & & & & & & & & & & & & & \\
\hline 19 & & & & & & & & & & & & & & & & & & & & & & & & \\
\hline 20 & & & & & & & & & & & & & & & & & & & & & & & & \\
\hline 2 & & & & & & & & & & & & & & & & & & & & & & & & \\
\hline 2 & & & & & & & & & & & & & & & & & & & & & & & & \\
\hline 23 & & & & & & & & & & & & & & & & & & & & & & & & 39 \\
\hline 2 & & & & & & & & & & & & & & & & & & & & & & & & \\
\hline 25 & & & & & & & & & & & & & & & & & & & & & & & & \\
\hline 26 & & & & & & & & & & & & & & & & & & & & & & & & \\
\hline 27 & & & & & & & & & & & & & & & & & & & & & & & & \\
\hline 28 & & & & & & & & & & & & & & & & & & & & & & & & \\
\hline 25 & & & & & & & & & & & & & & & & & & & & & & & & \\
\hline 38 & & & & & & & & & & & & & & & & & & & & & & & & \\
\hline & & & & & & & & & & & & & & & & & & & & & & & & \\
\hline 32 & & & & & & & & & & & & & & & & & & & & & & & & \\
\hline 33 & & & & & & & & & & & & & & & & & & & & & & & & \\
\hline 34 & & & & & & & & & & & & & & & & & & & & & & & & \\
\hline 3. & & & & & & & & & & & & & & & & & & & & & & & & \\
\hline & & & & & & & & & & & & & & & & & & & & & & & & \\
\hline & & & & & & & & & & & & & & & & & & & & & & & & \\
\hline & & & & & & & & & & & 3 & & & & & & & 2 & & & & & & \\
\hline & & & . & & 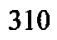 & & & & & & 3 & & & & & & 24 & 27 & & & 30 & & & 32 \\
\hline & 17 & 3 & 200 & 298 & 310 & & 80 & 578 & 30 & 300 & 373 & 300 & 84 & 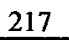 & 23 & 253 & 204 & 273 & 284 & 5 & 303 & SII & 310 & 32 \\
\hline
\end{tabular}

Fonte: VCP (2001). 
Durante o ciclo de vida da floresta a VCP prescreve para a região um grupo de atividades de condução distribuídas em implantação, manutenção e colheita. A implantação inicia-se com as atividades de limpeza, preparo do solo e plantio. As atividades de manutenção têm, como objetivo inicial, favorecer o estabelecimento da floresta com atividades de eliminação de mato-competição e adubação. e posteriormente, passam a ter funções de proteção contra pragas e incêndios através das roçadas e combates à formiga. As atividades de colheita iniciam-se com a limpeza da área para facilitar a entrada dos equipamentos que irão executar a colheita.

Considerou-se para toda área o uso do equipamento "harvester" em sistema de tora longa ${ }^{3}$ com custos médios praticados pela empresa de $\mathrm{R} \$ 6,50 /$ metro cúbico. Para o transporte da madeira da unidade de gestão até o carreador foi considerado o uso de um "forwarder" com custos médios praticados pela empresa de $\mathrm{R} \$ 2,50 /$ metro cúbico. O custo de transporte do carreador até a fábrica é calculado através do valor do frete, que segundo estimativas da empresa é de $\mathrm{R} \$ 0,0833 / \mathrm{t} . \mathrm{km}$ para a região.

A empresa conduz a floresta em até duas rotações com idades de corte próximas aos 7 anos. Os custos envolvidos na segunda rotação são geralmente mais baixos que na primeira devido principalmente à ausência de atividades de preparo de solo, plantio e por tratar-se de uma floresta com sistema radicular estabelecido. As Tabelas 5 e 6 descrevem as seqüências de atividades e custos envolvidos na condução das florestas utilizadas no estudo de caso desde a implantação até o preparo para colheita.

\footnotetext{
2 Nome genérico de trator florestal que na VCP executa atividades de corte, descascamento, seccionamento e empilhamento da madeira dentro da unidade de gestão.

${ }^{3}$ Seccionamento da árvore em toras de aproximadamente 6 metros de comprimento.

${ }^{4}$ Nome genérico de um caminhão florestal equipado com uma grua, desenvolvido para a retirada de madeira das áreas internas da unidade de gestão.
} 
Tabela 5. Custos anuais de atividades previstas para a condução das unidades de gestão durante a primeira rotação.

\begin{tabular}{clr}
\hline $\begin{array}{c}\text { Idade } \\
\text { (anos) }\end{array}$ & Atividade & $\begin{array}{r}\text { Total } \\
\text { (R\$/ha) }\end{array}$ \\
\hline 0 & Capina química manual área total I & 94,90 \\
0 & Preparo do solo mecanizado & 62,50 \\
0 & Adubação pré plantio & 179,28 \\
0 & Plantio & 242,15 \\
0 & subtotal & $\mathbf{5 7 8 , 8 3}$ \\
1 & Capina química manual área total I & 139,96 \\
1 & Capina química manual área total II & 125,11 \\
1 & Capina química manual área coroa pré & 64,18 \\
1 & Roçada manual I & 112,50 \\
1 & Combate formigas & 52,13 \\
1 & Adubação química 3 meses & 197,55 \\
1 & Aplicação de calcário & 44,82 \\
1 & Adubação fosfatada & 65,91 \\
1 & subtotal & $\mathbf{8 0 2 , 1 7}$ \\
2 & Capina química manual área total II & 162,65 \\
2 & Roçada manual I & 11,25 \\
2 & Combate formigas & 32,58 \\
2 & Adubação química 18 meses & 45,54 \\
& subtotal & $\mathbf{2 5 2 , 0 2}$ \\
3 & Capina química manual área total II & 62,56 \\
3 & Roçada manual I & 11,25 \\
3 & Combate formigas & 19,55 \\
3 & subtotal & $\mathbf{9 3 , 3 5}$ \\
4 & Capina química manual área total II & 62,56 \\
4 & Roçada manual I & 11,25 \\
4 & Combate formigas & 19,55 \\
4 & subtotal & $\mathbf{9 3 , 3 5}$ \\
$>=5$ & Capina química manual área total II & 6,26 \\
$>=5$ & Roçada manual II & 7,87 \\
$>=5$ & Combate formigas & 3,26 \\
$>=5$ & subtotal & $\mathbf{1 7 , 3 9}$ \\
colheita & Roçada pré corte química manual & 96,08 \\
colheita & Combate formigas & 32,58 \\
& subtotal & $\mathbf{1 2 8 , 6 6}$ \\
\hline & & \\
& & \\
\hline
\end{tabular}

Fonte: VCP (2001). 
Tabela 6. Custos anuais de atividades previstas para a condução das unidades de gestão durante a primeira rotação.

\begin{tabular}{clr}
\hline $\begin{array}{c}\text { Idade } \\
\text { (anos) }\end{array}$ & \multicolumn{1}{c}{ Atividade } & $\begin{array}{r}\text { Total } \\
\text { (R\$/ha) }\end{array}$ \\
\hline 0 & Capina química manual área total I & 139,96 \\
0 & Roçada manual I & 112,50 \\
0 & Combate formigas & 52,13 \\
$\mathbf{0}$ & subtotal & $\mathbf{3 0 4 , 5 9}$ \\
1 & Desbrota manual & 225,00 \\
1 & Capina química manual área total II & 12,49 \\
1 & Roçada manual I & 11,25 \\
1 & Combate formigas & 32,58 \\
1 & Adubação química 18 meses 2rot & $\mathbf{1 3 6 , 8 0}$ \\
$\mathbf{1}$ & subtotal & $\mathbf{4 1 8 , 1 2}$ \\
2 & Capina química manual área total II & $\mathbf{6 , 2 6}$ \\
2 & Roçada manual II & 7,87 \\
2 & Combate formigas & 3,26 \\
2 & subtotal & $\mathbf{1 7 , 3 9}$ \\
$>=3$ & Combate formigas & 32,58 \\
$>=3$ & subtotal & $\mathbf{3 2 , 5 8}$ \\
\hline
\end{tabular}

Fonte: VCP (2001).

\subsubsection{Geração de alternativas de regimes de manejo}

Embora seja prescrito para o manejo das unidades de gestão um mesmo grupo de atividades, os regimes de manejo poderão variar de acordo com as idades de colheita e opções de condução de segunda rotação. Desta forma, torna-se necessário listar o conjunto das possíveis alternativas de regimes de condução por unidade para posterior seleção daquela que melhor atenda aos objetivos propostos. A alternativa terá como resultado uma contribuição volumétrica em uma determinada data, resultando em custos e receitas distintos para cada uma delas.

A composição dos regimes de manejo utiliza as informações de seqüências de custos apresentadas nas Tabelas 5 e 6 e variações de idades de corte e volumes resultantes para cada unidade, Tabela 4. Aos regimes são relacionados os custos de manejo e os volumes de madeira produzidos pela floresta. Com as estimativas de volume aliadas às idades de corte é possível prever quanto e quando cada unidade de gestão poderá contribuir com madeira. 
Cada regime considera um ciclo florestal completo determinando o número de rotações e a duração de cada uma delas. A geração dos regimes alternativos é obtida através da combinação das idades de colheita de todas as rotações possíveis. A Figura 6 simula o resultado obtido a partir da prescrição de manejo para uma unidade de gestão. A situação criada prevê a condução da floresta em duas rotações com alternativas de corte dos 6 aos 9 anos, gerando 16 alternativas de manejo.

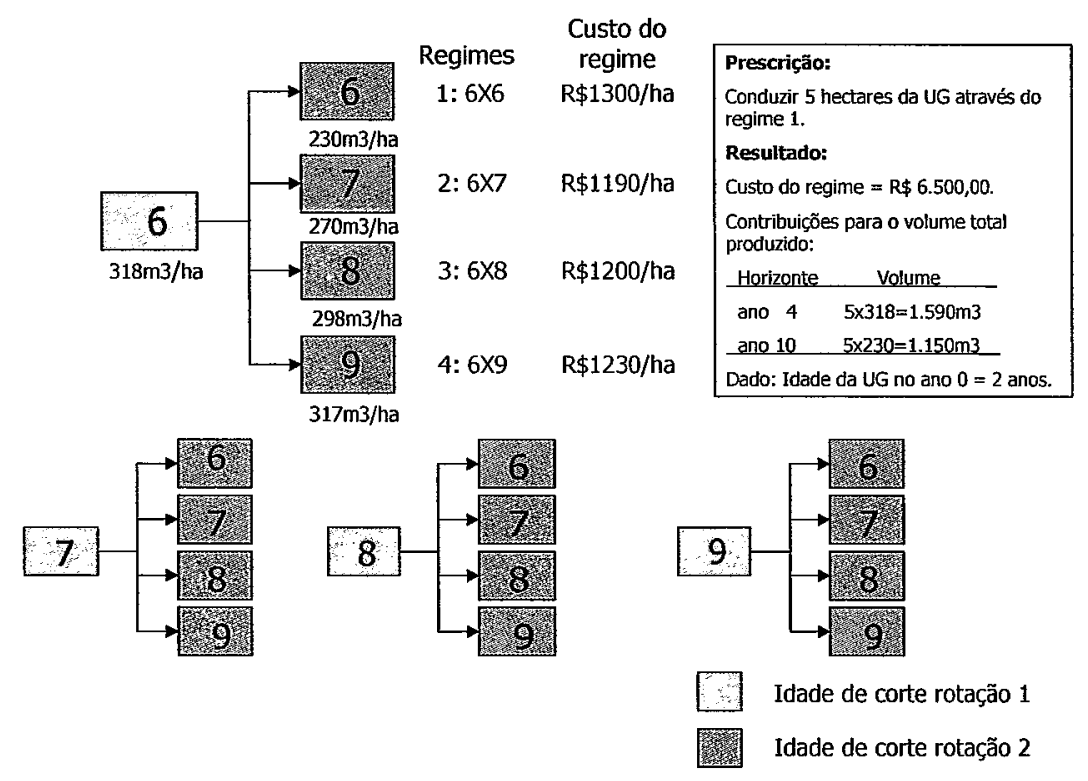

Figura 6 - Exemplo fictício de prescrição de manejo para unidade de gestão com 2 anos de idade no primeiro ano do horizonte de planejamento com 16 regimes alternativos.

No exemplo da Figura 5, a opção de condução de 5 hectares da unidade através do regime 1 resultaria em um custo total de $\mathrm{R} \$ 6.500,00$ (5 ha $\times \mathrm{R} \$ 1.300,00 / \mathrm{ha}$ ). Como o regime prevê colheitas aos 6 anos para as duas rotações e, considerando que a unidade de gestão estaria com idade inicial de 2 anos em primeira rotação, suas contribuições com madeira ocorreriam nos anos 4 e 10 do horizonte de planejamento. Segundo estimativas das tabelas de produção essas contribuições seriam de respectivamente 1.590 ( 5 ha $\times 318 \mathrm{~m}^{3} / \mathrm{ha}$ ) e 1150 (5 ha $230 \mathrm{~m}^{3} / \mathrm{ha}$ ) metros cúbicos. 


\subsubsection{Cálculo dos valores dos regimes}

A partir da data de colheita é possível localizar, ao longo do horizonte de planejamento, cada uma das atividades de implantação e manutenção. $\mathrm{O}$ valor presente líquido de cada regime é obtido através da subtração do valor presente dos custos das atividades do valor presente das receitas obtidas com a produção de madeira.

Os regimes prescrevem diferentes durações para o ciclo florestal. Ao comparálos, torna-se necessário ajustar seus valores para que estes possam refletir o estado da floresta ao final do horizonte de planejamento. Segundo Rodriguez et al. (1997), as conseqüências do uso de critérios inadequados, como a comparação direta do valor presente dos regimes em diferentes escalas temporais, levaria à não consideração do uso da terra após o término do ciclo e ainda a subestimativa de custos, resultantes do aumento ou diminuição do tamanho das rotações. Para a solução do problema, utiliza-se no ajuste a fórmula de Faustmann como sugerem Buongiorno \& Gilles (1987), Newman (1988) e Rodriguez et al. (1997).

Através da fórmula de Faustmann, também conhecida como valor técnico da terra ou valor esperado da terra (VET), é possível avaliar regimes com diferentes escalas temporais, pois pressupõe-se a repetição do regime perpetuamente. Desta forma, os regimes podem ser comparados pois passam a possuir o infinito como escala temporal. O VET utiliza o princípio da série de pagamentos periódicos perpétuos conforme descrito por Rodriguez (1991) e apresentado na equação (24).

$$
V 0=\frac{a}{\left[(1+i)^{p}-1\right]}
$$

onde: $V 0=$ valor presente da série de pagamentos periódicos perpétuos;

$\mathrm{p}=$ número de anos de duração do período;

$\mathrm{a}=$ pagamento periódico a cada $\mathrm{p}$ anos;

$\mathrm{i}=$ taxa de juros anual. 
Considerando que o ciclo avaliado se repete infinitas vezes e assumindo que não haveriam alterações de produtividade e técnicas de manejo e por conseqüência, alterações dos custos e receitas envolvidas, o VET é obtido substituindo na equação (24) o pagamento periódico pela receita líquida calculada no final de cada ciclo.

$$
V E T=\frac{R L_{p}}{\left.\left[(1+i)^{p}-1\right)\right]}
$$

onde: $\mathrm{RL}_{\mathrm{p}}=$ valor da receita líquida do ciclo no ano $\mathrm{p}$

Para promover o ajuste dos valores dos regimes deve-se, primeiramente, encontrar para cada unidade de manejo o regime que resulte em maior VET. Este processo é conhecido como determinação da idade ótima de colheita por critérios econômicos (Newman, 1988; Leuschner, 1990; Rodriguez et al., 1997 e Romero, 1997). Este valor deve ser somado ao final da última rotação prevista pelo regime . Rodriguez \& Moreira (1989) descrevem os critérios utilizados para proceder esta soma em diferentes situações.

Situação 1: se o intervalo de tempo entre o corte da última rotação do regime e o final do período de planejamento permite uma primeira rotação do ciclo economicamente ótimo, repete-se mais um ciclo do regime em questão e à receita obtida com o último corte desse ciclo soma-se o VET.

Situação 2: se o intervalo de tempo entre o corte da última rotação do regime e o final do período de planejamento não permite uma primeira rotação do ciclo economicamente ótimo, encerra-se o fluxo de caixa no ano de corte da última rotação do ciclo em questão e soma-se o VET do ciclo economicamente ótimo à receita obtida com esse último corte.

Situação 3: se o último corte do regime ocorre exatamente no último ano do horizonte de planejamento, encerra-se o fluxo de caixa nesse ano e soma-se o VET do ciclo economicamente ótimo à receita obtida com esse corte. 
O método de cálculo dos valores dos regimes é apresentado por Nobre \& Rodriguez (2001). Os autores desenvolveram um "software" que utiliza como informação para cada unidade de gestão, os custos anuais das atividades de manejo, tabelas de produção, taxa anual de juros, número mínimo e máximo de rotações e idades de corte. Como resultado o "software" calcula os valores de todos os regimes gerados, utilizando metodologia descrita anteriormente. Além dos valores dos regimes, são fornecidas as contribuições volumétricas de cada regime durante o horizonte de planejamento. A partir destas informações é possível estruturar os modelos de programação linear.

\subsection{Modelo tradicional}

Utilizou-se como base para o modelo tradicional a estrutura tipo I proposta por Johnson \& Scheurman (1977). O modelo é composto por função objetivo de maximização do valor total do projeto, restrições de área e controle anual de produção.

\subsubsection{Parâmetros}

O modelo utiliza as informações contidas nas Tabelas 3, 4, 5 e 6 . Cada UG pode ser conduzida através de uma ou duas rotações. A taxa de juros utilizada é de $10 \%$ ao ano e o valor da receita bruta por metro cúbico de madeira posto fábrica é de $R \$ 30,00$.

\subsubsection{Estrutura do modelo}

Com os valores dos regimes calculados, é possível elaborar o modelo matemático de programação linear. A formulação do modelo envolve as seguintes informações:

$\mathrm{N}$ = número total de unidades de manejo;

$\mathrm{M}=$ número total de regimes de manejo florestal;

$\mathrm{p}=$ número de períodos de colheita;

$A_{i}=$ área total da unidade $i$;

$\mathrm{X}_{\mathrm{ik}}=$ área da unidade $\mathrm{i}$ manejada através do o regime de manejo $\mathrm{k}$; 
$\mathrm{D}_{\mathrm{ik}}=$ valor presente por hectare colhido da unidade $\mathrm{i}$ através do regime $\mathrm{k}$;

$\mathrm{V}_{\mathrm{ijk}}=$ volume por hectare colhido na unidade $\mathrm{i}$ no período $\mathrm{j}$ através do regime $\mathrm{k}$;

com intervalos válịdos para os subscritos:

$\mathrm{i}=1,2, \ldots, \mathrm{N}$;

$\mathrm{j}=1,2, \ldots, \mathrm{p}$;

$\mathrm{k}=1,2, \ldots, \mathrm{M}$.

A função objetivo do modelo de programação linear que tentará maximizar o valor total do plano de manejo é dada por:

$\operatorname{Max} V T P=\sum_{i=1}^{N} \sum_{k=1}^{M} D_{i k} X_{i k}$

onde: VTP corresponde ao valor presente total do o fluxo de receitas líquidas do horizonte de planejamento.

Somadas as áreas dos regimes escolhidos para cada unidade, essas não poderão ultrapassar a área total da unidade de manejo, este controle é feito pelas seguintes restrições:

$$
\sum_{k=1}^{M} X_{i k}=A_{i}
$$

Exigências de cotas mínimas de produção são feitas, geralmente, com a imposição de cotas volumétricas anuais através das restrições:

$$
\sum_{i=1}^{N} \sum_{k=1}^{M} V_{i j k} X_{i k} \geq \mathrm{Esp}_{\mathrm{j}}
$$

onde: $\mathrm{Esp}_{\mathrm{j}}$ corresponde ao volume esperado para $\mathrm{o}$ ano $\mathrm{j}$

Como o estudo de caso representa apenas parte da área total de produção da empresa, torna-se difícil estimar as exigências volumétricas impostas para a área. Por este motivo, as cotas de produção anuais são calculadas intrinsecamente ao modelo, 
como mostram Rodriguez \& Borges (1999). De acordo com esses autores, é possível encontrar o valor mínimo que a área de estudo tenha capacidade de produzir, substituindo-se na equação (28) o valor do volume anual demandado pelo centro consumidor por uma variável contábil e adicionando restrições de controle de produção, como mostram as equações (29) e (30). Este valor mínimo é utilizado como volume de produção demandado pelo centro consumidor.

$$
\sum_{i=1}^{N} \sum_{k=1}^{M} V_{i j k} X_{i k}-\operatorname{Prod}_{j}=0
$$

$$
\operatorname{Pr} o d_{1}-\operatorname{Pr} o d_{j}<0
$$$$
(j=1,2, \ldots, p)
$$

onde: $\operatorname{Prod}_{1}$ é a variável contábil de produção de madeira no período 1.

\subsection{Modelos que otimizam múltiplos objetivos}

Antes da definição dos critérios de seleção, deve-se conhecer seu escopo de atuação. Isto é feito através da observação dos efeitos das prescrições do plano de colheita sobre fatores ambientais, sociais e econômicos. A partir desta observação o gestor poderá inserir no modelo critérios para a escolha de regimes que minimizem ou impeçam o impacto sobre os três fatores.

\subsubsection{Objetivos econômicos}

Ruitenbeek \& Cartier (1997) propõem uma lista de critérios e indicadores socioeconômicos de sustentabilidade para florestas de produção. As principais preocupações dos indicadores listados são a perpetuação e melhoria da qualidade de sistemas produtivos e da qualidade de vida de grupos afetados por estes sistemas como acionistas, funcionários, moradores das áreas de entorno entre outros.

Entre os principais pontos propostos pelos autores destacam-se a necessidade de geração de lucro, a perpetuidade da floresta e a possibilidade de seu uso múltiplo, a geração e manutenção de empregos, a viabilização do aumento da qualidade de vida da população envolvida entre outros. Considerar tais indicadores sob o ponto de vista do 
gestor florestal, significa identificar os efeitos de suas decisões sobre cada um destes pontos.

Conforme visto anteriormente, cada unidade de gestão possui diversas alternativas de regimes de manejo. Cada regime está relacionado a uma receita líquida e a uma contribuição volumétrica em um ano do horizonte de planejamento. A partir do controle dos parâmetros idade de corte e receita líquida, é possível considerar no modelo de decisão os critérios de lucratividade, perpetuação da floresta e possibilidade de uso múltiplo. $\mathrm{O}$ critério de lucratividade pode ser representado pela mesma equação de maximização do valor total do projeto que gera o plano tradicional, equação (26).

A perpetuidade da floresta é representada pelo ordenamento da produção, também conhecido como modelo de rendimentos sustentáveis (Borges, 1999). A implementação é feita através da substituição das restrições de produção que atendem à demanda anual da fábrica, equação (28), pela equação (29). O ordenamento é promovido, inserindo-se no conjunto de restrições imposições para produções anuais não decrescentes promovidas pela substituição da equação (30) pela (31) (Rodriguez e Borges, 1999).

$$
\operatorname{Prod}_{j+1}-\operatorname{Pr} o d_{j} \geq 0 \quad(j=1,2, \ldots, p)
$$

Com o critério de maximização do valor total do projeto, os volumes produzidos anualmente poderão ser menores do que a real capacidade produtiva da floresta. Isto acontece porque o modelo seleciona os regimes a partir de valores de receita líquida. Caso os valores produzidos anualmente não atendam à demanda por matéria prima, o centro consumidor poderá estar disposto a assumir maiores despesas autorizando a seleção de regimes com receitas líquidas menores. A real capacidade produtiva da floresta poderá ser representada pela maximização do volume de madeira produzido no primeiro ano do horizonte de planejamento. Como as produções subseqüentes deverão ser maiores ou iguais à produção do primeiro ano, o resultado volumétrico estará mais próximo da capacidade máxima de produção. O modelo que maximiza a produção é 
tratado como segundo objetivo, formado a partir da substituição da equação (26) pela equação (32) no modelo que maximiza o valor total do projeto.

$$
\operatorname{Max}: \operatorname{Pr} o d_{1}
$$

\subsubsection{Objetivos sociais}

Conforme apresentado nas Tabelas 5 e 6 a condução da floresta segue um conjunto de atividades ordenadas cronologicamente, sendo seus custos compostos pelos valores individuais de horas-homem, de horas-máquina e de insumos multiplicados por seus rendimentos por hectare. A partir dos rendimentos de cada atividade, expressos em horas-homem por hectare, é possível avaliar de forma generalizada os efeitos do plano de manejo sobre a demanda total por horas-homem durante todo horizonte de planejamento. A Tabela 7 apresenta somatória anual de horas-homem utilizadas para execução das atividades listadas nas Tabelas 5 e 6.

Tabela 7. Número de horas-homem necessárias para a implantação, manutenção e preparo para corte de um hectare de floresta segundo prescrições das Tabelas 5 e 6.

\begin{tabular}{ccr}
\hline Rotação & $\begin{array}{c}\text { Idade } \\
\text { (anos) }\end{array}$ & $\begin{array}{r}\text { Total de horas-homem } \\
\text { (horas/ha) }\end{array}$ \\
\hline 1 & 0 & 53,36 \\
1 & 1 & 73,28 \\
1 & 2 & 26,12 \\
1 & 3 & 11,08 \\
1 & 4 & 11,08 \\
1 & $>=5$ & 2,50 \\
1 & colheita & 4,80 \\
2 & 1 & 42,24 \\
2 & 2 & 56,04 \\
2 & $>=3$ & 2,50 \\
2 & colheita & 4,80 \\
\hline
\end{tabular}

Fonte: VCP (2001) 
A data de colheita é um marco em que onde se baseiam todas as atividades de condução da floresta, desta forma, a demanda anual por mão-de-obra poderá variar de acordo com a seleção dos regimes de manejo. Utilizando dados da Tabela 7, essas variações poderão ser calculadas a partir da somatória do número de horas-homem utilizadas por cada regime selecionado por ano, conforme apresentado na equação (33).

$$
\sum_{i=1}^{N} \sum_{k=1}^{M} H H_{i j k} X_{i k}=H H t_{j}
$$

onde: $\mathrm{HH}_{\mathrm{ijk}}$ corresponte ao número de horas-homem utilizadas pela unidade $\mathrm{i}$, regime k no ano j;

$\mathrm{HHt}_{\mathrm{j}}$ é o valor total de horas-homem utilizadas no ano $\mathrm{j}$.

Os efeitos destas variações podem ser prejudiciais à sustentabilidade social das regiões que abastecem a empresa com mão-de-obra. Estes efeitos podem ser amenizados quando considerada a minimização das variações anuais de demanda por horas-homem durante o processo de decisão. A equação (34), semelhante à equação (4), utiliza variáveis contábeis para captar estas variações.

$$
H H t_{j}-\operatorname{difp}_{j}+\operatorname{difn}_{j}=H H t_{j-1}
$$

onde: $\operatorname{difp}_{\mathrm{j}} \mathrm{e}$ difn $_{\mathrm{j}}$ são respectivamente desvios anuais totais, positivos e negativos de horas-homem demandadas; $\mathrm{HHt}_{\mathrm{j}-1}$ Ano anterior ao ano $\mathrm{j}$.

Sugere-se como terceiro objetivo do modelo multi-critério para a elaboração do plano de manejo a minimização da soma dos desvios anuais de demanda por horas homem, representado pela equação (35).

$$
\operatorname{Min} D H H=\sum_{j=1}^{p} \operatorname{difp}_{j}+\operatorname{difn}_{j}
$$

onde: DHH representa a somatória dos desvios anuais de demanda por horashomem. 


\subsubsection{Objetivos ecológicos}

Conforme descrito na sessão 2.2.2, rotações ecologicamente ótimas são geralmente maiores que as ótimas econômicas ou volumétricas. Seguindo esse raciocínio, pode-se dizer que para um mesmo período de tempo critérios ecológicos de seleção de regimes teriam preferência por aqueles que resultassem em um menor número de intervenções de colheitas.

Cada regime prescreve um número de intervenções de colheita durante o horizonte de planejamento. Regimes com rotações mais curtas prevêem um maior número de intervenções. Desta forma, maximizar o período rotacional teria o mesmo efeitos de minimizar o número de intervenções de colheita. Este valor é obtido através da combinação das idades de corte de primeira e segunda rotações, considerando as idades da unidade de gestão no início do horizonte de planejamento. A partir destas informações, o número de rotações é obtido através da contagem das prescrições de corte compreendidas no intervalo de 20 anos, considerado como horizonte de planejamento. A representação da função objetivo com base nestes valores é apresentada pela equação (36).

$$
\text { Min CT: } \sum_{i=1}^{N} \sum_{k=1}^{M} R_{i k} X_{i k}
$$

onde: $\mathrm{R}_{\mathrm{ik}}$ corresponde ao número de intervenções de colheitas da unidade $\mathrm{i}$ prescritas pelo regime $\mathrm{k}$;

CT corresponde ao total de intervenções de colheita durante o horizonte de planejamento.

Os modelos de programação linear permitem a seleção parcial de regimes de manejo, ou seja, uma unidade de gestão poderá ter parte de sua área conduzida por um ou mais regimes. Por esse motivo, a equação (37), proposta como quarto objetivo do 
modelo de geração do plano de manejo, pondera o número total de rotações pela área total da unidade de gestão.

$$
\sum_{i=1}^{N} \sum_{k=1}^{M} \frac{R_{i k}}{A_{i}} X_{i k}
$$

\subsubsection{Matriz de pagamentos}

Definidos os quatro objetivos, equações (26),(32),(35) e (37), é necessário conhecer para cada um o seu valor ótimo, dadas as restrições de produção e área. A seguir são apresentadas equações que compõem o modelo que maximiza o valor total do projeto:

\section{Maximizar}

$V T P: \sum_{i=1}^{N} \sum_{k=1}^{M} D_{i k} X_{i k}$

Sujeito a

$$
\begin{aligned}
& \sum_{k=1}^{M} X_{i k}=A_{i} \\
& \sum_{k=1}^{M} V_{i j k} X_{i k}=\operatorname{Pr} o d_{j} \\
& \operatorname{Pr} o d_{j+1}-\operatorname{Pr} o d_{j}=0 \\
& \sum_{i=1}^{N} \sum_{k=1}^{M} \frac{R_{i k}}{A_{i}} X_{i k}=C T \\
& \sum_{i=1}^{N} \sum_{k=1}^{M} H H_{i j k} X_{i k}=H H t_{j} \\
& H H t_{j}-\text { difp }_{j}+d i f n_{j}=H H t_{j-1} \\
& \sum_{j=1}^{p} d_{i f p_{j}}+\text { difn }_{j}=D H H
\end{aligned}
$$


As equações (39), (40) e (41) são consideradas restrições do problema, as equações (42), (43), (44) e (45) são utilizadas apenas para o cálculo das variáveis contábeis que irão compor a matriz de pagamentos. $O$ modelo a seguir procura maximizar o volume de madeira produzido. Estruturalmente o modelo trata como objetivo a o volume produzido no primeiro ano, transferindo a equação (38) para o conjunto de equações contábeis. A seguir é apresentado o modelo que maximiza o volume de madeira a ser produzido.

$$
\begin{aligned}
& \text { Maximizar } \\
& \text { Pr od } \\
& \text { Sujeito a } \\
& \sum_{i=1}^{N} \sum_{k=1}^{M} D_{i k} X_{i k}=V T P \\
& \text { e equações (39), (40), (41), (42), (43), (44) e (45). }
\end{aligned}
$$

O controle da variação do número de horas-homem utilizadas é feito pelas equações (43) que calcula a quantidade de horas utilizada anualmente, (44) que calcula a variação anual destas horas, e (45) que calcula o total de variações do horizonte de planejamento. $\mathrm{O}$ modelo que procura minimizar a variação anual de demanda por horashomem utiliza como função objetivo a equação (45), conforme apresentado a seguir:

$$
\begin{aligned}
& \text { Minimizar } \\
& D H H: \sum_{j=1}^{p} \operatorname{difp}_{j}+\operatorname{difn}_{j}
\end{aligned}
$$

Sujeito a

equações (39), (40), (41), (42), (43), (44) e (47).

O quarto objetivo procura minimizar o número de rotações totais durante o horizonte de planejamento. Esse total é calculado pela equação (42) que passa a ser tratada como função objetivo conforme apresentado a seguir: 


\section{Minimizar}

$C T: \sum_{i=1}^{N} \sum_{k=1}^{M} \frac{R_{i k}}{A_{i}} X_{i k}$

Sujeito a

equações (39), (40), (41), (43), (44), (45) e (47).

A matriz de pagamentos é composta pelos resultados armazenados nas variáveis contábeis de cada modelo o que resultará na matriz apresentada na Tabela 8.

Tabela 8. Estrutura da matriz de pagamentos baseada nos modelos de otimização individuais.

\begin{tabular}{lcccc}
\hline Modelos & VTP & $\begin{array}{c}\text { Produção } \\
(\mathbf{m})\end{array}$ & $\begin{array}{c}\text { Número } \\
\text { de cortes } \\
\text { (unid.) }\end{array}$ & $\begin{array}{c}\text { Variação } \\
\text { de HH } \\
\text { (horas) }\end{array}$ \\
\hline Max VTP & VTP* & Prod $_{1}$ & CT & DHH \\
Max Produção & VTP & Prod $_{\mathbf{1}}{ }^{*}$ & CT & DHH \\
Min Colheitas & VTP & Prod $_{1}$ & CT* & DHH \\
Min Var. HH & VTP & Prod $_{1}$ & CT & DHH* $^{*}$ \\
\hline
\end{tabular}

onde: * representa os valores ótimos obtidos durante a otimização individual

\subsubsection{Modelo proposto}

Os modelos de programação por metas dependem de um referencial técnico para cada dimensão geralmente baseado na opinião de especialistas. Além da definição das metas para cada objetivo existe a necessidade de definição dos desvios aceitáveis para cada uma delas. Com o objetivo de obter planos de manejo baseados em soluções imparciais, optou-se pela formulação de um modelo de programação compromisso. Conforme descrito anteriormente o modelo utiliza funções de distância para a busca de soluções, utilizando como critério de seleção a escolha daquela que se encontre mais próxima ao ponto ideal. A equação (50) representa o vetor de solução ideal baseada em informações da Tabela 8. 


$$
\mathrm{Z}^{*}=\left[\mathrm{VTP}^{*}, \operatorname{Prod}_{1}{ }^{*}, \mathrm{CT}^{*}, \mathrm{DHH}^{*}\right]
$$

São propostos dois modelos de programação compromisso. O primeiro, para a métrica $L=1$, procura minimizar a soma das distâncias da solução obtida em relação ao ponto ideal.

\section{Minimizar}

$D: d_{1}+d_{2}+d_{3}+d_{4}$

Re strições

$\sum_{i=1}^{N} \sum_{k=1}^{M} D_{i k} X_{i k}=V T P$

$\sum_{k=1}^{M} X_{i k}=A_{i}$

$\sum_{k=1}^{M} V_{i j k} X_{i k}=\operatorname{Prod}_{j}$

$\operatorname{Prod} d_{j+1}-{\operatorname{Pr} o d_{j}}_{j}=0$

$C T: \sum_{i=1}^{N} \sum_{k=1}^{M} \frac{R_{i k}}{A_{i}} X_{i k}$

$\sum_{i=1}^{N} \sum_{k=1}^{M} H H_{i j k} X_{i k}=H H t_{j}$

$H H t_{j}-\operatorname{difp}_{j}+\operatorname{difn}_{j}=H H t_{j-1}$

$\sum_{j=1}^{p} \operatorname{difp}_{j}+\operatorname{difn}_{j}=\mathrm{DHH}$

$\frac{V T P^{*}-V T P}{V T P^{*}-V T P}=d_{1}$

$\frac{\operatorname{Pr} o d_{1}^{*}-\operatorname{Pr} o d_{1}}{\operatorname{Pr} o d_{1}^{*}-\operatorname{Pr} o d_{\cdot 1}}=d_{2}$

$\frac{C T^{*}-C T}{C T^{*}-C T .}=d_{3}$

$\frac{D H H^{*}-D H H}{D H H^{*}-D H H_{0}}=d_{4}$

onde: $d_{1}$ é a distância entre a solução obtida para o VTP e o seu valor ótimo 
$\mathrm{d}_{2}$ é a distância entre a solução obtida para Prod 1 e o seu valor ótimo $\mathrm{d}_{3}$ é a distância entre a solução obtida para CT e o seu valor ótimo $\mathrm{d}_{4}$ é a distância entre a solução obtida para DHH e o seu valor ótimo * representa o melhor valor obtido para o objetivo - representa o pior valor obtido para o objetivo

As equações (60), (61), (62), (63) são utilizadas para cálculo do valor da distância entre a solução obtida e os valores ótimos de cada objetivo. Para evitar que as diferentes escalas de grandezas influenciem a seleção dos regimes, promove-se a normalização das distâncias conforme descrito para a equação (12).

O segundo modelo utiliza métrica L $\infty$ para cálculo das distâncias da solução obtida em relação ao ponto ideal. Diferente do modelo anterior, este modelo procura minimizar a maior distância entre os quatro objetivos. Para isso o modelo direciona todos os desvios para a mesma variável. Dessa forma a variável $\mathrm{d}$ assumirá o valor do objetivo que mais se distancia de seu valor ótimo, sendo este valor transferido para os demais objetivos.

\section{Minimizar}

$D: d$

Sujeito a

$$
\begin{aligned}
& \text { equações (52), (53), (54), (55), (56), (57), (58), (59) } \\
& \frac{V T P^{*}-V T P}{V T P^{*}-V T P .}=d \\
& \frac{\operatorname{Pr} o d_{1}^{*}-\operatorname{Pr} o d_{1}}{\operatorname{Pr} o d_{1}^{*}-\operatorname{Pr} o d_{\bullet 1}}=d \\
& \frac{C T^{*}-C T}{C T^{*}-C T}=d \\
& \frac{D H H^{*}-D H H}{D H H^{*}-D H H}=d
\end{aligned}
$$




\section{RESULTADOS E DISCUSSÃO}

A seguir são descritos os resultados obtidos para o estudo de caso. A sessão 4.1 apresenta valores obtidos para o modelo que servirá de parâmetro de comparação para os modelos propostos. Os resultados da otimização individual dos objetivos são apresentados na sessão 4.2. A sessão 4.3 apresenta resultados dos modelos propostos.

\subsection{Modelo tradicional}

O modelo utilizado como parâmetro de comparação procura maximizar o valor presente líquido total do projeto e regular a produção de forma a encontrar uma cota volumétrica que maximiza o menor valor de produção anual $\left(\mathrm{m}^{3} / \mathrm{ano}\right)$. Este valor, encontrado intrinsecamente, é utilizado como exigência volumétrica anual para os demais modelos.

A solução ótima obtida após 661 iterações resultou em valor total do projeto de $\mathrm{R} \$ 42.355 .625$. O patamar mínimo de produção estabeleceu-se com $313.103 \mathrm{~m}^{3} / \mathrm{ano}$. A Tabela 9 apresenta para o horizonte de planejamento os volumes anuais produzidos, os totais de áreas colhidas, a produtividade e o número de horas-homem utilizados durante o horizonte.

O valor total do projeto (VTP) é dado pela somatória dos valores dos regimes selecionados. Maximizar esta somatória significa priorizar a escolha dos regimes economicamente ótimos. Este valor é obtido com a maximização do valor esperado da terra (VET) através da fórmula de Faustmann, que recomenda períodos rotacionais economicamente ótimos. A Tabela 10 apresenta valores de idades que maximizam o VET para cada unidade de gestão do estudo de caso. 
Tabela 9. Volumes totais produzidos, áreas colhidas anualmente, produtividade e número de horas-homem para o modelo utilizado como parâmetro.

\begin{tabular}{crrrr}
\hline Ano & $\begin{array}{c}\text { Produção } \\
\mathbf{m}^{\mathbf{3}}\end{array}$ & $\begin{array}{c}\text { Área } \\
\text { ha }\end{array}$ & $\begin{array}{c}\text { Produtividade } \\
\mathbf{m}^{\mathbf{3}} \mathbf{h a}\end{array}$ & $\begin{array}{c}\text { Mão-de-obra } \\
\text { horas-homem }\end{array}$ \\
\hline $\mathbf{1}$ & 313.103 & 914,85 & 342,24 & 235.49 \\
$\mathbf{2}$ & 555.202 & $2.049,53$ & 270,89 & 168.75 \\
$\mathbf{3}$ & 313.103 & $1.097,51$ & 285,28 & 185.37 \\
$\mathbf{4}$ & 313.103 & $1.048,49$ & 298,62 & 192.11 \\
$\mathbf{5}$ & 313.103 & $\mathbf{1 . 0 4 8 , 9 6}$ & 298,48 & 148.10 \\
$\mathbf{6}$ & 376.749 & $1.296,35$ & 290,62 & 142.76 \\
$\mathbf{7}$ & 313.103 & $1.062,84$ & 294,59 & 142.89 \\
$\mathbf{8}$ & 323.245 & $1.258,45$ & 256,85 & 190.56 \\
$\mathbf{9}$ & 325.029 & $1.347,12$ & 241,27 & 230.91 \\
$\mathbf{1 0}$ & 313.103 & $1.242,47$ & 252,00 & 225.51 \\
$\mathbf{1 1}$ & 313.103 & $1.346,89$ & 232,46 & 227.55 \\
$\mathbf{1 2}$ & 313.103 & $1.311,31$ & 238,77 & 219.24 \\
$\mathbf{1 3}$ & 313.103 & $1.212,29$ & 258,27 & 221.16 \\
$\mathbf{1 4}$ & 363.537 & $1.392,23$ & 261,11 & 219.69 \\
$\mathbf{1 5}$ & 381.767 & $1.408,77$ & 270,99 & 181.99 \\
$\mathbf{1 6}$ & 313.103 & $1.047,56$ & 298,88 & 216.54 \\
$\mathbf{1 7}$ & 313.103 & $1.043,44$ & 300,06 & 240.30 \\
$\mathbf{1 8}$ & 313.103 & $1.202,64$ & 260,34 & 199.95 \\
$\mathbf{1 9}$ & 313.103 & $1.081,66$ & 289,46 & 210.14 \\
$\mathbf{2 0}$ & 385.972 & $1.437,24$ & 268,55 & 217.30 \\
Total & $\mathbf{6 . 7 8 1 . 8 3 9}$ & $\mathbf{2 4 . 8 5 0 , 6 0}$ & $\mathbf{2 7 2 . 9 0}$ & $\mathbf{4 . 0 1 6 . 3 8 0}$ \\
\hline & & & & \\
\hline
\end{tabular}

Fonte: Dados da pesquisa.

Observa-se na Tabela 10 uma predominância de idades de colheita economicamente ótimas próximas aos 7 anos. É importante ressaltar que estas idades são mais altas que as idades volumétricamente ótimas. Em trabalho que avalia os dois métodos, Rodriguez et al. (1997) justificam esta diferença, mostrando ser incorreta a generalização de que rotações economicamente ótimas são sempre mais curtas que as volumétricamente ótimas. 
Tabela 10. Idades que maximizam o valor econômico das rotações das unidades de gestão utilizadas no estudo de caso.

\begin{tabular}{cccccc}
\hline $\begin{array}{c}\text { Unidade } \\
\text { de Gestão }\end{array}$ & $\begin{array}{c}\text { VET } \\
\text { R\$ }\end{array}$ & $\begin{array}{c}\text { Idade } \\
\text { anos }\end{array}$ & $\begin{array}{c}\text { Unidade } \\
\text { de Gestão }\end{array}$ & $\begin{array}{c}\text { VET } \\
\text { R\$ }\end{array}$ & $\begin{array}{c}\text { Idade } \\
\text { anos }\end{array}$ \\
\hline $\mathbf{1}$ & $\mathbf{3 8 7 4 , 6 3}$ & $\mathbf{6}$ & $\mathbf{2 1}$ & 3355,96 & 7 \\
$\mathbf{2}$ & 1578,21 & 7 & $\mathbf{2 2}$ & 1369,04 & 7 \\
$\mathbf{3}$ & 3444,96 & 6 & $\mathbf{2 3}$ & 3123,26 & 7 \\
$\mathbf{4}$ & 3218,64 & 7 & $\mathbf{2 4}$ & 1930,00 & 7 \\
$\mathbf{5}$ & 490,069 & 7 & $\mathbf{2 5}$ & 2608,35 & 7 \\
$\mathbf{6}$ & 2052,24 & 7 & $\mathbf{2 6}$ & 3285,67 & 7 \\
$\mathbf{7}$ & 766,911 & 7 & $\mathbf{2 7}$ & 2287,2 & 7 \\
$\mathbf{8}$ & $\mathbf{- 2 7 9 , 2 8}$ & 8 & $\mathbf{2 8}$ & 2770,14 & 7 \\
$\mathbf{9}$ & 4532,11 & 6 & $\mathbf{2 9}$ & 4071,03 & $\mathbf{6}$ \\
$\mathbf{1 0}$ & 1568,08 & 7 & $\mathbf{3 0}$ & 390,196 & 7 \\
$\mathbf{1 1}$ & 3273,69 & 6 & $\mathbf{3 1}$ & $-290,72$ & 8 \\
$\mathbf{1 2}$ & 3007,76 & 7 & $\mathbf{3 2}$ & 2612,95 & 6 \\
$\mathbf{1 3}$ & 3589,04 & 6 & $\mathbf{3 3}$ & 1714,33 & 7 \\
$\mathbf{1 4}$ & 5555,49 & 6 & $\mathbf{3 4}$ & 422,493 & 7 \\
$\mathbf{1 5}$ & 1543,55 & 7 & $\mathbf{3 5}$ & $-1051,2$ & 10 \\
$\mathbf{1 6}$ & 1657,73 & 7 & $\mathbf{3 6}$ & 2042,89 & 7 \\
$\mathbf{1 7}$ & 3818,75 & 6 & $\mathbf{3 7}$ & 2042,89 & 7 \\
$\mathbf{1 8}$ & 2722,56 & 7 & $\mathbf{3 8}$ & 2042,89 & 7 \\
$\mathbf{1 9}$ & 3206,07 & $\mathbf{7}$ & $\mathbf{3 9}$ & 2042,89 & 7 \\
$\mathbf{2 0}$ & $\mathbf{1 4 3 3 , 0 2}$ & 7 & $\mathbf{4 0}$ & 2042,89 & 7 \\
\hline
\end{tabular}

Fonte: Dados da pesquisa.

A Figura 7 quadrante (a) apresenta as produções volumétricas anuais obtidas pelo modelo. Observa-se que para o segundo ano do horizonte existe um aumento da produção de madeira, caracterizando uma antecipação de receitas. Esta antecipação é concentrada no segundo ano devido a estruturação das restrições de ordenamento que exigem a transferência da menor produção para o primeiro ano. $O$ quadrante (b) apresenta o total de áreas a serem conduzidas ou reformadas. Observa-se uma concentração de regimes que sugerem a condução de segunda rotação no início do horizonte. Isto ocorre devido ao custo relativamente mais baixo das atividades de segunda rotação quando comparados à primeira, reforçando a afirmação de antecipação das maiores receitas. 
O quadrante (c) da Figura 7 apresenta distribuição das idades de corte. Conforme esperado, observa-se uma predominância de rotações com idades que maximizam o VET. Finalmente, o quadrante (d) apresenta informações de demanda anual por mão-deobra. Nesta figura observa-se uma menor demanda por mão-de-obra nos períodos em que se optou pela condução de segundas rotações, períodos em que os povoamentos exigem menor número de atividades.
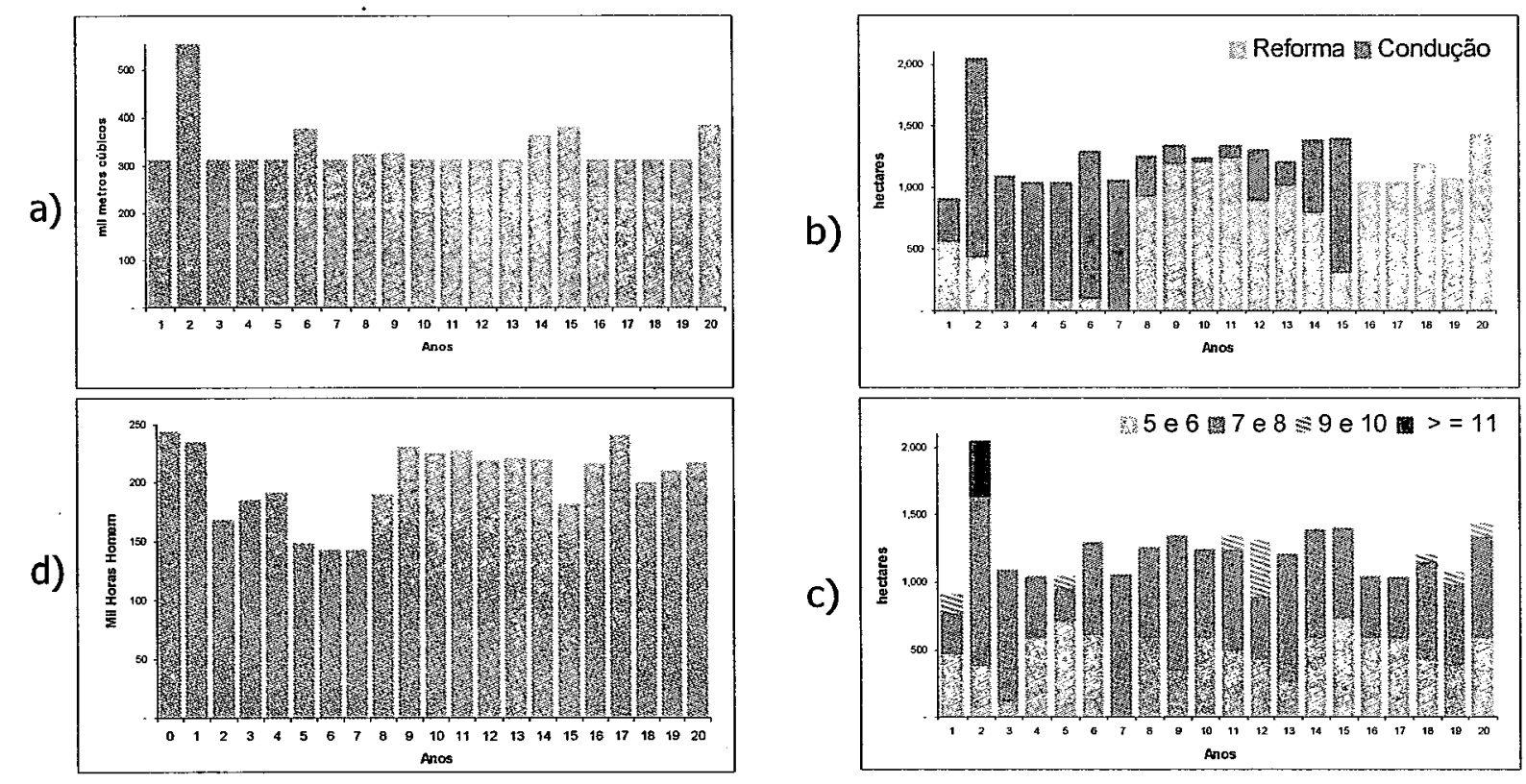

Figura 7 - Efeitos do modelo utilizado como parâmetro sobre a disponibilização madeira (a), formas de condução da floresta (b), distribuição de idades (c) e utilização de recursos humanos (d).

\subsection{Modelos que otimizam múltiplos objetivos}

Para a elaboração dos modelos que consideram múltiplas dimensões é necessária a otimização individual de cada objetivo proposto. A seguir são apresentadas as soluções obtidas para cada modelo de otimização individual e seus efeitos sobre o plano de manejo. 


\subsubsection{Maximização do valor total do projeto}

Dentre as restrições do modelo tradicional, aquelas que exigem o estabelecimento de um patamar mínimo de produção são substituídas pela imposição de produções anuais não decrescentes. Por este motivo torna-se necessária a obtenção de novos resultados para o modelo que maximiza o VTP.

A solução ótima obtida após 1.999 iterações resultou em valor total do projeto de $\mathrm{R} \$ 42.083 .887,00$. O volume anual de $342.723 \mathrm{~m}^{3}$, manteve-se fixo para todo horizonte. Da mesma forma que o modelo tradicional, foram priorizados os regimes que maximizam o VET. A Tabela 11 apresenta para o horizonte de planejamento volumes anuais produzidos, total de área colhida, produtividade e número de horas-homem utilizadas durante o horizonte.

Tabela 11. Volumes totais produzidos, áreas colhidas anualmente, produtividade e número de horas-homem para o modelo que maximiza VTP.

\begin{tabular}{crrrr}
\hline Ano & $\begin{array}{c}\text { Produção } \\
\mathbf{m}^{\mathbf{3}}\end{array}$ & $\begin{array}{c}\text { Área } \\
\text { ha }\end{array}$ & $\begin{array}{c}\text { Produtividade } \\
\mathbf{m}^{\mathbf{3}} / \mathbf{h a}\end{array}$ & $\begin{array}{c}\text { Mão-de-obra } \\
\text { horas-homem }\end{array}$ \\
\hline $\mathbf{1}$ & 342.723 & $1.046,11$ & 327,61 & 235.041 \\
$\mathbf{2}$ & 342.723 & $1.218,86$ & 281,18 & 162.329 \\
$\mathbf{3}$ & 342.723 & $\mathbf{1 . 1 0 1 , 2 8}$ & 311,20 & 148.591 \\
$\mathbf{4}$ & 342.723 & $1.277,30$ & 268,31 & 165.371 \\
$\mathbf{5}$ & 342.723 & $1.041,77$ & 328,97 & 161.498 \\
$\mathbf{6}$ & 342.723 & $1.141,26$ & 300,30 & 146.445 \\
$\mathbf{7}$ & 342.723 & $1.089,34$ & 314,61 & 138.696 \\
$\mathbf{8}$ & 342.723 & $1.226,68$ & 279,39 & 160.733 \\
$\mathbf{9}$ & 342.723 & $1.358,57$ & 252,26 & 216.538 \\
$\mathbf{1 0}$ & 342.723 & $1.332,89$ & 257,12 & 242.949 \\
$\mathbf{1 1}$ & 342.723 & $1.371,84$ & 249,82 & 225.859 \\
$\mathbf{1 2}$ & 342.723 & $1.520,55$ & 225,39 & 242.879 \\
$\mathbf{1 3}$ & 342.723 & $1.409,95$ & 243,07 & 245.376 \\
$\mathbf{1 4}$ & 342.723 & $1.468,33$ & 233,40 & 244.818 \\
$\mathbf{1 5}$ & 342.723 & $1.282,76$ & 267,17 & 192.326 \\
$\mathbf{1 6}$ & 342.723 & $1.202,47$ & 285,01 & 208.906 \\
$\mathbf{1 7}$ & 342.723 & $1.204,17$ & 284,61 & 265.815 \\
$\mathbf{1 8}$ & 342.723 & $1.228,60$ & 278,95 & 217.961 \\
$\mathbf{1 9}$ & 342.723 & $1.274,30$ & 268,94 & 224.164 \\
$\mathbf{2 0}$ & $\mathbf{3 4 2 . 7 2 3}$ & $1.437,86$ & 238,35 & 234.289 \\
$\mathbf{T o t a l}$ & $\mathbf{6 . 8 5 4 . 4 5 2}$ & $\mathbf{2 5 . 2 3 4 , 9 8}$ & $\mathbf{2 7 1 . 6 2}$ & $\mathbf{4 . 0 8 0 . 5 9 3}$ \\
\hline & & & &
\end{tabular}

Fonte: Dados da pesquisa 
A Figura 8 mostra as alterações na distribuição de áreas a serem reformadas e conduzidas (a) e a distribuição de idades de corte (c) em relação ao modelo tradicional. Estas variações ocorrem devido à maior restrição sobre as variações volumétricas anuais. Os mesmos efeitos das prescrições de condução de segunda rotação sobre a diminuição da demanda por mão-de-obra são evidenciados no quadrante (d).
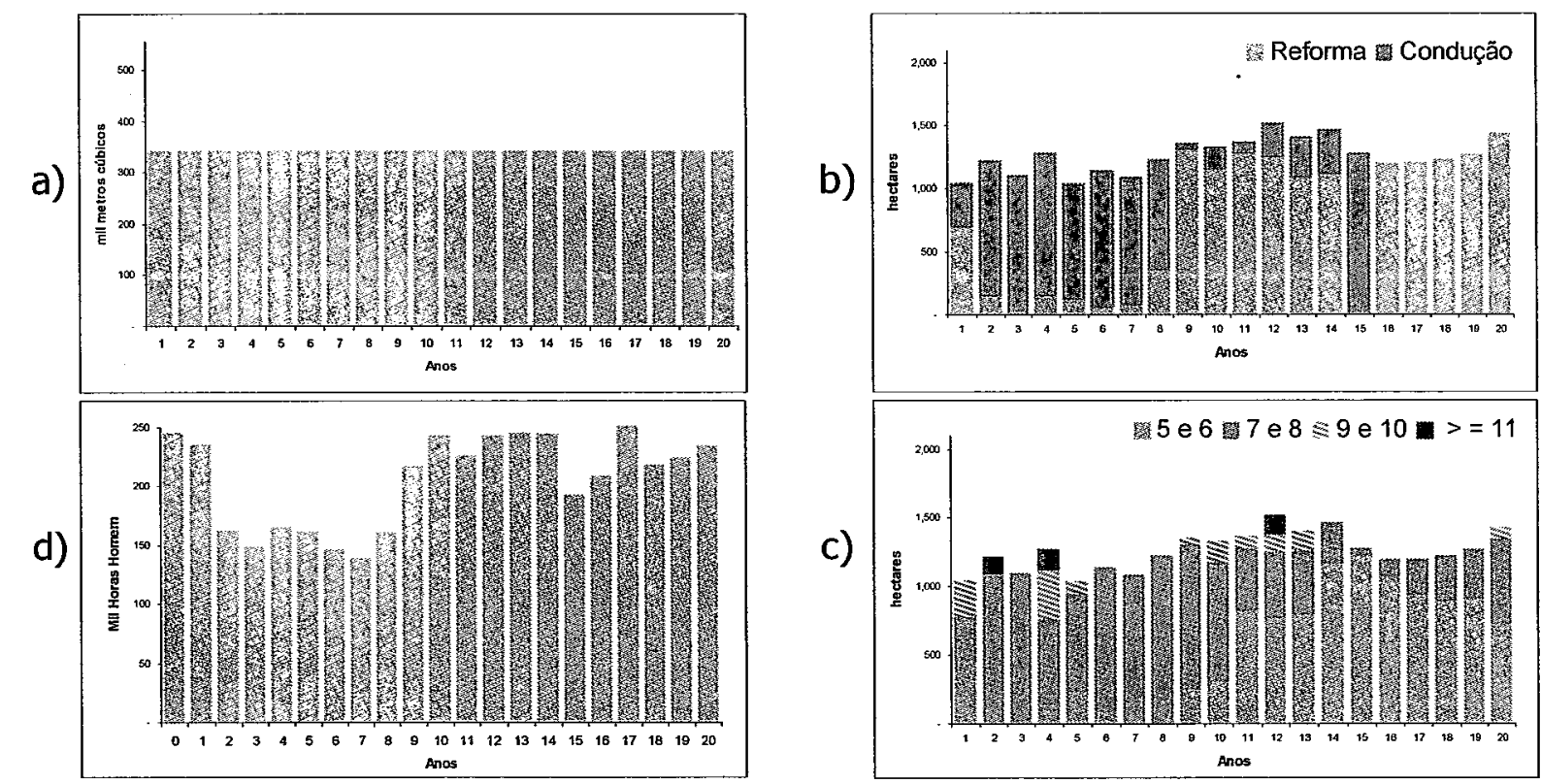

Figura 8 - Efeitos do modelo que maximiza VTP sobre a disponibilização madeira (a), formas de condução da floresta (b), distribuição de idades (c) e utilização de recursos humanos (d).

\subsubsection{Maximização da produção anual}

O segundo objetivo seleciona regimes que maximizam a produção volumétrica anual. Diferente da maximização do VTP, o modelo dá preferência aos regimes que resultem em rotações com períodos de duração próximos aos definidos pelas rotações volumetricamente ótimas. Para as equações de crescimento utilizadas esta maximização ocorre predominantemente aos 5 anos (Tabela 3 ). 
A solução ótima obtida após 1.056 iterações resultou em valor total do projeto de $\mathrm{R} \$ 3$ 38.405.864. O volume anual de $389.688 \mathrm{~m}^{3}$ manteve-se fixo para todo horizonte Figura 9 (a). A tabela 12 apresenta para o horizonte de planejamento volumes anuais produzidos, total de área colhida, produtividade e número de horas-homem utilizados durante o horizonte.

Tabela 12. Volumes totais produzidos, áreas colhidas anualmente, produtividade e número de horas-homem para o modelo que maximiza o volume produzido anualmente.

\begin{tabular}{crrrr}
\hline Ano & $\begin{array}{c}\text { Produção } \\
\mathbf{m}^{\mathbf{3}}\end{array}$ & \multicolumn{1}{c}{$\begin{array}{c}\text { Área } \\
\text { ha }\end{array}$} & $\begin{array}{c}\text { Produtividade } \\
\mathbf{m}^{\mathbf{3}} / \mathbf{h a}\end{array}$ & $\begin{array}{c}\text { Mão-de-obra } \\
\text { horas-homem }\end{array}$ \\
\hline $\mathbf{1}$ & 389.688 & $\mathbf{1 . 2 7 4 , 6 4}$ & 305,72 & 265.315 \\
$\mathbf{2}$ & 389.688 & $1.433,77$ & 271,79 & 254.019 \\
$\mathbf{3}$ & 389.688 & $1.362,13$ & 286,09 & 259.178 \\
$\mathbf{4}$ & 389.688 & $1.347,56$ & 289,18 & 255.531 \\
$\mathbf{5}$ & 389.688 & $1.374,75$ & 283,46 & 253.864 \\
$\mathbf{6}$ & 389.688 & $1.420,99$ & 274,24 & 259.900 \\
$\mathbf{7}$ & 389.688 & $1.539,50$ & 253,13 & 267.556 \\
$\mathbf{8}$ & 389.688 & $1.572,43$ & 247,82 & 277.588 \\
$\mathbf{9}$ & 389.688 & $1.694,66$ & 229,95 & 263.228 \\
$\mathbf{1 0}$ & 389.688 & $1.380,95$ & 282,19 & 266.273 \\
$\mathbf{1 1}$ & 389.688 & $1.522,18$ & 256,01 & 284.800 \\
$\mathbf{1 2}$ & 389.688 & $1.614,10$ & 241,43 & 273.697 \\
$\mathbf{1 3}$ & 389.688 & $1.639,50$ & 237,69 & 282.725 \\
$\mathbf{1 4}$ & 389.688 & $1.669,45$ & 233,42 & 286.612 \\
$\mathbf{1 5}$ & 389.688 & $1.535,93$ & 253,71 & 287.823 \\
$\mathbf{1 6}$ & 389.688 & $1.737,98$ & 224,22 & 267.154 \\
$\mathbf{1 7}$ & 389.688 & $1.745,10$ & 223,30 & 240.783 \\
$\mathbf{1 8}$ & 389.688 & $1.707,94$ & 228,16 & 259.622 \\
$\mathbf{1 9}$ & 389.688 & $1.767,03$ & 220,53 & 277.236 \\
$\mathbf{2 0}$ & 389.688 & $1.560,46$ & 249,73 & 280.038 \\
Total & $\mathbf{6 . 7 8 1 . 8 3 9}$ & $\mathbf{3 0 . 9 0 1 , 1 3}$ & $\mathbf{2 5 2 . 2 2}$ & $\mathbf{5 . 3 6 2 . 9 4 2}$ \\
\hline & & & & \\
\hline
\end{tabular}

Fonte: Dados da pesquisa.

As perdas de aproximadamente $15 \%$ dos volumes obtidos para segunda rotação em relação à primeira fazem com que as intervenções de condução de segundas rotações sejam evitadas, Figura 9 (b). O quadrante (c) demonstra, conforme previsto, predominância de idades de colheita próximas aos 5 anos. As produções volumétricas constantes e a seleção de regimes de apenas uma rotação resultaram na manutenção das variações de demanda por horas homem (d). 
a)

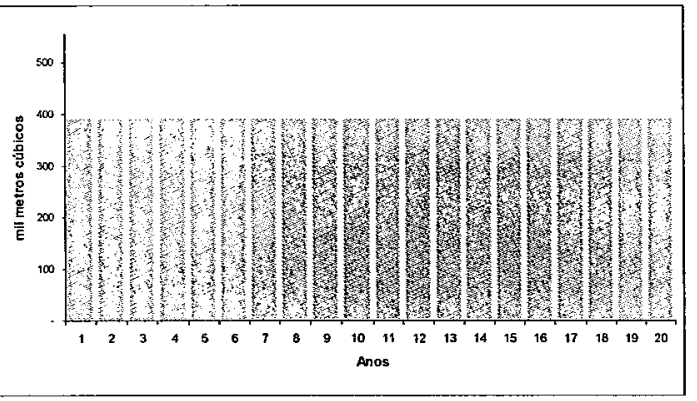

d)

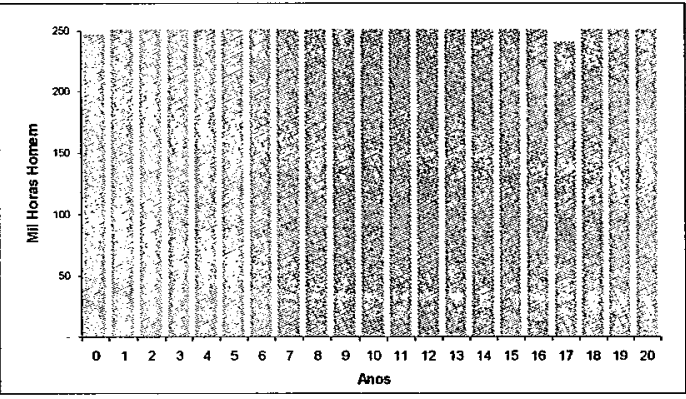

b)

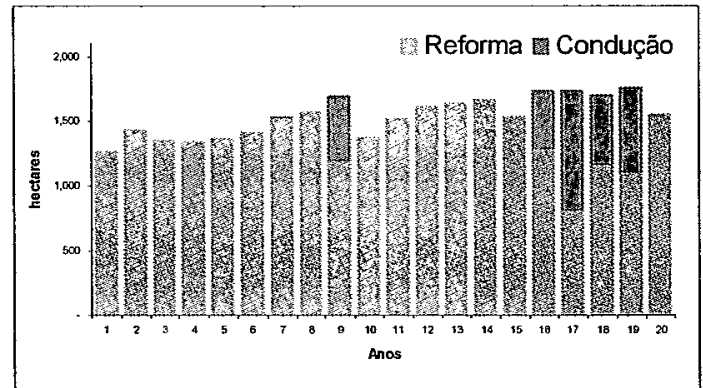

c)

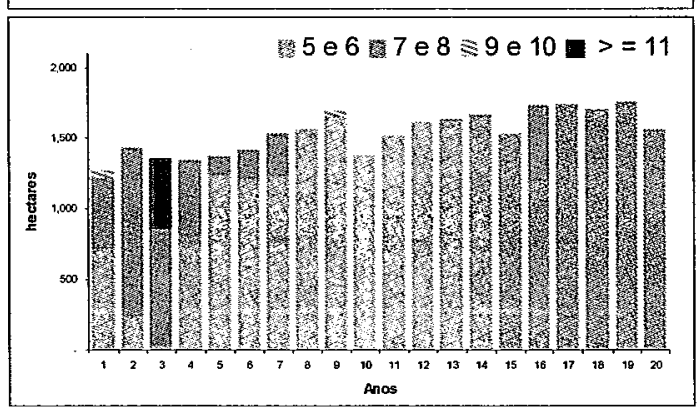

Figura 9 - Efeitos do modelo que maximiza produção sobre a disponibilização madeira (a), formas de condução da floresta (b), distribuição de idades (c) e utilização de recursos humanos(d).

\subsubsection{Minimização do número de intervenções de colheita}

O modelo procura atender as restrições mínimas de produção de forma eficiente, minimizando o número de intervenções de colheita durante o horizonte de planejamento. A solução ótima obtida após 871 iterações resultou em valor total do projeto de $\mathrm{R} \$ 35.560 .644$. O volume anual de $313.103 \mathrm{~m}^{3}$ manteve-se fixo para todo horizonte, Figura 10 (a), mostrando que as restrições mínimas de produção se comportaram de forma atuante. A Tabela 13 apresenta para o horizonte de planejamento os volumes anuais produzidos, o total de área colhida, a produtividade e o número de horas-homem utilizadas. 
Tabela 13. Volumes totais produzidos, áreas colhidas anualmente, produtividade e número de horas-homem para o modelo que minimiza o número de cortes.

\begin{tabular}{crrrr}
\hline Ano & $\begin{array}{c}\text { Produção } \\
\mathbf{m}^{\mathbf{3}}\end{array}$ & \multicolumn{1}{c}{$\begin{array}{c}\text { Área } \\
\text { ha }\end{array}$} & $\begin{array}{c}\text { Produtividade } \\
\mathbf{m}^{\mathbf{3}} \mathbf{h a}\end{array}$ & $\begin{array}{c}\text { Mão-de-obra } \\
\text { horas-homem }\end{array}$ \\
\hline $\mathbf{1}$ & 313.103 & $1.060,28$ & 295,30 & 224.921 \\
$\mathbf{2}$ & 313.103 & $1.029,58$ & 304,11 & 207.232 \\
$\mathbf{3}$ & 313.103 & $1.059,21$ & 295,60 & 202.221 \\
$\mathbf{4}$ & 313.103 & $1.064,50$ & 294,13 & 203.256 \\
$\mathbf{5}$ & 313.103 & $1.055,78$ & 296,56 & 199.935 \\
$\mathbf{6}$ & 313.103 & $1.041,76$ & 300,55 & 199.262 \\
$\mathbf{7}$ & 313.103 & $1.168,24$ & 268,01 & 206.583 \\
$\mathbf{8}$ & 313.103 & $1.313,16$ & 238,44 & 192.911 \\
$\mathbf{9}$ & 313.103 & $1.101,60$ & 284,23 & 202.236 \\
$\mathbf{1 0}$ & 313.103 & $1.193,99$ & 262,23 & 231.251 \\
$\mathbf{1 1}$ & 313.103 & 966,00 & 324,12 & 204.133 \\
$\mathbf{1 2}$ & 313.103 & 997,41 & 313,92 & 191.065 \\
$\mathbf{1 3}$ & 313.103 & $1.110,03$ & 282,07 & 181.920 \\
$\mathbf{1 4}$ & 313.103 & $1.117,19$ & 280,26 & 179.612 \\
$\mathbf{1 5}$ & 313.103 & $1.213,97$ & 257,92 & 214.307 \\
$\mathbf{1 6}$ & 313.103 & $1.170,16$ & 267,57 & 209.254 \\
$\mathbf{1 7}$ & 313.103 & $1.089,00$ & 287,51 & 150.795 \\
$\mathbf{1 8}$ & 313.103 & $\mathbf{1 . 0 3 7 , 0 2}$ & 301,93 & 135.935 \\
$\mathbf{1 9}$ & 313.103 & $\mathbf{1 . 2 4 8 , 5 7}$ & 250,77 & 205.395 \\
$\mathbf{2 0}$ & 313.103 & $1.287,79$ & 243,13 & 226.663 \\
$\mathbf{T o t a l}$ & $\mathbf{6 . 2 6 2 . 0 5 8}$ & $\mathbf{2 2 . 3 2 5 , 2 2}$ & $\mathbf{2 8 0 . 4 9}$ & $\mathbf{5 . 3 6 2 . 9 4 2}$ \\
\hline & & & & \\
\hline
\end{tabular}

Fonte: Dados da pesquisa.

Observa-se na Figura 10 (b) que a solução dá preferência à seleção de regimes com apenas uma rotação. Isto ocorre devido à necessidade de atendimento às metas de produção simultaneamente à minimização do número de intervenções de colheita. Desta forma, o modelo procura selecionar regimes de maior eficiência produtiva, o que geralmente ocorre na primeira rotação em idades de corte volumetricamente ótimas. Tal comportamento é semelhante ao encontrado no modelo que maximiza produção, sessão 4.2.2.

O quadrante (c) apresenta distribuição de idades de corte resultante das prescrições sugeridas pelo modelo. Observa-se na figura um discreto aumento das idades de corte em relação ao modelo tradicional, proporcionado pelas exigências da função objetivo. A participação de rotações mais longas é restringida pelas exigências anuais de 
produção e pela disponibilidade inicial de áreas com idades avançadas. As variações de demanda por horas de trabalho refletem principalmente a ocorrência de segundas rotações.
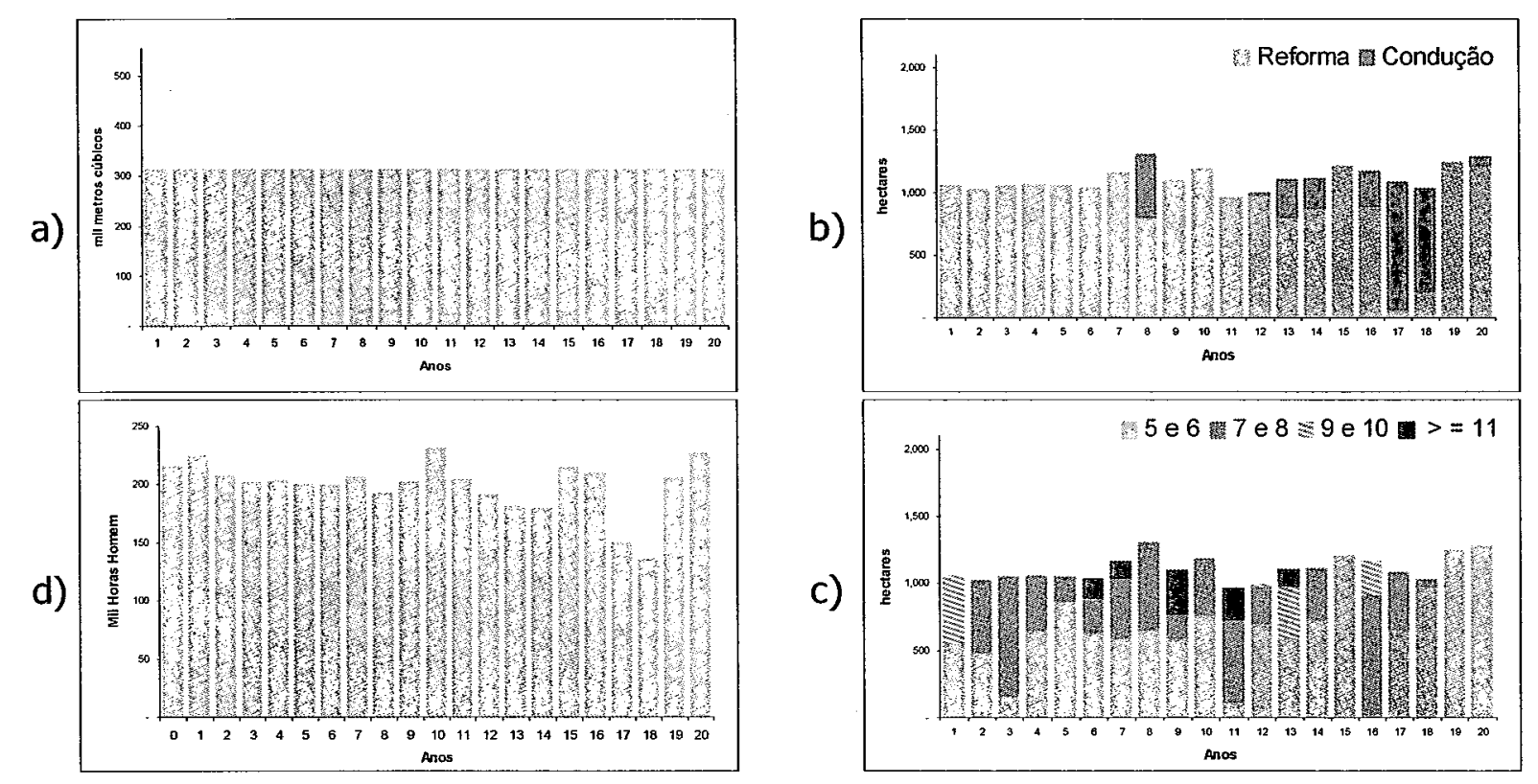

Figura 10 - Efeitos do modelo que minimiza número se intervenções de corte sobre a disponibilização madeira (a), formas de condução da floresta (b), distribuição de idades (c) e utilização de recursos humanos(d).

\subsubsection{Minimização das variações anuais de horas-homem}

Este modelo tenta abordar fatores sociais durante a seleção dos regimes, tentando minimizar a variação anual de demanda por mão-de-obra. A solução ótima obtida após 1.712 iterações resultou em valor total do projeto de $\mathrm{R} \$ 34.167 .734$. O volume anual de $313.103 \mathrm{~m}^{3}$ manteve-se fixo para todo horizonte, Figura 11 (a), mostrando que as restrições mínimas de produção se comportaram de forma atuante. A tabela 14 apresenta, para o horizonte de planejamento, volumes anuais produzidos, total de área colhida, produtividade e número de horas-homem utilizadas durante o horizonte. 
Tabela 14. Volumes totais produzidos, áreas colhidas anualmente, produtividade e número de horas-homem para o modelo que minimiza as variações da demanda anual por mão-de-obra.

\begin{tabular}{crrrr}
\hline Ano & $\begin{array}{c}\text { Produç̃o } \\
\mathbf{m}^{\mathbf{3}}\end{array}$ & \multicolumn{1}{c}{$\begin{array}{c}\text { Área } \\
\text { ha }\end{array}$} & $\begin{array}{c}\text { Produtividade } \\
\mathbf{m}^{\mathbf{3}} \mathbf{h} \mathbf{h a}\end{array}$ & $\begin{array}{c}\text { Mão-de-obra } \\
\text { horas-homem }\end{array}$ \\
\hline $\mathbf{1}$ & 313.103 & $1.031,71$ & 303,48 & $\mathbf{1 9 9 . 1 4 3}$ \\
$\mathbf{2}$ & 313.103 & $1.254,82$ & 249,52 & 199.143 \\
$\mathbf{3}$ & 313.103 & $1.083,54$ & 288,96 & 199.143 \\
$\mathbf{4}$ & 313.103 & $1.114,95$ & 280,82 & 199.143 \\
$\mathbf{5}$ & 313.103 & $1.156,65$ & 270,69 & 199.143 \\
$\mathbf{6}$ & 313.103 & $1.115,50$ & 280,68 & 199.143 \\
$\mathbf{7}$ & 313.103 & $1.235,52$ & 253,41 & 199.143 \\
$\mathbf{8}$ & 313.103 & $1.278,96$ & 244,81 & 199.143 \\
$\mathbf{9}$ & 313.103 & $1.249,98$ & 250,48 & 199.143 \\
$\mathbf{1 0}$ & 313.103 & 964,06 & 324,77 & 199.143 \\
$\mathbf{1 1}$ & 313.103 & $1.320,88$ & 237,04 & 199.143 \\
$\mathbf{1 2}$ & 313.103 & $1.127,83$ & 277,61 & 199.143 \\
$\mathbf{1 3}$ & 313.103 & $1.311,95$ & 238,65 & 199.143 \\
$\mathbf{1 4}$ & 313.103 & $1.210,66$ & 258,62 & 199.143 \\
$\mathbf{1 5}$ & 313.103 & $1.207,53$ & 259,29 & 199.143 \\
$\mathbf{1 6}$ & 313.103 & $1.236,86$ & 253,14 & 199.143 \\
$\mathbf{1 7}$ & 313.103 & $1.352,77$ & 231,45 & 199.143 \\
$\mathbf{1 8}$ & 313.103 & $\mathbf{1 . 1 9 4 , 2 9}$ & 262,16 & 199.143 \\
$\mathbf{1 9}$ & 313.103 & $\mathbf{1 . 2 1 6 , 8 4}$ & 257,30 & 199.143 \\
$\mathbf{2 0}$ & 313.103 & $\mathbf{1 . 2 5 6 , 6 2}$ & 249,16 & 199.143 \\
$\mathbf{T}$ & $\mathbf{6 . 2 6 2 . 0 5 8}$ & $\mathbf{2 3 . 9 2 1 , 9 2}$ & $\mathbf{2 6 1 , 7 7}$ & $\mathbf{3 . 9 8 2 . 8 6 0}$ \\
\hline
\end{tabular}

Fonte: Dados da pesquisa.

Para a manutenção dos valores de horas homem anuais o modelo prescreve uma relação constante entre área conduzida e reformada, Figura 11 (b). O quadrante (c) apresenta distribuição de idades de colheita onde pode-se observar a predominância de classes de 5 a 8 anos. A presença de colheitas de áreas com idades superiores a 8 anos se deve à necessidade de equilibrar o número de horas-homem utilizadas. 
a)

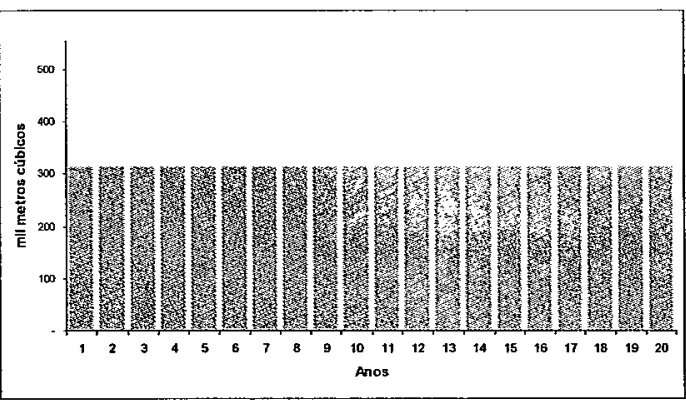

d)

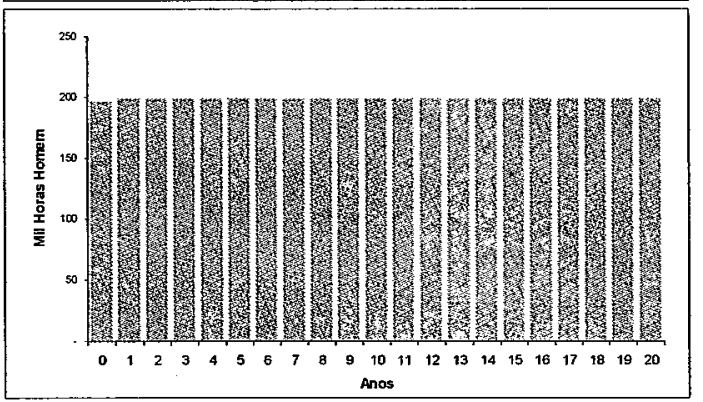

b)

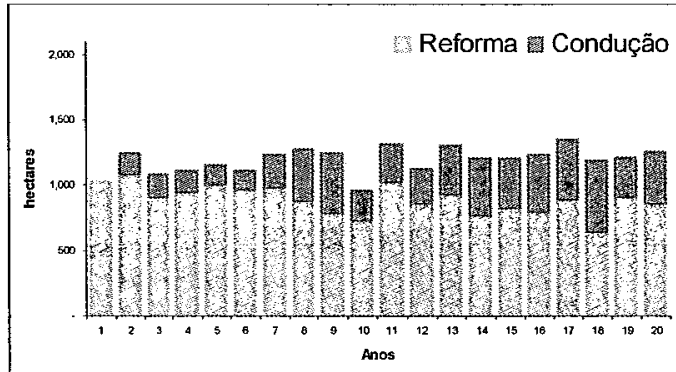

c)

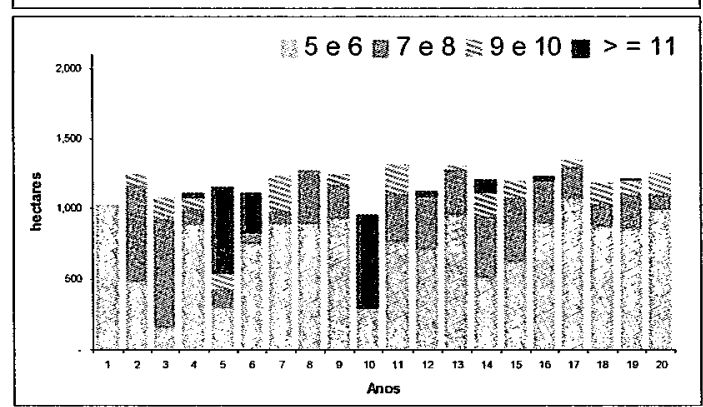

Figura 11 - Efeitos do modelo que minimiza a variação anual de demanda por horas homem sobre a disponibilização madeira (a), formas de condução da floresta (b), distribuição de idades (c) e utilização de recursos humanos (d).

\subsubsection{Matriz de pagamentos}

Os efeitos causados pela otimização individual dos objetivos sobre os demais podem ser observados na matriz de pagamentos apresentada na Tabela 15. Da análise das informações contidas na matriz de pagamentos observa-se que:

1. A otimização individual de todos os modelos gerou soluções factíveis por terem atendido a todos os conjuntos de restrições e eficientes (ou Pareto ótimas) por não existirem soluções dominadas, ou seja , nenhum dos modelos obteve resultados melhores que outros para todos os objetivos.

2. Existem conflitos entre os quatro objetivos considerados.

3. A exigência volumétrica mínima mostrou-se limitante para a otimização dos valores de número de corte e variação anual de demanda por mão-de-obra. 
Tabela 15. Matriz de pagamentos, efeitos causados pela otimização individual dos objetivos sobre os demais objetivos propostos (valores ótimos representados em negrito).

\begin{tabular}{lcccc}
\hline Modelos & VTP & $\begin{array}{c}\text { Produção no } \\
\text { primeiro ano } \\
(\mathbf{m} \mathbf{3})\end{array}$ & $\begin{array}{l}\text { Número } \\
\text { de cortes } \\
\text { (unid.) }\end{array}$ & $\begin{array}{l}\text { Variação } \\
\text { de HH } \\
\text { (horas) }\end{array}$ \\
\hline VTP & $\mathbf{4 2 . 0 8 3 . 8 8 7 , 0 0}$ & $342.723,00$ & 117,87 & $461.486,73$ \\
Produção & $38.405 .864,00$ & $\mathbf{3 8 9 . 6 8 8 , 0 0}$ & 145,83 & $192.948,00$ \\
Cortes & $35.560 .644,00$ & $313.103,00$ & $\mathbf{6 6 , 8 3}$ & $342.496,00$ \\
Var. HH & $34.167 .735,00$ & $313.103,00$ & 114,03 & $\mathbf{0}$ \\
\hline
\end{tabular}

Fonte: Dados da pesquisa

Através das variações do valor total do projeto para as diferentes soluções, é possível estimar os custos de oportunidade na forma de taxa de intercâmbio da solução economicamente ótima pelas demais soluções. Desta forma, a elevação do patamar mínimo de produção obtida com a maximização da produção no primeiro ano, custará para cada metro cúbico de madeira adicional $\mathbf{R} \$ 78,31$. Optar pela solução que minimiza o número de cortes em relação à economicamente ótima significa pagar pela diminuição de cada intervenção de corte $\mathrm{R} \$ 127.806,49$ e finalmente, optar pela solução socialmente ótima significa pagar pela diminuição de variação de cada hora de trabalho $\mathrm{R} \$ 17,15$.

O conflito entre objetivos pode também ser observado graficamente. A Figura 12 apresenta efeitos da otimização individual sobre os demais objetivos propostos. Os valores obtidos foram normalizados de forma que o melhor valor encontrado é representado por 1 e o pior, por 0 .

Observa-se na Figura 12 um desequilíbrio entre as soluções geradas, não havendo resposta aceitável como solução do problema de acordo com os critérios pré estabelecidos. Por este motivo são avaliadas as soluções dos modelos de programação compromisso. 


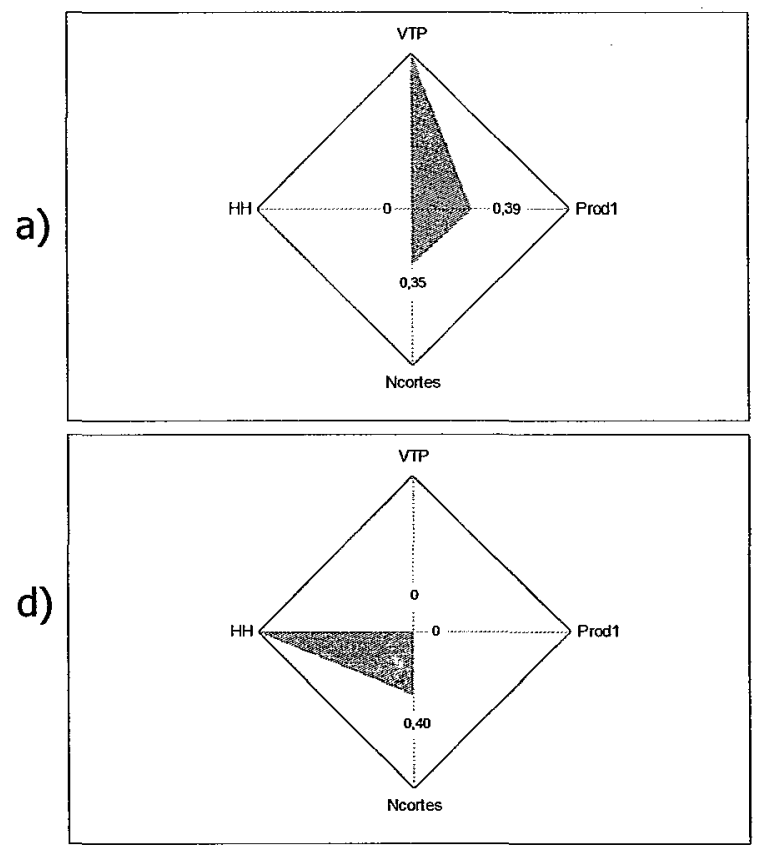

b)

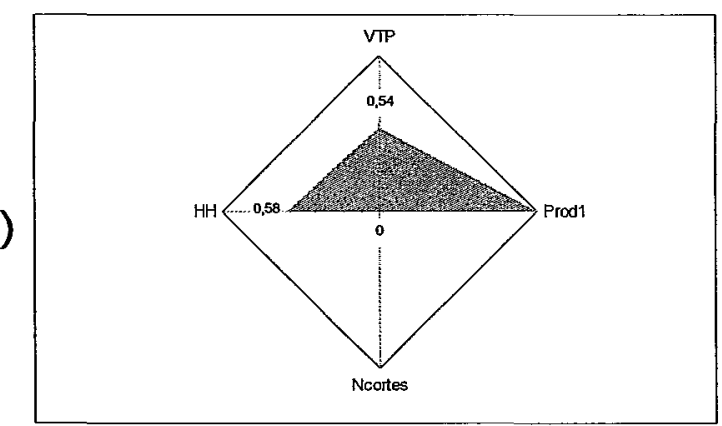

c)

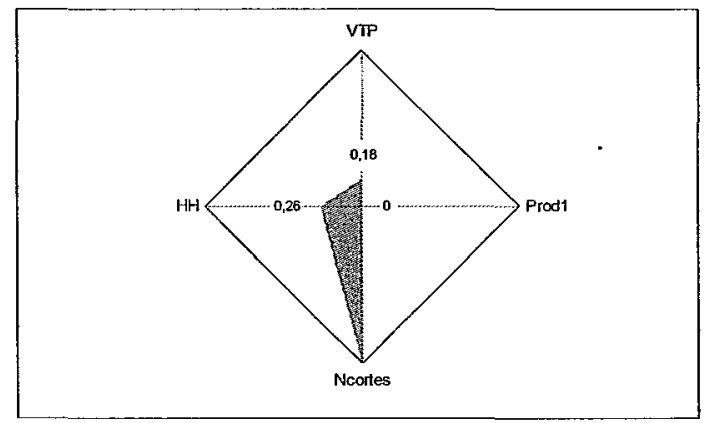

Figura 12 - Equilíbrio entre soluções que otimizam os objetivos maximização do valor total do projeto (a), maximização da produção (b), minimização do número de intervenções de corte (c) e minimização das variações de horas- dehomem utilizadas (d), valores normalizados.

Os modelos de programação compromisso têm como princípio básico utilizar os valores ótimos obtidos pelos modelos de otimização individual. Um vetor formado pelo conjunto de soluções ótimas é utilizado como ponto de referência para o centro de decisão. O objetivo do modelo compromisso é o de encontrar, através de uma função de distância, o vetor de solução que mais se aproxime do vetor ótimo.

\subsubsection{Modelo de programação compromisso métrica $\mathrm{L}=1$}

A função objetivo do modelo de programação compromisso para métrica $L=1$ procura minimizar a soma dos desvios da solução obtida para os critérios em relação ao vetor de solução ótimo. A solução ótima obtida após 4.105 iterações resultou em valor total do projeto de $\mathrm{R} \$ 40.762 .135\left(97 \%\right.$ do ótimo). O volume anual de $367.358 \mathrm{~m}^{3}(94 \%$ do ótimo) manteve-se fixo para todo horizonte, Figura 13 (a). A Tabela 16 apresenta 
para o horizonte de planejamento volumes anuais produzidos, total de área colhida, produtividade e número de horas-homem utilizadas durante o horizonte.

Tabela 16. Volumes totais produzidos, áreas colhidas anualmente, produtividade e número de horas de trabalho manual para o modelo de programação compromisso, métricá 1 .

\begin{tabular}{|c|c|c|c|c|}
\hline Ano & $\begin{array}{c}\text { Produção } \\
\mathbf{m}^{3}\end{array}$ & $\begin{array}{c}\text { Área } \\
\text { ha }\end{array}$ & $\begin{array}{c}\text { Produtividade } \\
\mathrm{m}^{3} / \mathrm{ha}\end{array}$ & $\begin{array}{l}\text { Mão-de-obra } \\
\text { horas-homem }\end{array}$ \\
\hline 1 & 367.358 & $1.169,02$ & 314,24 & 257.533 \\
\hline 2 & 367.358 & $1.279,34$ & 287,15 & 237.061 \\
\hline 3 & 367.358 & $1.253,33$ & 293,11 & 237.061 \\
\hline 4 & 367.358 & $1.255,19$ & 292,67 & 237.061 \\
\hline 5 & 367.358 & $1.248,91$ & 294,14 & 237.061 \\
\hline 6 & 367.358 & $1.295,59$ & 283,54 & 237.061 \\
\hline 7 & 367.358 & $1.239,12$ & 296,47 & 237.061 \\
\hline 8 & 367.358 & $1.397,90$ & 262,79 & 237.061 \\
\hline 9 & 367.358 & $1.425,05$ & 257,79 & 237.061 \\
\hline 10 & 367.358 & $1.302,71$ & 281,99 & 237.061 \\
\hline 11 & 367.358 & $1.308,69$ & 280,71 & 237.061 \\
\hline 12 & 367.358 & $1.326,06$ & 277,03 & 237.061 \\
\hline 13 & 367.358 & $1.326,36$ & 276,97 & 237.061 \\
\hline 14 & 367.358 & $1.288,55$ & 285,09 & 237.061 \\
\hline 15 & 367.358 & $1.364,19$ & 269,29 & 237.061 \\
\hline 16 & 367.358 & $1.353,06$ & 271,50 & 237.061 \\
\hline 17 & 367.358 & $1.371,58$ & 267,84 & 237.061 \\
\hline 18 & 367.358 & $1.346,67$ & 272,79 & 237.061 \\
\hline 19 & 367.358 & $1.384,28$ & 265,38 & 237.061 \\
\hline 20 & 367.358 & $1.442,30$ & 254,70 & 237.061 \\
\hline Total & 7.347 .156 & $26.377,89$ & 278,53 & $4.761 .698,4$ \\
\hline
\end{tabular}

Fonte: Dados da pesquisa.

Influenciado pelo objetivo que procura minimizar a variação de demanda por mão-de-obra e pelo que procura maximizar o volume produzido, o modelo sugere predominantemente regimes de apenas uma rotação. Por outro lado, a presença do objetivo que procura maximizar o valor total do projeto prioriza a seleção de regimes com idades de corte economicamente ótimas. Desta forma o quadrante (c) da Figura 13 difere da Figura 9 (c) pela ocorrência de colheitas com idades próximas aos 7 anos.

$\mathrm{O}$ alto grau de conflito entre a minimização do número de intervenções de colheita e os outros objetivos fez com que sua solução obtivesse maior distância em 
relação aos outros valores. Esta distância não é maior, provavelmente, pela influência positiva do bom desempenho dos objetivos que maximizam VTP e minimizam variações de horas-homem por gerarem prescrições de corte em idades mais avançadas ( 7 anos) que o modelo que maximiza produção (5 anos).
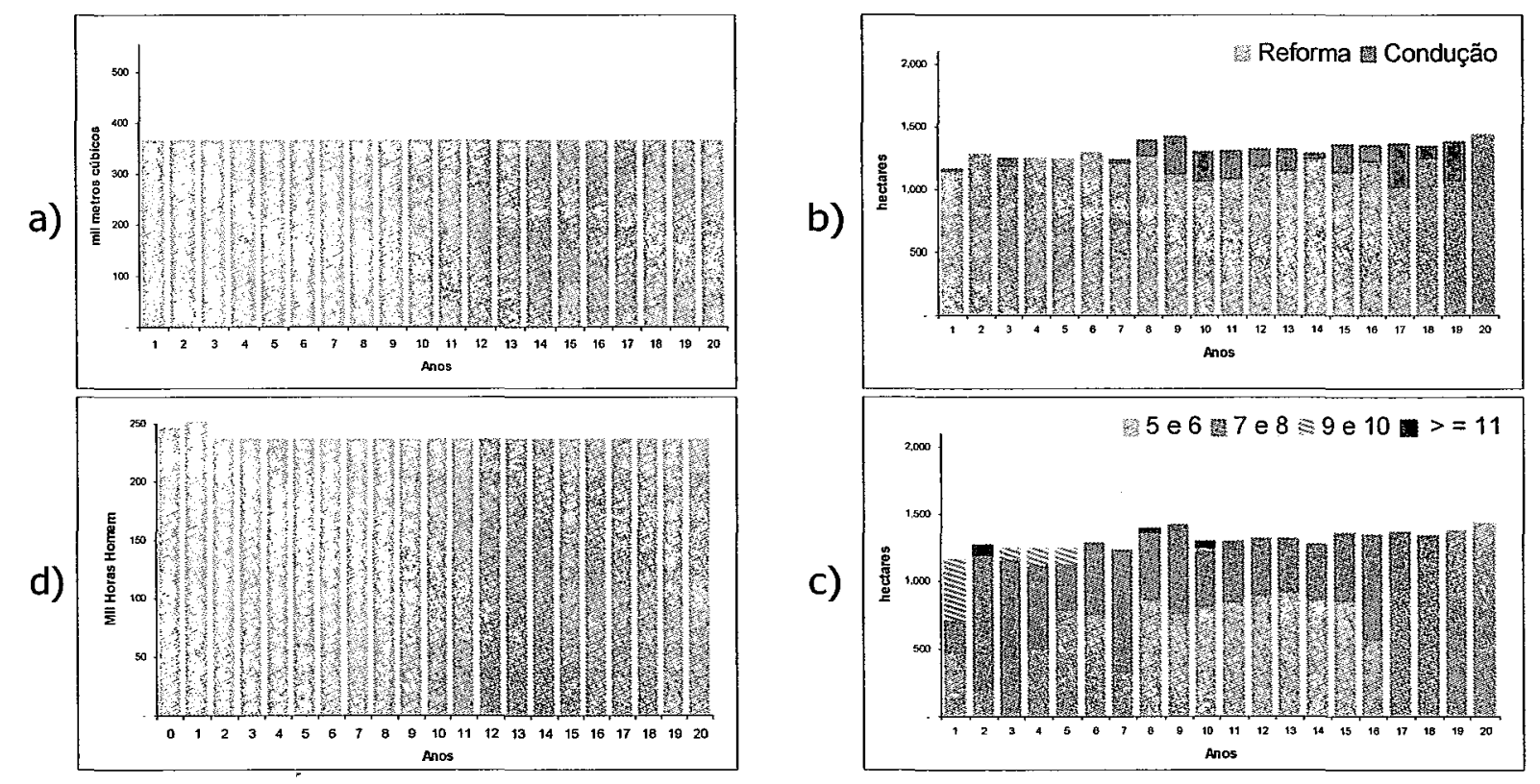

Figura 13 - Efeitos đo modelo compromisso métrica $L=1$ sobre a disponibilização madeira (a), formas de condução da floresta (b), distribuição de idades (c) e utilização de recursos humanos (d).

\subsubsection{Modelo de programação compromisso métrica $L=\infty$}

A função objetivo do modelo que utiliza a métrica infinito procura minimizar o maior entre todos os desvios individuais, sendo este desvio o que mais influenciará no processo de decisão.

A solução ótima obtida após 3.217 iterações resultou em valor total do projeto de $\mathrm{R} \$ 39.011 .068$ (93\% do ótimo). O volume anual de $359.960 \mathrm{~m}^{3}$ (92\% do ótimo) manteve-se fixo para todo horizonte, Figura 14 (a). A tabela 17 apresenta para o 
horizonte de planejamento volumes anuais produzidos, total de área colhida, produtividade e número de horas-homem utilizadas durante o horizonte.

Tabela 17. Volumes totais produzidos, áreas colhidas anualmente, produtividade e número de horas-homem para o modelo de programação compromisso, métrica infinito.

\begin{tabular}{|c|c|c|c|c|}
\hline Ano & $\begin{array}{c}\text { Produção } \\
\mathrm{m}^{3}\end{array}$ & $\begin{array}{c}\text { Área } \\
\text { ha }\end{array}$ & $\begin{array}{c}\text { Produtividad } \\
\text { e } \\
\mathbf{m}^{3} / \mathbf{h a}\end{array}$ & $\begin{array}{c}\text { Horas Homem } \\
\text { Horas }\end{array}$ \\
\hline 1 & 359.960 & $1.185,15$ & 303,73 & 259.144 \\
\hline 2 & 359.960 & $1.280,43$ & 281,12 & 236.642 \\
\hline 3 & 359.960 & $1.221,94$ & 294,58 & 236.642 \\
\hline 4 & 359.960 & $1.266,85$ & 284,14 & 236.642 \\
\hline 5 & 359.960 & $1.265,29$ & 284,49 & 236.642 \\
\hline 6 & 359.960 & $1.334,71$ & 269,69 & 236.642 \\
\hline 7 & 359.960 & $1.304,27$ & 275,99 & 236.642 \\
\hline 8 & 359.960 & $1.374,31$ & 261,92 & 236.642 \\
\hline 9 & 359.960 & $1.205,09$ & 298,70 & 236.642 \\
\hline 10 & 359.960 & $1.356,29$ & 265,40 & 236.642 \\
\hline 11 & 359.960 & $1.268,26$ & 283,82 & 236.642 \\
\hline 12 & 359.960 & $1.353,01$ & 266,04 & 236.642 \\
\hline 13 & 359.960 & $1.366,57$ & 263,40 & 236.642 \\
\hline 14 & 359.960 & $1.264,96$ & 284,56 & 236.642 \\
\hline 15 & 359.960 & $1.381,88$ & 260,49 & 236.642 \\
\hline 16 & 359.960 & $1.289,32$ & 279,19 & 236.642 \\
\hline 17 & 359.960 & $1.383,84$ & 260,12 & 236.642 \\
\hline 18 & 359.960 & $1.391,07$ & 258,77 & 236.642 \\
\hline 19 & 359.960 & $1.388,53$ & 259,24 & 236.642 \\
\hline 20 & 359.960 & $1.482,38$ & 242,83 & 252.608 \\
\hline Total & 7.199 .200 & $26.364,13$ & 273,07 & 4.771 .300 \\
\hline
\end{tabular}

Fonte: Dados da pesquisa.

Diferente da métrica $L=1$ a métrica $L=\infty$ tem como resultado um bom balanceamento entre as soluções obtidas e seus valores ótimos. Por este motivo, ao comparar seus resultados com os resultados do modelo que utiliza a métrica $L=1$, observa-se uma penalização de todos os objetivos para que seja possível a diminuição do número total de intervenções de colheita. $\mathrm{O}$ maior desvio deste objetivo está ligado às pressões exercidas pelas idades ótimas de colheita volumétricas e econômicas as quais forçam uma concentração das idades em classes de 5 a 7 anos. Outro fator importante reside na determinação da exigência volumétrica anual mínima. 
Graficamente, as soluções obtidas pelas duas métricas podem ser observadas na Figura 15. Comparando-se as duas soluções observa-se a diminuição dos valores de VTP, refletindo na diminuição de colheitas com idades economicamente ótimas, Figura14 (c). No mesmo gráfico, observa-se o recrutamento de áreas para corte com idades superiores aos 11 anos referentes à diminuição do número total de intervenções de colheita com o objetivo de aumentar o tamanho das rotações. O quadrante (d) apresenta pequenas variações entre o número de horas homem utilizadas.

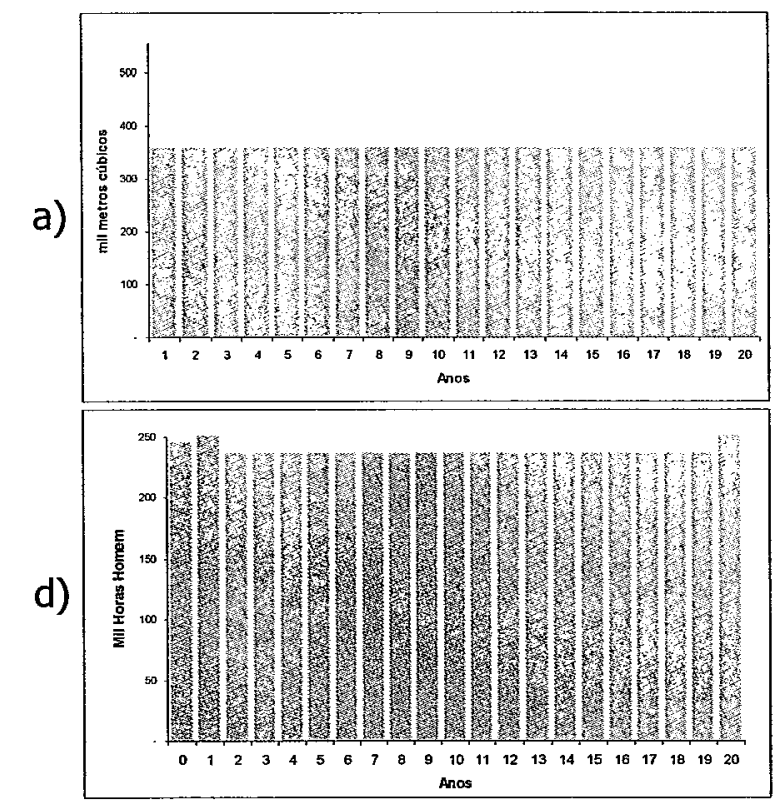

b)
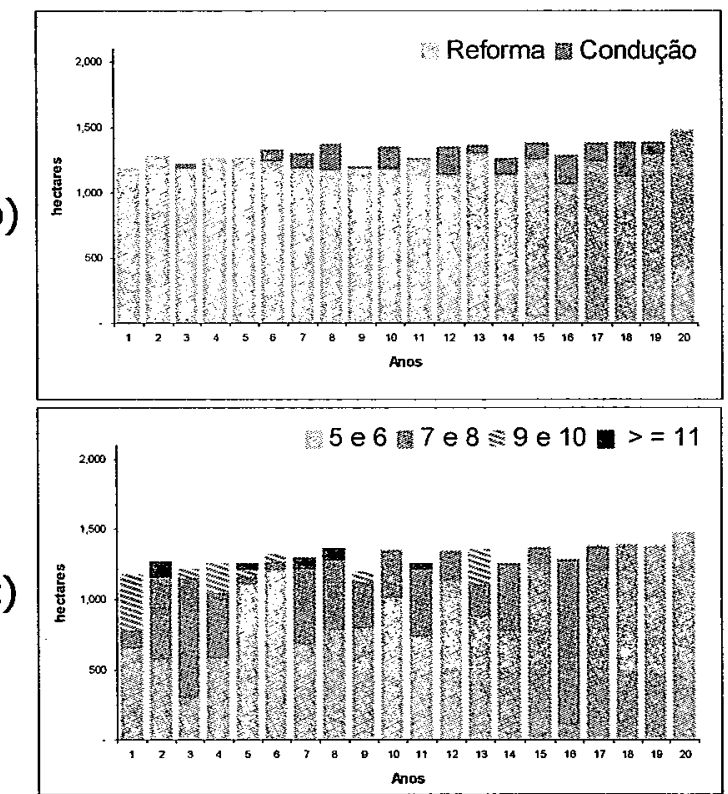

Figura 14 - Efeitos do modelo compromisso métrica $L=\infty$ sobre a disponibilização madeira (a), formas de condução da floresta (b), distribuição de idades (c) e utilização de recursos humanos (d). 
a)

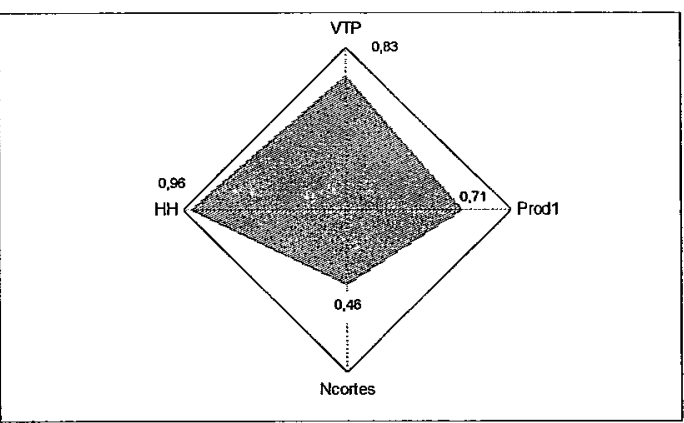

b)

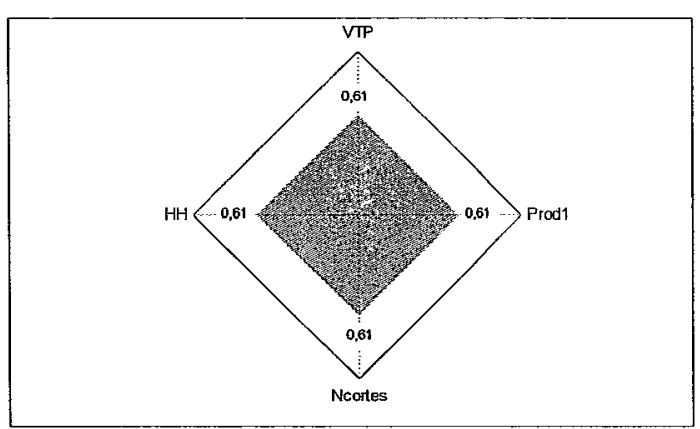

Figura 15 - Soluções obtidas para os modelos compromisso que utilizam a métrica $L=1$ (a) e. métrica $\mathrm{L}=\infty$ (b).

\subsection{Comparação entre modelo tradicional e os modelos propostos}

$\mathrm{O}$ modelo de programação compromisso que utilizou métrica $\mathrm{L}=1$ teve como principal característica a busca pelas melhore soluções individuais para os objetivos, diferente do modelo $\mathrm{L}=\infty$ que procurou soluções mais equilibradas como previa Ballestero (1997).

As soluções obtidas pelos modelos compromisso possuem claramente as influências dos objetivos otimizados individualmente. Um exemplo desta influência pode ser observado na Tabela 18 que apresenta o volume total produzido e a área total colhida no final do horizonte de planejamento. A melhor relação de produtividade foi encontrada pelo modelo que minimiza o número de intervenções de colheita, essa influência é transferida para os modelos compromisso que obtêm resultados melhores que o modelo tradicional.

A Tabela 19 apresenta receita líquida por metro cúbico produzido para cada modelo corrigidos em valores presentes a uma taxa de juros de $10 \%$ ao ano. Como esperado as maiores receitas foram obtidas pelos modelos que maximizam o valor total do projeto. As piores receitas foram obtidas pelos modelos que maximizam o volume produzido devido à escolha dos regimes ocorrer a partir da produtividade das unidades de gestão independentemente dos custos envolvidos. 
Tabela 18. Área total colhida e volume total produzido ao final do horizonte de planejamento estimados pelos objetivos utilizados.

\begin{tabular}{lrrr}
\hline Modelos & $\begin{array}{c}\text { Área Colhida } \\
\text { (ha em 20 anos) }\end{array}$ & $\begin{array}{c}\text { Produção } \\
\text { (m3 em 20 anos) }\end{array}$ & $\begin{array}{c}\text { Produtividade } \\
\text { (m3/ha) }\end{array}$ \\
\hline Tradicional & $24.850,60$ & 6.781 .839 & 272,90 \\
Max VTP & $25.234,98$ & 6.854 .452 & 271,63 \\
Max Prod & $30.901,13$ & 7.793 .762 & 252,22 \\
Min Colheita & $22.325,22$ & 6.262 .058 & 280,49 \\
Min Var.HH & $23.921,92$ & 6.262 .058 & 261,77 \\
LP = 1 & $26.377,89$ & 7.347 .156 & 278,53 \\
LP $=\infty$ & $26.364,13$ & 7.199 .200 & 273,07 \\
\hline
\end{tabular}

Fonte: Dados da Pesquisa

Tabela 19. Valores presentes dos volumes totais, das receitas líquidas totais e das receitas líquidas por metro cúbico previstos pelos modelos de otimização utilizados na pesquisa. Taxa de juros $10 \%$ ao ano.

\begin{tabular}{lccc}
\hline Modelo & $\begin{array}{c}\text { Volume presente } \\
(\mathbf{m 3})\end{array}$ & $\begin{array}{c}\text { Valor presente líquido } \\
(\mathbf{R} \$)\end{array}$ & $\begin{array}{c}\text { Receita líquida } \\
(\mathbf{R} \$ \mathbf{m 3})\end{array}$ \\
\hline Tradicional & $2.951 .969,32$ & $42.355 .625,00$ & 14,35 \\
Max VTP & $2.917 .790,69$ & $42.083 .887,00$ & 14,42 \\
Max Prod & $3.317 .634,47$ & $38.405 .864,00$ & 11,58 \\
Min Colheita & $2.665 .621,49$ & $35.560 .644,00$ & 13,34 \\
Min Var.HH & $2.665 .621,49$ & $34.167 .735,00$ & 12,82 \\
LP $=\mathbf{1}$ & $3.127 .524,04$ & $40.762 .135,00$ & 13,03 \\
$\mathbf{L P}=\infty$ & $3.064 .542,40$ & $39.011 .068,00$ & 12,73 \\
\hline
\end{tabular}

Fonte: Dados da Pesquisa

Comparando os resultados do modelo tradicional (Figura 16) com os modelos propostos (Figura $15 \mathrm{a} \mathrm{e} \mathrm{b),} \mathrm{o} \mathrm{único} \mathrm{objetivo} \mathrm{que} \mathrm{obteve} \mathrm{resultado} \mathrm{inferior} \mathrm{ao} \mathrm{modelo}$ tradicional foi aquele que maximiza o valor total do projeto.

Para os demais objetivos foram observadas as seguintes melhorias:

- os patamares mínimos de produção obtidos para as métricas $\mathrm{L}=1$ e $\mathrm{L}=\infty$ foram superiores ao modelo tradicional em respectivamente $52.255 \mathrm{~m}^{3} \mathrm{e}$ $46.857 \mathrm{~m}^{3}$.

- As variações anuais de horas-homem diminuíram 94,88\% para o modelo $\mathrm{L}=$ 1 e $55,27 \%$ para o modelo $\mathrm{L}=\infty$. 
- Para o objetivo de redução do número de intervenções de colheita as melhorias foram relativamente pouco significativas quando comparada aos outros objetivos, chegando a $4,57 \%$ para $L=1$ e $15,05 \%$ para $L=\infty$.

As reduções dos valores totais dos projetos representam indiretamente os custos de melhora das outras dimensões, ou seja, os custos de substituição do modelo tradicional de elaboração de planos de manejo pelos modelos propostos neste trabalho.

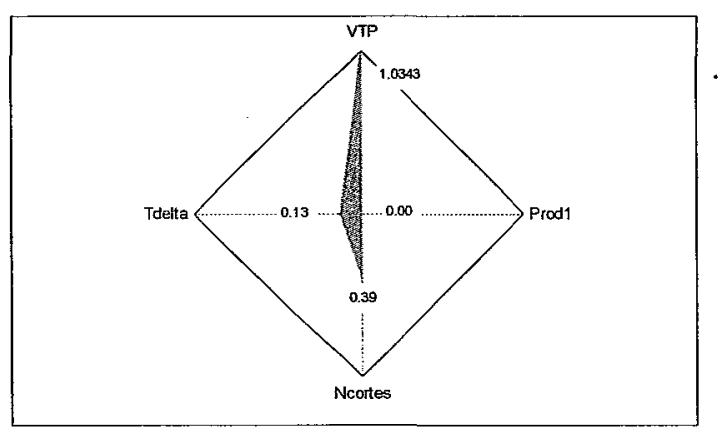

Figura 16 - Soluções obtidas para o modelo tradicional.

A partir da Tabela 19 observa-se que o custo de substituição do modelo tradicional pelo modelo que utiliza a métrica $L=1$ seria de $R \$ 1,32 / \mathrm{m} 3$ produzido. Para o modelo que procura o equilíbrio de soluções através da métrica $\mathrm{L}=\infty$ o custo seria de $\mathrm{R} \$ 1,62 / \mathrm{m} 3$ produzido. 


\section{CONCLUSÕES}

Como pode ser observado nas Figuras 15 e 16, o modelo tradicional resulta no maior valor total do projeto mas não satisfaz as dimensões social e ecológica representadas pela minimização da variação anual de horas trabalhadas e minimização das intervenções de colheita. Os planos de manejo resultantes são diferentes como pode ser comprovado ao se observar os dados das figuras 7, 13 e 14. Essas diferenças permitem confirmar a hipótese básica deste trabalho a qual afirma que a inclusão de compromissos sociais e ecológicos geram planos de manejo diferentes dos preconizados pelo modelo tradicional que enfatiza apenas o máximo valor total do projeto.

O controle de variações de demanda por horas-homem, poderia ser medido de forma indireta. Esse mesmo objetivo social poderia ser alcançado através de restrições operacionais de capacidade de reforma anual, prática comum nos modelos tradicionais.

O método sugerido, como demonstrado, dispensa inicialmente a declaração de valores para as metas sociais e ecológicas. Entretanto a sua utilização oferece valores iniciais para essas metas que podem ser ajustadas conforme os compromissos forem se definindo e as relações sociais e ecológicas forem evoluindo.

$\mathrm{O}$ equilíbrio de soluções obtido pelo modelo que utiliza métrica $\mathrm{L}=\infty$ mostrou maior relação com o esperado para modelos sustentáveis. Por outro lado, a proximidade de resultados obtidos pelo modelo que utiliza a métrica $\mathrm{L}=1$ em relação aos ótimos econômicos e volumétricos faz com que este modelo tenha maiores chances de substituição dos modelos tradicionais. 
Os modelos propostos revelaram-se de grande utilidade para a avaliação de variáveis antes não consideradas durante o processo de seleção de regimes de manejo. Pôde-se observar que, independente das dimensões propostas, o método mostrou-se de grande utilidade para a avaliação indireta dos custos de alterações dos critérios de decisão. Considerando o dinamismo do processo de busca pela sustentabilidade, novos objetivos poderiam ser incluídos e seus efeitos mensurados economicamente. 
ANEXOS 


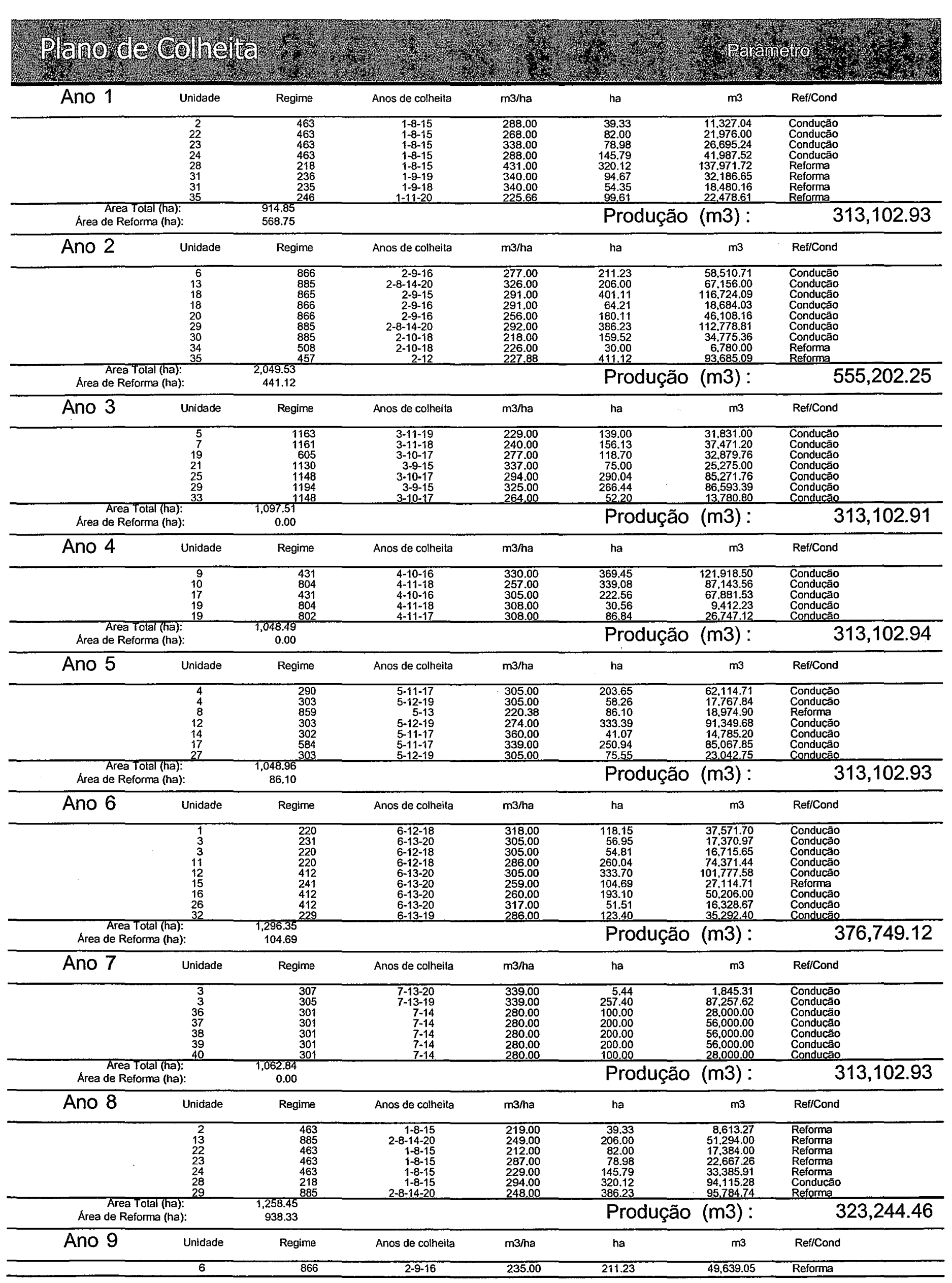




\begin{tabular}{|c|c|c|c|c|c|c|c|}
\hline & $\begin{array}{l}18 \\
18 \\
20 \\
21 \\
29 \\
31 \\
31 \\
\end{array}$ & $\begin{array}{r}866 \\
865 \\
866 \\
1130 \\
1194 \\
236 \\
235 \\
\end{array}$ & $\begin{array}{l}2-9-16 \\
2-9-15 \\
2-9-16 \\
3-9-15 \\
3-9-15 \\
1-9-19 \\
1-9-18 \\
\end{array}$ & $\begin{array}{l}247.00 \\
247.00 \\
218.00 \\
258.00 \\
248.00 \\
240.00 \\
240.00 \\
\end{array}$ & $\begin{array}{r}64.21 \\
401.11 \\
180.11 \\
75.00 \\
266.44 \\
94.67 \\
54.35 \\
\end{array}$ & $\begin{array}{r}15.858 .96 \\
99.075 .09 \\
39.263 .98 \\
19.350 .00 \\
66.077 .42 \\
22.719 .98 \\
13.044 .82 \\
\end{array}$ & $\begin{array}{l}\text { Reforma } \\
\text { Reforma } \\
\text { Reforma } \\
\text { Reforma } \\
\text { Reforma } \\
\text { Conducaáo } \\
\text { Conducâa } \\
\end{array}$ \\
\hline \multicolumn{2}{|c|}{$\begin{array}{c}\text { Area Total (ha): } \\
\text { Area de Reforma (ha): }\end{array}$} & $\begin{array}{l}1,347.12 \\
1,198.10\end{array}$ & & & \multicolumn{2}{|c|}{ Produção (m3): } & $325,029.29$ \\
\hline \multirow[t]{2}{*}{ Ano 10} & Unidade & Regime & Anos de colheita & $\mathrm{m} 3 / \mathrm{ha}$ & ha & $\mathrm{m}^{3}$ & Ref/Cond \\
\hline & $\begin{array}{r}9 \\
17 \\
19 \\
25 \\
30 \\
33 \\
34 \\
\end{array}$ & $\begin{array}{r}431 \\
431 \\
605 \\
1148 \\
885 \\
1148 \\
508 \\
\end{array}$ & $\begin{array}{l}4-10-16 \\
4-10-16 \\
3-10-17 \\
3-10-17 \\
2-10-18 \\
3-10-17 \\
2-10-18 \\
\end{array}$ & $\begin{array}{l}280.00 \\
259.00 \\
262.00 \\
250.00 \\
185.00 \\
224.00 \\
240.00 \\
\end{array}$ & $\begin{array}{r}369.45 \\
222.56 \\
118.70 \\
290.04 \\
159.52 \\
52.20 \\
30.00 \\
\end{array}$ & $\begin{array}{r}103.446 .00 \\
57.643 .66 \\
31.099 .27 \\
72.510 .00 \\
29.511 .20 \\
11.692 .80 \\
7.200 .00 \\
\end{array}$ & $\begin{array}{l}\text { Reforma } \\
\text { Reforma } \\
\text { Reforma } \\
\text { Reforma } \\
\text { Reforma } \\
\text { Reforma } \\
\text { Conducăo } \\
\end{array}$ \\
\hline \multicolumn{2}{|c|}{$\begin{array}{l}\text { Area Total (ha): } \\
\text { Area de Reforma (ha): }\end{array}$} & $\begin{array}{l}1,242.47 \\
1,212.47\end{array}$ & & & \multicolumn{2}{|c|}{ Produção (m3): } & $313,102.94$ \\
\hline \multirow[t]{2}{*}{ Ano 11} & Unidade & Regime & Anos de colheita & $\mathrm{m} 3 / \mathrm{ha}$ & ha & m3 & Ref/Cond \\
\hline & $\begin{array}{r}4 \\
5 \\
7 \\
10 \\
14 \\
17 \\
19 \\
19 \\
35 \\
\end{array}$ & $\begin{array}{r}290 \\
1163 \\
1161 \\
804 \\
302 \\
584 \\
804 \\
802 \\
246 \\
\end{array}$ & $\begin{array}{l}5-11-17 \\
3-11-19 \\
3-11-18 \\
4-11-18 \\
5-11-17 \\
5-11-17 \\
4-11-18 \\
4-11-17 \\
1-11-20 \\
\end{array}$ & $\begin{array}{l}259.00 \\
195.00 \\
204.00 \\
218.00 \\
306.00 \\
259.00 \\
262.00 \\
262.00 \\
192.37 \\
\end{array}$ & $\begin{array}{r}203.65 \\
139.00 \\
156.13 \\
339.08 \\
41.07 \\
250.94 \\
30.56 \\
86.84 \\
99.61 \\
\end{array}$ & $\begin{array}{r}52.746 .59 \\
27.105 .00 \\
31.850 .52 \\
73.919 .44 \\
12.567 .42 \\
64.992 .84 \\
8.006 .51 \\
22.752 .42 \\
19.162 .20 \\
\end{array}$ & $\begin{array}{l}\text { Reforma } \\
\text { Reforma } \\
\text { Reforma } \\
\text { Reforma } \\
\text { Reforma } \\
\text { Reforma } \\
\text { Reforma } \\
\text { Reforma } \\
\text { Conducão } \\
\end{array}$ \\
\hline \multicolumn{2}{|c|}{$\begin{array}{l}\text { Area Tolal (ha): } \\
\text { Area de Reforma (ha): }\end{array}$} & $\begin{array}{l}1,346.89 \\
1,247.27\end{array}$ & & & \multicolumn{2}{|c|}{ Produção (m3): } & $313,102.94$ \\
\hline \multirow[t]{2}{*}{ Ano 12} & Unidade & Regime & Anos de colheita & $\mathrm{m} 3 / \mathrm{ha}$ & ha & m3 & Ref/Cond \\
\hline & $\begin{array}{r}1 \\
3 \\
4 \\
11 \\
12 \\
27 \\
35 \\
\end{array}$ & $\begin{array}{l}220 \\
220 \\
303 \\
220 \\
303 \\
303 \\
457 \\
\end{array}$ & $\begin{array}{r}6-12-18 \\
6-12-18 \\
5-12-19 \\
6-12-18 \\
5-12-19 \\
5-12-19 \\
2-12 \\
\end{array}$ & $\begin{array}{l}270.00 \\
259.00 \\
288.00 \\
243.00 \\
259.00 \\
286.00 \\
192.37 \\
\end{array}$ & $\begin{array}{r}118.15 \\
54.81 \\
58.26 \\
260.04 \\
333.39 \\
75.55 \\
411.12 \\
\end{array}$ & $\begin{array}{l}31.900 .50 \\
14.194 .60 \\
16.777 .50 \\
63.189 .72 \\
86.348 .79 \\
21.607 .30 \\
79.084 .51 \\
\end{array}$ & $\begin{array}{l}\text { Reforma } \\
\text { Reforma } \\
\text { Reforma } \\
\text { Reforma } \\
\text { Reforma } \\
\text { Reforma } \\
\text { Conducăo } \\
\end{array}$ \\
\hline \multicolumn{2}{|c|}{$\begin{array}{l}\text { Area Tolal (ha): } \\
\text { Area de Reforma (ha): }\end{array}$} & $\begin{array}{r}1,311.31 \\
900.19\end{array}$ & & & \multicolumn{2}{|c|}{ Produção (m3): } & $313,102.92$ \\
\hline \multirow[t]{2}{*}{ Ano 13} & Unidade & Regime & Anos de colheita & $\mathrm{m} 3 / \mathrm{ha}$ & ha & $\mathrm{m} 3$ & Ref/Cond \\
\hline & $\begin{array}{r}3 \\
3 \\
3 \\
8 \\
12 \\
15 \\
16 \\
26 \\
32 \\
\end{array}$ & $\begin{array}{r}307 \\
231 \\
305 \\
859 \\
412 \\
241 \\
412 \\
412 \\
229 \\
\end{array}$ & $\begin{array}{l}7-13-20 \\
6-13-20 \\
7-13-19 \\
5-13 \\
6-13-20 \\
6-13-20 \\
6-13-20 \\
6-13-20 \\
6-13-19 \\
\end{array}$ & $\begin{array}{l}259.00 \\
288.00 \\
259.00 \\
240.00 \\
259.00 \\
305.00 \\
221.00 \\
269.00 \\
268.00 \\
\end{array}$ & $\begin{array}{r}5.44 \\
56.95 \\
257.40 \\
86.10 \\
333.70 \\
104.69 \\
193.10 \\
51.51 \\
123.40 \\
\end{array}$ & $\begin{array}{r}1.409 .84 \\
16.402 .75 \\
66.665 .85 \\
20.664 .00 \\
86.427 .52 \\
31.930 .45 \\
42.675 .10 \\
13.856 .19 \\
33.071 .20 \\
\end{array}$ & $\begin{array}{l}\text { Reforma } \\
\text { Reforma } \\
\text { Reforma } \\
\text { Conducáo } \\
\text { Reforma } \\
\text { Conducão } \\
\text { Reforma } \\
\text { Reforma } \\
\text { Reforma } \\
\end{array}$ \\
\hline \multicolumn{2}{|c|}{$\begin{array}{l}\text { Area Total (ha): } \\
\text { Area de Reforma (ha): }\end{array}$} & $\begin{array}{l}1,212.29 \\
1,021.50\end{array}$ & & & \multicolumn{2}{|c|}{ Produção (m3): } & $313,102.90$ \\
\hline \multirow[t]{2}{*}{ Ano 14} & Unidade & Regime & Anos de colheita & $\mathrm{m} 3 / \mathrm{ha}$ & ha & $\mathrm{m} 3$ & Ref/Cond \\
\hline & $\begin{array}{l}13 \\
29 \\
36 \\
37 \\
38 \\
39 \\
40 \\
\end{array}$ & $\begin{array}{l}885 \\
885 \\
301 \\
301 \\
301 \\
301 \\
301 \\
\end{array}$ & $\begin{array}{r}2-8-14-20 \\
2-8-14-20 \\
7-14 \\
7-14 \\
7-14 \\
7-14 \\
7-14 \\
\end{array}$ & $\begin{array}{l}293.00 \\
292.00 \\
238.00 \\
238.00 \\
238.00 \\
238.00 \\
238.00 \\
\end{array}$ & $\begin{array}{l}206.00 \\
386.23 \\
100.00 \\
200.00 \\
200.00 \\
200.00 \\
100.00 \\
\end{array}$ & $\begin{array}{r}60.358 .00 \\
112.778 .81 \\
23.800 .00 \\
47.600 .00 \\
47.600 .00 \\
47.600 .00 \\
23.800 .00 \\
\end{array}$ & $\begin{array}{l}\text { Conducáa } \\
\text { Condučão } \\
\text { Reforma } \\
\text { Reforma } \\
\text { Reforma } \\
\text { Reforma } \\
\text { Reforma } \\
\end{array}$ \\
\hline \multicolumn{2}{|c|}{$\begin{array}{l}\text { Area Total (ha): } \\
\text { Area de Reforma (ha): }\end{array}$} & $\begin{array}{r}1.392 .23 \\
800.00\end{array}$ & & & \multicolumn{2}{|c|}{ Produção (m3): } & $363,536.81$ \\
\hline \multirow[t]{2}{*}{ Ano 15} & Unidade & Regime & Anos de colheita & $\mathrm{m} 3 / \mathrm{ha}$ & ha & $\mathrm{m} 3$ & Ref/Cond \\
\hline & $\begin{array}{r}2 \\
18 \\
21 \\
22 \\
23 \\
24 \\
28 \\
29 \\
\end{array}$ & $\begin{array}{r}463 \\
865 \\
1130 \\
463 \\
463 \\
463 \\
218 \\
1194 \\
\end{array}$ & $\begin{array}{l}1-8-15 \\
2-9-15 \\
3-9-15 \\
1-8-15 \\
1-8-15 \\
1-8-15 \\
1-8-15 \\
3-9-15 \\
\end{array}$ & $\begin{array}{l}257.00 \\
261.00 \\
303.00 \\
250.00 \\
338.00 \\
269.00 \\
250.00 \\
292.00 \\
\end{array}$ & $\begin{array}{r}39.33 \\
401.11 \\
75.00 \\
82.00 \\
78.98 \\
145.79 \\
320.12 \\
266.44 \\
\end{array}$ & $\begin{array}{r}10.107 .81 \\
104.690 .68 \\
22.725 .00 \\
20.500 .00 \\
26.695 .24 \\
39.217 .51 \\
80.030 .00 \\
77.800 .83 \\
\end{array}$ & $\begin{array}{l}\text { Conducăo } \\
\text { Conducăo } \\
\text { Conducāo } \\
\text { Conducão } \\
\text { Conducăo } \\
\text { Conducão } \\
\text { Reforma } \\
\text { Conducăo } \\
\end{array}$ \\
\hline \multicolumn{2}{|c|}{$\begin{array}{l}\text { Area Total (ha): } \\
\text { Area de Reforma (ha): }\end{array}$} & $\begin{array}{l}1.408 .77 \\
320.12\end{array}$ & & & \multicolumn{2}{|c|}{ Produção (m3): } & $381,767.06$ \\
\hline \multirow[t]{2}{*}{ Ano 16} & Unidade & Regime & Anos de colheita & $\mathrm{m} 3 / \mathrm{ha}$ & ha & $\mathrm{m} 3$ & Ref/Cond \\
\hline & $\begin{array}{r}6 \\
9 \\
17 \\
18 \\
20 \\
\end{array}$ & $\begin{array}{l}866 \\
431 \\
431 \\
866 \\
866 \\
\end{array}$ & $\begin{array}{r}2-9-16 \\
4-10-16 \\
4-10-16 \\
2-9-16 \\
2-9-16 \\
\end{array}$ & $\begin{array}{l}277.00 \\
330.00 \\
305.00 \\
291.00 \\
256.00 \\
\end{array}$ & $\begin{array}{r}211.23 \\
369.45 \\
222.56 \\
64.21 \\
180.11 \\
\end{array}$ & $\begin{array}{r}58.510 .71 \\
121.918 .50 \\
67.881 .53 \\
18.684 .03 \\
46.108 .16 \\
\end{array}$ & $\begin{array}{l}\text { Reforma } \\
\text { Reforma } \\
\text { Reforma } \\
\text { Reforma } \\
\text { Reforma } \\
\end{array}$ \\
\hline \multicolumn{2}{|c|}{$\begin{array}{l}\text { Area Total (ha): } \\
\text { Area de Reforma (ha): }\end{array}$} & $\begin{array}{l}7.047 .56 \\
1.047 .56\end{array}$ & & & Prod & (m3): & $313,102.94$ \\
\hline \multirow[t]{2}{*}{ Ano 17} & Unidade & Regime & Anos de colheita & $\mathrm{m} 3 / \mathrm{ha}$ & ha & $\mathrm{m} 3$ & Ref/Cond \\
\hline & $\begin{array}{r}4 \\
14 \\
17 \\
19 \\
19 \\
25 \\
33 \\
\end{array}$ & $\begin{array}{r}290 \\
302 \\
584 \\
605 \\
802 \\
1148 \\
1148 \\
\end{array}$ & $\begin{array}{l}5-11-17 \\
5-11-17 \\
5-11-17 \\
3-10-17 \\
4-11-17 \\
3-10-17 \\
3-10-17 \\
\end{array}$ & $\begin{array}{l}305.00 \\
360.00 \\
305.00 \\
308.00 \\
277.00 \\
294.00 \\
264.00 \\
\end{array}$ & $\begin{array}{r}203.65 \\
41.07 \\
250.94 \\
118.70 \\
86.84 \\
290.04 \\
52.20 \\
\end{array}$ & $\begin{array}{l}62.114 .71 \\
14.785 .20 \\
76.535 .97 \\
36.559 .45 \\
24.055 .04 \\
85.271 .76 \\
13.780 .80 \\
\end{array}$ & $\begin{array}{l}\text { Reforma } \\
\text { Reforma } \\
\text { Reforma } \\
\text { Reforma } \\
\text { Reforma } \\
\text { Reforma } \\
\text { Reforma } \\
\end{array}$ \\
\hline \multicolumn{2}{|c|}{$\begin{array}{l}\text { Area Total (ha): } \\
\text { Area de Reforma (ha): }\end{array}$} & $\begin{array}{l}1,043.44 \\
1,043.44\end{array}$ & & & Proc & $(\mathrm{m} 3):$ & $313,102.93$ \\
\hline
\end{tabular}




\begin{tabular}{|c|c|c|c|c|c|c|c|}
\hline Ano 18 & Unidade & Regime & Anos de colheita & $\mathrm{m} 3 / \mathrm{ha}$ & ha & $\mathrm{m} 3$ & Ref/Cond \\
\hline & $\begin{array}{r}1 \\
3 \\
7 \\
10 \\
11 \\
19 \\
30 \\
31 \\
34 \\
\end{array}$ & $\begin{array}{r}220 \\
220 \\
1161 \\
804 \\
220 \\
804 \\
885 \\
235 \\
508 \\
\end{array}$ & $\begin{array}{l}6-12-18 \\
6-12-18 \\
3-11-18 \\
4-11-18 \\
6-12-18 \\
4-11-18 \\
2-10-18 \\
10-18 \\
2-10-18 \\
\end{array}$ & $\begin{array}{l}318.00 \\
305.00 \\
224.00 \\
257.00 \\
286.00 \\
308.00 \\
218.00 \\
209.00 \\
226.00 \\
\end{array}$ & $\begin{array}{r}118.15 \\
54.81 \\
156.13 \\
339.08 \\
260.04 \\
30.56 \\
159.52 \\
54.35 \\
30.00 \\
\end{array}$ & $\begin{array}{r}37.571 .70 \\
16.715 .65 \\
34.973 .12 \\
87.143 .56 \\
74.371 .44 \\
9.412 .23 \\
34.775 .36 \\
11.359 .86 \\
6.780 .00 \\
\end{array}$ & $\begin{array}{l}\text { Reforma } \\
\text { Reforma } \\
\text { Reforma } \\
\text { Reforma } \\
\text { Reforma } \\
\text { Reforma } \\
\text { Reforma } \\
\text { Reforma } \\
\text { Reforma } \\
\end{array}$ \\
\hline \multicolumn{2}{|c|}{$\begin{array}{l}\text { Area Total (ha): } \\
\text { Area de Reforma (ha): }\end{array}$} & $\begin{array}{l}1,202.64 \\
1,202.64 \\
\end{array}$ & & & \multicolumn{2}{|c|}{ Produção (m3): } & $313,102.92$ \\
\hline \multirow[t]{2}{*}{ Ano 19} & Unidade & Regime & Anos de colheita & $\mathrm{m} 3 / \mathrm{ha}$ & ha & $\mathrm{m} 3$ & Ref/Cond \\
\hline & $\begin{array}{r}33 \\
4 \\
5 \\
12 \\
27 \\
31 \\
32 \\
\end{array}$ & $\begin{array}{r}305 \\
303 \\
1163 \\
303 \\
303 \\
236 \\
229 \\
\end{array}$ & $\begin{array}{r}7-13-19 \\
5-12-19 \\
3-11-19 \\
5-12-19 \\
5-12-19 \\
1-9-19 \\
6-13-19 \\
\end{array}$ & $\begin{array}{l}305.00 \\
339.00 \\
229.00 \\
305.00 \\
336.00 \\
218.19 \\
286.00 \\
\end{array}$ & $\begin{array}{r}257.40 \\
58.26 \\
139.00 \\
333.39 \\
75.55 \\
94.67 \\
123.40 \\
\end{array}$ & $\begin{array}{r}78.506 .11 \\
19.748 .51 \\
31.831 .00 \\
101.684 .87 \\
25.384 .80 \\
20.655 .24 \\
35.292 .40 \\
\end{array}$ & $\begin{array}{l}\text { Reforma } \\
\text { Reforma } \\
\text { Reforma } \\
\text { Reforma } \\
\text { Reforma } \\
\text { Reforma } \\
\text { Reforma } \\
\end{array}$ \\
\hline \multicolumn{2}{|c|}{$\begin{array}{l}\text { Area Tolal (ha): } \\
\text { Area de Reforma (ha): }\end{array}$} & $\begin{array}{l}1,081.66 \\
1,081.66 \\
\end{array}$ & & & \multicolumn{2}{|c|}{ Produção (m3): } & $313,102.93$ \\
\hline \multirow[t]{2}{*}{ Ano 20} & Unidade & Regime & Anos de colheita & $\mathrm{m} 3 / \mathrm{ha}$ & ha & $\mathrm{m} 3$ & Ref/Cond \\
\hline & \begin{tabular}{r|}
3 \\
3 \\
12 \\
13 \\
15 \\
16 \\
26 \\
29 \\
35 \\
\end{tabular} & $\begin{array}{r}231 \\
307 \\
412 \\
885 \\
241 \\
412 \\
412 \\
885 \\
246 \\
\end{array}$ & $\begin{array}{r}6-13-20 \\
7-13-20 \\
6-13-20 \\
2-8-14-20 \\
6-13-20 \\
6-13-20 \\
6-13-20 \\
2-8-14-20 \\
1-11-20 \\
\end{array}$ & $\begin{array}{l}339.00 \\
339.00 \\
305.00 \\
249.00 \\
259.00 \\
260.00 \\
317.00 \\
248.00 \\
224.00 \\
\end{array}$ & $\begin{array}{r}56.95 \\
5.44 \\
333.70 \\
206.00 \\
104.69 \\
193.10 \\
51.51 \\
386.23 \\
99.61 \\
\end{array}$ & $\begin{array}{r}19.307 .41 \\
1.845 .31 \\
101.777 .58 \\
51.294 .00 \\
27.114 .71 \\
50.206 .00 \\
16.328 .67 \\
95.784 .74 \\
22.313 .45 \\
\end{array}$ & $\begin{array}{l}\text { Reforma } \\
\text { Reforma } \\
\text { Reforma } \\
\text { Reforma } \\
\text { Reforma } \\
\text { Reforma } \\
\text { Reforma } \\
\text { Reforma } \\
\text { Reforma } \\
\end{array}$ \\
\hline \multicolumn{2}{|c|}{$\begin{array}{l}\text { Area Total (ha): } \\
\text { Area de Reforma (ha): }\end{array}$} & $\begin{array}{l}1,437.24 \\
1,437.24\end{array}$ & & & \multicolumn{2}{|c|}{ Produção (m3): } & $385,971.87$ \\
\hline
\end{tabular}




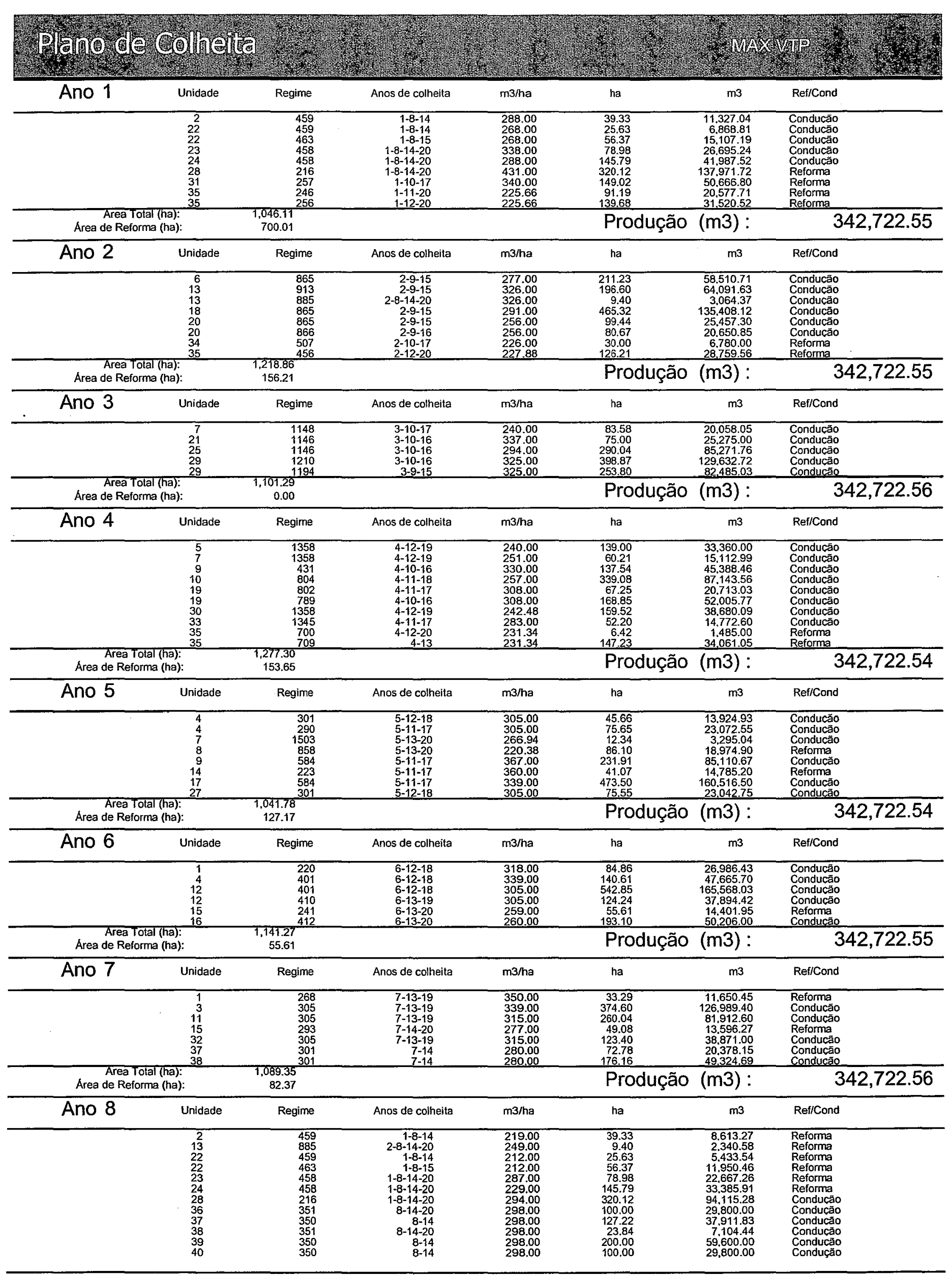




\begin{tabular}{|c|c|c|c|c|c|c|c|}
\hline \multicolumn{2}{|c|}{$\begin{array}{l}\text { Area Total (ha): } \\
\text { Área de Reforma (ha): }\end{array}$} & \multicolumn{3}{|l|}{$\begin{array}{r}1,226.68 \\
355.50\end{array}$} & \multicolumn{2}{|c|}{ Produção (m3): } & \multirow{2}{*}{$\begin{array}{r}342,722.56 \\
\text { Ref/Cond }\end{array}$} \\
\hline Ano 9 & Unidade & Regime & Anos de colheita & $\mathrm{m} 3 / \mathrm{ha}$ & ha & $\mathrm{m} 3$ & \\
\hline & $\begin{array}{l}6 \\
13 \\
18 \\
20 \\
20 \\
26 \\
29 \\
\end{array}$ & $\begin{array}{r}865 \\
913 \\
865 \\
865 \\
866 \\
572 \\
1194 \\
\end{array}$ & $\begin{array}{l}2-9-15 \\
2-9-15 \\
2-9-15 \\
2-9-15 \\
2-9-16 \\
9-16 \\
3-9-15 \\
\end{array}$ & $\begin{array}{l}235.00 \\
277.00 \\
247.00 \\
218.00 \\
218.00 \\
417.10 \\
248.00 \\
\end{array}$ & $\begin{array}{r}211.23 \\
196.60 \\
465.32 \\
99.44 \\
80.67 \\
51.51 \\
253.80 \\
\end{array}$ & $\begin{array}{r}49.639 .05 \\
54.458 .23 \\
114.934 .04 \\
21.678 .49 \\
17.585 .49 \\
21.484 .85 \\
62.942 .42 \\
\end{array}$ & $\begin{array}{l}\text { Reforma } \\
\text { Reforma } \\
\text { Reforma } \\
\text { Reforma } \\
\text { Reforma } \\
\text { Conducão } \\
\text { Reforma } \\
\end{array}$ \\
\hline \multicolumn{2}{|c|}{$\begin{array}{l}\text { Area Total (ha): } \\
\text { Area de Reforma (ha): }\end{array}$} & $\begin{array}{l}1,358.57 \\
1,307.06\end{array}$ & & & \multicolumn{2}{|c|}{ Produção (m3): } & $342,722.57$ \\
\hline \multirow[t]{2}{*}{ Ano 10} & Unidade & Regime & Anos de colheita & $\mathrm{m} 3 / \mathrm{ha}$ & ha & $\overline{\mathrm{m} 3}$ & Ref/Cond \\
\hline & $\begin{array}{r}7 \\
79 \\
19 \\
21 \\
25 \\
29 \\
31 \\
34 \\
\end{array}$ & $\begin{array}{r}1148 \\
431 \\
789 \\
1146 \\
1146 \\
1210 \\
257 \\
507 \\
\end{array}$ & $\begin{array}{l}3-10-17 \\
4-10-16 \\
4-10-16 \\
3-10-16 \\
3-10-16 \\
3-10-16 \\
1-10-17 \\
2-10-17 \\
\end{array}$ & $\begin{array}{l}190.00 \\
280.00 \\
235.00 \\
286.00 \\
250.00 \\
276.00 \\
251.00 \\
240.00 \\
\end{array}$ & $\begin{array}{r}83.58 \\
137.54 \\
168.85 \\
75.00 \\
290.04 \\
398.87 \\
149.02 \\
30.00 \\
\end{array}$ & $\begin{array}{r}15.879 .29 \\
38.511 .42 \\
39.679 .73 \\
21.450 .00 \\
72.510 .00 \\
110.088 .09 \\
37.404 .02 \\
7.200 .00 \\
\end{array}$ & $\begin{array}{l}\text { Reforma } \\
\text { Reforma } \\
\text { Reforma } \\
\text { Reforma } \\
\text { Reforma } \\
\text { Reforma } \\
\text { Conducão } \\
\text { Condução } \\
\end{array}$ \\
\hline \multicolumn{2}{|c|}{$\begin{array}{l}\text { Area Total (ha): } \\
\text { Area de Reforma (ha): }\end{array}$} & $\begin{array}{l}1,332.90 \\
1,153.88 \\
\end{array}$ & & & \multicolumn{2}{|c|}{ Produção (m3): } & $342,722.56$ \\
\hline \multirow{2}{*}{ Ano 11} & Unidade & Regime & Anos de colheita & $\mathrm{m} 3 / \mathrm{ha}$ & ha & m3 & Ref/Cond \\
\hline & $\begin{array}{r}4 \\
9 \\
10 \\
14 \\
17 \\
19 \\
33 \\
35 \\
\end{array}$ & $\begin{array}{r}290 \\
584 \\
804 \\
223 \\
584 \\
802 \\
1345 \\
246 \\
\end{array}$ & $\begin{array}{l}5-11-17 \\
5-11-17 \\
4-11-18 \\
5-11-17 \\
5-11-17 \\
4-11-17 \\
4-11-17 \\
1-11-20 \\
\end{array}$ & $\begin{array}{l}259.00 \\
280.00 \\
218.00 \\
360.00 \\
259.00 \\
262.00 \\
224.00 \\
192.37 \\
\end{array}$ & $\begin{array}{r}75.65 \\
231.91 \\
339.08 \\
41.07 \\
473.50 \\
67.25 \\
52.20 \\
91.19 \\
\end{array}$ & $\begin{array}{r}19.592 .75 \\
64.934 .57 \\
73.919 .44 \\
14.785 .20 \\
122.636 .50 \\
17.619 .53 \\
11.692 .80 \\
17.541 .75 \\
\end{array}$ & $\begin{array}{l}\text { Reforma } \\
\text { Reforma } \\
\text { Reforma } \\
\text { Reforma } \\
\text { Reforma } \\
\text { Reforma } \\
\text { Reforma } \\
\text { Conduçăo } \\
\end{array}$ \\
\hline \multicolumn{2}{|c|}{$\begin{array}{l}\text { Area Total (ha): } \\
\text { Area de Reforma (ha): }\end{array}$} & $\begin{array}{l}1,371.85 \\
1,280.66 \\
\end{array}$ & & & \multicolumn{2}{|c|}{ Produção (m3): } & $342,722.54$ \\
\hline \multirow{2}{*}{ Ano 12} & Unidade & Regime & Anos de colheita & $\mathrm{m} 3 / \mathrm{ha}$ & ha & $\mathrm{m} 3$ & Ref/Cond \\
\hline & $\begin{array}{r}1 \\
4 \\
4 \\
5 \\
7 \\
12 \\
27 \\
30 \\
35 \\
35 \\
35 \\
\end{array}$ & $\begin{array}{r}220 \\
401 \\
301 \\
1358 \\
1358 \\
401 \\
301 \\
1358 \\
700 \\
456 \\
256 \\
\end{array}$ & $\begin{array}{l}6-12-18 \\
6-12-18 \\
5-12-18 \\
4-12-19 \\
4-12-19 \\
6-12-18 \\
5-12-18 \\
4-12-19 \\
4-12-20 \\
2-12-20 \\
1-12-20 \\
\end{array}$ & $\begin{array}{l}270.00 \\
259.00 \\
288.00 \\
195.00 \\
204.00 \\
233.00 \\
286.00 \\
185.00 \\
174.00 \\
192.37 \\
199.45 \\
\end{array}$ & $\begin{array}{r}84.86 \\
140.61 \\
45.66 \\
139.00 \\
60.21 \\
542.85 \\
75.55 \\
159.52 \\
6.42 \\
126.21 \\
139.68 \\
\end{array}$ & $\begin{array}{r}22.913 .01 \\
36.417 .16 \\
13.148 .78 \\
27.105 .00 \\
12.283 .06 \\
126.483 .12 \\
21.607 .30 \\
29.511 .20 \\
1.116 .92 \\
24.277 .46 \\
27.859 .53 \\
\end{array}$ & $\begin{array}{l}\text { Reforma } \\
\text { Reforma } \\
\text { Reforma } \\
\text { Reforma } \\
\text { Reforma } \\
\text { Reforma } \\
\text { Reforma } \\
\text { Reforma } \\
\text { Conducáa } \\
\text { Conducáo } \\
\text { Conducāo } \\
\end{array}$ \\
\hline \multicolumn{2}{|c|}{$\begin{array}{c}\text { Area Total (ha): } \\
\text { Area de Reforma (ha): }\end{array}$} & $\begin{array}{l}1,520.56 \\
1,248.25\end{array}$ & & & Proc & (m3): & $342,722.55$ \\
\hline \multirow[t]{2}{*}{ Ano 13} & Unidade & Regime & Anos de colheita & $\mathrm{m} 3 / \mathrm{ha}$ & ha & $\mathrm{m} 3$ & Ref/Cond \\
\hline & $\begin{array}{r}1 \\
3 \\
7 \\
8 \\
11 \\
12 \\
15 \\
16 \\
32 \\
35 \\
\end{array}$ & $\begin{array}{r}268 \\
305 \\
1503 \\
858 \\
305 \\
410 \\
241 \\
412 \\
305 \\
709 \\
\end{array}$ & $\begin{array}{r}7-13-19 \\
7-13-19 \\
5-13-20 \\
5-13-20 \\
7-13-19 \\
6-13-19 \\
6-13-20 \\
6-13-20 \\
7-13-19 \\
4-13 \\
\end{array}$ & $\begin{array}{l}318.00 \\
259.00 \\
204.00 \\
240.00 \\
243.00 \\
259.00 \\
305.00 \\
221.00 \\
243.00 \\
183.00 \\
\end{array}$ & $\begin{array}{r}33.29 \\
374.60 \\
12.34 \\
86.10 \\
260.04 \\
124.24 \\
55.61 \\
193.10 \\
123.40 \\
147.23 \\
\end{array}$ & $\begin{array}{r}10.585 .27 \\
97.021 .40 \\
2.518 .11 \\
20.664 .00 \\
63.189 .72 \\
32.179 .20 \\
16.959 .83 \\
42.675 .10 \\
29.986 .20 \\
26.943 .71 \\
\end{array}$ & $\begin{array}{l}\text { Conducāa } \\
\text { Reforma } \\
\text { Reforma } \\
\text { Conducão } \\
\text { Reforma } \\
\text { Reforma } \\
\text { Conducão } \\
\text { Reforma } \\
\text { Reforma } \\
\text { Conducāo } \\
\end{array}$ \\
\hline \multicolumn{2}{|c|}{$\begin{array}{l}\text { Area Total (ha): } \\
\text { Area de Reforma (ha): }\end{array}$} & $\begin{array}{l}1,409.95 \\
1,087.73\end{array}$ & & & Proc & (m3): & $342,722.54$ \\
\hline \multirow[t]{2}{*}{ Ano 14} & Unidade & Regime & Anos de colheita & $\mathrm{m} 3 / \mathrm{ha}$ & ha & $\mathrm{m} 3$ & Ref/Cond \\
\hline & $\begin{array}{r}2 \\
13 \\
15 \\
22 \\
23 \\
24 \\
24 \\
28 \\
36 \\
37 \\
37 \\
38 \\
38 \\
39 \\
40 \\
\end{array}$ & $\begin{array}{r}459 \\
885 \\
293 \\
459 \\
458 \\
458 \\
216 \\
351 \\
301 \\
350 \\
351 \\
301 \\
350 \\
350 \\
\end{array}$ & $\begin{array}{r}1-8-14 \\
2-8-14-20 \\
7-14-20 \\
1-8-14 \\
1-8-14-20 \\
1-8-14-20 \\
1-8-14-20 \\
8-14-20 \\
7-14 \\
8-14 \\
8-14-20 \\
7-14 \\
8-14 \\
8-14 \\
\end{array}$ & $\begin{array}{l}231.00 \\
293.00 \\
305.00 \\
225.00 \\
304.00 \\
242.00 \\
225.00 \\
217.00 \\
238.00 \\
217.00 \\
217.00 \\
238.00 \\
217.00 \\
217.00 \\
\end{array}$ & $\begin{array}{r}39.33 \\
9.40 \\
49.08 \\
25.63 \\
78.98 \\
145.79 \\
320.12 \\
100.00 \\
72.78 \\
127.22 \\
23.84 \\
176.16 \\
200.00 \\
100.00 \\
\end{array}$ & $\begin{array}{r}9.085 .23 \\
2.754 .17 \\
14.970 .62 \\
5.766 .73 \\
24.009 .92 \\
35.281 .18 \\
72.027 .00 \\
21.700 .00 \\
17.31 .43 \\
27.606 .94 \\
5.173 .37 \\
41.925 .99 \\
43.400 .00 \\
21.700 .00 \\
\end{array}$ & $\begin{array}{l}\text { Conducāo } \\
\text { Conducaáo } \\
\text { Conducão } \\
\text { Conducáo } \\
\text { Conducão } \\
\text { Conducão } \\
\text { Reforma } \\
\text { Reforma } \\
\text { Reforma } \\
\text { Reforma } \\
\text { Reforma } \\
\text { Reforma } \\
\text { Reforma } \\
\text { Reforma } \\
\end{array}$ \\
\hline \multicolumn{2}{|c|}{$\begin{array}{l}\text { Area Total(ha): } \\
\text { Are } \\
\text { Area de Reforma (ha): }\end{array}$} & $\begin{array}{l}1,468.33 \\
1.120 .12 \\
\end{array}$ & & & Proc & $(\mathrm{m} 3):$ & $342,722.56$ \\
\hline \multirow[t]{2}{*}{ Ano 15} & Unidade & Regime & Anos de colneita & $\mathrm{m} 3 / \mathrm{ha}$ & ha & $\mathrm{m} 3$ & Ref/Cond \\
\hline & $\begin{array}{r}6 \\
13 \\
18 \\
20 \\
22 \\
29 \\
\end{array}$ & $\begin{array}{r}865 \\
913 \\
865 \\
865 \\
463 \\
1194 \\
\end{array}$ & $\begin{array}{l}2-9-15 \\
2-9-15 \\
2-9-15 \\
2-9-15 \\
1-8-15 \\
3-9-15 \\
\end{array}$ & $\begin{array}{l}249.00 \\
293.00 \\
261.00 \\
230.00 \\
250.00 \\
292.00 \\
\end{array}$ & $\begin{array}{r}211.23 \\
196.60 \\
465.32 \\
99.44 \\
56.37 \\
253.80 \\
\end{array}$ & $\begin{array}{r}52.596 .27 \\
57.603 .83 \\
121.448 .52 \\
22.871 .80 \\
14.092 .52 \\
74.109 .63 \\
\end{array}$ & $\begin{array}{l}\text { Conducāo } \\
\text { Conducāo } \\
\text { Conducão } \\
\text { Conducão } \\
\text { Conducão } \\
\text { Conducăo } \\
\end{array}$ \\
\hline \multicolumn{2}{|c|}{$\begin{array}{l}\text { Area Total (ha): } \\
\text { Area de Reforma (ha): }\end{array}$} & $\begin{array}{r}1,282.76 \\
0.00\end{array}$ & & & Proc & $(\mathrm{m} 3):$ & $342,722.57$ \\
\hline \multirow[t]{2}{*}{ Ano 16} & Unidade & Regime & Anos de colheita & m3/ha & ha & $\mathrm{m} 3$ & RefiCond \\
\hline & $\begin{array}{r}9 \\
19 \\
20 \\
21 \\
25 \\
\end{array}$ & $\begin{array}{r}431 \\
789 \\
866 \\
1146 \\
1146 \\
\end{array}$ & $\begin{array}{r}4-10-16 \\
4-10-16 \\
2-9-16 \\
3-10-16 \\
3-10-16 \\
\end{array}$ & $\begin{array}{l}330.00 \\
277.00 \\
256.00 \\
303.00 \\
265.00 \\
\end{array}$ & $\begin{array}{r}137.54 \\
168.85 \\
80.67 \\
75.00 \\
290.04 \\
\end{array}$ & $\begin{array}{l}45.388 .46 \\
46.771 .42 \\
20.650 .85 \\
22.725 .00 \\
76,860.60 \\
\end{array}$ & $\begin{array}{l}\text { Reforma } \\
\text { Reforma } \\
\text { Reforma } \\
\text { Reforma } \\
\text { Reforma } \\
\end{array}$ \\
\hline
\end{tabular}




\begin{tabular}{|c|c|c|c|c|c|c|c|}
\hline & $\begin{array}{l}26 \\
29 \\
\end{array}$ & $\begin{array}{r}572 \\
1210 \\
\end{array}$ & $\begin{array}{r}9-16 \\
3-10-16 \\
\end{array}$ & $\begin{array}{r}269.00 \\
292.00 \\
\end{array}$ & $\begin{array}{r}51.51 \\
398.87 \\
\end{array}$ & $\begin{array}{r}13.856 .19 \\
116.470 .01 \\
\end{array}$ & $\begin{array}{l}\text { Reforma } \\
\text { Reforma }\end{array}$ \\
\hline \multicolumn{2}{|c|}{$\begin{array}{l}\text { Area Tolal (ha): } \\
\text { Area de Reforma (ha): }\end{array}$} & \multicolumn{3}{|l|}{$\begin{array}{l}1,202.48 \\
1,202.48 \\
\end{array}$} & \multicolumn{2}{|c|}{ Produção (m3): } & $342,722.54$ \\
\hline \multirow[t]{2}{*}{ Ano 17} & Unidade & Regime & Anos de colheita & $\mathrm{m} 3 / \mathrm{ha}$ & ha & $\mathrm{m}^{3}$ & Ref/Cond \\
\hline & $\begin{array}{r}4 \\
7 \\
9 \\
14 \\
17 \\
19 \\
31 \\
33 \\
34 \\
\end{array}$ & $\begin{array}{r}290 \\
1148 \\
584 \\
223 \\
584 \\
802 \\
257 \\
1345 \\
507 \\
\end{array}$ & $\begin{array}{l}5-11-17 \\
3-10-17 \\
5-11-17 \\
5-11-17 \\
5-11-17 \\
4-1-17 \\
1-10-17 \\
4-11-17 \\
2-10-17 \\
\end{array}$ & $\begin{array}{l}305.00 \\
224.00 \\
330.00 \\
360.00 \\
305.00 \\
277.00 \\
187.00 \\
237.00 \\
211.00 \\
\end{array}$ & $\begin{array}{r}75.65 \\
83.58 \\
231.91 \\
41.07 \\
473.50 \\
67.25 \\
149.02 \\
52.20 \\
30.00 \\
\end{array}$ & $\begin{array}{r}23.072 .55 \\
18.720 .85 \\
76.530 .03 \\
14.785 .20 \\
144.417 .50 \\
18.628 .28 \\
27.866 .74 \\
12.371 .40 \\
6,330.00 \\
\end{array}$ & $\begin{array}{l}\text { Reforma } \\
\text { Reforma } \\
\text { Reforma } \\
\text { Reforma } \\
\text { Reforma } \\
\text { Reforma } \\
\text { Reforma } \\
\text { Reforma } \\
\text { Reforma } \\
\end{array}$ \\
\hline \multicolumn{2}{|c|}{$\begin{array}{l}\text { Area Total (ha): } \\
\text { Area de Reforma (ha): }\end{array}$} & $\begin{array}{l}1,204.17 \\
1,204.17\end{array}$ & & & Proc & $(\mathrm{m} 3):$ & $342,722.55$ \\
\hline \multirow[t]{2}{*}{ Ano 18} & Unidade & Regime & Anos de colheita & $\mathrm{m} 3 / \mathrm{ha}$ & ha & $\mathrm{m3}$ & Ref/Cond \\
\hline & $\begin{array}{r}1 \\
4 \\
4 \\
10 \\
12 \\
27 \\
\end{array}$ & $\begin{array}{r}220 \\
301 \\
401 \\
804 \\
401 \\
301 \\
\end{array}$ & $\begin{array}{l}6-12-18 \\
5-12-18 \\
6-12-18 \\
4-11-18 \\
6-12-18 \\
5-12-18 \\
\end{array}$ & $\begin{array}{l}318.00 \\
305.00 \\
305.00 \\
257.00 \\
274.00 \\
305.00 \\
\end{array}$ & $\begin{array}{r}84.86 \\
45.66 \\
140.61 \\
339.08 \\
542.85 \\
75.55 \\
\end{array}$ & $\begin{array}{r}26.986 .43 \\
13.924 .93 \\
42.885 .07 \\
87.143 .56 \\
148.739 .81 \\
23.042 .75 \\
\end{array}$ & $\begin{array}{l}\text { Reforma } \\
\text { Reforma } \\
\text { Reforma } \\
\text { Reforma } \\
\text { Reforma } \\
\text { Reforma } \\
\end{array}$ \\
\hline \multicolumn{2}{|c|}{$\begin{array}{l}\text { Area Total (ha): } \\
\text { Area de Reforma (ha): }\end{array}$} & $\begin{array}{l}1,228.60 \\
1,228.60 \\
\end{array}$ & & & Proc & (m3): & $342,722.55$ \\
\hline \multirow[t]{2}{*}{ Ano 19} & Unidade & Regime & Anos de colheita & $\mathrm{m} 3 / \mathrm{ha}$ & ha & $\mathrm{m} 3$ & Ref/Cond \\
\hline & $\begin{array}{r}1 \\
3 \\
5 \\
7 \\
11 \\
12 \\
30 \\
32 \\
\end{array}$ & $\begin{array}{r}268 \\
305 \\
1358 \\
1358 \\
305 \\
410 \\
1358 \\
305 \\
\end{array}$ & $\begin{array}{l}7-13-19 \\
7-13-19 \\
4-12-19 \\
4-12-19 \\
7-13-19 \\
6-13-19 \\
4-12-19 \\
7-13-19 \\
\end{array}$ & $\begin{array}{l}270.00 \\
305.00 \\
214.00 \\
224.00 \\
286.00 \\
274.00 \\
204.00 \\
286.00 \\
\end{array}$ & $\begin{array}{r}33.29 \\
374.60 \\
139.00 \\
60.21 \\
260.04 \\
124.24 \\
159.52 \\
123.40 \\
\end{array}$ & $\begin{array}{r}8.987 .49 \\
114.253 .00 \\
29.746 .00 \\
13.487 .29 \\
74.371 .44 \\
34.042 .86 \\
32.542 .08 \\
35.292 .40 \\
\end{array}$ & $\begin{array}{l}\text { Reforma } \\
\text { Reforma } \\
\text { Reforma } \\
\text { Reforma } \\
\text { Reforma } \\
\text { Reforma } \\
\text { Reforma } \\
\text { Reforma } \\
\end{array}$ \\
\hline \multicolumn{2}{|c|}{$\begin{array}{l}\text { Area Total (ha): } \\
\text { Área de Reforma (ha): }\end{array}$} & $\begin{array}{l}1,274.30 \\
1,274.30 \\
\end{array}$ & & & Pro & (m3): & $342,722.56$ \\
\hline \multirow[t]{2}{*}{ Ano 20} & Unidade & Regime & Anos de colheita & $\mathrm{m} 3 / \mathrm{ha}$ & ha & m3 & Ref/Cond \\
\hline & $\begin{array}{r}7 \\
8 \\
13 \\
15 \\
15 \\
16 \\
23 \\
24 \\
28 \\
35 \\
35 \\
35 \\
35 \\
36 \\
38 \\
\end{array}$ & $\begin{array}{r}1503 \\
858 \\
885 \\
241 \\
293 \\
412 \\
458 \\
458 \\
216 \\
256 \\
456 \\
700 \\
246 \\
351 \\
351 \\
\end{array}$ & $\begin{array}{r}5-13-20 \\
5-13-20 \\
2-8-14-20 \\
6-13-20 \\
7-14-20 \\
6-13-20 \\
1-8-14-20 \\
1-8-14-20 \\
1-8-14-20 \\
1-12-20 \\
2-12-20 \\
4-12-20 \\
1-11-20 \\
8-14-20 \\
8-14-20 \\
\end{array}$ & $\begin{array}{l}224.00 \\
187.00 \\
249.00 \\
259.00 \\
232.00 \\
260.00 \\
258.00 \\
206.00 \\
265.00 \\
214.00 \\
214.00 \\
214.00 \\
224.00 \\
255.00 \\
255.00 \\
\end{array}$ & $\begin{array}{r}12.34 \\
86.10 \\
9.40 \\
55.61 \\
49.08 \\
193.10 \\
78.98 \\
145.79 \\
320.12 \\
139.68 \\
126.21 \\
6.42 \\
91.19 \\
100.00 \\
23.84 \\
\end{array}$ & $\begin{array}{r}2.764 .99 \\
16.100 .70 \\
2.340 .58 \\
14.401 .95 \\
11.387 .49 \\
50.206 .00 \\
20.376 .84 \\
30.032 .74 \\
84.831 .80 \\
29.892 .10 \\
27.007 .87 \\
1.373 .69 \\
20.426 .51 \\
25.500 .00 \\
6.079 .30 \\
\end{array}$ & $\begin{array}{l}\text { Reforma } \\
\text { Reforma } \\
\text { Reforma } \\
\text { Reforma } \\
\text { Reforma } \\
\text { Reforma } \\
\text { Reforma } \\
\text { Reforma } \\
\text { Reforma } \\
\text { Reforma } \\
\text { Reforma } \\
\text { Reforma } \\
\text { Reforma } \\
\text { Reforma } \\
\text { Reforma } \\
\end{array}$ \\
\hline \multicolumn{2}{|c|}{$\begin{array}{l}\text { Area Total (ha): } \\
\text { Area de Reforma (ha): }\end{array}$} & $\begin{array}{l}1,437.86 \\
1.437 .86\end{array}$ & & & \multicolumn{2}{|c|}{ Produção (m3): } & $342,722.56$ \\
\hline
\end{tabular}




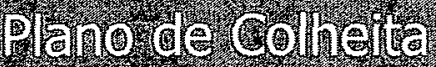
$\frac{1}{A n 0} 11$

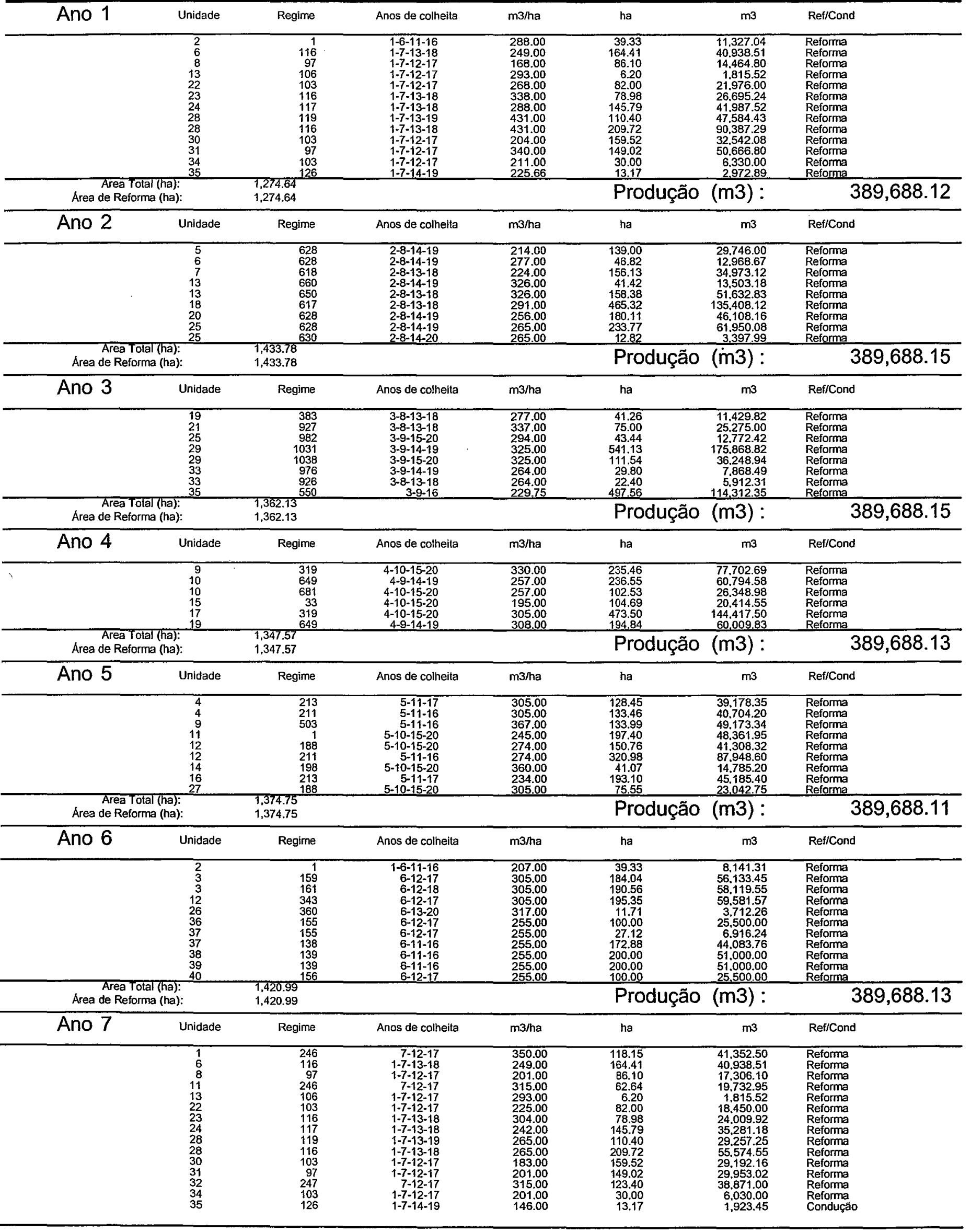




\begin{tabular}{|c|c|c|c|c|c|c|c|}
\hline \multicolumn{2}{|c|}{$\begin{array}{l}\text { Area Total (ha): } \\
\text { Area de Reforma (ha): }\end{array}$} & \multicolumn{3}{|l|}{$\begin{array}{l}1,539.51 \\
1,526.33\end{array}$} & \multicolumn{2}{|c|}{ Produção (m3): } & \multirow[t]{2}{*}{$389,688.11$} \\
\hline Ano 8 & Unidade & Regime & Anos de colheita & $\mathrm{m} 3 / \mathrm{ha}$ & ha & $\mathrm{m} 3$ & \\
\hline & $\begin{array}{r}5 \\
6 \\
7 \\
13 \\
13 \\
18 \\
19 \\
20 \\
21 \\
25 \\
25 \\
33 \\
\end{array}$ & $\begin{array}{r}628 \\
628 \\
618 \\
660 \\
650 \\
617 \\
383 \\
628 \\
927 \\
630 \\
628 \\
926 \\
\end{array}$ & $\begin{array}{l}2-8-14-19 \\
2-8-14-19 \\
2-8-13-18 \\
2-8-14-19 \\
2-8-13-18 \\
2-8-13-18 \\
3-8-13-18 \\
2-8-14-19 \\
3-8-13-18 \\
2-8-14-20 \\
2-14-19 \\
3-8-13-18 \\
\end{array}$ & $\begin{array}{l}192.00 \\
249.00 \\
201.00 \\
293.00 \\
293.00 \\
261.00 \\
233.00 \\
230.00 \\
255.00 \\
265.00 \\
265.00 \\
199.00 \\
\end{array}$ & $\begin{array}{r}139.00 \\
46.82 \\
156.13 \\
41.42 \\
158.38 \\
465.32 \\
41.26 \\
180.11 \\
75.00 \\
12.82 \\
233.77 \\
22.40 \\
\end{array}$ & $\begin{array}{r}26.688 .00 \\
11,657.76 \\
31,382.13 \\
12,136.29 \\
46.406 .19 \\
121.448 .52 \\
9.614 .26 \\
41.425 .30 \\
19.125 .00 \\
3.397 .99 \\
61.950 .08 \\
4.456 .62 \\
\end{array}$ & $\begin{array}{l}\text { Reforma } \\
\text { Reforma } \\
\text { Reforma } \\
\text { Reforma } \\
\text { Reforma } \\
\text { Reforma } \\
\text { Reforma } \\
\text { Reforma } \\
\text { Reforma } \\
\text { Reforma } \\
\text { Reforma } \\
\text { Reforma } \\
\end{array}$ \\
\hline \multicolumn{2}{|c|}{$\begin{array}{l}\text { Area Total (ha): } \\
\text { Area de Reforma (ha): }\end{array}$} & $\begin{array}{l}1,572.44 \\
1,572.44\end{array}$ & & & \multicolumn{2}{|c|}{ Produção (m3): } & $389,688.15$ \\
\hline \multirow[t]{2}{*}{ Ano 9} & Unidade & Regime & Anos de colheita & $\mathrm{m} 3 / \mathrm{ha}$ & ha & m3 & Ref/Cond \\
\hline & $\begin{array}{l}10 \\
19 \\
25 \\
26 \\
29 \\
29 \\
33 \\
35 \\
\end{array}$ & $\begin{array}{r}649 \\
649 \\
982 \\
557 \\
1031 \\
1038 \\
976 \\
550 \\
\end{array}$ & $\begin{array}{r}4-9-14-19 \\
4-9-14-19 \\
3-9-15-20 \\
9-16 \\
3-9-14-19 \\
3-9-15-20 \\
3-9-14-19 \\
3-9-16 \\
\end{array}$ & $\begin{array}{l}194.00 \\
233.00 \\
265.00 \\
417.10 \\
292.00 \\
292.00 \\
237.00 \\
146.00\end{array}$ & $\begin{array}{r}236.55 \\
194.84 \\
43.44 \\
39.80 \\
541.13 \\
111.54 \\
29.80 \\
497.56 \\
\end{array}$ & $\begin{array}{r}45.891 .63 \\
45.397 .04 \\
11.512 .55 \\
16.600 .35 \\
158.011 .37 \\
32.568 .28 \\
7.063 .76 \\
72.643 .13 \\
\end{array}$ & $\begin{array}{l}\text { Reforma } \\
\text { Reforma } \\
\text { Reforma } \\
\text { Reforma } \\
\text { Reforma } \\
\text { Reforma } \\
\text { Reforma } \\
\text { Conducāo } \\
\end{array}$ \\
\hline \multicolumn{2}{|c|}{$\begin{array}{l}\text { Area fotal (ha): } \\
\text { Area de Reforma (ha): }\end{array}$} & $\begin{array}{l}1,694,67 \\
1,197.11\end{array}$ & & & Prod & $(\mathrm{m} 3):$ & $389,688.12$ \\
\hline \multirow[t]{2}{*}{ Ano 10} & Unidade & Regime & Anos de colheita & $\mathrm{m} 3 / \mathrm{ha}$ & ha & $\mathrm{m} 3$ & Ref/Cond \\
\hline & $\begin{array}{r}9 \\
10 \\
11 \\
12 \\
14 \\
15 \\
17 \\
27 \\
\end{array}$ & $\begin{array}{r}319 \\
681 \\
1 \\
188 \\
198 \\
33 \\
319 \\
188 \\
\end{array}$ & $\begin{array}{l}4-10-15-20 \\
4-10-15-20 \\
5-10-15-20 \\
5-10-15-20 \\
5-10-15-20 \\
4-10-15-20 \\
4-10-15-20 \\
5-10-15-20 \\
\end{array}$ & $\begin{array}{l}330.00 \\
231.00 \\
245.00 \\
230.00 \\
303.00 \\
274.00 \\
305.00 \\
261.00 \\
\end{array}$ & $\begin{array}{r}235.46 \\
102.53 \\
197.40 \\
150.76 \\
41.07 \\
104.69 \\
473.50 \\
75.55 \\
\end{array}$ & $\begin{array}{r}77.702 .69 \\
23.683 .32 \\
48.361 .95 \\
34.674 .87 \\
12.444 .21 \\
28.685 .06 \\
144.417 .50 \\
19.718 .55 \\
\end{array}$ & $\begin{array}{l}\text { Reforma } \\
\text { Reforma } \\
\text { Reforma } \\
\text { Reforma } \\
\text { Reforma } \\
\text { Reforma } \\
\text { Reforma } \\
\text { Reforma } \\
\end{array}$ \\
\hline \multicolumn{2}{|c|}{$\begin{array}{l}\text { Area Total (ha): } \\
\text { Area de Reforma (ha): }\end{array}$} & $\begin{array}{l}1,380.95 \\
1,380.95 \\
\end{array}$ & & & Prod & $(m 3):$ & $389,688.15$ \\
\hline \multirow[t]{2}{*}{ Ano 11} & Unidade & Regime & Anos de colheita & $\mathrm{m} 3 / \mathrm{ha}$ & ha & $\mathrm{m} 3$ & Ref/Cond \\
\hline & $\begin{array}{r}2 \\
4 \\
4 \\
9 \\
12 \\
16 \\
37 \\
38 \\
39 \\
\end{array}$ & $\begin{array}{r}1 \\
211 \\
213 \\
503 \\
211 \\
213 \\
138 \\
139 \\
139 \\
\end{array}$ & $\begin{array}{r}1-6-11-16 \\
5-11-16 \\
5-11-17 \\
5-11-16 \\
5-11-16 \\
5-11-17 \\
6-11-16 \\
6-11-16 \\
6-11-16 \\
\end{array}$ & $\begin{array}{l}207.00 \\
305.00 \\
305.00 \\
330.00 \\
274.00 \\
234.00 \\
217.00 \\
217.00 \\
217.00 \\
\end{array}$ & $\begin{array}{r}39.33 \\
133.46 \\
128.45 \\
133.99 \\
320.98 \\
193.10 \\
172.88 \\
200.00 \\
200.00 \\
\end{array}$ & $\begin{array}{r}8.141 .31 \\
40.704 .20 \\
39.178 .35 \\
44.215 .81 \\
87.948 .60 \\
45.185 .40 \\
37.514 .42 \\
43.400 .00 \\
43.400 .00 \\
\end{array}$ & $\begin{array}{l}\text { Reforma } \\
\text { Reforma } \\
\text { Reforma } \\
\text { Reforma } \\
\text { Reforma } \\
\text { Reforma } \\
\text { Reforma } \\
\text { Reforma } \\
\text { Reforma } \\
\end{array}$ \\
\hline \multicolumn{2}{|c|}{$\begin{array}{c}\text { Area Total (ha): } \\
\text { Area de Reforma (ha): }\end{array}$} & $\begin{array}{l}1,522.19 \\
1,522.19 \\
\end{array}$ & & & Proc & $(\mathrm{m} 3):$ & $389,688.09$ \\
\hline \multirow[t]{2}{*}{ Ano 12} & Unidade & Regime & Anos de colheita & m3/ha & ha & $\mathrm{m3}$ & Ref/Cond \\
\hline & $\begin{array}{r}1 \\
3 \\
3 \\
8 \\
11 \\
12 \\
13 \\
22 \\
30 \\
31 \\
32 \\
34 \\
36 \\
37 \\
40 \\
\end{array}$ & $\begin{array}{r}246 \\
159 \\
161 \\
97 \\
246 \\
343 \\
106 \\
103 \\
103 \\
97 \\
247 \\
103 \\
155 \\
155 \\
156 \\
\end{array}$ & $\begin{array}{r}7-12-17 \\
6-12-17 \\
6-12-18 \\
1-7-12-17 \\
7-12-17 \\
6-12-17 \\
1-7-12-17 \\
1-7-12-17 \\
1-7-12-17 \\
1-7-12-17 \\
7-12-17 \\
1-7-12-17 \\
6-12-17 \\
6-12-17 \\
6-12-17 \\
\end{array}$ & $\begin{array}{l}271.00 \\
305.00 \\
305.00 \\
169.00 \\
245.00 \\
274.00 \\
246.00 \\
189.00 \\
154.00 \\
169.00 \\
245.00 \\
169.00 \\
255.00 \\
255.00 \\
255.00 \\
\end{array}$ & $\begin{array}{r}118.15 \\
184.04 \\
190.56 \\
86.10 \\
62.64 \\
195.35 \\
6.20 \\
82.00 \\
159.52 \\
149.02 \\
123.40 \\
30.00 \\
100.00 \\
27.12 \\
100.00 \\
\end{array}$ & $\begin{array}{r}32.018 .65 \\
56.133 .45 \\
58.119 .55 \\
14.550 .90 \\
15.347 .85 \\
53.525 .73 \\
1.524 .29 \\
15.498 .00 \\
24.566 .08 \\
25.184 .38 \\
30.233 .00 \\
5.070 .00 \\
25.500 .00 \\
6.916 .24 \\
25.500 .00 \\
\end{array}$ & $\begin{array}{l}\text { Reforma } \\
\text { Reforma } \\
\text { Reforma } \\
\text { Reforma } \\
\text { Reforma } \\
\text { Reforma } \\
\text { Reforma } \\
\text { Reforma } \\
\text { Reforma } \\
\text { Reforma } \\
\text { Reforma } \\
\text { Reforma } \\
\text { Reforma } \\
\text { Reforma } \\
\text { Reforma } \\
\end{array}$ \\
\hline \multicolumn{2}{|c|}{$\begin{array}{l}\text { Area Total (ha): } \\
\text { Area de Reforma (ha): }\end{array}$} & $\begin{array}{l}1,614.10 \\
1,614.10 \\
\end{array}$ & & & Proc & $(\mathrm{m} 3):$ & $389,688.12$ \\
\hline \multirow[t]{2}{*}{ Ano 13} & Unidade & Regime & Anos de colheita & m3/ha & ha & $\mathrm{m} 3$ & Ref/Cond \\
\hline & $\begin{array}{r}6 \\
7 \\
13 \\
18 \\
19 \\
21 \\
23 \\
24 \\
26 \\
28 \\
28 \\
33 \\
\end{array}$ & $\begin{array}{r}116 \\
618 \\
650 \\
617 \\
383 \\
927 \\
116 \\
117 \\
360 \\
119 \\
116 \\
926 \\
\end{array}$ & $\begin{array}{r}1-7-13-18 \\
2-8-13-18 \\
2-8-13-18 \\
2-8-13-18 \\
3-8-13-18 \\
3-8-13-18 \\
1-7-13-18 \\
1-7-13-18 \\
6-13-20 \\
1-7-13-19 \\
1-7-13-18 \\
3-8-13-18 \\
\end{array}$ & $\begin{array}{l}249.00 \\
169.00 \\
246.00 \\
220.00 \\
233.00 \\
255.00 \\
304.00 \\
242.00 \\
317.00 \\
265.00 \\
265.00 \\
199.00 \\
\end{array}$ & $\begin{array}{r}164.41 \\
156.13 \\
158.38 \\
465.32 \\
41.26 \\
75.00 \\
78.98 \\
145.79 \\
11.71 \\
110.40 \\
209.72 \\
22.40 \\
\end{array}$ & $\begin{array}{r}40.938 .51 \\
26.385 .97 \\
38.962 .19 \\
102.370 .40 \\
9.614 .26 \\
19.125 .00 \\
24.009 .92 \\
35.281 .18 \\
3.712 .26 \\
29.257 .25 \\
55.574 .55 \\
4.456 .62 \\
\end{array}$ & $\begin{array}{l}\text { Reforma } \\
\text { Reforma } \\
\text { Reforma } \\
\text { Reforma } \\
\text { Reforma } \\
\text { Reforma } \\
\text { Reforma } \\
\text { Reforma } \\
\text { Reforma } \\
\text { Reforma } \\
\text { Reforma } \\
\text { Reforma } \\
\end{array}$ \\
\hline \multicolumn{2}{|c|}{$\begin{array}{l}\text { Area Total (ha): } \\
\text { Área de Reforma (ha): }\end{array}$} & $\begin{array}{l}1,639.50 \\
1,639.50 \\
\end{array}$ & & & Proc & $(m 3):$ & $389,688.12$ \\
\hline \multirow[t]{2}{*}{ Ano 14} & Unidade & Regime & Anos de colheita & $\mathrm{m} 3 / \mathrm{ha}$ & ha & m3 & Ref/Cond \\
\hline & $\begin{array}{r}5 \\
6 \\
10 \\
13 \\
19 \\
20 \\
25 \\
25 \\
29 \\
33 \\
35 \\
\end{array}$ & $\begin{array}{r}628 \\
628 \\
649 \\
660 \\
649 \\
628 \\
630 \\
628 \\
1031 \\
976 \\
126 \\
\end{array}$ & $\begin{array}{l}2-8-14-19 \\
2-8-14-19 \\
4-9-14-19 \\
2-8-14-19 \\
4-9-14-19 \\
2-8-14-19 \\
2-8-14-20 \\
2-8-14-19 \\
3-9-14-19 \\
3-9-14-19 \\
1-7-14-19 \\
\end{array}$ & $\begin{array}{l}192.00 \\
249.00 \\
194.00 \\
293.00 \\
233.00 \\
230.00 \\
265.00 \\
265.00 \\
245.00 \\
199.00 \\
200.00 \\
\end{array}$ & $\begin{array}{r}139.00 \\
46.82 \\
236.55 \\
41.42 \\
194.84 \\
180.11 \\
12.82 \\
233.77 \\
541.13 \\
29.80 \\
13.17 \\
\end{array}$ & $\begin{array}{r}26.688 .00 \\
11.657 .76 \\
45.891 .63 \\
12.136 .29 \\
45.397 .04 \\
41.425 .30 \\
3.397 .99 \\
61.950 .08 \\
132.578 .03 \\
5.931 .17 \\
2,634.86 \\
\end{array}$ & $\begin{array}{l}\text { Reforma } \\
\text { Reforma } \\
\text { Reforma } \\
\text { Reforma } \\
\text { Reforma } \\
\text { Reforma } \\
\text { Reforma } \\
\text { Reforma } \\
\text { Reforma } \\
\text { Reforma } \\
\text { Reforma } \\
\end{array}$ \\
\hline
\end{tabular}




\begin{tabular}{|c|c|c|c|c|c|c|c|}
\hline \multicolumn{2}{|c|}{$\begin{array}{l}\text { Area Total (ha): } \\
\text { Area de Reforma (ha): }\end{array}$} & \multicolumn{3}{|l|}{$\begin{array}{l}1,669.45 \\
1,669.45 \\
\end{array}$} & \multicolumn{2}{|c|}{ Produção (m3): } & \multirow{2}{*}{$\begin{array}{l}389,688.16 \\
\text { Ref/Cond }\end{array}$} \\
\hline Ano 15 & Unidade & Regime & Anos de colheita & m3/ha & ha & m3 & \\
\hline & $\begin{array}{r}9 \\
10 \\
11 \\
12 \\
14 \\
15 \\
17 \\
25 \\
27 \\
29 \\
\end{array}$ & $\begin{array}{r}319 \\
681 \\
1 \\
188 \\
198 \\
33 \\
319 \\
982 \\
188 \\
1038 \\
\end{array}$ & $\begin{array}{r}4-10-15-20 \\
4-10-15-20 \\
5-10-15-20 \\
5-10-15-20 \\
5-10-15-20 \\
4-10-15-20 \\
4-10-15-20 \\
3-9-15-20 \\
5-10-15-20 \\
3-9-15-20 \\
\end{array}$ & $\begin{array}{l}277.00 \\
194.00 \\
245.00 \\
230.00 \\
303.00 \\
230.00 \\
256.00 \\
265.00 \\
261.00 \\
292.00 \\
\end{array}$ & $\begin{array}{r}235.46 \\
102.53 \\
197.40 \\
150.76 \\
41.07 \\
104.69 \\
473.50 \\
43.44 \\
75.55 \\
111.54 \\
\end{array}$ & $\begin{array}{r}65.223 .17 \\
19.889 .89 \\
48.361 .95 \\
34.674 .87 \\
12.444 .21 \\
24.078 .70 \\
121.216 .00 \\
11.512 .55 \\
19.718 .55 \\
32.568 .28 \\
\end{array}$ & $\begin{array}{l}\text { Reforma } \\
\text { Reforma } \\
\text { Reforma } \\
\text { Reforma } \\
\text { Reforma } \\
\text { Reforma } \\
\text { Reforma } \\
\text { Reforma } \\
\text { Reforma } \\
\text { Reforma } \\
\end{array}$ \\
\hline \multicolumn{2}{|c|}{$\begin{array}{c}\text { Area Toial (ha): } \\
\text { Area de Reforma (ha): }\end{array}$} & $\begin{array}{l}1,535.93 \\
1.535 .93 \\
\end{array}$ & & & \multicolumn{2}{|c|}{ Produção (m3): } & $389,688.17$ \\
\hline \multirow[t]{2}{*}{ Ano 16} & Unidade & Regime & Anos de colheita & $\mathrm{m} 3 / \mathrm{ha}$ & ha & m3 & Ref/Cond \\
\hline & $\begin{array}{r}2 \\
4 \\
9 \\
12 \\
26 \\
35 \\
37 \\
38 \\
39 \\
\end{array}$ & $\begin{array}{r}11 \\
211 \\
503 \\
211 \\
557 \\
550 \\
138 \\
139 \\
139 \\
\end{array}$ & $\begin{array}{r}1-6-11-16 \\
5-11-16 \\
5-11-16 \\
5-11-16 \\
9-16 \\
3-9-16 \\
6-11-16 \\
6-11-16 \\
6-11-16 \\
\end{array}$ & $\begin{array}{l}207.00 \\
256.00 \\
277.00 \\
230.00 \\
317.00 \\
200.00 \\
217.00 \\
217.00 \\
217.00 \\
\end{array}$ & $\begin{array}{r}39.33 \\
133.46 \\
133.99 \\
320.98 \\
39.80 \\
497.56 \\
172.88 \\
200.00 \\
200.00 \\
\end{array}$ & $\begin{array}{r}8.141 .31 \\
34.164 .84 \\
37.114 .48 \\
73.825 .47 \\
12.616 .41 \\
99.511 .14 \\
37.514 .42 \\
43.400 .00 \\
43.400 .00 \\
\end{array}$ & $\begin{array}{l}\text { Reforma } \\
\text { Reforma } \\
\text { Reforma } \\
\text { Reforma } \\
\text { Conducaso } \\
\text { Reforma } \\
\text { Reforma } \\
\text { Conducão } \\
\text { Conducão } \\
\end{array}$ \\
\hline \multicolumn{2}{|c|}{$\begin{array}{l}\text { Area Total (ha): } \\
\text { Area de Reforma (ha): }\end{array}$} & $\begin{array}{l}1,737.99 \\
1,298.19\end{array}$ & & & \multicolumn{2}{|c|}{ Produção (m3): } & $389,688.07$ \\
\hline \multirow[t]{2}{*}{ Ano 17} & Unidade & Regime & Anos de colheita & $\mathrm{m} 3 / \mathrm{ha}$ & ha & $\mathrm{m3}$ & Ref/Cond \\
\hline & $\begin{array}{r}1 \\
3 \\
4 \\
8 \\
11 \\
12 \\
13 \\
16 \\
22 \\
30 \\
31 \\
32 \\
34 \\
36 \\
37 \\
40 \\
\end{array}$ & $\begin{array}{l}246 \\
159 \\
213 \\
97 \\
246 \\
343 \\
106 \\
213 \\
103 \\
103 \\
97 \\
247 \\
103 \\
155 \\
155 \\
156 \\
\end{array}$ & $\begin{array}{r}7-12-17 \\
6-12-17 \\
5-11-17 \\
1-7-12-17 \\
7-12-17 \\
6-12-17 \\
1-7-12-17 \\
5-11-17 \\
1-7-12-17 \\
1-7-12-17 \\
1-7-12-17 \\
7-12-17 \\
1-7-12-17 \\
6-12-17 \\
6-12-17 \\
6-12-17 \\
\end{array}$ & $\begin{array}{l}271.00 \\
256.00 \\
305.00 \\
169.00 \\
245.00 \\
230.00 \\
246.00 \\
234.00 \\
189.00 \\
154.00 \\
169.00 \\
245.00 \\
169.00 \\
217.00 \\
217.00 \\
217.00 \\
\end{array}$ & $\begin{array}{r}118.15 \\
184.04 \\
128.45 \\
86.10 \\
62.64 \\
195.35 \\
6.20 \\
193.10 \\
82.00 \\
159.52 \\
149.02 \\
123.40 \\
30.00 \\
100.00 \\
27.12 \\
100.00 \\
\end{array}$ & $\begin{array}{r}32.018 .65 \\
47.115 .29 \\
39.178 .35 \\
14.550 .90 \\
15.347 .85 \\
44.930 .36 \\
1,524.29 \\
45.185 .40 \\
15.498 .00 \\
24.566 .08 \\
25.184 .38 \\
30.233 .00 \\
5.070 .00 \\
21.700 .00 \\
5.885 .58 \\
21.700 .00 \\
\end{array}$ & $\begin{array}{l}\text { Reforma } \\
\text { Reforma } \\
\text { Reforma } \\
\text { Condução } \\
\text { Reforma } \\
\text { Conducáo } \\
\text { Reforma } \\
\text { Reforma } \\
\text { Conducaao } \\
\text { Conducâo } \\
\text { Conducăo } \\
\text { Conducão } \\
\text { Conducão } \\
\text { Reforma } \\
\text { Reforma } \\
\text { Conducăa } \\
\end{array}$ \\
\hline \multicolumn{2}{|c|}{$\begin{array}{l}\text { Area Total (ha): } \\
\text { Area de Reforma (ha): }\end{array}$} & $\begin{array}{r}1,745.10 \\
819.71\end{array}$ & & & \multicolumn{2}{|c|}{ Produção (m3) : } & $389,688.14$ \\
\hline \multirow[t]{2}{*}{ Ano 18} & Unidade & Regime & Anos de colheita & $\mathrm{m} 3 / \mathrm{ha}$ & ha & $\mathrm{m} 3$ & Ref/Cond \\
\hline & $\begin{array}{r}3 \\
6 \\
7 \\
13 \\
18 \\
19 \\
21 \\
23 \\
24 \\
28 \\
33 \\
\end{array}$ & $\begin{array}{c}161 \\
116 \\
618 \\
650 \\
617 \\
383 \\
927 \\
116 \\
117 \\
116 \\
926 \\
\end{array}$ & $\begin{array}{r}6-12-18 \\
1-7-13-18 \\
2-8-13-18 \\
2-8-13-18 \\
2-8-13-18 \\
3-8-13-18 \\
3-8-13-18 \\
1-7-13-18 \\
1-7-13-18 \\
1-7-13-18 \\
3-8-13-18 \\
\end{array}$ & $\begin{array}{l}305.00 \\
209.00 \\
169.00 \\
246.00 \\
220.00 \\
233.00 \\
255.00 \\
255.00 \\
203.00 \\
222.00 \\
199.00 \\
\end{array}$ & $\begin{array}{r}190.56 \\
164.41 \\
156.13 \\
158.38 \\
465.32 \\
41.26 \\
75.00 \\
78.98 \\
145.79 \\
209.72 \\
22.40 \\
\end{array}$ & $\begin{array}{r}58.119 .55 \\
34.362 .04 \\
26.385 .97 \\
38.962 .19 \\
102.370 .40 \\
9.614 .26 \\
19.125 .00 \\
20.139 .90 \\
29.595 .37 \\
46.556 .80 \\
4.456 .62 \\
\end{array}$ & $\begin{array}{l}\text { Reforma } \\
\text { Reforma } \\
\text { Conducāo } \\
\text { Conducāo } \\
\text { Reforma } \\
\text { Reforma } \\
\text { Conducão } \\
\text { Reforma } \\
\text { Conducão } \\
\text { Reforma } \\
\text { Reforma } \\
\end{array}$ \\
\hline \multicolumn{2}{|c|}{$\begin{array}{l}\text { Area Total (ha): } \\
\text { Area de Reforma (ha): }\end{array}$} & $\begin{array}{l}1,707.94 \\
1,172.64\end{array}$ & & & \multicolumn{2}{|c|}{ Produção (m3): } & $389,688.11$ \\
\hline \multirow[t]{2}{*}{ Ano 19} & Unidade & Regime & Anos de colheita & $\mathrm{m} 3 / \mathrm{ha}$ & ha & $\mathrm{m} 3$ & Ref/Cond \\
\hline & $\begin{array}{r}5 \\
6 \\
10 \\
13 \\
19 \\
20 \\
25 \\
28 \\
29 \\
33 \\
35 \\
\end{array}$ & $\begin{array}{r}628 \\
628 \\
649 \\
660 \\
649 \\
628 \\
628 \\
119 \\
1031 \\
976 \\
126 \\
\end{array}$ & $\begin{array}{l}2-8-14-19 \\
2-8-14-19 \\
4-9-14-19 \\
2-8-14-19 \\
4-9-14-19 \\
2-8-14-19 \\
2-8-14-19 \\
1-1-13-19 \\
3-9-14-19 \\
3-9-14-19 \\
1-7-14-19 \\
\end{array}$ & $\begin{array}{l}161.00 \\
209.00 \\
194.00 \\
246.00 \\
233.00 \\
193.00 \\
222.00 \\
265.00 \\
245.00 \\
199.00 \\
123.00 \\
\end{array}$ & $\begin{array}{r}139.00 \\
46.82 \\
236.55 \\
41.42 \\
194.84 \\
180.11 \\
233.77 \\
110.40 \\
541.13 \\
29.80 \\
13.17 \\
\end{array}$ & $\begin{array}{r}22.379 .00 \\
9.785 .02 \\
45.891 .63 \\
10.189 .52 \\
45.397 .04 \\
34.761 .23 \\
51.897 .80 \\
29.257 .25 \\
132.578 .03 \\
5.931 .17 \\
1.620 .44 \\
\end{array}$ & $\begin{array}{l}\text { Reforma } \\
\text { Reforma } \\
\text { Reforma } \\
\text { Reforma } \\
\text { Reforma } \\
\text { Reforma } \\
\text { Reforma } \\
\text { Conducaso } \\
\text { Conduça } \\
\text { Reforma } \\
\text { Reforma } \\
\end{array}$ \\
\hline \multicolumn{2}{|c|}{$\begin{array}{l}\text { Area Tolal (ha): } \\
\text { Area de Reforma (ha): }\end{array}$} & $\begin{array}{l}1,767.03 \\
1,115.49\end{array}$ & & & \multicolumn{2}{|c|}{ Produção (m3): } & $389,688.14$ \\
\hline \multirow[t]{2}{*}{ Ano 20} & Unidade & Regime & Anos de colheita & $\mathrm{m} 3 / \mathrm{ha}$ & ha & m3 & Ref/Cond \\
\hline & $\begin{array}{l}9 \\
10 \\
11 \\
12 \\
14 \\
15 \\
17 \\
25 \\
25 \\
26 \\
27 \\
29 \\
\end{array}$ & $\begin{array}{r}319 \\
681 \\
1 \\
188 \\
198 \\
33 \\
319 \\
982 \\
630 \\
360 \\
188 \\
1038\end{array}$ & $\begin{array}{r}4-10-15-20 \\
4-10-15-20 \\
5-10-15-20 \\
5-10-15-20 \\
5-10-15-20 \\
4-10-15-20 \\
4-10-15-20 \\
3-9-15-20 \\
2-8-14-20 \\
6-13-20 \\
5-10-15-20 \\
3-9-15-20\end{array}$ & $\begin{array}{l}277.00 \\
194.00 \\
245.00 \\
230.00 \\
303.00 \\
230.00 \\
256.00 \\
222.00 \\
265.00 \\
317.00 \\
261.00 \\
245.00\end{array}$ & $\begin{array}{r}235.46 \\
102.53 \\
197.40 \\
150.76 \\
41.07 \\
104.69 \\
473.50 \\
43.44 \\
12.82 \\
11.71 \\
75.55 \\
111.54\end{array}$ & $\begin{array}{r}65.223 .17 \\
19.889 .89 \\
48.361 .95 \\
34.674 .87 \\
12.444 .21 \\
24.078 .70 \\
121.216 .00 \\
9.644 .48 \\
3.397 .99 \\
3.712 .26 \\
19.718 .55 \\
27.326 .12\end{array}$ & $\begin{array}{l}\text { Reforma } \\
\text { Reforma } \\
\text { Reforma } \\
\text { Reforma } \\
\text { Reforma } \\
\text { Reforma } \\
\text { Reforma } \\
\text { Reforma } \\
\text { Reforma } \\
\text { Reforma } \\
\text { Reforma } \\
\text { Reforma } \\
\end{array}$ \\
\hline \multicolumn{2}{|c|}{$\begin{array}{l}\text { Area Total (ha): } \\
\text { Area de Reforma (ha): }\end{array}$} & $\begin{array}{l}1.560 .47 \\
1,560.47\end{array}$ & & & Proc & $(\mathrm{m} 3):$ & $389,688.19$ \\
\hline
\end{tabular}




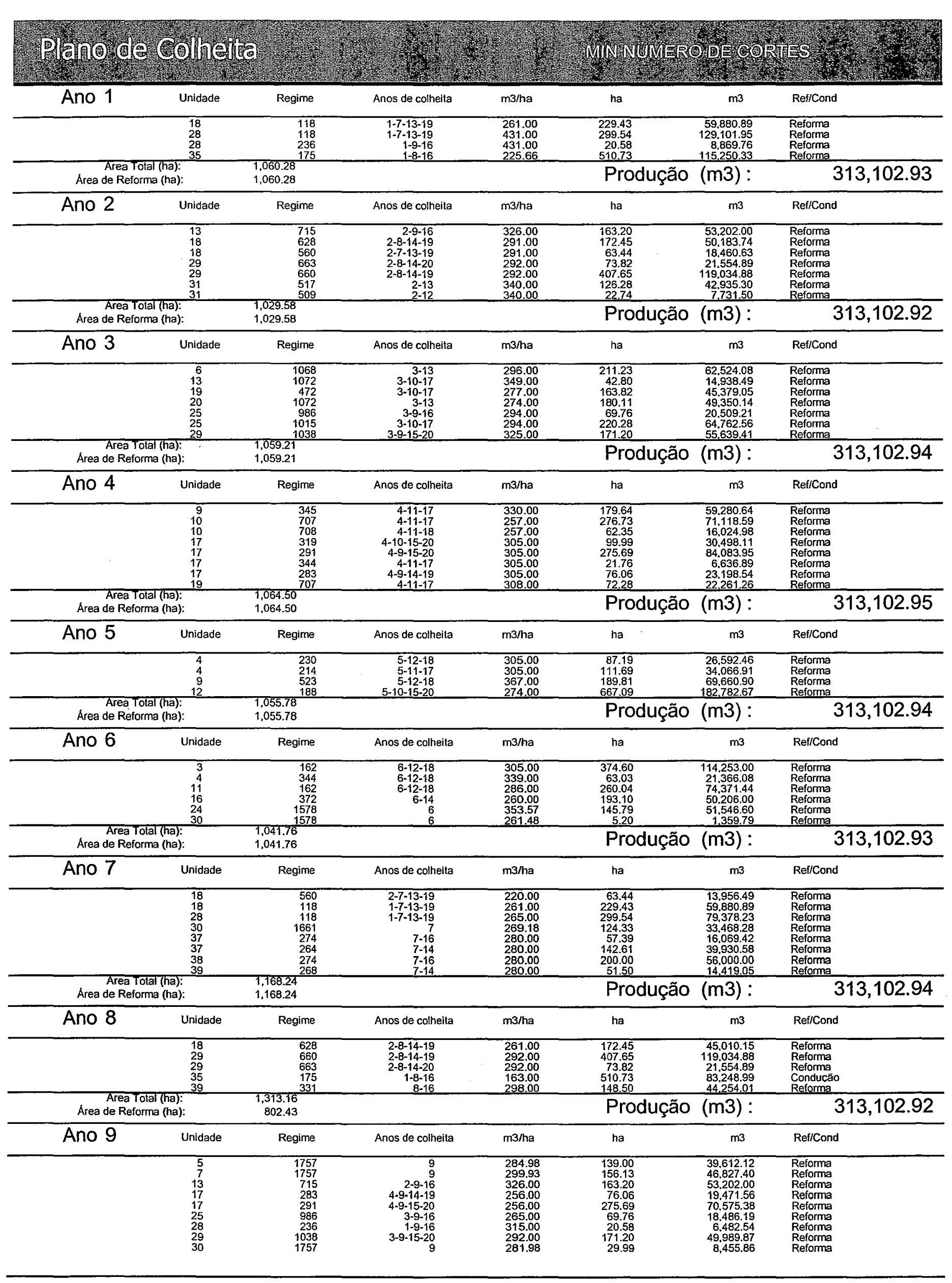




\begin{tabular}{|c|c|c|c|c|c|c|c|}
\hline \multicolumn{2}{|c|}{$\begin{array}{l}\text { Area Total (ha): } \\
\text { Area de Reforma (ha): }\end{array}$} & \multicolumn{3}{|l|}{$\begin{array}{l}1.101 .60 \\
1.101 .60\end{array}$} & \multicolumn{2}{|c|}{ Produçăo (m3): } & \multirow{2}{*}{$\begin{array}{l}313,102.93 \\
\text { Ref/Cond }\end{array}$} \\
\hline Ano 10 & Unidade & Regime & Anos de colheita & $\mathrm{m} 3 / \mathrm{ha}$ & ha & $\mathrm{m} 3$ & \\
\hline & $\begin{array}{l}12 \\
13 \\
17 \\
19 \\
25 \\
\end{array}$ & $\begin{array}{r}188 \\
1072 \\
319 \\
472 \\
1015 \\
\end{array}$ & $\begin{array}{r}5-10-15-20 \\
3-10-17 \\
4-10-15-20 \\
3-10-17 \\
3-10-17 \\
\end{array}$ & $\begin{array}{l}230.00 \\
326.00 \\
305.00 \\
308.00 \\
294.00 \\
\end{array}$ & $\begin{array}{r}667.09 \\
42.80 \\
99.99 \\
163.82 \\
220.28 \\
\end{array}$ & $\begin{array}{r}153.430 .71 \\
13.954 .01 \\
30.498 .11 \\
50.457 .58 \\
64.762 .56 \\
\end{array}$ & $\begin{array}{l}\text { Reforma } \\
\text { Reforma } \\
\text { Reforma } \\
\text { Reforma } \\
\text { Reforma } \\
\end{array}$ \\
\hline \multicolumn{2}{|c|}{$\begin{array}{l}\text { Area Total (ha): } \\
\text { Area de Reforma (ha): }\end{array}$} & $\begin{array}{l}1,193.99 \\
1,193.99\end{array}$ & & & Proc & $(\mathrm{m} 3):$ & $313,102.96$ \\
\hline \multirow[t]{2}{*}{ Ano 11} & Unidade & Regime & Anos de colheita & $\mathrm{m} 3 / \mathrm{ha}$ & ha & $\mathrm{m3}$ & Ref/Cond \\
\hline & $\begin{array}{r}1 \\
4 \\
9 \\
10 \\
10 \\
17 \\
19 \\
32 \\
\end{array}$ & $\begin{array}{l}442 \\
214 \\
345 \\
707 \\
708 \\
344 \\
707 \\
442 \\
\end{array}$ & $\begin{array}{r}11 \\
5-11-17 \\
4-11-17 \\
4-11-17 \\
4-11-18 \\
4-11-17 \\
4-11-17 \\
11 \\
\end{array}$ & $\begin{array}{l}421.98 \\
305.00 \\
367.00 \\
257.00 \\
257.00 \\
339.00 \\
308.00 \\
376.59 \\
\end{array}$ & $\begin{array}{r}118.15 \\
111.69 \\
179.64 \\
276.73 \\
62.35 \\
21.76 \\
72.28 \\
123.40 \\
\end{array}$ & $\begin{array}{l}49.856 .38 \\
34.066 .91 \\
65.927 .26 \\
71.118 .59 \\
16.024 .98 \\
7.376 .74 \\
22.261 .26 \\
46.470 .85 \\
\end{array}$ & $\begin{array}{l}\text { Reforma } \\
\text { Reforma } \\
\text { Reforma } \\
\text { Reforma } \\
\text { Reforma } \\
\text { Reforma } \\
\text { Reforma } \\
\text { Reforma } \\
\end{array}$ \\
\hline \multicolumn{2}{|c|}{$\begin{array}{l}\text { Area Total (ha): } \\
\text { Area de Reforma (ha): }\end{array}$} & $\begin{array}{l}966.00 \\
966.00 \\
\end{array}$ & & & Proc & $(\mathrm{m} 3):$ & $313,102.96$ \\
\hline \multirow[t]{2}{*}{ Ano 12} & Unidade & Regime & Anos de colheita & $\mathrm{m} 3 / \mathrm{ha}$ & ha & $\mathrm{m} 3$ & Ref/Cond \\
\hline & $\begin{array}{r}3 \\
4 \\
4 \\
9 \\
11 \\
31 \\
\end{array}$ & $\begin{array}{r}162 \\
230 \\
344 \\
523 \\
162 \\
509 \\
\end{array}$ & $\begin{array}{r}6-12-18 \\
5-12-18 \\
6-12-18 \\
5-12-18 \\
6-12-18 \\
2-12 \\
\end{array}$ & $\begin{array}{l}305.00 \\
339.00 \\
305.00 \\
367.00 \\
286.00 \\
265.51 \\
\end{array}$ & $\begin{array}{r}374.60 \\
87.19 \\
63.03 \\
189.81 \\
260.04 \\
22.74 \\
\end{array}$ & $\begin{array}{r}114.253 .00 \\
29.556 .87 \\
19.223 .17 \\
69.660 .90 \\
74,371.44 \\
6.037 .54 \\
\end{array}$ & $\begin{array}{l}\text { Reforma } \\
\text { Reforma } \\
\text { Reforma } \\
\text { Reforma } \\
\text { Reforma } \\
\text { Conducäo } \\
\end{array}$ \\
\hline \multicolumn{2}{|c|}{$\begin{array}{l}\text { Area Total (ha): } \\
\text { Area de Reforma (ha): }\end{array}$} & $\begin{array}{l}997.41 \\
974.67 \\
\end{array}$ & & & Proc & $(\mathrm{m} 3):$ & $313,102.93$ \\
\hline \multirow[t]{2}{*}{ Ano 13} & Unidade & Regime & Anos de colheita & $\mathrm{m} 3 / \mathrm{ha}$ & ha & $\mathrm{m} 3$ & Ref/Cond \\
\hline & $\begin{array}{r}6 \\
18 \\
18 \\
20 \\
28 \\
31 \\
\end{array}$ & $\begin{array}{r}1068 \\
118 \\
560 \\
1072 \\
118 \\
517 \\
\end{array}$ & $\begin{array}{r}3-13 \\
1-7-13-19 \\
2-7-13-19 \\
3-13 \\
1-7-13-19 \\
2-13 \\
\end{array}$ & $\begin{array}{l}323.48 \\
261.00 \\
261.00 \\
300.20 \\
265.00 \\
276.29 \\
\end{array}$ & $\begin{array}{r}211.23 \\
229.43 \\
63.44 \\
180.11 \\
299.54 \\
126.28 \\
\end{array}$ & $\begin{array}{l}68.328 .16 \\
59.880 .89 \\
16.557 .47 \\
54.068 .65 \\
79.378 .23 \\
34.889 .52 \\
\end{array}$ & $\begin{array}{l}\text { Reforma } \\
\text { Reforma } \\
\text { Reforma } \\
\text { Conducāo } \\
\text { Reforma } \\
\text { Conducāo } \\
\end{array}$ \\
\hline \multicolumn{2}{|c|}{$\begin{array}{l}\text { Area Total (ha): } \\
\text { Area de Reforma (ha): }\end{array}$} & $\begin{array}{r}1,110.03 \\
803.64 \\
\end{array}$ & & & Proc & $(\mathrm{m} 3):$ & $313,102.93$ \\
\hline \multirow[t]{2}{*}{ Ano 14} & Unidade & Regime & Anos de colheita & $\mathrm{m} 3 / \mathrm{ha}$ & ha & $\mathrm{m3}$ & Ref/Cond \\
\hline & $\begin{array}{l}16 \\
17 \\
18 \\
29 \\
29 \\
37 \\
39 \\
\end{array}$ & $\begin{array}{r}372 \\
283 \\
628 \\
663 \\
660 \\
264 \\
268 \\
\end{array}$ & $\begin{array}{r}6-14 \\
4-9-14-19 \\
2-8-14-19 \\
2-8-14-20 \\
2-8-14-19 \\
7-14 \\
7-14 \\
\end{array}$ & $\begin{array}{l}278.00 \\
256.00 \\
261.00 \\
292.00 \\
292.00 \\
280.00 \\
280.00 \\
\end{array}$ & $\begin{array}{r}193.10 \\
76.06 \\
172.45 \\
73.82 \\
407.65 \\
142.61 \\
51.50 \\
\end{array}$ & $\begin{array}{r}53.681 .80 \\
19.471 .56 \\
45.010 .15 \\
21.554 .89 \\
119.034 .88 \\
39.930 .58 \\
14.419 .05 \\
\end{array}$ & $\begin{array}{l}\text { Conducāo } \\
\text { Reforma } \\
\text { Reforma } \\
\text { Reforma } \\
\text { Reforma } \\
\text { Reforma } \\
\text { Conducáa } \\
\end{array}$ \\
\hline \multicolumn{2}{|c|}{$\begin{array}{l}\text { Area Total (ha): } \\
\text { Area de Reforma (ha): }\end{array}$} & $\begin{array}{r}1,117.19 \\
872.59 \\
\end{array}$ & & & Proc & $(\mathrm{m} 3):$ & $313,102.91$ \\
\hline \multirow[t]{2}{*}{ Ano 15} & Unidade & Regime & Anos de colheita & $\mathrm{m} 3 / \mathrm{ha}$ & ha & $\mathrm{m} 3$ & Ref/Cond \\
\hline & $\begin{array}{r}12 \\
17 \\
17 \\
29 \\
\end{array}$ & $\begin{array}{r}188 \\
291 \\
319 \\
1038 \\
\end{array}$ & $\begin{array}{r}5-10-15-20 \\
4-9-15-20 \\
4-10-15-20 \\
3-9-15-20 \\
\end{array}$ & $\begin{array}{l}230.00 \\
305.00 \\
256.00 \\
292.00 \\
\end{array}$ & $\begin{array}{r}667.09 \\
275.69 \\
99.99 \\
171.20 \\
\end{array}$ & $\begin{array}{r}153.430 .71 \\
84.083 .95 \\
25.598 .41 \\
49.989 .87 \\
\end{array}$ & $\begin{array}{l}\text { Reforma } \\
\text { Reforma } \\
\text { Reforma } \\
\text { Reforma } \\
\end{array}$ \\
\hline \multicolumn{2}{|c|}{$\begin{array}{l}\text { Area Total (ha): } \\
\text { Area de Reforma (ha): }\end{array}$} & $\begin{array}{l}1,213.97 \\
1,213.97\end{array}$ & & & Proc & $(\mathrm{m} 3):$ & $313,102.94$ \\
\hline \multirow[t]{2}{*}{ Ano 16} & Unidade & Regime & Anos de colheita & $\mathrm{m} 3 / \mathrm{ha}$ & ha & $\mathrm{m} 3$ & Ref/Cond \\
\hline & $\begin{array}{l}13 \\
25 \\
28 \\
35 \\
37 \\
38 \\
39 \\
\end{array}$ & $\begin{array}{r}715 \\
986 \\
236 \\
175 \\
274 \\
274 \\
331 \\
\end{array}$ & $\begin{array}{r}2-9-16 \\
3-9-16 \\
1-9-16 \\
1-8-16 \\
7-16 \\
7-16 \\
8-16 \\
\end{array}$ & $\begin{array}{l}326.00 \\
294.00 \\
294.00 \\
214.00 \\
310.00 \\
310.00 \\
298.00 \\
\end{array}$ & $\begin{array}{r}163.20 \\
69.76 \\
20.58 \\
510.73 \\
57.39 \\
200.00 \\
148.50 \\
\end{array}$ & $\begin{array}{r}53.202 .00 \\
20.509 .21 \\
6.050 .37 \\
109.296 .22 \\
17.791 .15 \\
62.000 .00 \\
44.254 .01 \\
\end{array}$ & $\begin{array}{l}\text { Reforma } \\
\text { Reforma } \\
\text { Conducão } \\
\text { Reforma } \\
\text { Conducão } \\
\text { Conducão } \\
\text { Reforma } \\
\end{array}$ \\
\hline \multicolumn{2}{|c|}{$\begin{array}{l}\text { Area Total(ha): } \\
\text { Area de Reforma (ha): }\end{array}$} & $\begin{array}{r}1,170.16 \\
892.19 \\
\end{array}$ & & & Proc & $(\mathrm{m} 3):$ & $313,102.96$ \\
\hline \multirow[t]{2}{*}{ Ano 17} & Unidade & Regime & Anos de colheita & $\mathrm{m} 3 / \mathrm{ha}$ & ha & $\mathrm{m3}$ & Ref/Cond \\
\hline & $\begin{array}{r}4 \\
9 \\
10 \\
13 \\
17 \\
19 \\
19 \\
25 \\
\end{array}$ & $\begin{array}{r}214 \\
345 \\
707 \\
1072 \\
344 \\
472 \\
707 \\
1015 \\
\end{array}$ & $\begin{array}{l}5-11-17 \\
4-11-17 \\
4-11-17 \\
3-10-17 \\
4-11-17 \\
3-10-17 \\
4-11-17 \\
3-10-17 \\
\end{array}$ & $\begin{array}{l}305.00 \\
330.00 \\
231.00 \\
326.00 \\
305.00 \\
308.00 \\
277.00 \\
294.00 \\
\end{array}$ & $\begin{array}{r}111.69 \\
179.64 \\
276.73 \\
42.80 \\
21.76 \\
163.82 \\
72.28 \\
220.28 \\
\end{array}$ & $\begin{array}{r}34.066 .91 \\
59.280 .64 \\
63.923 .71 \\
13.954 .01 \\
6.636 .89 \\
50.457 .58 \\
20.020 .67 \\
64.762 .56 \\
\end{array}$ & $\begin{array}{l}\text { Conducão } \\
\text { Conducão } \\
\text { Conducăo } \\
\text { Reforma } \\
\text { Reforma } \\
\text { Conducão } \\
\text { Conducão } \\
\text { Conducão } \\
\end{array}$ \\
\hline \multicolumn{2}{|c|}{$\begin{array}{l}\text { Area Total (ha): } \\
\text { Area de Reforma (ha): }\end{array}$} & $\begin{array}{r}1,089.00 \\
64.56\end{array}$ & & & Proc & $(\mathrm{m} 3):$ & $313,102.97$ \\
\hline \multirow[t]{2}{*}{ Ano 18} & Unidade & Regime & Anos de colheita & m3/ha & ha & $\mathrm{m} 3$ & Ref/Cond \\
\hline & $\begin{array}{r}3 \\
4 \\
4 \\
9 \\
10 \\
11 \\
\end{array}$ & $\begin{array}{r}162 \\
344 \\
230 \\
523 \\
708 \\
162 \\
\end{array}$ & $\begin{array}{l}6-12-18 \\
6-12-18 \\
5-12-18 \\
5-12-18 \\
4-11-18 \\
6-12-18 \\
\end{array}$ & $\begin{array}{l}305.00 \\
305.00 \\
305.00 \\
330.00 \\
257.00 \\
286.00 \\
\end{array}$ & $\begin{array}{r}374.60 \\
63.03 \\
87.19 \\
189.81 \\
62.35 \\
260.04 \\
\end{array}$ & $\begin{array}{r}114.253 .00 \\
19.223 .17 \\
26.592 .46 \\
62.637 .86 \\
16.024 .98 \\
74.371 .44 \\
\end{array}$ & $\begin{array}{l}\text { Conducăo } \\
\text { Reforma } \\
\text { Reforma } \\
\text { Conducăo } \\
\text { Reforma } \\
\text { Conduçăo } \\
\end{array}$ \\
\hline \multicolumn{2}{|c|}{$\begin{array}{l}\text { Area Total (ha): } \\
\text { Área de Reforma (ha): }\end{array}$} & $\begin{array}{r}1,037.02 \\
212.57\end{array}$ & & & Pro & (m3): & $313,102.92$ \\
\hline Ano 19 & Unidade & Regime & Anos de colheita & m3/ha & ha & $\mathrm{m3}$ & Ref/Cond \\
\hline
\end{tabular}




\begin{tabular}{|c|c|c|c|c|c|c|c|}
\hline & $\begin{array}{l}17 \\
18 \\
18 \\
18 \\
28 \\
29 \\
\end{array}$ & $\begin{array}{l}283 \\
560 \\
118 \\
628 \\
118 \\
660 \\
\end{array}$ & $\begin{array}{l}4-9-14-19 \\
2-7-13-19 \\
17-13-19 \\
2-8-14-19 \\
1-7-13-19 \\
2-8-14-19\end{array}$ & $\begin{array}{l}256.00 \\
261.00 \\
261.00 \\
220.00 \\
265.00 \\
245.00\end{array}$ & $\begin{array}{r}76.06 \\
63.44 \\
229.43 \\
172.45 \\
299.54 \\
407.65 \\
\end{array}$ & $\begin{array}{l}19.471 .56 \\
16.557 .47 \\
59.880 .89 \\
37.939 .59 \\
79.378 .23 \\
99.875 .15 \\
\end{array}$ & $\begin{array}{l}\text { Reforma } \\
\text { Reforma } \\
\text { Reforma } \\
\text { Reforma } \\
\text { Reforma } \\
\text { Reforma } \\
\end{array}$ \\
\hline \multicolumn{2}{|c|}{$\begin{array}{l}\text { Area Total (ha): } \\
\text { Area de Reforma (ha): }\end{array}$} & $\begin{array}{l}1,248.57 \\
1,248.57\end{array}$ & & & \multicolumn{2}{|c|}{ Produção (m3): } & $313,102.91$ \\
\hline \multirow[t]{2}{*}{ Ano 20} & Unidade & Regime & Anos de colheita & $\mathrm{m} 3 / \mathrm{ha}$ & ha & $\mathrm{m} 3$ & Ref/Cond \\
\hline & $\begin{array}{l}12 \\
17 \\
17 \\
29 \\
29 \\
\end{array}$ & $\begin{array}{r}188 \\
319 \\
291 \\
1038 \\
663 \\
\end{array}$ & $\begin{array}{r}5-10-15-20 \\
4-10-15-20 \\
4-9-15-20 \\
3-9-15-20 \\
2-8-14-20 \\
\end{array}$ & $\begin{array}{l}230.00 \\
256.00 \\
256.00 \\
245.00 \\
292.00 \\
\end{array}$ & $\begin{array}{r}667.09 \\
99.99 \\
275.69 \\
171.20 \\
73.82 \\
\end{array}$ & $\begin{array}{r}153.430 .71 \\
25.598 .41 \\
70.575 .38 \\
41.943 .56 \\
21.554 .89 \\
\end{array}$ & $\begin{array}{l}\text { Reforma } \\
\text { Reforma } \\
\text { Reforma } \\
\text { Reforma } \\
\text { Conducão } \\
\end{array}$ \\
\hline \multicolumn{2}{|c|}{$\begin{array}{l}\text { Area Total (ha): } \\
\text { Area de Reforma (ha): }\end{array}$} & $\begin{array}{l}1,287.79 \\
1,213.97\end{array}$ & & & Proc & (m3): & $313,102.94$ \\
\hline
\end{tabular}

84 
Ano 1

\section{Unidade}

Anos de colheita

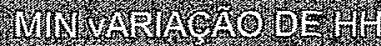

m3/ha

ha
160.05
55.97

59.94

53.79
219.50

219.50

16.90
91.59

91.59
139.72

Produção (m3) : m3 Ref/Cond

39.852.18

39.852.18 Reforma

$\begin{array}{ll}16.400 .67 & \text { Reforma } \\ 17,563.01 & \text { Reforma }\end{array}$

12.370.94 Reforma

48.729 .69

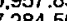

Reforma

Reforma

Reforma Reforma

\begin{tabular}{|c|c|c|c|c|c|c|c|}
\hline Ano 2 & Unidade & Regime & Anos de colheita & m3/ha & ha & m3 & Ref/Cond \\
\hline & \begin{tabular}{r|}
6 \\
10 \\
10 \\
10 \\
18 \\
18 \\
18 \\
19 \\
22 \\
25 \\
25 \\
30 \\
30 \\
31 \\
\end{tabular} & $\begin{array}{r}569 \\
126 \\
48 \\
75 \\
804 \\
651 \\
568 \\
263 \\
544 \\
562 \\
582 \\
896 \\
607 \\
433 \\
\end{array}$ & $\begin{array}{r}2-7-14-19 \\
2-9-14-20 \\
2-7-12-17 \\
2-8-13-18 \\
2-7-14 \\
2-8-13-19 \\
2-7-13 \\
2-7-14-19 \\
2-7-12-17 \\
2-7-13-20 \\
2-7-17 \\
2-11-18 \\
2-7-14 \\
2-9-15 \\
\end{array}$ & $\begin{array}{l}277.00 \\
194.00 \\
194.00 \\
194.00 \\
291.00 \\
291.00 \\
291.00 \\
233.00 \\
280.00 \\
265.00 \\
265.00 \\
218.00 \\
218.00 \\
340.00 \\
\end{array}$ & $\begin{array}{r}51.18 \\
98.94 \\
90.61 \\
149.53 \\
47.43 \\
165.41 \\
252.49 \\
77.88 \\
82.00 \\
25.41 \\
45.13 \\
49.47 \\
110.05 \\
9.30 \\
\end{array}$ & $\begin{array}{r}14.177 .16 \\
19.194 .63 \\
17.578 .40 \\
29.008 .49 \\
13.800 .73 \\
48.132 .91 \\
73.474 .47 \\
18.145 .64 \\
22.960 .00 \\
6.733 .12 \\
11.959 .16 \\
10.784 .96 \\
23.990 .40 \\
3.162 .85 \\
\end{array}$ & $\begin{array}{l}\text { Reforma } \\
\text { Reforma } \\
\text { Reforma } \\
\text { Reforma } \\
\text { Conducāo } \\
\text { Reforma } \\
\text { Reforma } \\
\text { Conducão } \\
\text { Reforma } \\
\text { Reforma } \\
\text { Reforma } \\
\text { Conducão } \\
\text { Reforma } \\
\text { Reforma } \\
\end{array}$ \\
\hline \multicolumn{2}{|c|}{$\begin{array}{l}\text { Area Total (ha): } \\
\text { Area de Reforma (ha): }\end{array}$} & $\begin{array}{l}1,254.82 \\
1,080.04\end{array}$ & & & \multicolumn{2}{|c|}{ Produção (m3) : } & $313,102.94$ \\
\hline \multirow[t]{2}{*}{ Ano 3} & Unidade & Regime & Anos de colheita & $\mathrm{m} 3 / \mathrm{ha}$ & ha & $\mathrm{m} 3$ & Ref/Cond \\
\hline & $\begin{array}{r}5 \\
5 \\
7 \\
8 \\
19 \\
19 \\
21 \\
21 \\
24 \\
29 \\
29 \\
\end{array}$ & $\begin{array}{r}998 \\
945 \\
983 \\
568 \\
411 \\
384 \\
1182 \\
959 \\
926 \\
1176 \\
1060 \\
\end{array}$ & $\begin{array}{r}3-9-14 \\
3-8-15-20 \\
3-9-15 \\
3-8-15-20 \\
3-8-19 \\
3-8-13-18 \\
3-13-20 \\
3-8-13-18 \\
3-8-13-18 \\
3-8-18 \\
3-9-16 \\
\end{array}$ & $\begin{array}{l}229.00 \\
229.00 \\
240.00 \\
200.00 \\
277.00 \\
277.00 \\
337.00 \\
337.00 \\
320.33 \\
325.00 \\
325.00 \\
\end{array}$ & $\begin{array}{r}120.85 \\
18.15 \\
85.87 \\
86.10 \\
12.01 \\
146.21 \\
28.36 \\
24.44 \\
145.79 \\
148.95 \\
266.81 \\
\end{array}$ & $\begin{array}{r}27.675 .22 \\
4.155 .78 \\
20.609 .47 \\
17.220 .00 \\
3.326 .22 \\
40.501 .19 \\
9.556 .48 \\
8.235 .81 \\
46.701 .21 \\
48.409 .85 \\
86.711 .66 \\
\end{array}$ & $\begin{array}{l}\text { Reforma } \\
\text { Reforma } \\
\text { Reforma } \\
\text { Reforma } \\
\text { Reforma } \\
\text { Reforma } \\
\text { Conducão } \\
\text { Reforma } \\
\text { Reforma } \\
\text { Conducão } \\
\text { Reforma } \\
\end{array}$ \\
\hline \multicolumn{2}{|c|}{$\begin{array}{c}\text { Area Total (ha): } \\
\text { Área de Reforma (ha): }\end{array}$} & $\begin{array}{l}1,083.54 \\
906.23\end{array}$ & & & Pro & $(\mathrm{m} 3):$ & $313,102.90$ \\
\hline \multirow[t]{2}{*}{ Ano 4} & Unidade & Regime & Anos de colheita & $\mathrm{m} 3 / \mathrm{ha}$ & ha & m3 & Ref/Cond \\
\hline & $\begin{array}{r}2 \\
2 \\
4 \\
4 \\
7 \\
15 \\
17 \\
17 \\
21 \\
26 \\
29 \\
\end{array}$ & $\begin{array}{r}1319 \\
1299 \\
116 \\
59 \\
1247 \\
73 \\
387 \\
294 \\
1195 \\
5 \\
1426 \\
\end{array}$ & $\begin{array}{r}4-9-17 \\
4-16 \\
4-9-14-19 \\
4-11-17 \\
4-11-16 \\
4-12-17 \\
4-14-20 \\
4-9-15 \\
4-9-14-19 \\
4-9-14-20 \\
4-11-20 \\
\end{array}$ & $\begin{array}{l}321.31 \\
321.31 \\
256.00 \\
256.00 \\
251.00 \\
195.00 \\
305.00 \\
305.00 \\
361.00 \\
215.00 \\
348.00 \\
\end{array}$ & $\begin{array}{r}3.88 \\
35.45 \\
76.99 \\
184.92 \\
70.26 \\
104.69 \\
169.30 \\
304.20 \\
22.20 \\
51.51 \\
91.55 \\
\end{array}$ & $\begin{array}{r}1.246 .42 \\
11.390 .67 \\
19.710 .39 \\
47.338 .57 \\
17.634 .56 \\
20.414 .55 \\
51.635 .19 \\
92.782 .32 \\
8.015 .57 \\
11.074 .65 \\
31.860 .06 \\
\end{array}$ & $\begin{array}{l}\text { Conducāo } \\
\text { Reforma } \\
\text { Conducāo } \\
\text { Reforma } \\
\text { Reforma } \\
\text { Reforma } \\
\text { Reforma } \\
\text { Reforma } \\
\text { Reforma } \\
\text { Reforma } \\
\text { Conducão } \\
\end{array}$ \\
\hline \multicolumn{2}{|c|}{$\begin{array}{l}\text { Area Total (ha): } \\
\text { Area de Reforma (ha): }\end{array}$} & $\begin{array}{r}1,114.95 \\
942.53\end{array}$ & & & Pro & $(\mathrm{m} 3):$ & $313,102.95$ \\
\hline \multirow[t]{2}{*}{ Ano 5} & Unidade & Regime & Anos de colheita & $\mathrm{m} 3 / \mathrm{ha}$ & ha & $\mathrm{m} 3$ & Ref/Cond \\
\hline & $\begin{array}{r}9 \\
9 \\
11 \\
11 \\
11 \\
23 \\
29 \\
33 \\
34 \\
35 \\
35 \\
35 \\
39 \\
\end{array}$ & $\begin{array}{r}577 \\
608 \\
9 \\
88 \\
51 \\
1434 \\
1514 \\
1381 \\
855 \\
772 \\
778 \\
758 \\
1\end{array}$ & $\begin{array}{r}5-10-19 \\
5-13 \\
5-10-18 \\
5-10-15-20 \\
5-12-18 \\
5-13-18 \\
5-13-20 \\
5-10-15-20 \\
5-10-18 \\
5-12 \\
5-13-19 \\
5-11-17 \\
5-10-15-20 \\
\end{array}$ & $\begin{array}{l}367.00 \\
367.00 \\
245.00 \\
245.00 \\
245.00 \\
414.14 \\
364.00 \\
296.00 \\
254.00 \\
232.71 \\
232.71 \\
232.71 \\
217.00 \\
\end{array}$ & $\begin{array}{r}97.76 \\
28.10 \\
11.14 \\
32.82 \\
188.10 \\
78.98 \\
53.77 \\
52.20 \\
30.00 \\
83.66 \\
129.52 \\
297.55 \\
73.05 \\
\end{array}$ & $\begin{array}{r}35.878 .73 \\
10.311 .97 \\
2.728 .76 \\
8.041 .61 \\
46.084 .38 \\
32.709 .15 \\
19.571 .26 \\
15.451 .20 \\
7.619 .86 \\
19.469 .10 \\
30.140 .66 \\
69.244 .48 \\
15.851 .76 \\
\end{array}$ & $\begin{array}{l}\text { Conducão } \\
\text { Conducão } \\
\text { Reforma } \\
\text { Conducão } \\
\text { Reforma } \\
\text { Reforma } \\
\text { Reforma } \\
\text { Reforma } \\
\text { Reforma } \\
\text { Reforma } \\
\text { Reforma } \\
\text { Reforma } \\
\text { Reforma } \\
\end{array}$ \\
\hline \multicolumn{2}{|c|}{$\begin{array}{l}\text { Area Total (ha): } \\
\text { Area de Reforma (ha): }\end{array}$} & $\begin{array}{r}1,156.65 \\
997.96\end{array}$ & & & Pro & $(\mathrm{m} 3):$ & $313,102.92$ \\
\hline \multirow[t]{2}{*}{ Ano 6} & Unidade & Regime & Anos de colheita & $\mathrm{m} 3 / \mathrm{ha}$ & ha & m3 & Ref/Cond \\
\hline & $\begin{array}{l}11 \\
11 \\
13 \\
13 \\
20 \\
27 \\
28 \\
28 \\
28 \\
29 \\
37 \\
39 \\
\end{array}$ & $\begin{array}{r}162 \\
173 \\
1613 \\
75 \\
1564 \\
329 \\
1 \\
948 \\
19 \\
69 \\
200 \\
140 \\
\end{array}$ & $\begin{array}{r}6-12-18 \\
6-13-18 \\
6-12-17 \\
1-6-11-20 \\
6-15-20 \\
6-11-18 \\
1-6-11-16 \\
6-12-17 \\
1-6-12-17 \\
1-6-11-17 \\
6 \\
6-11-17 \\
\end{array}$ & $\begin{array}{l}318.00 \\
286.00 \\
403.17 \\
246.00 \\
311.54 \\
336.00 \\
222.00 \\
305.37 \\
222.00 \\
245.00 \\
255.00 \\
255.00 \\
\end{array}$ & $\begin{array}{r}118.15 \\
27.98 \\
90.08 \\
59.94 \\
126.32 \\
75.55 \\
234.24 \\
68.98 \\
16.90 \\
91.59 \\
200.00 \\
5.76 \\
\end{array}$ & $\begin{array}{r}37,571.70 \\
8.002 .22 \\
36.318 .93 \\
14.745 .73 \\
39.354 .15 \\
25.384 .80 \\
52.001 .48 \\
21.063 .44 \\
3.752 .11 \\
22.440 .14 \\
51.000 .00 \\
1.468 .19 \\
\end{array}$ & $\begin{array}{l}\text { Reforma } \\
\text { Reforma } \\
\text { Reforma } \\
\text { Conducāo } \\
\text { Reforma } \\
\text { Reforma } \\
\text { Reforma } \\
\text { Reforma } \\
\text { Reforma } \\
\text { Conducão } \\
\text { Reforma } \\
\text { Reforma } \\
\end{array}$ \\
\hline \multicolumn{2}{|c|}{$\begin{array}{l}\text { Area Total (ha): } \\
\text { Area de Reforma (ha): }\end{array}$} & $\begin{array}{r}1,115.50 \\
963.96\end{array}$ & & & Pro & $(\mathrm{m} 3):$ & $313,102.89$ \\
\hline \multirow[t]{2}{*}{ Ano 7} & Unidade & Regime & Anos de colheita & $\mathrm{m} 3 / \mathrm{ha}$ & ha & $\mathrm{m} 3$ & Rei/Cond \\
\hline & $\begin{array}{l}6 \\
9\end{array}$ & $\begin{array}{l}569 \\
730\end{array}$ & $\begin{array}{r}2-7-14-19 \\
7-12-19\end{array}$ & $\begin{array}{l}209.00 \\
411.00\end{array}$ & $\begin{array}{r}51.18 \\
243.59\end{array}$ & $\begin{array}{r}10.696 .85 \\
100,115.41\end{array}$ & $\begin{array}{l}\text { Reforma } \\
\text { Reforma }\end{array}$ \\
\hline
\end{tabular}




\begin{tabular}{|c|c|c|c|c|c|c|c|}
\hline 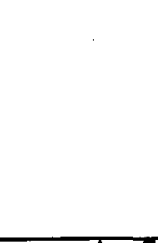 & $\begin{array}{l}10 \\
13 \\
18 \\
18 \\
19 \\
20 \\
22 \\
25 \\
25 \\
30 \\
36 \\
\end{array}$ & $\begin{array}{r}48 \\
166 \\
804 \\
568 \\
263 \\
130 \\
544 \\
582 \\
562 \\
607 \\
268 \\
\end{array}$ & $\begin{array}{r}2-7-12-17 \\
1-7-13-19 \\
2-7-14 \\
2-7-13 \\
2-7-14-19 \\
1-7-14-19 \\
2-7-12-17 \\
2.7-17 \\
2-7-13-20 \\
2-7-14 \\
7-14 \\
\end{array}$ & $\begin{array}{l}194.00 \\
293.00 \\
187.00 \\
220.00 \\
198.00 \\
230.00 \\
189.00 \\
222.00 \\
222.00 \\
154.00 \\
280.00 \\
\end{array}$ & $\begin{array}{r}90.61 \\
55.97 \\
47.43 \\
252.49 \\
77.88 \\
53.79 \\
82.00 \\
45.13 \\
25.41 \\
110.05 \\
100.00 \\
\end{array}$ & $\begin{array}{r}17.578 .40 \\
16.400 .67 \\
8.868 .51 \\
55.547 .71 \\
15.419 .90 \\
12.370 .94 \\
15.498 .00 \\
10.018 .62 \\
5.640 .58 \\
16.947 .35 \\
28.000 .00 \\
\end{array}$ & $\begin{array}{l}\text { Conducāo } \\
\text { Conduçāo } \\
\text { Reforma } \\
\text { Reforma } \\
\text { Reforma } \\
\text { Reforma } \\
\text { Reforma } \\
\text { Reforma } \\
\text { Reforma } \\
\text { Conducão } \\
\text { Reforma }\end{array}$ \\
\hline \multicolumn{2}{|c|}{$\begin{array}{l}\text { Area Total (ha): } \\
\text { Area de Reforma (ha): }\end{array}$} & $\begin{array}{r}1,235.52 \\
978.89\end{array}$ & & & \multicolumn{2}{|c|}{ Produção (m3): } & $313,102.93$ \\
\hline \multirow[t]{2}{*}{ Ano 8} & Unidade & Regime & Anos de colheita & m3/ha & ha & $\mathrm{m3}$ & Ref/Cond \\
\hline & $\begin{array}{r}5 \\
8 \\
10 \\
18 \\
19 \\
19 \\
21 \\
24 \\
25 \\
29 \\
32 \\
38 \\
\end{array}$ & $\begin{array}{r}945 \\
568 \\
75 \\
651 \\
411 \\
384 \\
959 \\
926 \\
192 \\
1176 \\
345 \\
353 \\
\end{array}$ & $\begin{array}{r}3-8-15-20 \\
3-8-15-20 \\
2-8-13-18 \\
2-8-13-19 \\
3-8-19 \\
3-8-13-18 \\
3-8-13-18 \\
3-8-13-18 \\
1-8-15-20 \\
3-8-18 \\
8-16 \\
8-15 \\
\end{array}$ & $\begin{array}{l}161.00 \\
169.00 \\
231.00 \\
261.00 \\
233.00 \\
233.00 \\
255.00 \\
203.00 \\
294.00 \\
208.00 \\
334.00 \\
298.00 \\
\end{array}$ & $\begin{array}{r}18.15 \\
86.10 \\
149.53 \\
165.41 \\
12.01 \\
146.21 \\
24.44 \\
145.79 \\
219.50 \\
148.95 \\
32.58 \\
130.30 \\
\end{array}$ & $\begin{array}{r}2.921 .75 \\
14.550 .90 \\
34.541 .04 \\
43.170 .76 \\
2.797 .86 \\
34.067 .79 \\
6.231 .84 \\
29.595 .37 \\
64.533 .91 \\
30.982 .31 \\
10.880 .52 \\
38,828.89 \\
\end{array}$ & $\begin{array}{l}\text { Reforma } \\
\text { Conducăo } \\
\text { Reforma } \\
\text { Conducão } \\
\text { Reforma } \\
\text { Reforma } \\
\text { Conducăo } \\
\text { Reforma } \\
\text { Reforma } \\
\text { Reforma } \\
\text { Reforma } \\
\text { Conduçăo } \\
\end{array}$ \\
\hline \multicolumn{2}{|c|}{$\begin{array}{l}\text { Area Total (ha): } \\
\text { Area de Reforma (ha): }\end{array}$} & $\begin{array}{r}, 278.96 \\
872.72\end{array}$ & & & \multicolumn{2}{|c|}{ Produção (m3): } & $313,102.94$ \\
\hline \multirow{2}{*}{ Ano 9} & Unidade & Regime & Anos de colheita & $\mathrm{m} 3 / \mathrm{ha}$ & ha & $\mathrm{m3}$ & Refi/Cond \\
\hline & $\begin{array}{r}2 \\
4 \\
5 \\
7 \\
10 \\
17 \\
21 \\
26 \\
29 \\
31 \\
31 \\
38 \\
\end{array}$ & $\begin{array}{r}1319 \\
116 \\
998 \\
983 \\
126 \\
294 \\
1195 \\
5 \\
1060 \\
433 \\
210 \\
383 \\
\end{array}$ & $\begin{array}{r}4-9-17 \\
4-9-14-19 \\
3-9-14 \\
3-9-15 \\
2-9-14-20 \\
4-9-15 \\
4-9-14-19 \\
4-9 \cdot 14-20 \\
3-9-16 \\
2-9.15 \\
1-9-14-19 \\
9-15-20 \\
\end{array}$ & $\begin{array}{l}176.00 \\
218.00 \\
192.00 \\
201.00 \\
257.00 \\
256.00 \\
255.00 \\
215.00 \\
292.00 \\
224.00 \\
240.00 \\
310.00 \\
\end{array}$ & $\begin{array}{r}3.88 \\
76.99 \\
.120 .85 \\
85.87 \\
98.94 \\
304.20 \\
22.20 \\
51.51 \\
266.81 \\
9.30 \\
139.72 \\
69.70 \\
\end{array}$ & $\begin{array}{r}682.74 \\
16.784 .63 \\
23.203 .68 \\
17.260 .43 \\
25.427 .94 \\
77.876 .30 \\
5.661 .97 \\
11.074 .65 \\
77.907 .09 \\
2.083 .76 \\
33.532 .20 \\
21.607 .53 \\
\end{array}$ & $\begin{array}{l}\text { Reforma } \\
\text { Reforma } \\
\text { Conducâo } \\
\text { Reforma } \\
\text { Reforma } \\
\text { Reforma } \\
\text { Reforma } \\
\text { Reforma } \\
\text { Conducão } \\
\text { Reforma } \\
\text { Reforma } \\
\text { Conducáa } \\
\end{array}$ \\
\hline \multicolumn{2}{|c|}{$\begin{array}{l}\text { Area Total (ha): } \\
\text { A8 } \\
\text { Área de Reforma (ha): }\end{array}$} & $\begin{array}{l}1,249.98 \\
792.63\end{array}$ & & & \multicolumn{2}{|c|}{ Produção (m3): } & $313,102.92$ \\
\hline \multirow[t]{2}{*}{ Ano 10} & Unidade & Regime & Anos de colheita & $\mathrm{m} 3 / \mathrm{ha}$ & ha & $\mathrm{m} 3$ & Ref/Cond \\
\hline & $\begin{array}{r}9 \\
11 \\
11 \\
12 \\
12 \\
33 \\
34 \\
39 \\
\end{array}$ & $\begin{array}{r}577 \\
9 \\
88 \\
595 \\
582 \\
1381 \\
855 \\
1 \\
\end{array}$ & $\begin{array}{r}5-10-19 \\
5-10-18 \\
5-10-15-20 \\
10-17 \\
10-16 \\
5-10-15-20 \\
5-10-18 \\
5-10-15-20 \\
\end{array}$ & $\begin{array}{l}235.00 \\
245.00 \\
208.00 \\
373.66 \\
373.66 \\
199.00 \\
169.00 \\
217.00 \\
\end{array}$ & $\begin{array}{r}97.76 \\
11.14 \\
32.82 \\
229.61 \\
437.48 \\
52.20 \\
30.00 \\
73.05 \\
\end{array}$ & $\begin{array}{r}22.974 .12 \\
2.728 .76 \\
6.827 .16 \\
85.797 .15 \\
163.466 .17 \\
10.387 .80 \\
5.070 .00 \\
15,851.76 \\
\end{array}$ & $\begin{array}{l}\text { Reforma } \\
\text { Reforma } \\
\text { Reforma } \\
\text { Conducāo } \\
\text { Reforma } \\
\text { Reforma } \\
\text { Reforma } \\
\text { Reforma } \\
\end{array}$ \\
\hline \multicolumn{2}{|c|}{$\begin{array}{l}\text { Area Total (ha): } \\
\text { Area de Reforma (ha): }\end{array}$} & $\begin{array}{l}964.06 \\
734.45\end{array}$ & & & \multicolumn{2}{|c|}{ Produção (m3): } & $313,102.93$ \\
\hline \multirow[t]{2}{*}{ Ano 11} & Unidade & Regime & Anos de colheita & $m 3 / h a$ & na & $\mathrm{m3}$ & Ref/Cond \\
\hline & $\begin{array}{r}4 \\
6 \\
7 \\
13 \\
27 \\
28 \\
29 \\
29 \\
30 \\
35 \\
39 \\
\end{array}$ & $\begin{array}{r}59 \\
280 \\
1247 \\
75 \\
329 \\
1 \\
69 \\
1426 \\
896 \\
758 \\
140 \\
\end{array}$ & $\begin{array}{r}4-11-17 \\
1-11-16 \\
4-11-16 \\
1-6-11-20 \\
6-11-18 \\
1-6-11-16 \\
1-6-11-17 \\
4-11-20 \\
2-11-18 \\
5-11-17 \\
6-11-17 \\
\end{array}$ & $\begin{array}{l}339.00 \\
323.48 \\
224.00 \\
209.00 \\
261.00 \\
222.00 \\
208.00 \\
276.00 \\
195.00 \\
146.00 \\
217.00 \\
\end{array}$ & $\begin{array}{r}184.92 \\
160.05 \\
70.26 \\
59.94 \\
75.55 \\
234.24 \\
91.59 \\
91.55 \\
49.47 \\
297.55 \\
5.76 \\
\end{array}$ & $\begin{array}{r}62.686 .63 \\
51.772 .23 \\
15.737 .61 \\
12.527 .88 \\
19.718 .55 \\
52.001 .48 \\
19.051 .22 \\
25.268 .33 \\
9.647 .10 \\
43.442 .49 \\
1.249 .40 \\
\end{array}$ & $\begin{array}{l}\text { Reforma } \\
\text { Reforma } \\
\text { Reforma } \\
\text { Reforma } \\
\text { Reforma } \\
\text { Reforma } \\
\text { Reforma } \\
\text { Reforma } \\
\text { Reforma } \\
\text { Conducaso } \\
\text { Reforma } \\
\end{array}$ \\
\hline \multicolumn{2}{|c|}{$\begin{array}{l}\text { Area Total (ha): } \\
\text { Area de Reforma (ha): }\end{array}$} & $\begin{array}{l}1,320.88 \\
1,023.33\end{array}$ & & & \multicolumn{2}{|c|}{ Produção (m3): } & $313,102.91$ \\
\hline \multirow[t]{2}{*}{ Ano 12} & Unidade & Regime & Anos de colheita & $\mathrm{m} 3 / \mathrm{ha}$ & ha & $\mathrm{m} 3$ & Refi/Cond \\
\hline & $\begin{array}{r}1 \\
9 \\
10 \\
11 \\
13 \\
14 \\
15 \\
22 \\
28 \\
28 \\
35 \\
\end{array}$ & $\begin{array}{r}162 \\
730 \\
48 \\
51 \\
1613 \\
646 \\
73 \\
544 \\
19 \\
948 \\
772 \\
\end{array}$ & $\begin{array}{r}6-12-18 \\
7-12-19 \\
2-7-12-17 \\
5-12-18 \\
6-12-17 \\
12-17 \\
4-12-17 \\
2-7-12-17 \\
1-6-12-17 \\
6-12-17 \\
5-12 \\
\end{array}$ & $\begin{array}{l}318.00 \\
277.00 \\
165.00 \\
315.00 \\
293.00 \\
519.46 \\
327.00 \\
189.00 \\
265.00 \\
265.00 \\
163.00 \\
\end{array}$ & $\begin{array}{r}118.15 \\
243.59 \\
90.61 \\
188.10 \\
90.08 \\
41.07 \\
104.69 \\
82.00 \\
16.90 \\
68.98 \\
83.66 \\
\end{array}$ & $\begin{array}{r}37.571 .70 \\
67.474 .37 \\
14.950 .70 \\
59.251 .34 \\
26.394 .32 \\
21.334 .48 \\
34.233 .63 \\
15.498 .00 \\
4.478 .87 \\
18.279 .06 \\
13.636 .73 \\
\end{array}$ & $\begin{array}{l}\text { Reforma } \\
\text { Reforma } \\
\text { Reforma } \\
\text { Conducão } \\
\text { Reforma } \\
\text { Reforma } \\
\text { Reforma } \\
\text { Reforma } \\
\text { Reforma } \\
\text { Reforma } \\
\text { Conducäo } \\
\end{array}$ \\
\hline \multicolumn{2}{|c|}{$\begin{array}{l}\text { Area Total (ha): } \\
\text { Area de Reforma (ha): }\end{array}$} & $\begin{array}{r}1,127.83 \\
856.07\end{array}$ & & & \multicolumn{2}{|c|}{ Produção (m3): } & $313,102.91$ \\
\hline Ano 13 & Unidade & Regime & Anos de colheita & $\mathrm{m} 3 / \mathrm{ha}$ & ha & m3 & Ref/Cond \\
\hline ' & $\begin{array}{l}9 \\
10 \\
11 \\
13 \\
18 \\
18 \\
19 \\
21 \\
21 \\
23 \\
24 \\
25 \\
29 \\
35\end{array}$ & $\begin{array}{r}608 \\
75 \\
173 \\
166 \\
568 \\
651 \\
384 \\
1182 \\
959 \\
1434 \\
926 \\
5622 \\
1514 \\
778\end{array}$ & $\begin{array}{r}5-13 \\
2-8-13-18 \\
6-13-18 \\
1-7-13-19 \\
2-7-13 \\
2-8-13-19 \\
3-8-13-18 \\
3-13-20 \\
3-8-13-18 \\
5-13-18 \\
3-8-13-18 \\
2-7-13-20 \\
5-13-20 \\
5-13-19\end{array}$ & $\begin{array}{l}334.00 \\
194.00 \\
315.00 \\
249.00 \\
261.00 \\
187.00 \\
233.00 \\
338.20 \\
217.00 \\
362.00 \\
203.00 \\
265.00 \\
348.00 \\
174.00\end{array}$ & $\begin{array}{r}28.10 \\
149.53 \\
27.98 \\
55.97 \\
252.49 \\
165.41 \\
146.21 \\
28.36 \\
24.44 \\
78.98 \\
145.79 \\
25.41 \\
53.77 \\
129.52\end{array}$ & $\begin{array}{r}9.384 .73 \\
29.008 .49 \\
8.813 .64 \\
13.937 .77 \\
65.899 .78 \\
30.930 .77 \\
34.067 .79 \\
9.590 .38 \\
5.303 .18 \\
28.590 .76 \\
29.595 .37 \\
6.733 .12 \\
18.710 .99 \\
22,536.10\end{array}$ & $\begin{array}{l}\text { Reforma } \\
\text { Reforma } \\
\text { Reforma } \\
\text { Reforma } \\
\text { Conducão } \\
\text { Reforma } \\
\text { Reforma } \\
\text { Reforma } \\
\text { Reforma } \\
\text { Reforma } \\
\text { Reforma } \\
\text { Reforma } \\
\text { Reforma } \\
\text { Condução }\end{array}$ \\
\hline
\end{tabular}




\begin{tabular}{|c|c|c|c|c|c|c|c|}
\hline \multicolumn{2}{|c|}{$\begin{array}{l}\text { Area Total (ha): } \\
\text { Area de Reforma (ha): }\end{array}$} & \multirow{2}{*}{$\begin{array}{r}1,311.95 \\
929.94 \\
\text { Regime }\end{array}$} & \multirow[b]{2}{*}{ Anos de colheita } & \multirow[b]{2}{*}{$\mathrm{m} 3 / \mathrm{ha}$} & \multicolumn{2}{|c|}{ Produção (m3): } & \multirow{2}{*}{$\begin{array}{l}313,102.88 \\
\text { Ref/Cond }\end{array}$} \\
\hline Ano 14 & Unidade & & & & ha & $\mathrm{m} 3$ & \\
\hline & $\begin{array}{r}4 \\
5 \\
6 \\
10 \\
17 \\
18 \\
19 \\
20 \\
21 \\
26 \\
30 \\
31 \\
32 \\
36\end{array}$ & $\begin{array}{r}116 \\
998 \\
569 \\
126 \\
387 \\
804 \\
263 \\
130 \\
1195 \\
5 \\
607 \\
210 \\
471 \\
268\end{array}$ & $\begin{array}{r}4-9-14-19 \\
3-9-14 \\
2-7-14-19 \\
2-9-14-20 \\
4-14-20 \\
2-7-14 \\
2-7-14-19 \\
1-7-14-19 \\
4-9-14-19 \\
4-9-14-20 \\
2-7-14 \\
1-9-74-19 \\
44-19 \\
7-14 \\
4\end{array}$ & $\begin{array}{l}256.00 \\
137.00 \\
277.00 \\
194.00 \\
400.77 \\
291.00 \\
308.00 \\
256.00 \\
255.00 \\
215.00 \\
173.00 \\
169.00 \\
403.77 \\
280.00\end{array}$ & $\begin{array}{r}76.99 \\
120.85 \\
51.18 \\
98.94 \\
169.30 \\
47.43 \\
77.88 \\
53.79 \\
22.20 \\
51.51 \\
110.05 \\
139.72 \\
90.82 \\
100.00\end{array}$ & $\begin{array}{r}19.710 .39 \\
16.556 .79 \\
14.177 .16 \\
19.194 .63 \\
67.848 .38 \\
13.800 .73 \\
23.986 .52 \\
13.769 .40 \\
5.661 .97 \\
11.074 .65 \\
19.038 .25 \\
23.612 .26 \\
36.671 .82 \\
28.000 .00\end{array}$ & $\begin{array}{l}\text { Reforma } \\
\text { Reforma } \\
\text { Reforma } \\
\text { Reforma } \\
\text { Reforma } \\
\text { Reforma } \\
\text { Conducão } \\
\text { Conducăo } \\
\text { Conducão } \\
\text { Conducão } \\
\text { Reforma } \\
\text { Conducão } \\
\text { Reforma } \\
\text { Conducáo }\end{array}$ \\
\hline \multicolumn{2}{|c|}{$\begin{array}{l}\text { Area Total (ha): } \\
\text { Area de Reforma (ha): }\end{array}$} & $\begin{array}{l}7,210.66 \\
765.56\end{array}$ & & & \multicolumn{2}{|c|}{ Produção (m3): } & $313,102.95$ \\
\hline \multirow[t]{2}{*}{ Ano 15} & Unidade & Regime & Anos de colheita & m3/ha & ha & $\mathrm{m} 3$ & Ref/Cond \\
\hline & $\begin{array}{r}5 \\
7 \\
8 \\
11 \\
17 \\
20 \\
25 \\
31 \\
33 \\
38 \\
38 \\
39 \\
\end{array}$ & $\begin{array}{r}945 \\
983 \\
568 \\
88 \\
294 \\
1564 \\
192 \\
433 \\
1381 \\
383 \\
353 \\
1 \\
\end{array}$ & $\begin{array}{r}3-8-15-20 \\
3-9-15 \\
3-8-15-20 \\
5-10-15-20 \\
4-9-15 \\
6-9-20 \\
1-8-15-20 \\
2-9-15 \\
5-10-9-15-20 \\
9-15-20 \\
8-15 \\
5-10-15-20 \\
\end{array}$ & $\begin{array}{l}214.00 \\
201.00 \\
187.00 \\
245.00 \\
305.00 \\
287.00 \\
294.00 \\
201.00 \\
199.00 \\
217.00 \\
238.00 \\
217.00\end{array}$ & $\begin{array}{r}18.15 \\
85.87 \\
86.10 \\
32.82 \\
304.20 \\
126.32 \\
219.50 \\
9.30 \\
52.20 \\
69.70 \\
130.30 \\
73.05 \\
\end{array}$ & $\begin{array}{r}3.883 .56 \\
17.260 .43 \\
16.100 .70 \\
8.041 .61 \\
92.782 .32 \\
36.254 .79 \\
64.533 .91 \\
1.869 .80 \\
10.387 .80 \\
15.125 .27 \\
31.010 .99 \\
15.851 .76 \\
\end{array}$ & $\begin{array}{l}\text { Condução } \\
\text { Reforma } \\
\text { Reforma } \\
\text { Reforma } \\
\text { Conducăo } \\
\text { Reforma } \\
\text { Reforma } \\
\text { Conducão } \\
\text { Conducáo } \\
\text { Reforma } \\
\text { Reforma } \\
\text { Reforma } \\
\end{array}$ \\
\hline \multicolumn{2}{|c|}{$\begin{array}{c}\text { Area Total (ha): } \\
\text { Area de Reforma (ha): }\end{array}$} & $\begin{array}{r}1,207.53 \\
823.67\end{array}$ & & & \multicolumn{2}{|c|}{ Produção (m3): } & $313,102.95$ \\
\hline \multirow[t]{2}{*}{ Ano 16} & Unidade & Regime & Anos de colheita & $\mathrm{m} 3 / \mathrm{ha}$ & ha & $\mathrm{m} 3$ & Ref/Cond \\
\hline & $\begin{array}{r}2 \\
6 \\
7 \\
12 \\
28 \\
29 \\
32 \\
\end{array}$ & $\begin{array}{r}1299 \\
280 \\
1247 \\
582 \\
1 \\
1060 \\
345 \\
\end{array}$ & $\begin{array}{r}4-16 \\
1-11-16 \\
4-11-16 \\
10-16 \\
1-6-11-16 \\
3-9-16 \\
8-16 \\
\end{array}$ & $\begin{array}{l}321.31 \\
209.00 \\
169.00 \\
274.00 \\
222.00 \\
276.00 \\
334.00 \\
\end{array}$ & $\begin{array}{r}35.45 \\
160.05 \\
70.26 \\
437.48 \\
234.24 \\
266.81 \\
32.58 \\
\end{array}$ & $\begin{array}{r}11.390 .67 \\
33.450 .22 \\
11.873 .47 \\
119.868 .34 \\
52.001 .48 \\
73.638 .21 \\
10.880 .52 \\
\end{array}$ & $\begin{array}{l}\text { Reforma } \\
\text { Reforma } \\
\text { Reforma } \\
\text { Conducāo } \\
\text { Reforma } \\
\text { Reforma } \\
\text { Reforma } \\
\end{array}$ \\
\hline \multicolumn{2}{|c|}{$\begin{array}{l}\text { Area Total (ha): } \\
\text { Area de Reforma (ha): }\end{array}$} & $\begin{array}{l}1,236.86 \\
799.38\end{array}$ & & & \multicolumn{2}{|c|}{ Produção (m3): } & $313,102.91$ \\
\hline \multirow[t]{2}{*}{ Ano 17} & Unidade & Regime & Anos de colheita & m3/ha & ha & $\mathrm{m} 3$ & Ref/Cond \\
\hline & $\begin{array}{r}2 \\
4 \\
10 \\
12 \\
13 \\
14 \\
15 \\
22 \\
25 \\
28 \\
28 \\
29 \\
35 \\
39 \\
\end{array}$ & $\begin{array}{r}1319 \\
59 \\
48 \\
595 \\
1613 \\
646 \\
73 \\
544 \\
582 \\
19 \\
948 \\
69 \\
758 \\
140 \\
\end{array}$ & $\begin{array}{r}4-9-17 \\
4-11-17 \\
2-7-12-17 \\
10-17 \\
6-12-17 \\
12-17 \\
4-12-17 \\
2-7-12-17 \\
2-7-17 \\
1-6-12-17 \\
6-12-17 \\
1-6-11-17 \\
5-11-17 \\
6-11-17 \\
\end{array}$ & $\begin{array}{l}275.00 \\
305.00 \\
194.00 \\
259.00 \\
246.00 \\
303.00 \\
230.00 \\
189.00 \\
349.42 \\
222.00 \\
222.00 \\
292.00 \\
139.00 \\
255.00\end{array}$ & $\begin{array}{r}3.88 \\
184.92 \\
90.61 \\
229.61 \\
90.08 \\
41.07 \\
104.69 \\
82.00 \\
45.13 \\
16.90 \\
68.98 \\
91.59 \\
297.55 \\
5.76 \\
\end{array}$ & $\begin{array}{r}1.066 .78 \\
56.399 .47 \\
17.578 .40 \\
59.470 .10 \\
22.160 .42 \\
12.444 .21 \\
24.078 .70 \\
15.498 .00 \\
15.768 .87 \\
3.752 .11 \\
15.313 .03 \\
26.74 .98 \\
41.359 .63 \\
1.468 .19 \\
\end{array}$ & $\begin{array}{l}\text { Reforma } \\
\text { Conducão } \\
\text { Conducão } \\
\text { Reforma } \\
\text { Reforma } \\
\text { Conducąo } \\
\text { Reforma } \\
\text { Reforma } \\
\text { Conducão } \\
\text { Conducão } \\
\text { Reforma } \\
\text { Conducẫo } \\
\text { Reforma } \\
\text { Reforma }\end{array}$ \\
\hline \multicolumn{2}{|c|}{$\begin{array}{l}\text { Area Total (ha): } \\
\text { Area de Reforma (ha): }\end{array}$} & $\begin{array}{l}1,352.77 \\
882.55\end{array}$ & & & \multicolumn{2}{|c|}{ Produção (m3) : } & $313,102.89$ \\
\hline \multirow[t]{2}{*}{ Ano 18} & Unidade & Regime & Anos de colheita & $\mathrm{m} 3 / \mathrm{ha}$ & ha & $\mathrm{m} 3$ & Ref/Cond \\
\hline & $\begin{array}{l}1 \\
10 \\
11 \\
11 \\
11 \\
19 \\
21 \\
23 \\
24 \\
27 \\
29 \\
30 \\
34 \\
\end{array}$ & $\begin{array}{r}162 \\
75 \\
51 \\
9 \\
93 \\
173 \\
384 \\
959 \\
1434 \\
926 \\
329 \\
1176 \\
896 \\
855 \\
\end{array}$ & $\begin{array}{r}6-12-18 \\
2-8-13-18 \\
5-12-18 \\
5-10-18 \\
6-13-18 \\
3-8-13-18 \\
3-8-13-18 \\
5-13-18 \\
3-8-13-18 \\
6-11-18 \\
3-8-18 \\
2-11-18 \\
5-10-18 \\
\end{array}$ & $\begin{array}{l}318.00 \\
194.00 \\
243.00 \\
334.00 \\
245.00 \\
233.00 \\
255.00 \\
255.00 \\
203.00 \\
336.00 \\
386.21 \\
204.00 \\
240.00 \\
\end{array}$ & $\begin{array}{r}118.15 \\
149.53 \\
188.10 \\
11.14 \\
27.98 \\
146.21 \\
24.44 \\
78.98 \\
145.79 \\
75.55 \\
148.95 \\
49.47 \\
30.00 \\
\end{array}$ & $\begin{array}{r}37.571 .70 \\
29.008 .49 \\
45.708 .18 \\
3.720 .03 \\
6.855 .05 \\
34.067 .79 \\
6.231 .84 \\
20.139 .90 \\
29.595 .37 \\
25.384 .80 \\
57.527 .44 \\
10.092 .35 \\
7.200 .00 \\
\end{array}$ & $\begin{array}{l}\text { Conduçá } \\
\text { Conducaao } \\
\text { Reforma } \\
\text { Reforma } \\
\text { Reforma } \\
\text { Conducão } \\
\text { Conducáo } \\
\text { Conducáo } \\
\text { Reforma } \\
\text { Reforma } \\
\text { Reforma } \\
\text { Reforma } \\
\text { Conducão } \\
\end{array}$ \\
\hline \multicolumn{2}{|c|}{$\begin{array}{l}\text { Area Total (ha): } \\
\text { Area de Reforma (ha): }\end{array}$} & $\begin{array}{l}1,194.29 \\
646.98\end{array}$ & & & Proc & $\frac{r, 2000}{(\mathrm{~m} 3)}:$ & $313,102.94$ \\
\hline \multirow[t]{2}{*}{ Ano 19} & Unidade & Regime & Anos de colheita & $\mathrm{m} 3 / \mathrm{ha}$ & ha & $\mathrm{m} 3$ & Ref/Cond \\
\hline & $\begin{array}{r}4 \\
6 \\
9 \\
9 \\
93 \\
13 \\
18 \\
19 \\
19 \\
20 \\
21 \\
31 \\
32 \\
35 \\
\end{array}$ & $\begin{array}{r}116 \\
569 \\
730 \\
577 \\
166 \\
651 \\
263 \\
411 \\
130 \\
1195 \\
210 \\
471 \\
778\end{array}$ & $\begin{array}{r}4-9-14-19 \\
2-7-14-19 \\
7-12-19 \\
5-10-19 \\
1-7-13-19 \\
2-8-13-19 \\
2-7-14-19 \\
3-8-19 \\
1-7-14-19 \\
4-9-14-19 \\
1-9-14-19 \\
14-19 \\
5-13-19 \\
\end{array}$ & $\begin{array}{l}256.00 \\
209.00 \\
367.00 \\
411.00 \\
293.00 \\
261.00 \\
198.00 \\
377.45 \\
164.00 \\
217.00 \\
141.00 \\
245.00 \\
139.00 \\
\end{array}$ & $\begin{array}{r}76.99 \\
51.18 \\
243.59 \\
97.76 \\
55.97 \\
165.41 \\
77.88 \\
12.01 \\
53.79 \\
22.20 \\
139.72 \\
90.82 \\
129.52 \\
\end{array}$ & $\begin{array}{r}19.710 .39 \\
10.696 .85 \\
89.397 .46 \\
40.180 .26 \\
16.400 .67 \\
43.170 .76 \\
15.419 .90 \\
4.532 .46 \\
8.821 .02 \\
4.818 .22 \\
19.700 .17 \\
22.251 .78 \\
18.002 .98 \\
\end{array}$ & $\begin{array}{l}\text { Reforma } \\
\text { Reforma } \\
\text { Conducáo } \\
\text { Reforma } \\
\text { Conduca } \\
\text { Reforma } \\
\text { Reforma } \\
\text { Conducáo } \\
\text { Reforma } \\
\text { Reforma } \\
\text { Reforma } \\
\text { Reforma } \\
\text { Reforma }\end{array}$ \\
\hline \multicolumn{2}{|c|}{$\begin{array}{l}\text { Area Total (ha): } \\
\text { Area de Reforma (ha): }\end{array}$} & $\begin{array}{l}1,216.84 \\
905.27\end{array}$ & & & Proc & $\frac{18,002.98}{(\mathrm{~m} 3):}$ & $313,102.92$ \\
\hline \multirow[t]{2}{*}{ Ano 20} & Unidade & Regime & Anos de colheita & m3/ha & ha & m3 & Ref/Cond \\
\hline & $\begin{array}{l}5 \\
8\end{array}$ & $\begin{array}{l}945 \\
568\end{array}$ & $\begin{array}{l}3-8-15-20 \\
3-8-15-20\end{array}$ & $\begin{array}{l}137.00 \\
169.00\end{array}$ & $\begin{array}{l}18.15 \\
86.10\end{array}$ & $\begin{array}{r}2.486 .21 \\
14,550.90\end{array}$ & $\begin{array}{l}\text { Reforma } \\
\text { Reforma }\end{array}$ \\
\hline
\end{tabular}




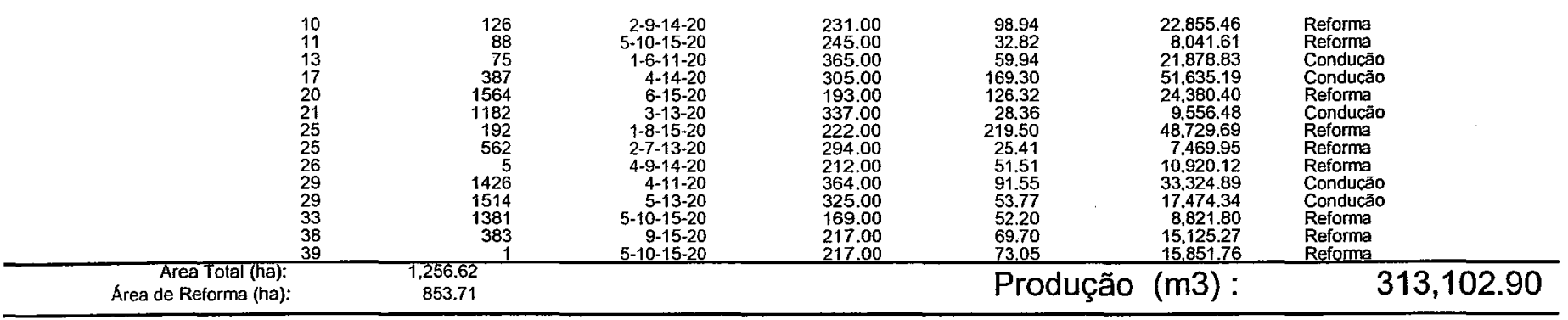




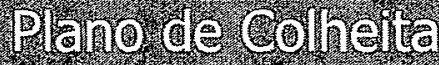
Ano 1

Unidate

2.

Anos de colheila

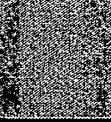

9.1.1.

m

$\mathrm{m} 3 / \mathrm{ha}$

ha $\mathrm{m3}$

Ref/Cond

\begin{tabular}{|c|c|c|c|c|c|c|c|}
\hline & $\begin{array}{r}2 \\
2 \\
22 \\
23 \\
23 \\
24 \\
28 \\
31 \\
31 \\
35 \\
35 \\
35 \\
\end{array}$ & $\begin{array}{r}256 \\
279 \\
463 \\
195 \\
193 \\
195 \\
118 \\
178 \\
217 \\
207 \\
174 \\
175 \\
\end{array}$ & $\begin{array}{r}1-9 \\
1-10 \\
1-8-15 \\
1-8-15 \\
1-8-15 \\
1-8-15 \\
1-13-15 \\
1-7-13-19 \\
1-8-15 \\
1-9-16 \\
1-9.16 \\
1-8-15 \\
1-8-16 \\
\end{array}$ & $\begin{array}{l}288.00 \\
288.00 \\
268.00 \\
338.00 \\
338.00 \\
288.00 \\
431.00 \\
340.00 \\
340.00 \\
225.66 \\
225.66 \\
225.66 \\
\end{array}$ & $\begin{array}{r}12.72 \\
17.42 \\
22.33 \\
37.69 \\
41.29 \\
145.79 \\
320.12 \\
112.14 \\
36.88 \\
290.19 \\
131.02 \\
1.42 \\
\end{array}$ & $\begin{array}{r}3.663 .91 \\
5.018 .31 \\
5.983 .56 \\
12.739 .15 \\
13.956 .09 \\
41.987 .52 \\
137.971 .72 \\
38.127 .74 \\
12.539 .06 \\
65.483 .68 \\
29.566 .80 \\
320.28 \\
\end{array}$ & $\begin{array}{l}\text { Reforma } \\
\text { Reforma } \\
\text { Condučão } \\
\text { Reforma } \\
\text { Reforma } \\
\text { Reforma } \\
\text { Reforma } \\
\text { Reforma } \\
\text { Reforma } \\
\text { Reforma } \\
\text { Reforma } \\
\text { Reforma } \\
\end{array}$ \\
\hline \multicolumn{2}{|c|}{$\begin{array}{l}\text { Area Total (ha): } \\
\text { Area de Reforma (ha): }\end{array}$} & $\begin{array}{l}1,169.02 \\
1,146.69\end{array}$ & & & \multicolumn{2}{|c|}{ Produção (m3): } & $367,357.81$ \\
\hline \multirow[t]{2}{*}{ Ano 2} & Unidade & Regime & Anos de colheita & $\mathrm{m} 3 / \mathrm{ha}$ & ha & $\mathrm{m} 3$ & Ref/Cond \\
\hline & $\begin{array}{r}2 \\
6 \\
13 \\
18 \\
20 \\
29 \\
29 \\
35 \\
\end{array}$ & $\begin{array}{l}721 \\
677 \\
660 \\
630 \\
677 \\
660 \\
662 \\
431 \\
\end{array}$ & $\begin{array}{r}2-10 \\
2-9-16 \\
2-8-14-19 \\
2-8-14-20 \\
2-9-16 \\
2-8-14-19 \\
2-8-14-20 \\
2-10-17 \\
\end{array}$ & $\begin{array}{l}300.20 \\
277.00 \\
326.00 \\
291.00 \\
256.00 \\
292.00 \\
292.00 \\
227.88 \\
\end{array}$ & $\begin{array}{r}9.18 \\
211.23 \\
206.00 \\
465.32 \\
111.25 \\
65.77 \\
122.48 \\
88.10 \\
\end{array}$ & $\begin{array}{r}2.756 .84 \\
58.510 .71 \\
67.156 .00 \\
135.408 .12 \\
28.481 .18 \\
19.204 .37 \\
35.765 .30 \\
20.075 .29 \\
\end{array}$ & $\begin{array}{l}\text { Reforma } \\
\text { Reforma } \\
\text { Reforma } \\
\text { Reforma } \\
\text { Reforma } \\
\text { Reforma } \\
\text { Reforma } \\
\text { Reforma } \\
\end{array}$ \\
\hline \multicolumn{2}{|c|}{$\begin{array}{c}\text { Area Total (ha): } \\
\text { Area de Reforma (ha): } \\
\end{array}$} & $\begin{array}{l}1,279.34 \\
1,279.34\end{array}$ & & & \multicolumn{2}{|c|}{ Produção (m3): } & $367,357.81$ \\
\hline \multirow[t]{2}{*}{ Ano 3} & Unidade & Regime & Anos de colheita & $\mathrm{m} 3 / \mathrm{ha}$ & ha & m3 & Ref/Cond \\
\hline & $\begin{array}{r}5 \\
7 \\
7 \\
20 \\
21 \\
22 \\
25 \\
25 \\
25 \\
25 \\
29 \\
30 \\
\end{array}$ & $\begin{array}{r}1047 \\
1148 \\
1026 \\
1014 \\
986 \\
1047 \\
1014 \\
1012 \\
982 \\
986 \\
1038 \\
1148 \\
\end{array}$ & $\begin{array}{r}3-11 \\
3-10-17 \\
3-10-17 \\
3-10-17 \\
3-9-16 \\
3-11 \\
3-10-17 \\
3-10-16 \\
3-9-15-20 \\
3-9-16 \\
3-9-15-20 \\
3-10-17 \\
\end{array}$ & $\begin{array}{l}229.00 \\
240.00 \\
240.00 \\
274.00 \\
337.00 \\
295.91 \\
294.00 \\
294.00 \\
294.00 \\
294.00 \\
325.00 \\
229.00 \\
\end{array}$ & $\begin{array}{r}107.55 \\
30.79 \\
125.34 \\
68.86 \\
75.00 \\
55.67 \\
8.92 \\
55.77 \\
162.73 \\
60.62 \\
464.42 \\
31.66 \\
\end{array}$ & $\begin{array}{r}24.629 .77 \\
7.388 .88 \\
30.082 .32 \\
18.866 .38 \\
25.275 .00 \\
17.657 .69 \\
2.621 .80 \\
16.984 .47 \\
47.843 .56 \\
17.821 .93 \\
150.935 .75 \\
7.250 .28 \\
\end{array}$ & $\begin{array}{l}\text { Reforma } \\
\text { Conducão } \\
\text { Reforma } \\
\text { Reforma } \\
\text { Reforma } \\
\text { Reforma } \\
\text { Reforma } \\
\text { Reforma } \\
\text { Reforma } \\
\text { Reforma } \\
\text { Reforma } \\
\text { Conducão }\end{array}$ \\
\hline \multicolumn{2}{|c|}{$\begin{array}{l}\text { Area Total (ha): } \\
\text { Area de Reforma (ha): }\end{array}$} & $\begin{array}{l}1,253.33 \\
1,190.88\end{array}$ & & & \multicolumn{2}{|c|}{ Produção (m3): } & $367,357.84$ \\
\hline \multirow[t]{2}{*}{ Ano 4} & Unidade & Regime & Anos de colheita & $\mathrm{m} 3 / \mathrm{ha}$ & ha & $\mathrm{m} 3$ & Ref/Cond \\
\hline & $\begin{array}{r}9 \\
9 \\
10 \\
10 \\
10 \\
10 \\
17 \\
19 \\
19 \\
30 \\
33 \\
33 \\
\end{array}$ & $\begin{array}{r}319 \\
323 \\
717 \\
706 \\
687 \\
708 \\
319 \\
686 \\
685 \\
1277 \\
1277 \\
1263 \\
\end{array}$ & $\begin{array}{r}4-10-15-20 \\
4-10-16 \\
4-11-18 \\
4-11-17 \\
4-10-17 \\
4-11-18 \\
4-10-15-20 \\
4-10-16 \\
4-10-16 \\
4-12 \\
4-12 \\
4-11 \\
\end{array}$ & $\begin{array}{l}330.00 \\
330.00 \\
257.00 \\
257.00 \\
257.00 \\
257.00 \\
305.00 \\
308.00 \\
308.00 \\
242.48 \\
283.00 \\
283.00 \\
\end{array}$ & $\begin{array}{r}96.85 \\
272.60 \\
24.48 \\
93.75 \\
77.12 \\
143.73 \\
130.50 \\
127.41 \\
108.69 \\
127.86 \\
19.75 \\
32.45 \\
\end{array}$ & $\begin{array}{r}31.961 .06 \\
89.957 .44 \\
6.292 .34 \\
24.093 .65 \\
19.819 .35 \\
36.938 .25 \\
39.801 .25 \\
39.242 .34 \\
33.476 .46 \\
31.003 .09 \\
5.588 .77 \\
9.183 .83 \\
\end{array}$ & $\begin{array}{l}\text { Reforma } \\
\text { Reforma } \\
\text { Reforma } \\
\text { Reforma } \\
\text { Reforma } \\
\text { Reforma } \\
\text { Reforma } \\
\text { Reforma } \\
\text { Reforma } \\
\text { Reforma } \\
\text { Reforma } \\
\text { Reforma } \\
\end{array}$ \\
\hline \multicolumn{2}{|c|}{$\begin{array}{l}\text { Area Total (ha): } \\
\text { Area de Reforma (ha): }\end{array}$} & $\begin{array}{l}1,255.19 \\
1,255.19\end{array}$ & & & \multicolumn{2}{|c|}{ Produção (m3): } & $367,357.82$ \\
\hline \multirow[t]{2}{*}{ Ano 5} & Unidade & Regime & Anos de colheita & $\mathrm{m} 3 / \mathrm{ha}$ & ha & m3 & Ref/Cond \\
\hline & $\begin{array}{r}4 \\
5 \\
8 \\
12 \\
12 \\
17 \\
17 \\
\end{array}$ & $\begin{array}{r}214 \\
1443 \\
859 \\
230 \\
213 \\
506 \\
505 \\
\end{array}$ & $\begin{array}{r}5-11-17 \\
5-13 \\
5-13 \\
5-12-18 \\
5-11-17 \\
5-11-17 \\
5-11-17 \\
\end{array}$ & $\begin{array}{l}305.00 \\
253.64 \\
220.38 \\
274.00 \\
274.00 \\
339.00 \\
339.00 \\
\end{array}$ & $\begin{array}{r}261.91 \\
31.45 \\
86.10 \\
284.31 \\
242.14 \\
85.87 \\
257.14 \\
\end{array}$ & $\begin{array}{r}79.882 .55 \\
7.976 .02 \\
18.974 .90 \\
77.900 .61 \\
66.345 .35 \\
29.109 .22 \\
87.169 .17 \\
\end{array}$ & $\begin{array}{l}\text { Reforma } \\
\text { Reforma } \\
\text { Reforma } \\
\text { Reforma } \\
\text { Reforma } \\
\text { Reforma } \\
\text { Reforma } \\
\end{array}$ \\
\hline \multicolumn{2}{|c|}{$\begin{array}{l}\text { Area Total'(ha): } \\
\text { Area de Reforma (ha): }\end{array}$} & $\begin{array}{l}1,248.91 \\
1,248.91\end{array}$ & & & \multicolumn{2}{|c|}{ Produção (m3): } & $367,357.83$ \\
\hline \multirow[t]{2}{*}{ Ano 6} & Unidade & Regime & Anos de colheita & $\mathrm{m} 3 / \mathrm{ha}$ & ha & $\mathrm{m} 3$ & Ref/Cond \\
\hline & $\begin{array}{c}1 \\
3 \\
11 \\
11 \\
12 \\
14 \\
15 \\
16 \\
27 \\
27 \\
38 \\
39 \\
\end{array}$ & $\begin{array}{l}161 \\
161 \\
161 \\
162 \\
344 \\
376 \\
244 \\
358 \\
366 \\
368 \\
157 \\
157\end{array}$ & $\begin{array}{r}6-12-18 \\
6-12-18 \\
6-12-18 \\
6-12-18 \\
6-12-18 \\
6-13 \\
6-14 \\
6-13-14 \\
6-19 \\
6-13 \\
6-14 \\
6-12-18 \\
6-12-18 \\
\end{array}$ & $\begin{array}{l}318.00 \\
305.00 \\
286.00 \\
286.00 \\
305.00 \\
401.00 \\
259.00 \\
260.00 \\
336.00 \\
336.00 \\
255.00 \\
255.00 \\
\end{array}$ & $\begin{array}{r}118.15 \\
19.94 \\
161.86 \\
98.18 \\
140.64 \\
41.07 \\
91.72 \\
193.10 \\
55.24 \\
20.31 \\
155.37 \\
200.00 \\
\end{array}$ & $\begin{array}{r}37.571 .70 \\
6.081 .58 \\
46.293 .22 \\
28.078 .22 \\
42.896 .69 \\
16.469 .07 \\
23.756 .46 \\
50.206 .00 \\
18.560 .64 \\
6.824 .16 \\
39.620 .06 \\
51.000 .00 \\
\end{array}$ & $\begin{array}{l}\text { Reforma } \\
\text { Reforma } \\
\text { Reforma } \\
\text { Reforma } \\
\text { Reforma } \\
\text { Reforma } \\
\text { Reforma } \\
\text { Reforma } \\
\text { Reforma } \\
\text { Reforma } \\
\text { Reforma } \\
\text { Reforma } \\
\end{array}$ \\
\hline \multicolumn{2}{|c|}{$\begin{array}{l}\text { Area Total (ha): } \\
\text { Area de Reforma (ha): }\end{array}$} & $\begin{array}{l}1,295.59 \\
1,295.59\end{array}$ & & & \multicolumn{2}{|c|}{ Produção (m3): } & $367,357.81$ \\
\hline Ano 7 & Unidade & Regime & Anos de colheita & $\mathrm{m} 3 / \mathrm{ha}$ & ha & m3 & Ref/Cond \\
\hline & $\begin{array}{r}3 \\
3 \\
15 \\
15 \\
28 \\
32 \\
32 \\
36 \\
37\end{array}$ & $\begin{array}{l}262 \\
263 \\
290 \\
298 \\
118 \\
278 \\
275 \\
264 \\
254\end{array}$ & $\begin{array}{r}7-13-19 \\
7-13-19 \\
7-14 \\
7-15 \\
1-7-13-19 \\
7-14 \\
7-14 \\
7-14 \\
7-13-19 \\
7\end{array}$ & $\begin{array}{l}339.00 \\
339.00 \\
277.00 \\
277.00 \\
265.00 \\
315.00 \\
315.00 \\
280.00 \\
280.00\end{array}$ & $\begin{array}{r}44.88 \\
309.78 \\
10.19 \\
2.78 \\
320.12 \\
45.35 \\
78.05 \\
100.00 \\
200.00\end{array}$ & $\begin{array}{r}15.213 .85 \\
105.016 .03 \\
2.822 .74 \\
768.90 \\
84.831 .80 \\
14.286 .07 \\
24.584 .93 \\
28.000 .00 \\
56.000 .00\end{array}$ & $\begin{array}{l}\text { Reforma } \\
\text { Reforma } \\
\text { Reforma } \\
\text { Reforma } \\
\text { Reforma } \\
\text { Reforma } \\
\text { Reforma } \\
\text { Reforma } \\
\text { Reforma }\end{array}$ \\
\hline
\end{tabular}




\begin{tabular}{|c|c|c|c|c|c|c|c|}
\hline & $\begin{array}{l}38 \\
38 \\
40\end{array}$ & $\begin{array}{l}254 \\
295 \\
264\end{array}$ & $\begin{array}{r}7-13-19 \\
7-13-199 \\
7-14\end{array}$ & $\begin{array}{l}280.00 \\
280.00 \\
280.00\end{array}$ & $\begin{array}{l}14.99 \\
29.64 \\
83.35\end{array}$ & $\begin{array}{r}4.196 .84 \\
8.298 .81 \\
23.337 .89 \\
23.37\end{array}$ & $\begin{array}{l}\text { Reforma } \\
\text { Conducáo } \\
\text { Reforma }\end{array}$ \\
\hline \multicolumn{2}{|c|}{$\begin{array}{l}\text { Area Tolal (ha): } \\
\text { Area de Reforma (ha): }\end{array}$} & $\begin{array}{l}1,239.12 \\
1,209.48\end{array}$ & & & \multicolumn{2}{|c|}{ Produção (m3): } & $367,357.84$ \\
\hline \multirow[t]{2}{*}{ Ano 8} & Unidade & Regime & Anos de collheita & $\mathrm{m} 3 / \mathrm{ha}$ & ha & $\mathrm{m} 3$ & Ref/Cond \\
\hline & $\begin{array}{l}13 \\
13 \\
22 \\
23 \\
23 \\
24 \\
29 \\
29 \\
31 \\
34 \\
35 \\
35 \\
40 \\
\end{array}$ & $\begin{array}{r}660 \\
630 \\
463 \\
195 \\
193 \\
195 \\
662 \\
660 \\
178 \\
1781 \\
175 \\
174 \\
330 \\
\end{array}$ & $\begin{array}{r}2-8-14-19 \\
2-8-14-20 \\
1-8-15 \\
1-8-15 \\
1-8-15 \\
1-8-15 \\
2-8-14-15 \\
2-8-14-20 \\
1-8-19 \\
1-8 \\
1-8-16 \\
1-8-15 \\
8-15 \\
\end{array}$ & $\begin{array}{l}293.00 \\
261.00 \\
212.00 \\
338.00 \\
338.00 \\
269.00 \\
292.00 \\
292.00 \\
224.00 \\
275.53 \\
163.00 \\
163.00 \\
298.00 \\
\end{array}$ & $\begin{array}{r}206.00 \\
465.32 \\
22.33 \\
37.69 \\
41.29 \\
145.79 \\
122.48 \\
65.77 \\
112.14 \\
30.00 \\
1.42 \\
131.02 \\
16.65 \\
\end{array}$ & $\begin{array}{r}60.358 .00 \\
121.448 .52 \\
4.733 .26 \\
12.739 .15 \\
13.956 .09 \\
39.217 .51 \\
35.765 .30 \\
19.204 .37 \\
25.119 .45 \\
8.265 .93 \\
231.35 \\
21.357 .04 \\
4.961 .82 \\
\end{array}$ & $\begin{array}{l}\text { Reforma } \\
\text { Reforma } \\
\text { Reforma } \\
\text { Reforma } \\
\text { Reforma } \\
\text { Reforma } \\
\text { Reforma } \\
\text { Reforma } \\
\text { Reforma } \\
\text { Reforma } \\
\text { Conducáo } \\
\text { Conducáo } \\
\text { Reforma }\end{array}$ \\
\hline \multicolumn{2}{|c|}{$\begin{array}{l}\text { Area Tolal (ha): } \\
\text { Avea de Reforma (ha): }\end{array}$} & $\begin{array}{l}1,397.90 \\
1,265.46\end{array}$ & & & \multicolumn{2}{|c|}{ Produção (m3): } & $367,357.79$ \\
\hline \multirow[t]{2}{*}{ Ano 9} & Unidade & Regime & Anos de colheita & $\mathrm{m} 3 / \mathrm{ha}$ & ha & $m 3$ & Ref/Cond \\
\hline & $\begin{array}{r}2 \\
6 \\
20 \\
21 \\
25 \\
25 \\
29 \\
31 \\
35 \\
\end{array}$ & $\begin{array}{c}256 \\
677 \\
677 \\
986 \\
986 \\
982 \\
1038 \\
217 \\
207 \\
\end{array}$ & $\begin{array}{r}1-9 \\
2-9.16 \\
2-9.16 \\
3-9.16 \\
3-9.16 \\
3-9-9.16 \\
3-9.15-20 \\
3-9 .-20 \\
1-9.16 \\
1-9.16 \\
\end{array}$ & $\begin{array}{l}275.00 \\
277.00 \\
256.00 \\
303.00 \\
265.00 \\
265.00 \\
292.00 \\
240.00 \\
174.00 \\
\end{array}$ & $\begin{array}{r}12.72 \\
211.23 \\
111.25 \\
75.00 \\
60.62 \\
162.73 \\
464.42 \\
36.88 \\
290.19 \\
290.19\end{array}$ & 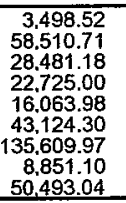 & $\begin{array}{l}\text { Conducāo } \\
\text { Refioma } \\
\text { Reforma } \\
\text { Reforma } \\
\text { Reforma } \\
\text { Reforma } \\
\text { Reforma } \\
\text { Reforma } \\
\text { Conducăo }\end{array}$ \\
\hline \multicolumn{2}{|c|}{$\begin{array}{l}\text { Area Total (ha): } \\
\text { Area de Reforma (ha): }\end{array}$} & $\begin{array}{l}1,425.05 \\
1,122.13 \\
\end{array}$ & & & \multicolumn{2}{|c|}{ Produção (m3): } & $367,357.80$ \\
\hline \multirow[t]{2}{*}{ Ano 10} & Unidade & Regime & Anos de colheilta & $\mathrm{m} 3 / \mathrm{ha}$ & ha & $\mathrm{m3}$ & Ref/Cond \\
\hline & $\begin{array}{r}2 \\
2 \\
7 \\
7 \\
9 \\
9 \\
10 \\
17 \\
19 \\
19 \\
20 \\
25 \\
25 \\
26 \\
30 \\
35 \\
\end{array}$ & $\begin{array}{r}721 \\
279 \\
1026 \\
1148 \\
323 \\
319 \\
687 \\
319 \\
685 \\
686 \\
1014 \\
1014 \\
1012 \\
591 \\
1148 \\
431 \\
\end{array}$ & $\begin{array}{r}2-10 \\
1-10 \\
3-10.17 \\
3-10-17 \\
4-10-16 \\
4-10-15-20 \\
4-10-17 \\
4-10-15-17 \\
4-10-16 \\
4-10-16 \\
3-10-16 \\
3-10-17 \\
3-10-17 \\
3-10-16 \\
3-10-10 \\
2-10-17 \\
2-10-17 \\
\end{array}$ & $\begin{array}{l}275.00 \\
288.00 \\
224.00 \\
190.00 \\
330.00 \\
330.00 \\
231.00 \\
305.00 \\
277.00 \\
277.00 \\
256.00 \\
294.00 \\
294.00 \\
444.86 \\
173.00 \\
174.00 \\
\end{array}$ & $\begin{array}{r}9.18 \\
17.42 \\
125.34 \\
30.79 \\
272.60 \\
96.85 \\
77.12 \\
130.50 \\
108.69 \\
127.41 \\
68.86 \\
8.92 \\
57.77 \\
51.51 \\
31.66 \\
88.10 \\
\end{array}$ & $\begin{array}{r}2.525 .44 \\
5.018 .31 \\
28.076 .83 \\
5.849 .83 \\
89.957 .44 \\
31.961 .06 \\
17.814 .28 \\
39.801 .25 \\
30.107 .07 \\
35.292 .63 \\
17.626 .98 \\
2.621 .80 \\
16.984 .47 \\
22.914 .77 \\
5.477 .28 \\
15.328 .70 \\
15.32 .70 \\
\end{array}$ & 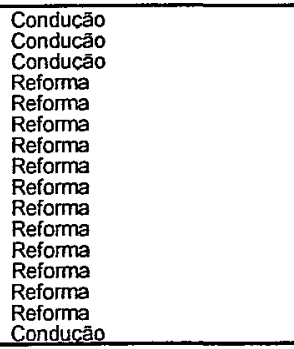 \\
\hline \multicolumn{2}{|c|}{$\begin{array}{l}\text { Area Total (ha): } \\
\text { Area de Reforma (ha): }\end{array}$} & $\begin{array}{l}1,302.71 \\
1,062.66 \\
\end{array}$ & & & \multicolumn{2}{|c|}{ Produção (m3) : } & $367,357.85$ \\
\hline \multirow[t]{2}{*}{ Ano 11} & Unidade & Regime & Anos de colhelita & $\mathrm{m} 3 / \mathrm{ha}$ & ha & $\mathrm{m} 3$ & RefiCond \\
\hline & $\begin{array}{l}4 \\
5 \\
10 \\
10 \\
10 \\
12 \\
17 \\
17 \\
22 \\
33 \\
\end{array}$ & $\begin{array}{c}214 \\
1047 \\
708 \\
706 \\
717 \\
213 \\
506 \\
505 \\
1047 \\
1263 \\
\end{array}$ & $\begin{array}{r}5-11-17 \\
3-11 \\
4-11-18 \\
4-11-17 \\
4-11-18 \\
5-11-17 \\
5-11-17 \\
5-11-17 \\
3-11 \\
4-11 \\
\end{array}$ & $\begin{array}{l}305.00 \\
229.00 \\
257.00 \\
257.00 \\
257.00 \\
274.00 \\
235.00 \\
305.00 \\
268.00 \\
264.00 \\
264\end{array}$ & $\begin{array}{r}261.91 \\
107.55 \\
143.73 \\
93.75 \\
24.48 \\
242.14 \\
85.87 \\
257.14 \\
59.67 \\
32.45 \\
\end{array}$ & $\begin{array}{l}79.882 .55 \\
24.629 .77 \\
36.938 .25 \\
24.093 .65 \\
6.292 .34 \\
66.345 .35 \\
26.189 .71 \\
78.426 .54 \\
15.992 .44 \\
8.567 .25 \\
\end{array}$ & $\begin{array}{l}\text { Reforma } \\
\text { Conducáo } \\
\text { Reforma } \\
\text { Reforma } \\
\text { Conducáo } \\
\text { Reforma } \\
\text { Reforma } \\
\text { Reforma } \\
\text { Conducáa } \\
\text { Conducăa } \\
\end{array}$ \\
\hline \multicolumn{2}{|c|}{$\begin{array}{l}\text { Area Total (ha): } \\
\text { Area de Reforma (ha): }\end{array}$} & $\begin{array}{l}1,308.69 \\
1,084.53\end{array}$ & & & \multicolumn{2}{|c|}{ Produção (m3): } & $367,357.85$ \\
\hline \multirow[t]{2}{*}{ Ano 12} & Unidade & Regime & Anos de colhelta & $\mathrm{m} 3 \mathrm{ha}$ & ha & $\mathrm{m} 3$ & Ref/Cond \\
\hline & $\begin{array}{r}1 \\
3 \\
11 \\
11 \\
12 \\
12 \\
30 \\
33 \\
38 \\
39 \\
\end{array}$ & $\begin{array}{c}161 \\
161 \\
162 \\
161 \\
230 \\
344 \\
1277 \\
1277 \\
157 \\
157\end{array}$ & $\begin{array}{r}6-12-18 \\
6-12-18 \\
6-12-18 \\
6-12-18 \\
5-12-18 \\
6-12-18 \\
4-12 \\
4-12 \\
4-12-18 \\
6-12-18\end{array}$ & $\begin{array}{l}318.00 \\
305.00 \\
286.00 \\
286.00 \\
335.00 \\
274.00 \\
218.00 \\
283.00 \\
255.00 \\
255.00 \\
255\end{array}$ & $\begin{array}{r}118.15 \\
19.94 \\
98.18 \\
161.86 \\
284.31 \\
140.64 \\
127.86 \\
19.75 \\
155.37 \\
200.00\end{array}$ & $\begin{array}{l}37.571 .70 \\
6.081 .58 \\
28.078 .22 \\
46.293 .22 \\
86.714 .19 \\
38.536 .70 \\
27.873 .35 \\
5.588 .77 \\
39.620 .06 \\
51.000 .00\end{array}$ & $\begin{array}{l}\text { Reforma } \\
\text { Reforma } \\
\text { Reforma } \\
\text { Reforma } \\
\text { Reforma } \\
\text { Reforma } \\
\text { Conducaco } \\
\text { Conducao } \\
\text { Reforma } \\
\text { Reforma }\end{array}$ \\
\hline \multicolumn{2}{|c|}{$\begin{array}{l}\text { Area Total (ha): } \\
\text { Area de Reforma (ha): }\end{array}$} & $\begin{array}{l}1,326.06 \\
1,178.46 \\
\end{array}$ & & & \multicolumn{2}{|c|}{ Produção (m3) : } & $367,357.79$ \\
\hline \multirow[t]{2}{*}{ Ano 13} & Unidade & Regime & Anos de colheita & m3/ha & ha & $m 3$ & Reficond \\
\hline & $\begin{array}{r}3 \\
3 \\
5 \\
8 \\
14 \\
16 \\
27 \\
28 \\
37 \\
38 \\
38 \\
\end{array}$ & $\begin{array}{r}262 \\
263 \\
1443 \\
859 \\
376 \\
358 \\
366 \\
118 \\
254 \\
254 \\
295 \\
\end{array}$ & $\begin{array}{r}7-13-19 \\
7-13-19 \\
5-13 \\
5-13 \\
6-13 \\
6-13-19 \\
6-19 \\
6-13 \\
1 \cdot 7-13-19 \\
7-13-19 \\
7-13-19 \\
7-13-19 \\
\end{array}$ & $\begin{array}{l}305.00 \\
3350.00 \\
225.00 \\
240.00 \\
40.00 \\
260.00 \\
336.00 \\
26.00 \\
25.00 \\
25.00 \\
25.00 \\
217.00 \\
\end{array}$ & $\begin{array}{r}4.88 \\
309.78 \\
31.45 \\
86.10 \\
41.07 \\
193.10 \\
55.24 \\
320.12 \\
200.00 \\
14.99 \\
29.64 \\
\end{array}$ & $\begin{array}{r}13.687 .97 \\
94.483 .45 \\
7.201 .23 \\
20.664 .00 \\
16.469 .07 \\
50.206 .00 \\
18.560 .64 \\
88.431 .80 \\
51.000 .00 \\
3.822 .12 \\
6.431 .58 \\
\end{array}$ & $\begin{array}{l}\text { Reforma } \\
\text { Reforma } \\
\text { Conduccalo } \\
\text { Conduccáo } \\
\text { Reforma } \\
\text { Reforma } \\
\text { Conduccáo } \\
\text { Reforma } \\
\text { Reforma } \\
\text { Reforma } \\
\text { Reforma } \\
\end{array}$ \\
\hline \multicolumn{2}{|c|}{$\begin{array}{l}\text { Area Total (ha): } \\
\text { Area de Reforma (ha): } \\
\end{array}$} & $\begin{array}{l}, 326.36 \\
1.153 .58 \\
\end{array}$ & & & \multicolumn{2}{|c|}{ Produção (m3): } & $367,357.85$ \\
\hline Ano 14 & Unidade & Regime & Anos de colheita & $\mathrm{m} 3 \mathrm{ha}$ & ha & m3 & RefiCond \\
\hline & $\begin{array}{l}13 \\
15 \\
15 \\
\end{array}$ & $\begin{array}{l}660 \\
244 \\
290 \\
\end{array}$ & $\begin{array}{r}2 \cdot 8-8-14-19 \\
6-14 \\
7-14 \\
\end{array}$ & $\begin{array}{l}293.00 \\
32.700 \\
305.00 \\
\end{array}$ & $\begin{array}{r}206.00 \\
91.72 \\
10.19 \\
\end{array}$ & $\begin{array}{r}60.358 .00 \\
29.993 .68 \\
3.108 .07 \\
\end{array}$ & $\begin{array}{l}\text { Reforma } \\
\text { Reforma } \\
\text { Reformma } \\
\end{array}$ \\
\hline
\end{tabular}




\begin{tabular}{|c|c|c|c|c|c|c|c|}
\hline & $\begin{array}{l}18 \\
27 \\
29 \\
29 \\
32 \\
32 \\
36 \\
40 \\
\end{array}$ & $\begin{array}{l}630 \\
368 \\
660 \\
662 \\
275 \\
278 \\
264 \\
264 \\
\end{array}$ & $\begin{array}{r}2-8-14-20 \\
6-14 \\
2-8-14-19 \\
2-8-14-20 \\
7-14 \\
7-14 \\
7-14 \\
7-14 \\
\end{array}$ & $\begin{array}{l}261.00 \\
358.00 \\
292.00 \\
292.00 \\
315.00 \\
315.00 \\
280.00 \\
280.00 \\
\end{array}$ & $\begin{array}{r}465.32 \\
20.31 \\
65.77 \\
122.48 \\
78.05 \\
45.35 \\
100.00 \\
83.35 \\
\end{array}$ & $\begin{array}{r}121.448 .52 \\
7.270 .98 \\
19.204 .37 \\
35.765 .30 \\
24.584 .93 \\
14.286 .07 \\
28.000 .00 \\
23.337 .89 \\
\end{array}$ & $\begin{array}{l}\text { Reforma } \\
\text { Reforma } \\
\text { Reforma } \\
\text { Reforma } \\
\text { Reforma } \\
\text { Conduc5o } \\
\text { Reforma } \\
\text { Reforma } \\
\end{array}$ \\
\hline \multicolumn{2}{|c|}{$\begin{array}{l}\text { Area Total (ha): } \\
\text { Area de Reforma (ha): }\end{array}$} & \multicolumn{3}{|l|}{$\begin{array}{l}1,288.55 \\
1,243.19\end{array}$} & \multicolumn{2}{|c|}{ Produção (m3): } & $367,357.82$ \\
\hline \multirow[t]{2}{*}{ Ano 15} & Unidade & Regime & Anos de colheita & $\mathrm{m} 3 / \mathrm{ha}$ & ha & $\mathrm{m} 3$ & Ref/Cond \\
\hline & $\begin{array}{r}99 \\
15 \\
17 \\
22 \\
23 \\
23 \\
24 \\
25 \\
29 \\
31 \\
35 \\
40 \\
\end{array}$ & $\begin{array}{r}319 \\
298 \\
319 \\
463 \\
195 \\
193 \\
195 \\
982 \\
1038 \\
178 \\
174 \\
330 \\
\end{array}$ & $\begin{array}{r}4-10-15-20 \\
7-15 \\
4-10-15-20 \\
1-8-15 \\
1-8-15 \\
1-8-15 \\
1-8-15 \\
3-9-15-20 \\
3-9-15-20 \\
1-8-15 \\
1-8-15 \\
8-15 \\
\end{array}$ & $\begin{array}{l}277.00 \\
327.00 \\
256.00 \\
250.00 \\
338.00 \\
338.00 \\
269.00 \\
265.00 \\
292.00 \\
224.00 \\
200.00 \\
280.00 \\
\end{array}$ & $\begin{array}{r}96.85 \\
2.78 \\
130.50 \\
22.33 \\
37.69 \\
41.29 \\
145.79 \\
162.73 \\
464.42 \\
112.14 \\
131.02 \\
16.65 \\
\end{array}$ & $\begin{array}{r}26.827 .92 \\
907.69 \\
33.406 .95 \\
5.581 .68 \\
12.739 .15 \\
13.956 .09 \\
39.217 .51 \\
43.124 .30 \\
135.609 .97 \\
25.119 .45 \\
26.204 .96 \\
4.662 .11 \\
\end{array}$ & $\begin{array}{l}\text { Reforma } \\
\text { Conducāo } \\
\text { Reforma } \\
\text { Conducäo } \\
\text { Conducāo } \\
\text { Reforma } \\
\text { Conducáo } \\
\text { Reforma } \\
\text { Reforma } \\
\text { Reforma } \\
\text { Reforma } \\
\text { Conducăa }\end{array}$ \\
\hline \multicolumn{2}{|c|}{$\begin{array}{l}\text { Area Total (ha): } \\
\text { Area de Reforma (ha): }\end{array}$} & \multicolumn{3}{|l|}{$\begin{array}{l}1,364.19 \\
1,138.95\end{array}$} & \multicolumn{2}{|c|}{ Produção $(\mathrm{m} 3)$ : } & $367,357.77$ \\
\hline \multirow[t]{2}{*}{ Ano 16} & Unicade & Regime & Anos de colheita & $\mathrm{m} 3 / \mathrm{ha}$ & ha & $\mathrm{m} 3$ & Ref/Cond \\
\hline & $\begin{array}{r}6 \\
9 \\
19 \\
19 \\
20 \\
21 \\
25 \\
25 \\
31 \\
35 \\
35 \\
\end{array}$ & $\begin{array}{r}677 \\
323 \\
686 \\
685 \\
677 \\
986 \\
1012 \\
986 \\
217 \\
175 \\
207 \\
\end{array}$ & $\begin{array}{r}2-9-16 \\
4-10-16 \\
4-10-16 \\
4-10-16 \\
2-9-16 \\
3-9-16 \\
3-10-16 \\
3-9-16 \\
1-9-16 \\
1-8-16 \\
1-9-16 \\
\end{array}$ & $\begin{array}{l}277.00 \\
330.00 \\
277.00 \\
277.00 \\
256.00 \\
337.00 \\
265.00 \\
294.00 \\
224.00 \\
214.00 \\
200.00 \\
\end{array}$ & $\begin{array}{r}211.23 \\
272.60 \\
127.41 \\
108.69 \\
111.25 \\
75.00 \\
57.77 \\
60.62 \\
36.88 \\
1.42 \\
290.19 \\
\end{array}$ & $\begin{array}{r}58.510 .71 \\
89.957 .44 \\
35.292 .63 \\
30.107 .07 \\
28.481 .18 \\
25.275 .00 \\
15.309 .13 \\
17.821 .93 \\
8.261 .03 \\
303.73 \\
58.037 .98 \\
\end{array}$ & $\begin{array}{l}\text { Reforma } \\
\text { Reforma } \\
\text { Conducäo } \\
\text { Reforma } \\
\text { Reforma } \\
\text { Reforma } \\
\text { Reforma } \\
\text { Reforma } \\
\text { Reforma } \\
\text { Reforma } \\
\text { Reforma }\end{array}$ \\
\hline \multicolumn{2}{|c|}{$\begin{array}{c}\text { Area Total (ha): } \\
\text { Area de Reforma (ha): }\end{array}$} & $\begin{array}{l}1,353.06 \\
1,225.65\end{array}$ & & & \multicolumn{2}{|c|}{ Produção (m3): } & $367,357.82$ \\
\hline \multirow[t]{2}{*}{ Ano 17} & Unidade & Regime & Anos de colheita & $\mathrm{m} 3 / \mathrm{ha}$ & ha & $\mathrm{m} 3$ & Ref/Cond \\
\hline & $\begin{array}{r}4 \\
7 \\
7 \\
10 \\
10 \\
12 \\
17 \\
17 \\
20 \\
25 \\
30 \\
35 \\
\end{array}$ & $\begin{array}{r}214 \\
1026 \\
1148 \\
687 \\
706 \\
213 \\
505 \\
506 \\
1014 \\
1014 \\
1148 \\
431 \\
\end{array}$ & $\begin{array}{l}5-11-17 \\
3-10-17 \\
3-10-17 \\
4-10-17 \\
4-11-17 \\
5-11-17 \\
5-11-17 \\
5-11-17 \\
3-10-17 \\
3-10-17 \\
3-10-17 \\
2-10-17 \\
\end{array}$ & $\begin{array}{l}305.00 \\
190.00 \\
224.00 \\
257.00 \\
231.00 \\
274.00 \\
305.00 \\
305.00 \\
256.00 \\
294.00 \\
204.00 \\
200.00 \\
\end{array}$ & $\begin{array}{r}261.91 \\
125.34 \\
30.79 \\
77.12 \\
93.75 \\
242.14 \\
257.14 \\
85.87 \\
68.86 \\
81.92 \\
31.66 \\
88.10 \\
\end{array}$ & $\begin{array}{r}79.882 .55 \\
23.815 .17 \\
6.896 .29 \\
19.819 .35 \\
21.656 .16 \\
66.345 .35 \\
78.426 .54 \\
26.189 .71 \\
17.626 .98 \\
2.621 .80 \\
6.458 .76 \\
17.619 .20 \\
\end{array}$ & $\begin{array}{l}\text { Conducäo } \\
\text { Reforma } \\
\text { Reforma } \\
\text { Reforma } \\
\text { Reforma } \\
\text { Reforma } \\
\text { Reforma } \\
\text { Conducäo } \\
\text { Reforma } \\
\text { Reforma } \\
\text { Reforma } \\
\text { Reforma } \\
\end{array}$ \\
\hline \multicolumn{2}{|c|}{$\begin{array}{l}\text { Area Tolal (ha): } \\
\text { Area de Reforma (ha): }\end{array}$} & $\begin{array}{l}1,371.58 \\
1,023.80\end{array}$ & & & \multicolumn{2}{|c|}{ Produção (m3): } & $367,357.87$ \\
\hline \multirow[t]{2}{*}{ Ano 18} & Unidade & Regime & Anos de colheita & $\mathrm{m} 3 / \mathrm{ha}$ & ha & m3 & Ref/Cond \\
\hline & $\begin{array}{r}1 \\
3 \\
10 \\
10 \\
11 \\
11 \\
12 \\
12 \\
38 \\
39 \\
\end{array}$ & $\begin{array}{r}161 \\
161 \\
717 \\
708 \\
162 \\
161 \\
230 \\
344 \\
157 \\
157 \\
\end{array}$ & $\begin{array}{l}6-12-18 \\
6-12-18 \\
4-11-18 \\
4-1-18 \\
6-12-18 \\
6-12-18 \\
5-12-18 \\
6-12-18 \\
6-12-18 \\
6-12-18 \\
\end{array}$ & $\begin{array}{l}318.00 \\
305.00 \\
218.00 \\
257.00 \\
286.00 \\
286.00 \\
274.00 \\
274.00 \\
255.00 \\
255.00 \\
\end{array}$ & $\begin{array}{r}118.15 \\
19.94 \\
24.48 \\
143.73 \\
98.18 \\
161.86 \\
284.31 \\
140.64 \\
155.37 \\
200.00 \\
\end{array}$ & $\begin{array}{r}37.571 .70 \\
6.081 .58 \\
5.337 .47 \\
36.938 .25 \\
28.078 .22 \\
46.293 .22 \\
77.900 .61 \\
38.536 .70 \\
39.620 .06 \\
51.000 .00 \\
\end{array}$ & $\begin{array}{l}\text { Reforma } \\
\text { Reforma } \\
\text { Reforma } \\
\text { Reforma } \\
\text { Conducáo } \\
\text { Reforma } \\
\text { Reforma } \\
\text { Reforma } \\
\text { Reforma } \\
\text { Reforma } \\
\end{array}$ \\
\hline \multicolumn{2}{|c|}{$\begin{array}{l}\text { Area Total (ha): } \\
\text { Area de Reforma (ha): }\end{array}$} & $\begin{array}{l}1,346.67 \\
1,248.49\end{array}$ & & & Proc & $(\mathrm{m} 3):$ & $367,357.82$ \\
\hline \multirow[t]{2}{*}{ Ano 19} & Unidade & Regime & Anos de colheita & m3/ha & ha & $\mathrm{m} 3$ & Ref/Cond \\
\hline & $\begin{array}{r}3 \\
3 \\
13 \\
16 \\
28 \\
29 \\
37 \\
38 \\
38 \\
\end{array}$ & $\begin{array}{l}263 \\
262 \\
660 \\
358 \\
118 \\
660 \\
254 \\
254 \\
295 \\
\end{array}$ & $\begin{array}{r}7-13-19 \\
7-13-19 \\
2-8-14-19 \\
6-13-19 \\
1-7-13-19 \\
2-8-14-19 \\
7-13-19 \\
7-13-19 \\
7-13-19 \\
\end{array}$ & $\begin{array}{l}305.00 \\
305.00 \\
246.00 \\
234.00 \\
265.00 \\
245.00 \\
2555.00 \\
255.00 \\
255.00 \\
\end{array}$ & $\begin{array}{r}309.78 \\
44.88 \\
206.00 \\
193.10 \\
320.12 \\
65.77 \\
200.00 \\
14.99 \\
29.64 \\
\end{array}$ & $\begin{array}{r}94.483 .45 \\
13.687 .97 \\
50.676 .00 \\
45.185 .40 \\
84.831 .80 \\
16.113 .26 \\
51.000 .00 \\
3.822 .12 \\
7.557 .84 \\
\end{array}$ & $\begin{array}{l}\text { Conducăo } \\
\text { Reforma } \\
\text { Reforma } \\
\text { Reforma } \\
\text { Reforma } \\
\text { Reforma } \\
\text { Reforma } \\
\text { Reforma } \\
\text { Reforma } \\
\end{array}$ \\
\hline \multicolumn{2}{|c|}{$\begin{array}{l}\text { Area Tolal (ha): } \\
\text { Area de Reforma (ha): }\end{array}$} & $\begin{array}{l}1,384.28 \\
1,074.49\end{array}$ & & & Proc & (m3): & $367,357.84$ \\
\hline \multirow[t]{2}{*}{ Ano 20} & Unidade & Regime & Anos de colheita & m3/ha & ha & m3 & Ref/Cond \\
\hline & $\begin{array}{r}17 \\
17 \\
18 \\
25 \\
29 \\
29 \\
\end{array}$ & $\begin{array}{r}319 \\
319 \\
630 \\
982 \\
662 \\
1038 \\
\end{array}$ & $\begin{array}{r}4-10-15-20 \\
4-10-15-20 \\
2-8-14-20 \\
3-9-15-20 \\
2-8-14-20 \\
3-9-15-20 \\
\end{array}$ & $\begin{array}{l}277.00 \\
256.00 \\
261.00 \\
222.00 \\
292.00 \\
245.00 \\
\end{array}$ & $\begin{array}{r}96.85 \\
130.50 \\
465.32 \\
162.73 \\
122.48 \\
464.42 \\
\end{array}$ & $\begin{array}{r}26.827 .92 \\
33.406 .95 \\
121.448 .52 \\
36.126 .77 \\
35.765 .30 \\
113.782 .34 \\
\end{array}$ & $\begin{array}{l}\text { Reforma } \\
\text { Reforma } \\
\text { Reforma } \\
\text { Reforma } \\
\text { Reforma } \\
\text { Reforma } \\
\end{array}$ \\
\hline \multicolumn{2}{|c|}{$\begin{array}{l}\text { Area Total (ha): } \\
\text { Area de Reforma (ha): }\end{array}$} & $\begin{array}{l}1,442.30 \\
1.442 .30\end{array}$ & & & Proc & (m3): & $367,357.80$ \\
\hline
\end{tabular}




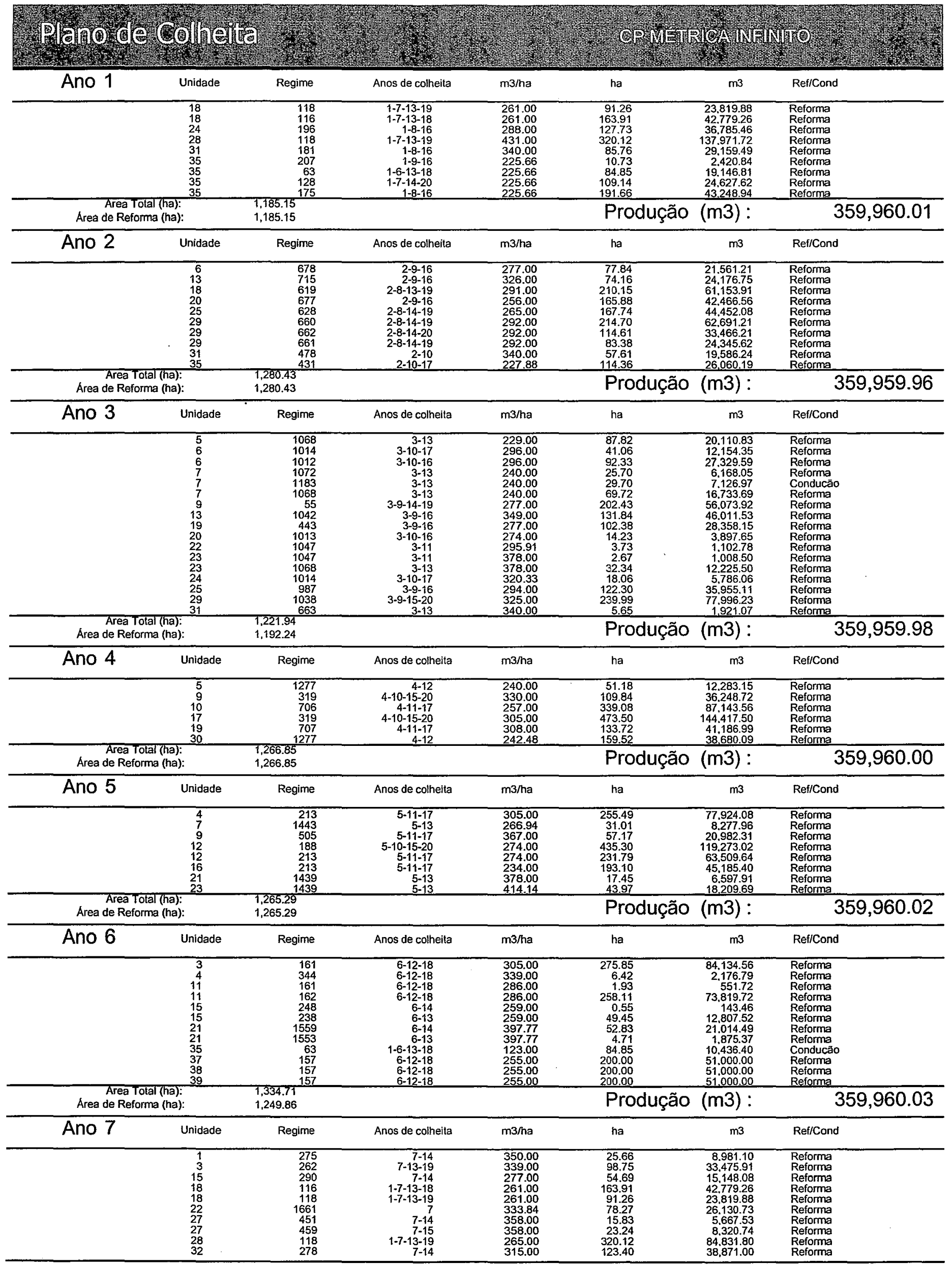




\begin{tabular}{|c|c|c|c|c|c|c|c|}
\hline & $\begin{array}{l}35 \\
36 \\
40 \\
\end{array}$ & $\begin{array}{r}128 \\
264 \\
272 \\
\end{array}$ & $\begin{array}{r}1-7-14-20 \\
7-14 \\
7-15 \\
\end{array}$ & $\begin{array}{l}146.00 \\
280.00 \\
280.00\end{array}$ & $\begin{array}{l}\begin{array}{l}109.14 \\
100.00 \\
100.00\end{array} \\
100\end{array}$ & $\begin{array}{l}\begin{array}{l}15.933 .99 \\
28.000 .00 \\
28.000 .00\end{array} \\
\end{array}$ & $\begin{array}{l}\text { Conducáo } \\
\text { Reforma } \\
\text { Reforma } \\
\end{array}$ \\
\hline \multicolumn{2}{|c|}{$\begin{array}{c}\text { Area Total (ha): } 40 \\
\text { Area de Reforma (ha): }\end{array}$} & $\begin{array}{l}1,304.27 \\
1,195.13\end{array}$ & & & \multicolumn{2}{|c|}{ Produção (m3): } & $359,960.02$ \\
\hline \multirow[t]{2}{*}{ Ano 8} & Unidade & Regime & Anos de collheita & $\mathrm{m} 3 / \mathrm{ha}$ & ha & $\mathrm{m} 3$ & Ref/Cond \\
\hline & $\begin{array}{r}1 \\
8 \\
18 \\
24 \\
25 \\
29 \\
29 \\
29 \\
31 \\
35 \\
\end{array}$ & $\begin{array}{c}345 \\
1011 \\
619 \\
196 \\
628 \\
661 \\
662 \\
660 \\
181 \\
175 \\
\end{array}$ & $\begin{array}{r}8-16 \\
8 \\
2-8-13-19 \\
1-8-16 \\
2-8-14-19 \\
2-8-14-19 \\
2-8-14-20 \\
2-8-14-19 \\
1-8-16 \\
1-8-16 \\
\end{array}$ & $\begin{array}{l}373.00 \\
242.13 \\
261.00 \\
266.00 \\
265.00 \\
292.00 \\
292.00 \\
292.00 \\
224.00 \\
163.00 \\
\end{array}$ & $\begin{array}{r}92.49 \\
86.10 \\
210.15 \\
127.73 \\
167.74 \\
83.38 \\
114.61 \\
214.70 \\
85.76 \\
191.66 \\
\end{array}$ & $\begin{array}{l}34.498 .66 \\
20.847 .16 \\
54.849 .38 \\
34.358 .64 \\
44.452 .08 \\
24.445 .62 \\
33.466 .21 \\
62.691 .21 \\
19.210 .96 \\
31.240 .09 \\
\end{array}$ & $\begin{array}{l}\text { Reforma } \\
\text { Reforma } \\
\text { Reforma } \\
\text { Reforma } \\
\text { Reforma } \\
\text { Reforma } \\
\text { Reforma } \\
\text { Reforma } \\
\text { Reforma } \\
\text { Conducăo }\end{array}$ \\
\hline \multicolumn{2}{|c|}{$\begin{array}{l}\text { Area Tolal (ha): } \\
\text { Area de Reforma (ha): }\end{array}$} & $\begin{array}{l}1,374,31 \\
1,182.66\end{array}$ & & & \multicolumn{2}{|c|}{ Produção (m3): } & $359,960.00$ \\
\hline \multirow[t]{2}{*}{ Ano 9} & Unidade & Regime & Anos de colheita & m3/ha & ha & $\mathrm{m} 3$ & RefiCond \\
\hline & $\begin{array}{l}6 \\
9 \\
13 \\
13 \\
14 \\
19 \\
20 \\
25 \\
27 \\
29 \\
35\end{array}$ & $\begin{array}{r}678 \\
55 \\
1042 \\
715 \\
594 \\
443 \\
677 \\
987 \\
566 \\
1038 \\
207\end{array}$ & $\begin{array}{r}2-9-16 \\
3-9-14-19 \\
3-9-16 \\
2-9-16 \\
3-9-16 \\
2-9-16 \\
3-9-16 \\
3-16 \\
9-9-15-20 \\
1-9-16\end{array}$ & $\begin{array}{l}277.00 \\
330.00 \\
293.00 \\
326.00 \\
471.72 \\
277.00 \\
256.00 \\
265.00 \\
390.40 \\
292.00 \\
174.00\end{array}$ & $\begin{array}{r}77.84 \\
202.43 \\
131.84 \\
74.16 \\
41.07 \\
102.38 \\
165.88 \\
122.30 \\
36.48 \\
239.99 \\
10.93\end{array}$ & $\begin{aligned} 21.561 .21 \\
66.802 .86 \\
38.628 .59 \\
24.476 .75 \\
19.373 .42 \\
28.358 .15 \\
42.466 .56 \\
32.408 .52 \\
14.240 .64 \\
70.076 .61 \\
1.866 .65\end{aligned}$ & $\begin{array}{l}\text { Reforma } \\
\text { Reforma } \\
\text { Reforma } \\
\text { Reforma } \\
\text { Reforma } \\
\text { Reforma } \\
\text { Reforma } \\
\text { Reforma } \\
\text { Reforma } \\
\text { Reforma } \\
\text { Conducáa }\end{array}$ \\
\hline \multicolumn{2}{|c|}{$\begin{array}{l}\text { Area Tolol (ha): } \\
\text { Area de Reforma (ha): }\end{array}$} & $\begin{array}{l}7,205.09 \\
1,194.36\end{array}$ & & & \multicolumn{2}{|c|}{ Produção (m3): } & $359,959.97$ \\
\hline \multirow[t]{2}{*}{ Ano 10} & Unidade & Regime & Anos de colheita & $\mathrm{m} 3 / \mathrm{ha}$ & ha & m3 & Ref/Cond \\
\hline & $\begin{array}{c}6 \\
6 \\
9 \\
12 \\
17 \\
20 \\
24 \\
31 \\
35 \\
\end{array}$ & $\begin{array}{c}1012 \\
1014 \\
319 \\
188 \\
319 \\
1013 \\
1014 \\
478 \\
431 \\
\end{array}$ & $\begin{array}{r}3-10-16 \\
3-10.17 \\
4-10-15-20 \\
5-10-15-20 \\
4-10-15-20 \\
3-10.16 \\
3-10-17 \\
2-10 \\
2-10-17 \\
2\end{array}$ & $\begin{array}{l}277.00 \\
277.00 \\
330.00 \\
230.00 \\
30500 \\
256.00 \\
266.00 \\
240.00 \\
74.00 \\
\end{array}$ & $\begin{array}{r}92.33 \\
41.06 \\
109.84 \\
435.30 \\
473.50 \\
14.23 \\
18.06 \\
57.61 \\
114.36 \\
\end{array}$ & 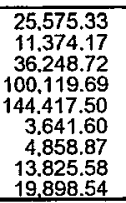 & 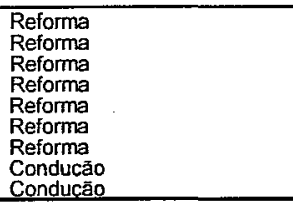 \\
\hline \multicolumn{2}{|c|}{$\begin{array}{l}\text { Area Total(ha): } \\
\text { Area de Reforma (ha): }\end{array}$} & $\begin{array}{l}1,36.29 \\
1,184.33\end{array}$ & & & Prod & (m3): & $359,960.00$ \\
\hline \multirow[t]{2}{*}{ Ano 11} & Unidade & Regime & Anos de colheita & m3ha & ha & $\overline{\mathrm{m} 3}$ & Ref/Cond \\
\hline & $\begin{array}{r}4 \\
9 \\
10 \\
12 \\
16 \\
19 \\
19 \\
22 \\
23 \\
26 \\
\end{array}$ & $\begin{array}{r}213 \\
5505 \\
7766 \\
213 \\
213 \\
707 \\
1047 \\
1047 \\
609 \\
609\end{array}$ & $\begin{array}{r}5-11-17 \\
5-11-17 \\
4-1-17 \\
5-11-17 \\
5-11-17 \\
5-11-17 \\
3-17 \\
3-11 \\
311 \\
11\end{array}$ & $\begin{array}{l}305.00 \\
330.00 \\
255.00 \\
274.00 \\
234.00 \\
330.00 \\
268.00 \\
366.00 \\
469.40 \\
\end{array}$ & $\begin{array}{l}255.49 \\
57.17 \\
339.08 \\
231.79 \\
193.10 \\
133.72 \\
3.73 \\
2.67 \\
51.51 \\
\end{array}$ & $\begin{array}{r}77.924 .08 \\
18.866 .93 \\
88.743 .56 \\
663.599 .64 \\
45.185 .40 \\
41.186 .90 \\
998.78 \\
965.78 \\
24.178 .80 \\
\end{array}$ & 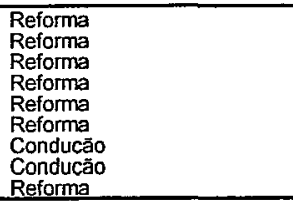 \\
\hline \multicolumn{2}{|c|}{$\begin{array}{l}\text { Area Total (ha): } \\
\text { Area de Reforma (ha): }\end{array}$} & $\begin{array}{l}1,268.26 \\
1,261.86\end{array}$ & & & Prod & (m3): & $359,960.00$ \\
\hline \multirow[t]{2}{*}{ Ano 12} & Unidade & Regime & Anos de colheita & $\mathrm{m} 3 / \mathrm{ha}$ & ha & $\mathrm{m} 3$ & Ref/Cond \\
\hline & $\begin{array}{l}3 \\
4 \\
5 \\
11 \\
11 \\
30 \\
37 \\
38 \\
39 \\
\end{array}$ & $\begin{array}{c}161 \\
344 \\
1277 \\
161 \\
162 \\
1277 \\
157 \\
157 \\
157 \\
\end{array}$ & $\begin{array}{l}6-12-18 \\
6-12-18 \\
4-12 \\
6-12-18 \\
6-12-18 \\
4-18 \\
6-12-12 \\
6-12-18 \\
6-12-18 \\
6-12-18 \\
\end{array}$ & $\begin{array}{l}305.00 \\
305.00 \\
22.00 \\
286.00 \\
286.00 \\
218.00 \\
255.00 \\
255.00 \\
255.00 \\
\end{array}$ & $\begin{array}{r}275.85 \\
61.42 \\
18.18 \\
183 \\
258.11 \\
159.52 \\
200.00 \\
200.00 \\
200.00 \\
200\end{array}$ & $\begin{array}{l}84.134 .56 \\
1.958 .47 \\
11.720 .17 \\
7351.72 \\
73.819 .72 \\
334.7175 .36 \\
51.000 .00 \\
51.000 .00 \\
51,000.00 \\
5\end{array}$ & $\begin{array}{l}\text { Reforma } \\
\text { Reforma } \\
\text { Conductao } \\
\text { Reforma } \\
\text { Reforma } \\
\text { Conducaio } \\
\text { Reforma } \\
\text { Reforma } \\
\text { Reforma } \\
\text { Reforma }\end{array}$ \\
\hline \multicolumn{2}{|c|}{$\begin{array}{l}\text { Area Total (ha): } \\
\text { Área de Reforma (ha): }\end{array}$} & $\begin{array}{l}1,353.01 \\
1,142.31\end{array}$ & & & \multicolumn{2}{|c|}{ Produção (m3) : } & $359,960.00$ \\
\hline \multirow[t]{2}{*}{ Ano 13} & Unidade & Regime & Anos de colheita & $\mathrm{m} 3 \mathrm{ha}$ & ha & $\mathrm{m} 3$ & Ref/Cond \\
\hline & $\begin{array}{r}3 \\
5 \\
7 \\
7 \\
7 \\
7 \\
15 \\
18 \\
18 \\
18 \\
21 \\
21 \\
23 \\
23 \\
28 \\
31 \\
35 \\
\end{array}$ & $\begin{array}{r}262 \\
1068 \\
1183 \\
1068 \\
1068 \\
1072 \\
1443 \\
238 \\
118 \\
1619 \\
116 \\
155 \\
1553 \\
1439 \\
1068 \\
1439 \\
118 \\
1663 \\
63 \\
\end{array}$ & $\begin{array}{r}7-13-19 \\
3-13 \\
3-13 \\
3-13 \\
3-13 \\
3-13 \\
5-13 \\
6-13 \\
6-7-13 \\
2-13-19 \\
2-8-13-19 \\
1-7-13-18 \\
6-13 \\
5-13 \\
3-13 \\
5-13 \\
5-13 \\
1-7-13-19 \\
3-13 \\
1-6-13-18 \\
-1-13 \\
\end{array}$ & 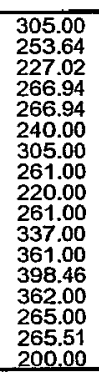 & $\begin{array}{l}98.75 \\
87.82 \\
29.70 \\
69.72 \\
25.70 \\
31.01 \\
49.45 \\
91.26 \\
210.15 \\
163.91 \\
4.71 \\
17.45 \\
32.34 \\
43.97 \\
320.12 \\
5.65 \\
84.85 \\
\end{array}$ & $\begin{array}{l}3.118 .45 \\
22.274 .60 \\
6.741 .52 \\
18.612 .14 \\
6.860 .45 \\
7.442 .50 \\
15.082 .22 \\
23.819 .88 \\
46.233 .20 \\
42.779 .26 \\
1.588 .26 \\
6.301 .85 \\
12.887 .14 \\
15.916 .92 \\
84.831 .80 \\
1.500 .17 \\
16.969 .76 \\
\end{array}$ & $\begin{array}{l}\text { Reforma } \\
\text { Reforma } \\
\text { Reforma } \\
\text { Reforma } \\
\text { Conducáo } \\
\text { Conducáa } \\
\text { Reforma } \\
\text { Reforma } \\
\text { Reforma } \\
\text { Reforma } \\
\text { Reforma } \\
\text { Reforma } \\
\text { Reforma } \\
\text { Reforma } \\
\text { Reforma } \\
\text { Reforma } \\
\text { Reforma } \\
\end{array}$ \\
\hline \multicolumn{2}{|c|}{$\begin{array}{l}\text { Area Total (ha): } \\
\text { Area de Reforma (ha): }\end{array}$} & $\begin{array}{l}1,366.57 \\
1,309.86 \\
\end{array}$ & & & \multicolumn{2}{|c|}{ Produção (m3): } & $359,960.02$ \\
\hline Ano 14 & Unidade & Regime & Anos de colhelta & m3/ha & ha & $\mathrm{m} 3$ & RefiCond \\
\hline & $\begin{array}{r}1 \\
9 \\
15 \\
15 \\
21 \\
25 \\
27\end{array}$ & $\begin{array}{r}275 \\
55 \\
248 \\
290 \\
1559 \\
628 \\
451\end{array}$ & $\begin{array}{r}7-14 \\
3-9-14-19 \\
6-14 \\
7-14 \\
6-14 \\
6-8-14 \\
2-8-19 \\
7-14\end{array}$ & $\begin{array}{l}350.00 \\
277.00 \\
327.00 \\
305.00 \\
361.00 \\
265.00 \\
336.00\end{array}$ & $\begin{array}{r}25.66 \\
202.43 \\
0.55 \\
54.69 \\
52.83 \\
167.74 \\
15.83\end{array}$ & $\begin{array}{r}8.981 .10 \\
56.1073 .92 \\
161.13 \\
16.679 .29 \\
19.971 .85 \\
44.452 .08 \\
5,319.25 \\
\end{array}$ & $\begin{array}{l}\text { Reforma } \\
\text { Reforma } \\
\text { Conducáa } \\
\text { Reforma } \\
\text { Reforma } \\
\text { Reforma } \\
\text { Reforma }\end{array}$ \\
\hline
\end{tabular}




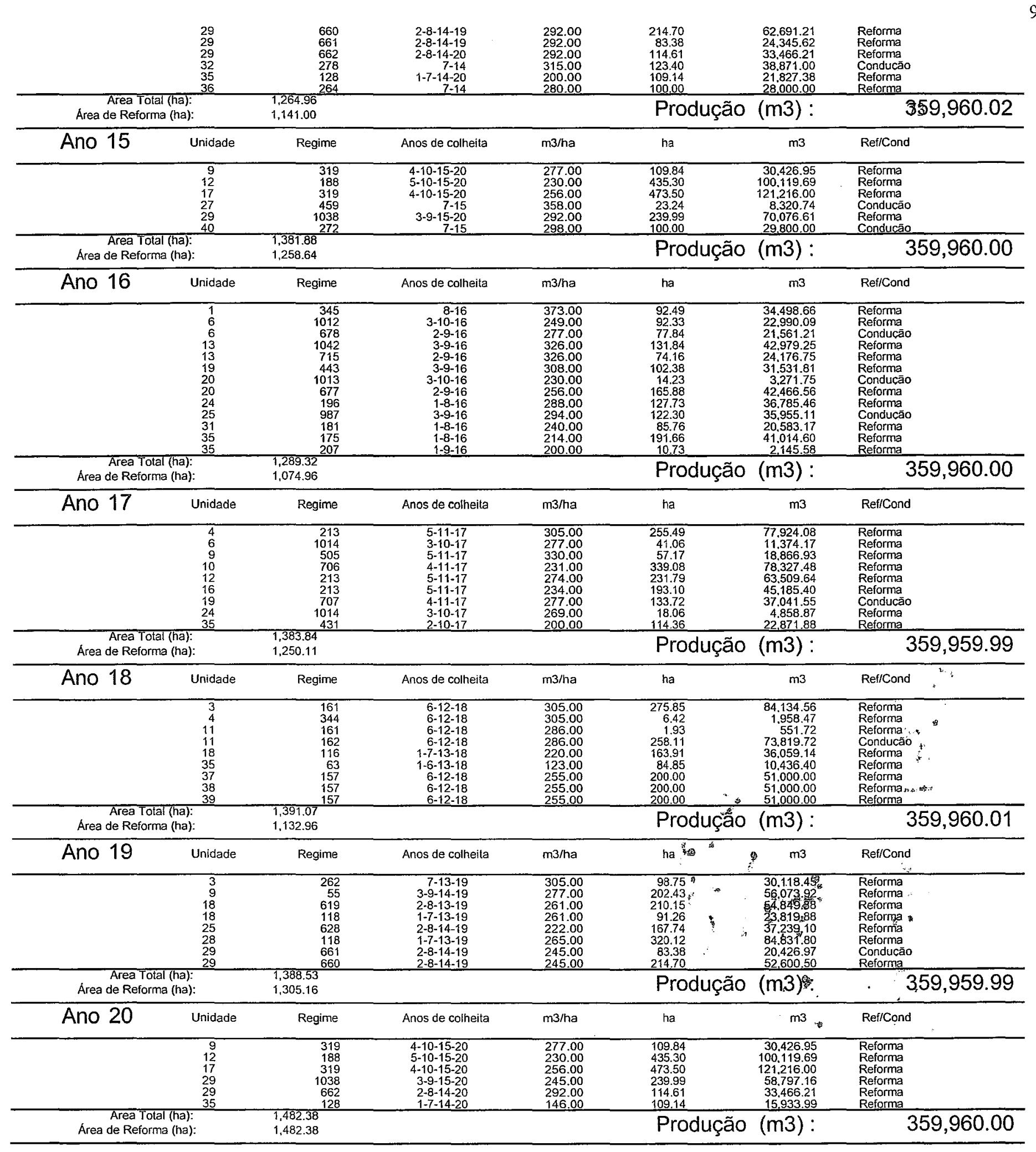




\section{REFERÊNCIAS BIBLIOGRÁFICAS}

ALVES, M.J.; CLÍMACO, J. Using cutting planes in na interactive reference point approach for multiobjective integer linear programming problems. European Journal of Operational Research, v.177, p.565-577, 1999.

BALLESTERO, E. Selecting the CP metric: a risk aversion aproach. European Journal of Operational Research, v.97, p.593-596, 1997.

BATEMAN, T.S; SNELL, S.A. Administração: construindo vantagem competitiva. São Paulo: Editora Atlas, 1998. 539p.

BORGES, J.G. Paradigmas, tecnologias e equívocos em gestão de recursos florestais. Revista Florestal, v.11, p.27-34, 1999.

BRACELPA. Relatório estatístico florestal. São Paulo: Associação Brasileira de Celulose e Papel, 1999. 97p.

BUONGIORNO, J.; GILLES, J.K. Forest management and economics. New York: Macmillan, 1987. 289p.

CAIXETA-FILHO, J.V. Pesquisa operacional: técnicas de otimização aplicadas a sistemas agroindustriais. São Paulo: Editora Atlas, 2001. 171p.

CLUTTER, J.L.; FORTSON, J.C.; PIENAAR, L.V.; BRISTER, G.H.; BAILEY, R.L. Timber management: a quantitative approach. Malabar: Krieger Publishing, 1992. 335p. 
COLE, D.C.; EYLES, J.; GIBSON, B.L. Indicators of human health in ecosystems: what do we measure? The Science of the Total Environment, v.224, p.201-213, 1998.

DIAZ-BALTEIRO,L.;ROMERO,C. Modeling timber harvest scheduling problems with multiple criteria: an aplication in spain. Forest Science, v.44, n.1, p.47-57, Feb. 1998.

DYKSTRA, D. Research on criteria and indicators: were do we go from here (A CIFOR perspective). Rome: IPAP, 1998. 5p. (Next Steps for C\&I Development and Application).

FARRELL, E.P.; FÜHRER, E.; RYAN, D.; ANDERSSON, F.; HÜTTL, R.; PIUSSI, P. European forest ecosystems: building the future on the legacy of the past. Forest Ecology and Management, v.132, n. 1, p. 5-15, June 2000.

FERRER, F.F.; AGUILAR, J.;PEÑA, J. Téenicas de reducción en bases de datos. Sevilla: Universidade de Sevilla, Júlio, 2000 7p. (Informe técnico LSI-2000-09).

FOX, T.R. Sustained productivity in intensively managed forest plantation. Forest Ecology and Management, v.138, p.187-202, 2000.

GLADWIN, T.N.; KENNELLY, J.J.; KRAUSE, T.S. Shifting paradigms for sustainable development: implications for management theory and research. Academy of Management Review, v.20, n.4, p.874-907,1995.

GONZÁLEZ-CABAN, A.; FENN,M.E.; SCATENA, F.N. Concepts, criteria, and indicatords for monitoring sustainability. Mexico: USDA, 1995. 23p. (Forest Service General Technical Report, RM-GTR-266).

GONZÁLES-PACHÓN, J.;ROMERO, C. Distance-based consensus methods: a goal programming approach. The International Journal of Management Science, v.27, p. 341-347, 1999. 
HUNT, C.B.; AUSTER, E.R. Proactive environmental management: avoiding the toxic trap. Sloan Management Review, v.4, p. 7-18, 1990.

JOHNSON, K.N.; SCHEURMAN, H.L. Techniques for precribing optimal timber harvest and investment under different objectives- discussion and synthesis. Forest Sciency, v.1, p. 23-31, 1977.

KENT, B. M. Forest service land management planners, introduction to linear programming. Colorado: USDA, 1989. 38p. (Forest Service General Technical Report).

KLEMPERER, W.D. Forest resource economics and finance. New York: McGraw-Hill, 1996. 551p.

LACLAU, J.-P.; BOUILLET, J.-P.; RANGER, J. Dynameics of biomass and nutrient accumulation in a clonal plantation of Eucalyptus in Congo. Forest Ecology and Management, v.128, n., p.181-196, 2000.

LEUSCHENER, W.A. Intorduction to forest resource management. New York: John Wiley, 1984. 513p.

LEUSCHENER, W.A. Forest regulation, harvest scheduling and planning techniques. New York: John Wiley, 1990. 313p.

LIMA, W.P. Impacto ambiental do eucalipto. São Paulo: EDUSP, 1997. 302p.

MARQUES, J.F.; COMUNE, A.E. A teoria neoclássica e a valoração ambiental. In: ROMEIRO, A.R.; REYDON, B.P.; LEONARDI, M.L.A. (Ed.) Economia do meio ambiente. Campinas: UNICAMP, IE, 1996. cap.2, p.21-42.

MENDONZA,G.A.; PRABHU,R. Multiple criteria decision making approaches to assessing forest sustainability using criteria and indicators: a case study. Forest Ecology and Management, v.131 p. 107-126, 2000. 
MORRIS, D.M.; KIMMINS, J.P.; DUCKERT, D.R. The use of soil organic matter as a criterion of relative sustainability of forest management alternatives: a modeling approach using Forecast. Forest Ecology and Management, v.94, p.61-78, 1997.

NEWMAN, D.H. The optimal forest rotation: a discussion and annotade bibliography North Carolina: USDA, 1988. 52p. (Forest Service General Technical Report, SE-48)

NOBRE, S.R; RODRIGUEZ, L.C.E. Um método para composição e avaliação econômica de regimes de talhadia simples. Scientia Forestalis, v.60, n.1, 2001. /No prelo/

PEARCE, D.; PUTZ, F.; VANCLAY, J.K. A sustainable forest future. London: Center for Social and Economic Research on the Global Environment, 1999. 65p. (Working Paper, GEC 99-15).

PIETRZAK, J. Pareto optimum tests. Computers \& Structures, v.71, p.35-42, 1999.

POGGIANI, F.; SCHUMACHER,.. M.V. Atmospheric inputs compared with nutrients removed by harvesting from eucalyptus plantation. Implications for sustainability. In: IUFRO CONFERENCE ON SILVICULTURE AND IMPROVEMENT OF EUCALYPTS, Salvador, 1997. Anais. Colombo: EMBRAPA, CNPF, 1997. v.4, p.68-74.

POGGIANI, F.; STAPE, J.L.; GONÇALVES, J.L.M. Indicadores de sustentabilidade das plantações florestais. In: WORKSHOP SOBRE MONITORAMENTO AMBIENTAL EM ÁREAS FLORESTADAS, Piracicaba, 1997. Anais. Piracicaba: IPEF, 1998. p.33-43.

PRITCHETT, W.L.; FISHER, R.F. Properties and management of forest soils. New York: John Wiley, 1987, 510p. 
REIS, M.D.G.F.; BARROS, N.F.; KIMMINS, J.P. Acúmulo de nutrientes em uma seqüência de idade de Eucalyptus grandis Whill (ex-Maiden) plantado no cerrado em duas áreas com diferentes produtividades, em Minas Gerais. Revista Árvore, v.11, n.1, p.1-15, 1987.

RENNINGS, K.; WIGGERING, H. Steps towards indicators of sustainable development: Linking economic and ecological concepts. Ecological Economics, v.20, p.25-36, 1997.

RICHARDSON; B.; SKINNER, M.F.; WEST, G. The role of forest productivity in defining the sustainability of plantation forests in New Zeland. Forest Ecology and Management, v.122, p.125-137, 1999.

RODRIGUEZ, L.C.E.. Tópicos de economia florestal. Piracicaba: ESALQ, Depto. Ciências Florestais, $1991.47 \mathrm{p}$.

RODRIGUEZ, L.C.E.; BORGES, J.G. Técnicas matemáticas para determinação de níveis sustentáveis de produção florestal. Revista Florestal, v.11, p.83-92, 1999.

RODRIGUEZ, L.C.E.; BUENO, A.R.S.; RODRIGUES, F.A. Rotações de eucaliptos mais longas: análise volumétrica e econômica. Scientia Forestalis, v.51, n.1, p.15-28, 1997.

RODRIGUEZ, L.C.E.; MOREIRA, R.M. Gerenciamento de florestas de eucaliptos com modelos de programação linear. Série Técnica IPEF, v.6, n.19, p.23-29, 1989.

ROMERO, C. Teoria de la decisión multicriterio: conceptos, técnicas y aplicaciones. Madrid: Alianza Editorial, 1993. 195p.

ROMERO, C. Economia de los recursos ambientales y naturales. Madrid: Alianza Editorial, 1997. 215p. 
ROMERO, C.; RIOS, V.; DIAZ-BALTEIRO, L. Optimal forest rotation when carbon captured is considered: theory and applications. Journal of the Operational Research Society, v.49, p.121-131, 1998.

RUITENBEEK, J.; CARTIER, C.A. Rational explotations: economic criteria \& indicators for sustainable management of tropical forests. Ottawa: Center for International Forestry Research, 1998. 55p. (Ocasional Paper n.17/98).

SAMSON, D. Managerial decision analysis. Homewood: The Irwin Series in Quantitative Analysis for Business, 1988. 743p.

SCOTT, A. Trust law, sustainability, and responsible action. Ecological Economics, v.31, n 1, p. 139-154, Oct. 1999.

SMITH, C.; THWAITES, R. ForesTIM: evaluating plantation forest land management by identifying unsustainable pratices. Australian Forestry, v.61, n.2 p.89-102, 1998.

SOCIEDADE BRASILEIRA DE SILVICULTURA. http://www.sbs.ong.br (27 set. 2001).

STEUER, R.E. Multiple criteria optimization: theory, computation and aplication. New York: John Wiley, 1986. 546p.

TURNER, J.; LAMBERT, M. Change in organic carbon in forest plantation soils in eastern Australia. Forest Ecology and Management, v.133, p.231-247, 2000.

UNITED NATIONS CONFERENCE ON ENVIRONMENT AND SUSTAINABLE DEVELOPMENT. Combating deforestation programme areas. Rio de Janeiro: UNCED, 1992. 321p.

VAN BUEREN, E.M.L.; BLOM,E.M. Hierarchical framework for the formulation of sustainable forest management standards. Leiden: Tropenbos Foundation, 1997. 82p.

VINCKE, P. Multicriteria decision-aid. London: John Wiley, 1992. 182p. 
WANG, J.R.; ZHONG, A.L.; SIMARD, S.W.; KIMMINS, J.P. Aboveground biomass and nutrient accumulation in age sequence of paper birch (Betula papyrifera) in interior Cedar Hemlock zone, British Columbia. Forest Ecology and Management, v.83, p.27-38, 1996.

WARE, G.O.; CLUTTER, J.L. A mathematical programming system of the management of industrial forests. Forest Science, v.17, n.4, p.428-445, 1971.

WONNACOTT, P.; WONNACOTT, R. Economia. São Paulo: Makron Books, 1994. 866p.

YANAI, R.D.; ARTHUR, M.A.; SICCAMA, T.G.; FEDERER, C.A. Challenges of measuring forest floor organic matter dynamics: repeated mesures from a chronosequence. Forest Ecology and Management, v.138, p.273-283, 2000. 